\title{
Aerosol direct radiative effects over the northwest Atlantic, northwest Pacific, and North Indian Oceans: estimates based on in-situ chemical and optical measurements and chemical transport modeling
}

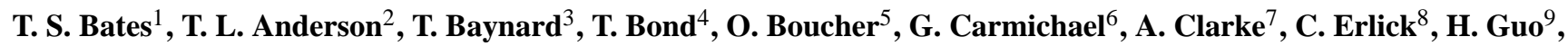
L. Horowitz ${ }^{10}$, S. Howell ${ }^{7}$, S. Kulkarni ${ }^{6}$, H. Maring ${ }^{11}$, A. McComiskey ${ }^{12}$, A. Middlebrook ${ }^{3}$, K. Noone ${ }^{13}$, C. D. O'Dowd ${ }^{14}$, J. Ogren ${ }^{12}$, J. Penner ${ }^{9}$, P. K. Quinn ${ }^{1}$, A. R. Ravishankara ${ }^{3}$, D. L. Savoie ${ }^{15}$, S. E. Schwartz ${ }^{16}$, Y. Shinozuka ${ }^{7}$, Y. Tang ${ }^{6}$, R. J. Weber ${ }^{17}$, and Y. Wu ${ }^{2}$

${ }^{1}$ Pacific Marine Environmental Laboratory, NOAA, Seattle, WA, USA

${ }^{2}$ Department of Atmospheric Sciences, University of Washington, Seattle, WA, USA

${ }^{3}$ Earth System Research Laboratory, NOAA, Boulder, CO, USA

${ }^{4}$ Department of Civil and Environmental Engineering, University of Illinois, Urbana, IL, USA

${ }^{5}$ Climate, Chemistry and Ecosystems Team, Met Office, Exeter, UK

${ }^{6}$ Center for Global and Regional Environmental Research, University of Iowa, Iowa City, IA, USA

${ }^{7}$ Department of Oceanography, University of Hawaii, Honolulu, Hawaii, USA

${ }^{8}$ Department of Atmospheric Sciences, The Hebrew University of Jerusalem, Jerusalem, Israel

${ }^{9}$ Department of Atmospheric, Oceanic and Space Sciences, University of Michigan, Ann Arbor, MI, USA

${ }^{10}$ Geophysical Fluid Dynamics Laboratory, NOAA, Princeton, New Jersey, USA

${ }^{11}$ Radiation Science Program, NASA Headquarters, Washington, D.C., USA

${ }^{12}$ Climate Monitoring and Diagnostics Laboratory, NOAA, Boulder, CO, USA

${ }^{13}$ International Geosphere Biosphere Program, Stockholm, Sweden

${ }^{14}$ Department of Experimental Physics \& Environmental Change Institute, National University of Ireland, Galway, Ireland

${ }^{15}$ Rosenstiel School of Marine and Atmospheric Science, University of Miami, Miami, FL, USA

${ }^{16}$ Environmental Sciences Department, Brookhaven National Laboratory, Upton, NY, USA

${ }^{17}$ School of Earth and Atmospheric Sciences, Georgia Institute of Technology, Atlanta, GA, USA

Received: 31 August 2005 - Published in Atmos. Chem. Phys. Discuss.: 3 January 2006

Revised: 16 March 2006 - Accepted: 17 March 2006 - Published: 22 May 2006

\begin{abstract}
The largest uncertainty in the radiative forcing of climate change over the industrial era is that due to aerosols, a substantial fraction of which is the uncertainty associated with scattering and absorption of shortwave (solar) radiation by anthropogenic aerosols in cloud-free conditions (IPCC, 2001). Quantifying and reducing the uncertainty in aerosol influences on climate is critical to understanding climate change over the industrial period and to improving predictions of future climate change for assumed emission scenarios. Measurements of aerosol properties during major field campaigns in several regions of the globe during the past decade are contributing to an enhanced understanding of atmospheric aerosols and their effects on light scattering and climate. The present study, which focuses on three regions
\end{abstract}

Correspondence to: T. S. Bates

(tim.bates@noaa.gov) downwind of major urban/population centers (North Indian Ocean (NIO) during INDOEX, the Northwest Pacific Ocean (NWP) during ACE-Asia, and the Northwest Atlantic Ocean (NWA) during ICARTT), incorporates understanding gained from field observations of aerosol distributions and properties into calculations of perturbations in radiative fluxes due to these aerosols. This study evaluates the current state of observations and of two chemical transport models (STEM and MOZART). Measurements of burdens, extinction optical depth (AOD), and direct radiative effect of aerosols (DRE - change in radiative flux due to total aerosols) are used as measurement-model check points to assess uncertainties. In-situ measured and remotely sensed aerosol properties for each region (mixing state, mass scattering efficiency, single scattering albedo, and angular scattering properties and their dependences on relative humidity) are used as input parameters to two radiative transfer models (GFDL and University

Published by Copernicus GmbH on behalf of the European Geosciences Union. 
of Michigan) to constrain estimates of aerosol radiative effects, with uncertainties in each step propagated through the analysis. Constraining the radiative transfer calculations by observational inputs increases the clear-sky, 24-h averaged AOD (34 $\pm 8 \%)$, top of atmosphere (TOA) DRE (32 $\pm 12 \%)$, and TOA direct climate forcing of aerosols (DCF - change in radiative flux due to anthropogenic aerosols) (37 $\pm 7 \%$ ) relative to values obtained with "a priori" parameterizations of aerosol loadings and properties (GFDL RTM). The resulting constrained clear-sky TOA DCF is $-3.3 \pm 0.47,-14 \pm 2.6$, $-6.4 \pm 2.1 \mathrm{Wm}^{-2}$ for the NIO, NWP, and NWA, respectively. With the use of constrained quantities (extensive and intensive parameters) the calculated uncertainty in DCF was $25 \%$ less than the "structural uncertainties" used in the IPCC-2001 global estimates of direct aerosol climate forcing. Such comparisons with observations and resultant reductions in uncertainties are essential for improving and developing confidence in climate model calculations incorporating aerosol forcing.

\section{Introduction}

Scattering and absorption of solar radiation by atmospheric aerosol particles exert a substantial influence on the Earth's radiation budget (e.g., Charlson et al., 1992; Ramanathan and Vogelmann, 1997; IPCC, 2001). Of particular interest for climate models representing climate change over the industrial period are the top-of-atmosphere (TOA) and surface direct climate forcings, defined here as the changes in the respective net fluxes due to scattering and absorption of shortwave (solar) radiation by aerosols of anthropogenic origin in cloud-free conditions. TOA forcing is important to local and global radiation budgets; surface forcing is important to surface heating and water evaporation. Here direct climate forcing by aerosols (DCF) is defined as a change in a given radiative flux due to anthropogenic aerosols; this change in flux due to anthropogenic aerosols is in addition to the change in flux due to natural aerosols. The change in flux due to the total aerosol (anthropogenic plus natural) relative to an aerosol-free sky is denoted here as the aerosol direct radiative effect (DRE). Here the term "direct" refers to the interaction of aerosols with solar radiation in cloud-free situations and excludes the radiative influences of aerosols within clouds ("indirect" effects). Both DRE and DCF are commonly expressed in units watts per square meter $\left(\mathrm{Wm}^{-2}\right)$.

Local instantaneous changes in shortwave radiative flux due to scattering and absorption of solar radiation by atmospheric aerosols in cloud-free conditions depend on the vertical integrals of the pertinent aerosol optical properties, the vertical distributions of these properties, the solar zenith angle, the surface reflectance and its angular distribution function, and water vapor amount and vertical distribution. The optical properties of the aerosol depend on its chemical com- position and microphysical properties (size distribution, sizedistributed composition, and particle shape), which in many instances are strongly influenced by relative humidity $(R H)$. The aerosol properties required for radiative transfer calculations of DRE are the scattering coefficient $\sigma_{s p}$, the absorption coefficient $\sigma_{a p}$, and the phase function (or in many radiation transfer codes the average of the cosine of the phase function, denoted by the asymmetry parameter, $g$ ). All of these properties must be known as a function of wavelength and as a function of three-dimensional location. In principle these properties can be calculated from Mie theory (or extensions thereof for nonspherical particles) for specified size dependent concentration, composition, shape, and mixing state. Calculations of DCF require the aerosol to be apportioned into natural and anthropogenic components.

Because aerosol concentrations and compositions are spatially inhomogeneous, even the most intensive measurements are not able to represent the quantities needed to calculate DRE. Therefore, the requisite information must be approximated with the help of models. Here the approach taken is to determine DRE and DCF using a semi-empirical approach in which chemical transport models (CTMs) are used to calculate dry mass concentrations of the dominant aerosol species (sulfate, organic carbon, black carbon, sea salt and dust) as a function of latitude, longitude and altitude, and in-situ measurements are used to calculate the corresponding optical properties for each aerosol type (e.g., sea salt, dust, sulfate/carbonaceous) (Fig. 1). Because aerosol composition and optical properties are strongly dependent on particle size the pertinent aerosol properties are determined for two size classes, specifically the accumulation mode (particle dry aerodynamic diameter, $0.1 \mu \mathrm{m}<D_{p}<1 \mu \mathrm{m}$ ) and the coarse mode $\left(1 \mu \mathrm{m}<D_{p}<10 \mu \mathrm{m}\right)$. (Throughout this paper unless otherwise specified, the size variable is the dry aerodynamic diameter; for spherical particles the geometric diameter $D_{g}$ is related to the aerodynamic diameter approximately as $D_{g}=D_{a} / \rho^{1 / 2}$ where $\rho$ is the dry particle specific gravity). Commonly measured aerosol properties pertinent to this approach are for each mode and type:

(1) Mass scattering efficiency $\left(\mathrm{m}^{2} \mathrm{~g}^{-1}\right), \alpha_{s p} \equiv \sigma_{s p} / m$ where $\sigma_{s p}$ and $m$ are the light scattering coefficient and mass concentration of the pertinent aerosol mode.

(2) Single-scattering albedo for each mode, $\omega_{0}$, the ratio of light scattering coefficient to light extinction coefficient (the sum of scattering and absorption coefficients), $\omega_{0}=\sigma_{s p} /\left(\sigma_{s p}+\sigma_{a p}\right)$. Combining $\alpha_{s p}$ and $\omega_{0}$ provides the radiative transfer models with a measure of the mass absorption efficiency.

(3) Hemispheric backscattered fraction, $b$; this quantity is derived from measurements made with an integrating nephelometer as the ratio of the angular corrected backscattering coefficient $\left(90\right.$ to $180^{\circ}$ ) to the total scattering coefficient $\left(0\right.$ to $180^{\circ}$ ). Knowledge of $b$ permits 


\section{Measurement Based Inputs}

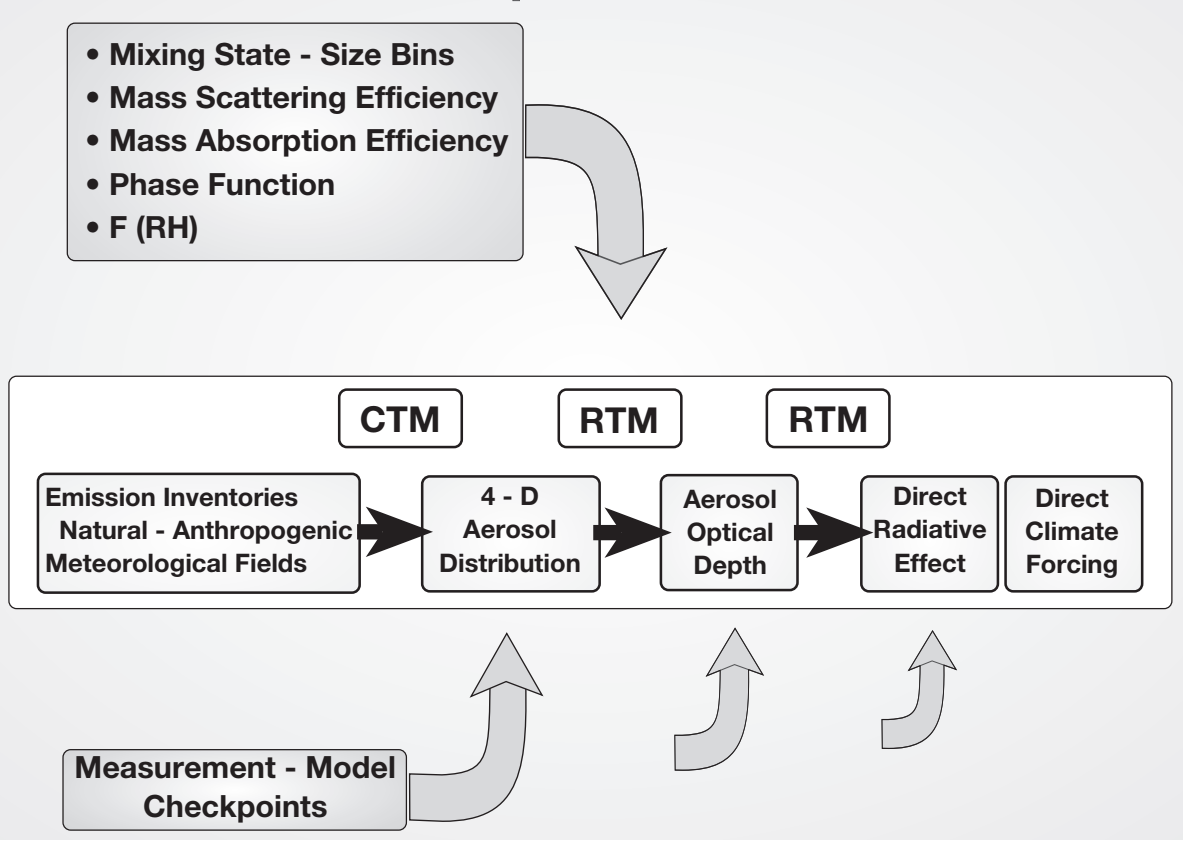

Fig. 1. Schematic of the approach taken here to calculate the direct radiative effect (DRE) and direct climate forcing (DCF) and to narrow their uncertainties. Emission inventories and meteorological fields were used in CTMs to calculate dry 4-D aerosol distributions. The RTMs used these distributions and in-situ measurement based optical properties to calculate aerosol optical depth, DRE and DCF. Measurements and model output were compared at three points in the process.

an estimation of the phase function or asymmetry parameter.

(4) The dependence of aerosol light scattering coefficient on relative humidity relative to that at a low reference relative humidity, $f_{\sigma_{s p}}\left(R H, R H_{\mathrm{ref}}\right)=\sigma_{s p}(R H) / \sigma_{s p}\left(R H_{\mathrm{ref}}\right)$. The single scattering albedo, the hemispheric backscattered fraction, and the asymmetry parameter are likewise functions of relative humidity.

(5) The aerosol extinction optical depth (commonly aerosol optical depth or aerosol optical thickness) is the vertical integral of the aerosol extinction coefficient, $\tau_{e p}=\int \sigma_{e p} d z$. To the extent that the local aerosol extinction coefficient may be expressed as a sum over several aerosol species, then similarly, $\tau_{e p}=\sum \tau_{e p, i}$.

All of the above quantities are functions of wavelength. Measurements at two or more wavelengths permit the wavelength dependence of the optical properties to be determined. The 4-D aerosol distributions from CTM calculations (three spatial dimensions plus time) together with optical properties derived from measurements are then used as input to radiative transfer model (RTM) calculations to determine DRE and DCF.

Another key measured quantity characterizing aerosol radiative influences is the radiative efficiency, $\varepsilon$, defined as the change $\Delta F$ in the pertinent radiative flux component (top of atmosphere or surface) due to scattering and absorption by the aerosol in the column, divided by the aerosol extinction optical depth:

$\varepsilon=\Delta F / \tau_{e p}$

To first approximation (valid at aerosol optical thickness sufficiently small that multiple aerosol scattering is a small fraction of aerosol extinction) DRE and DCF are linear in the amount of aerosol present, as represented by $\tau_{e p}$. Thus, in the limit of low aerosol optical depth, for optical depth $\tau_{A}$ of species $A$ and $\tau_{B}$ of species $B$ the linearity assumption,

$\Delta F=\varepsilon_{A} \tau_{A}+\varepsilon_{B} \tau_{B}$

is expected to hold. This relation is the basis of use of forcing efficiency as a measurable aerosol property that can be compared with observations and used to constrain estimates of DRE and DCF. We note, however, that non-linearities can be important in global-mean calculations.

Aerosol properties have been intensely measured over several regions of the globe in major international field campaigns conducted during the past decade (Yu et al., 2005). These measurements provide in-situ and remotely sensed aerosol data that can be used in calculations of aerosol distributions and their radiative effects. The present study examines DRE and DCF over the North Indian, northwestern 


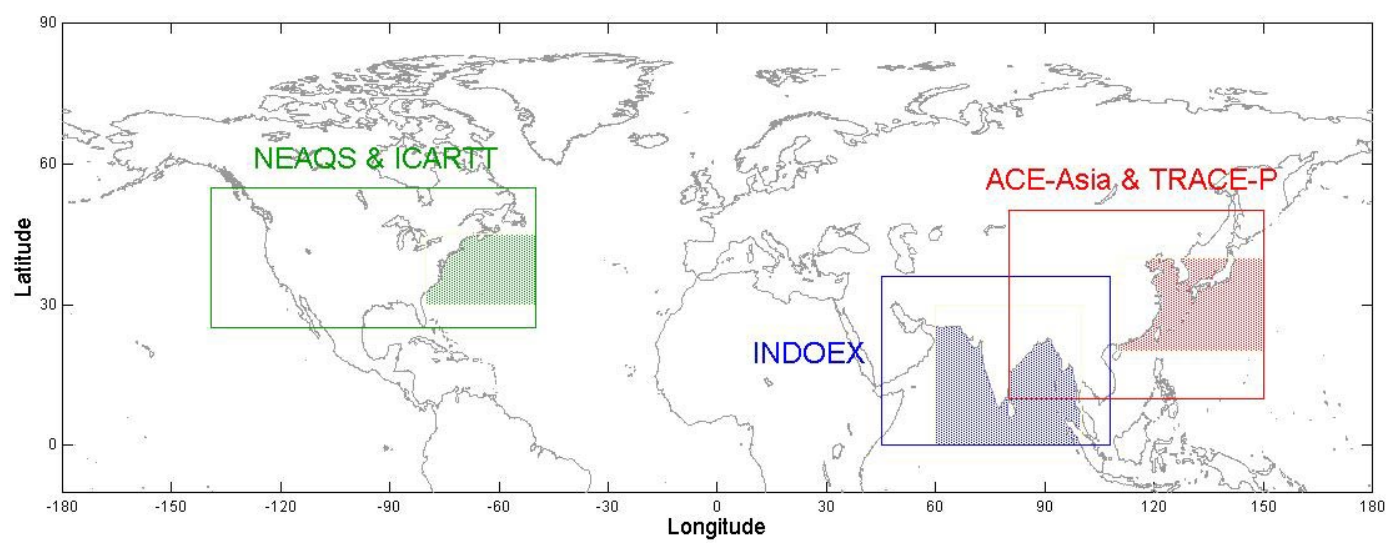

Fig. 2. Location of intensive measurement campaigns that are the sources of data employed in the present study. The solid boxes show the regional CTM domains. The shaded areas show the regions used (with ocean only mask) for the DRE and DCF calculations. In the text these regions are referred to as North Indian Ocean (NIO), northwest Pacific Ocean (NWP) and northwest Atlantic Ocean (NWA).

Table 1. Regions and time periods used in the CTM and RTM calculations.

\begin{tabular}{|c|c|c|c|}
\hline Intensive Campaign & $\begin{array}{c}\text { NIO } \\
\text { INDOEX }\end{array}$ & $\begin{array}{c}\text { NWP } \\
\text { ACE-Asia and TRACE-P }\end{array}$ & $\begin{array}{c}\text { NWA } \\
\text { NEAQS and ICARTT }\end{array}$ \\
\hline \multicolumn{4}{|l|}{ CTM domain } \\
\hline Latitude & $0-36^{\circ} \mathrm{N}$ & $10-50^{\circ} \mathrm{N}$ & $25-55^{\circ} \mathrm{N}$ \\
\hline Longitude & $45-108^{\circ} \mathrm{E}$ & $80-150^{\circ} \mathrm{E}$ & $50-139^{\circ} \mathrm{W}$ \\
\hline \multicolumn{4}{|l|}{ RTM domain ${ }^{\mathrm{a}}$} \\
\hline Latitude & $0-30^{\circ} \mathrm{N}$ & $20-40^{\circ} \mathrm{N}$ & $30-45^{\circ} \mathrm{N}$ \\
\hline Longitude & $60-100^{\circ} \mathrm{E}$ & $110-150^{\circ} \mathrm{E}$ & $50-80^{\circ} \mathrm{W}$ \\
\hline Measurement Time Period & February-March 1999 & March-April 2001 & $\begin{array}{l}\text { July-August } 2002 \\
\text { July-August } 2004\end{array}$ \\
\hline CTM Time Period & 14 February-27 March 1999 & 1 March-15 April 2001 & 1 July-17 August 2004 \\
\hline Overview reference & Ramanathan et al. (2001) & $\begin{array}{l}\text { Huebert et al. (2004) } \\
\text { Jacob et al. (2003) }\end{array}$ & Quinn and Bates (2003) \\
\hline
\end{tabular}

${ }^{\text {a }}$ RTM calculations were restricted to oceanic portions of indicated domains.

Pacific, and northwestern Atlantic Oceans (Fig. 2 and Table 1). These regions are selected because of the large anthropogenic aerosol sources upwind of these ocean basins and the availability of suitable measurement data sets: North Indian Ocean (1999 - INDOEX); northwestern Pacific Ocean (2001 - ACE-Asia and TRACE-P); and northwestern Atlantic Ocean (2002 - NEAQS; 2004 - ICARTT). Aerosol concentrations and their radiative impacts are particularly large in these regions, with diurnally averaged clear-sky surface DRE as great as $-30 \mathrm{Wm}^{-2}$ (Russell et al., 1999; Ramanathan et al., 2001; Conant et al., 2003); here the negative sign denotes a decrease in the net incoming radiative flux to Earth. Restriction of the examination to ocean areas, which are characterized by low surface reflectance, minimizes the influence of uncertainty in this reflectance.

This study summarizes in-situ data from these regions from the above named campaigns (Sect. 3), compares the data from these campaigns with available longer term monitoring data (Sect. 3), compares the chemical data from the intensive campaigns with results of CTM calculations (Sect. 4), and uses the CTM distributions and in-situ measured aerosol optical properties in RTMs to calculate regional aerosol optical depth, DRE, DCF, and aerosol radiative efficiency (forcing per unit optical depth) (Sect. 5). This analysis is one of three aerosol-related studies being prepared for the Climate Change Science Program (CCSP) to support policymaking 
and adaptive management. A goal of the CCSP is to improve quantification of the factors contributing to changes in Earth's climate and related systems (CCSP, 2004). The purposes of this study are (1) to review the measurement-based understanding of the chemical and optical aerosol properties downwind of North America, India, and Asia; (2) to use this measurement-based understanding to calculate DRE, DCF, and aerosol radiative efficiency in these areas and (3) to compare this measurement-based approach to previous calculations (e.g., IPCC, 2001) of DRE, DCF, and aerosol radiative efficiency that are used in global parameterizations.

\section{Background}

This section sets forth pertinent general concepts and definitions of the several aerosol types treated in the models and summarizes properties of these aerosols pertinent to their forcing and to the modeled representation of this forcing.

Bulk analysis of atmospheric aerosol reveals it to be a complex mix of water-insoluble components (often mineral dusts, flyash, some water insoluble organic carbon, and black carbon) and water soluble components (sulfates, nitrates, sea-salt, ammonium and organic acids as well as other organic carbon compounds) (Podzimek, 1990; Quinn and Bates, 2004; Sellegri et al., 2003; Cavalli et al., 2004; O'Dowd et al., 2004). The state of mixing of this atmospheric aerosol has long been recognized as being important for understanding and modeling the role of aerosol in the atmosphere. Models for estimating aerosol radiative effects or interpreting satellite radiances need to specify whether the aerosols are being treated as internal or external mixtures over the relevant size classes (Jacobson, 2001; Lohmann et al., 1999; Riemer et al., 2004).

Although a range of distinctions might be made when defining mixing states, here, for the purpose of calculating optical properties external and internal mixtures are defined as follows:

External Mixture - Different aerosol components are present in separate particles. Absorption and scattering coefficients are additive among the separate components.

Homogeneous Internal Mixture - Different aerosol components within a given size range comprise a uniform, homogeneous mixture in all particles associated with those components.

These definitions, which may be considered as limiting cases of a continuum of situations, serve as the basis for modeling the aerosol optical properties and radiative influences reported here.

Often models of aerosol optical properties and forcing represent these aerosols as external mixtures because this treatment is convenient to implement (Liousse et al., 1996;
Mishchenko et al., 2004). However, if the aerosol is internally mixed this simplification may not adequately represent the optical properties (Chylek et al., 1995; Fuller et al., 1999) or its response to changing humidity (Martin, 2000; Martin et al., 2003). Because the soluble components take up water at relative humidity $(R H)$ below $100 \%$, water is often a major constituent of aerosol particulate matter. The amount of condensed-phase water present in the aerosol increases as the $R H$ increases and changes the scattering properties of the aerosol (Tang, 1996; Carrico et al., 2003). This uptake of water influences the scattering coefficient mainly through size and is partially offset by changes in refractive index. Additionally, some insoluble species like soot or dust may have their light scattering and absorbing properties substantially increased when coated by or mixed with soluble species (Chylek et al., 1995; Fuller et al., 1999; Mishchenko et al., 2004). Consequently, the size dependent state of mixing of the aerosol is needed to properly relate ambient radiative properties to the composition and microphysical structure of the aerosol and the associated optical properties of this aerosol.

Separation of the aerosol into fractions having dry aerodynamic diameters nominally greater than and less than $1 \mu \mathrm{m}$ is commonly employed (Quinn and Bates, 2004; Quinn et al., 2000) to help distinguish characteristics of the accumulation and coarse modes. However, in practice the separation used in this approach does not isolate the overlapping tails of these separate modes, and this must be kept in mind when interpreting bulk size-classified chemistry (Sect. 3.4). Even with separation into these two size categories, it is not possible to determine the state of mixing of the aerosol from such bulk measurements. Size resolved measurements of aerosol volatility have helped distinguish refractory (e.g. soot, dust, sea-salt) vs. non-refractory species (sulfates, nitrates and organic carbon) (Clarke et al., 2004). Size selective tandem differential mobility analyzers equipped with humidity control (Swietlicki et al., 2000; Zhou et al., 2001) permit inferences to be drawn about mixing state from size-resolved growth or, when followed by thermal volatility analysis (Burtscher et al., 2001; Clarke et al., 2004; Johnson et al., 2004a; Philippin et al., 2004) permit identification of the refractory fraction of the mixed aerosol within a size class. Single-particle microscopic analysis has been used to directly identify particle mixing state (Andreae et al., 1986; Posfai et al., 1999; Pósfai et al., 2003), and new results using soft X-ray spectromicroscopy (Maria et al., 2004; Russell et al., 2002) provide detailed maps of organic carbon functional groups and regions of different compositions within individual particles. Although such techniques are revealing, they can be laborious and slow, and their representation of the aerosol population is often statistically uncertain. Single-particle aerosol mass spectrometers, by providing rapid size-resolved characterization of the chemical mixing state of single particles, allow a greatly improved statistical representation of the properties of individual particles (Cziczo et al., 2004; Guazzotti 


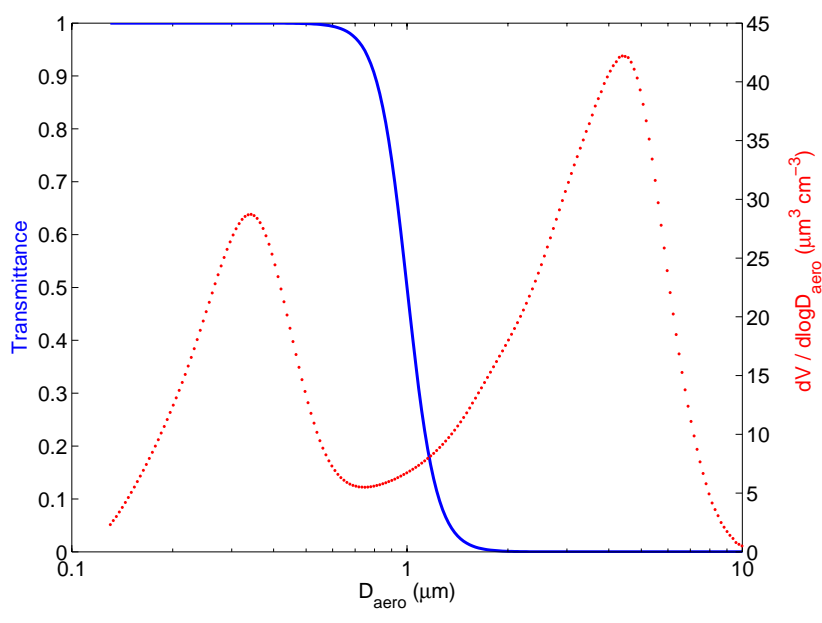

Fig. 3. Transmittance of Berner-type impactor having size cut at aerodynamic diameter $D_{\text {aero }}=1 \mu \mathrm{m}$ as function of $D_{\text {aero }}$ showing sigmoidal size cut (Wang and John, 1988). The dotted curve shows a representative "dry" bimodal volume size distribution $d V / d \log D_{\text {aero }}$ measured over the north Pacific (Clarke et al., 2004).

et al., 2003; Murphy et al., 1998b), although questions remain about the quantitative interpretation of the mass spectra to yield composition of individual particles. These new techniques are providing the critical information needed to relate aerosol chemical and optical properties.

The following discussion summarizes current understanding of the effective state of mixing for ambient aerosol sizes and those properties most important for modeling or interpreting aerosol direct radiative effects at visible wavelengths. In this context, the aerosol particles of greatest importance have dry diameters between approximately $100 \mathrm{~nm}$ and $10 \mu \mathrm{m}$ because particles with sizes outside of this range generally contribute little to radiative effects at visible wavelengths. For smaller particles both the mass concentration and the mass scattering efficiency are quite small. For larger particles atmospheric residence times are generally sufficiently short that the particles contribute little to scattering and absorption on regional scales.

In the discussion of aerosol properties and radiative effects aerosols are generally distinguished into two modes, by size, the accumulation mode (particle dry aerodynamic diameter, $0.1 \mu \mathrm{m}<D_{p}<1 \mu \mathrm{m}$ ) and the coarse mode $\left(1 \mu \mathrm{m}<D_{p}<10 \mu \mathrm{m}\right)$. Observationally the two modes are nominally resolved with an impactor with a $50 \%$ aerodynamic cutoff diameter of $1 \mu \mathrm{m}$ (Fig. 3), which is applied after the aerosol has been dried to a low relative humidity. It should be stressed that there is transmittance of the tail of the coarse-mode into the small size cut and vice versa, confounding the interpretation.

A further consideration with respect to most measurements is that the upper limit of the coarse mode (again using a Berner-type impactor) is restricted to $10 \mu \mathrm{m}$ aerodynamic diameter. This is done for two reasons. First, most measurements have poor (and poorly known) sampling efficiencies for larger particles, and second, the contributions by larger particles to aerosol scattering and absorption at visible wavelengths are generally small, even when there is substantial particle mass concentration in this size range. Summarizing measurements of the size distribution of sea salt aerosol, Lewis and Schwartz (2004) showed that the mass concentration distribution, $d M / d \log r_{80}$, peaks at a value of $r_{80}$ (radius at $80 \%$ relative humidity, roughly equal to dry diameter) of about $7 \mu \mathrm{m}$, with roughly half of the sea salt aerosol mass in the $r_{80}$ range 3.5 to $15 \mu \mathrm{m}$. Similarly the light scattering coefficient of sea salt aerosol, $d \sigma / d \log r_{80}$, peaks at $r_{80}=2.5 \mu \mathrm{m}$, with roughly half of the light scattering coefficient in the $r_{80}$ range 1.25 to $5 \mu \mathrm{m}$. The mass scattering efficiency is inversely proportional to particle size. Hence, the mass scattering efficiency for particles having dry diameters greater than $10 \mu \mathrm{m}$ is much smaller than values generally reported for coarse-mode aerosol extinction. This sampling strategy has implications on the choice of mass scattering efficiency to be employed in the comparisons with observations and in the calculations of aerosol optical depth and direct radiative effect. Here, the scattering coefficient is modeled as the product of the modeled mass concentration and the mass scattering efficiency measured for particles having dry diameters less than $10 \mu \mathrm{m}$. If a large mass concentration above $10 \mu \mathrm{m}$ were included in the model calculation together with the measured mass scattering efficiency of $1-10 \mu \mathrm{m}$ particles, unreasonably large scattering would be generated.

\subsection{Aerosol in the free troposphere}

Measurements of the composition of individual accumulation-mode particles $\left(0.1 \mu \mathrm{m}<D_{p}<1 \mu \mathrm{m}\right)$ in the free troposphere show that organic carbon and sulfates are both present in most particles and at times in comparable amounts (Brock et al., 2004; Murphy et al., 1998b; Novakov et al., 1997). Even in the remote free troposphere a substantial fraction of the accumulation mode particles can originate from biomass burning and other continental sources (Hudson et al., 2004; Moore et al., 2003; Posfai et al., 1999; Sheridan, 1994), with substantial additional mass added through continued photochemical production of sulfates, nitrates, and organic carbon. Although generally only a very small mass fraction of the aerosol in the remote free troposphere consists of refractory soot or other primary anthropogenic particles, presumably because of uptake of secondary particulate matter onto these particles during transport from surface sources to the free troposphere (Brock et al., 2004; Sheridan, 1994), the number fraction of particles with such refractory cores can be as great as 50\% (Clarke and Kapustin, 2002).

During pronounced transport events, often evident during March/April over the North Indian Ocean and North 
Pacific Ocean, June/July over the equatorial Atlantic Ocean, or September/October over the South Atlantic Ocean, both accumulation-mode and coarse-mode aerosol can be present in the free troposphere at concentrations comparable to those observed near sources even after transport as far as $10000 \mathrm{~km}$ (Clarke et al., 2001; Jaffe et al., 2004; Moore et al., 2003; Sellegri et al., 2003). Often multiple distinct plumes of air with characteristics of different sources are present at different altitudes over the same location and interleaved between more typical remote free troposphere aerosol. An example is shown in Fig. 4. Such plumes in the free troposphere tend to dominate aerosol optical properties within the column (Clarke and Kapustin, 2002). During dust transport events in the free troposphere, coarse-mode crustal particles often contain trace amounts of sulfate, ammonium, nitrate, and/or organic carbon resulting from condensation of precursor gases. Particles derived from organic matter produced from biomass combustion, identified by the presence of trace amounts of potassium, also contribute substantially to the supermicrometer mode on an episodic basis. Observations such as these demonstrate the need for accurate modeling of the 3$\mathrm{D}$ aerosol fields if the radiative influence of these aerosols is to be accurately represented in global models.

\subsection{Aerosol in the marine boundary layer}

The ocean is a source of primary and secondary aerosols to the overlying marine boundary layer. Continental aerosols are often also a major component of the aerosol over the oceans because of residence times of days to weeks, together with the typical speeds of boundary-layer transport winds $\left(5 \mathrm{~m} \mathrm{~s}^{-1} \approx 500 \mathrm{~km} \mathrm{day}^{-1}\right)$. In the present context, continental aerosols may be distinguished into several broad categories: primary aerosols from windblown dust, primary aerosols from mobile and stationary combustion sources, and secondary aerosols from gas-to-particle conversion of natural and anthropogenic gaseous precursors (these may be either new particles formed by nucleation in the atmosphere, or they may form from gas-to-particle conversion that can add particle mass to existing aerosol particles). These several categories are briefly discussed here in the context of the present examination of DRE in the marine atmosphere.

\subsubsection{Primary sea-spray aerosol}

Sea-spray aerosol particles, which are produced by bubblebursting and wave-tearing processes, consist both of inorganic sea-salt ions and biogenic organic compounds that had been preferentially concentrated in the ocean-surface microlayer. Sea-salt production and concentration have been studied extensively and have been quantified as the largest global aerosol mass flux, dominating all aerosol types in most remote marine regions (Warneck, 1988; Lewis and Schwartz, 2004).
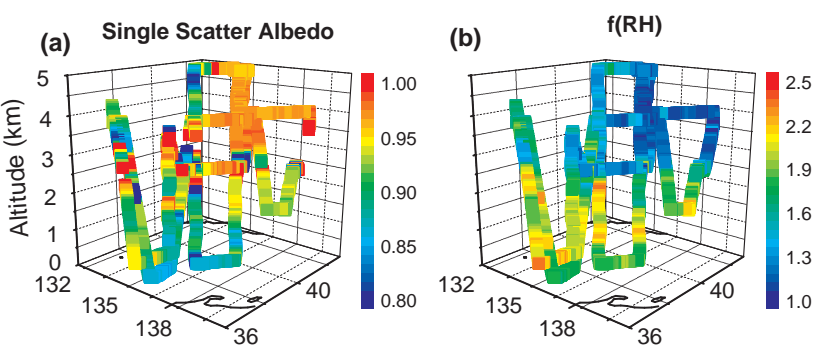

(c) $\quad \mathrm{PIS} \mathrm{Ca}^{2+}\left(\mu \mathrm{g} / \mathrm{stdm}^{3}\right)$

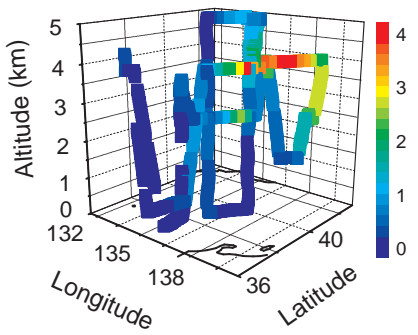

(d) $\mathrm{PILS} \mathrm{SO}_{4}^{2-}\left(\mu \mathrm{g} / \mathrm{stdm}^{3}\right)$

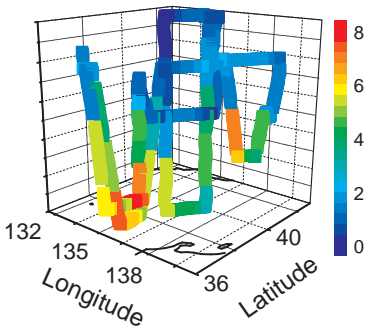

Fig. 4. Typical spatial scales, variability and coupling between aerosol optical properties and related chemical signatures are shown for data collected during ACE-Asia aboard the NSF/NCAR C-130 (Anderson et al., 2003; Clarke et al., 2004; Lee et al., 2003). This flight path for 8 April 2001 represents a box approximately $400 \mathrm{~km}$ square and $5 \mathrm{~km}$. Dust outflow at larger altitudes to the north is evident from the aerosol exhibiting large single scattering albedo (a), a low humidity dependence of the scattering coefficient $f \sigma_{s p}(80,40)$ (b), and large calcium concentrations (c). Combustion derived aerosols near the surface to the south are evident from the large concentrations of sulfate (d) and consequent large values of $f \sigma_{s p}(80,40)(b)$. These aerosols also contain large concentrations of black carbon (not shown) which result in small single scattering albedo values (a). The concentrations of ionic species were measured with a particle-into-liquid sampler (PILS) and ion chromatograph. The species mixing ratios are given at 1 atmosphere and $25^{\circ} \mathrm{C}$.

In regions of low biological activity, recently formed seaspray aerosol consists mainly of sea-salt aerosol from breaking waves. This material is essentially externally mixed with other aerosol species when present, throughout the dry diameter range 0.010 and $20 \mu \mathrm{m}$ (Clarke et al., 2003). Freshly emitted sea-salt is dominated by a mixture of oceanic salts, but other substances (e.g., methansulfonate, sulfate) may subsequently admix with sea salt as it ages (Andreae et al., 1986; Chameides and Stelson, 1992; Clarke and Porter, 1993; Murphy et al., 1998a; Quinn and Bates, 2004). It has been demonstrated that the light scattering properties of these internally mixed salts can be accurately calculated as if they were external mixtures (Tang et al., 1997). Some internal mixing with dust has been identified in near surface samples downwind of dust source regions (Zhang and Iwasaka, 2004) and a few samples in the remote Pacific (Andreae et al., 1986), but it is not clear how frequently such situations occur. 
Recent improvements in aerosol sampling and analysis techniques have yielded a growing body of evidence that primary sea spray particles frequently contain organic carbon (Middlebrook et al., 1998; Allan et al., 2004). Recently it has been argued from bulk aerosol analysis that over the biologically productive North Atlantic Ocean, organic carbon could comprise more than $50 \%$ of the sub-micrometer mass (O'Dowd et al., 2004); however, in supermicrometer sea spray aerosol the organic mass is a few percent at most (Lewis and Schwartz, 2004). In the study by O'Dowd et al. (2004), the majority of the organic matter was present as non-water soluble organic carbon, suggesting that the water uptake and hygroscopic growth factor of sub-micrometer sea-spray enriched in organic matter would be substantially less than that for inorganic sea-spray. The significance of internally mixed organic carbon upon the hygroscopic properties of the sea-salt aerosol remains unclear. Common terpenes evidently exert no effect (Cruz and Pandis, 2000), whereas some other organic carbon compounds result in suppression of the rate or extent of hygroscopic growth (Wise et al., 2003). The latter is shown also in model calculations (Ming and Russell, 2001; Randles et al., 2004). However for the coarse mode any such effects are assumed here to be small.

\subsubsection{Primary dust aerosol}

Soil dust is a primary continental emission that is transported to the marine environment. The mass of this aerosol component is mainly in the diameter range greater than $1 \mu \mathrm{m}$. In and near dust-source regions where there has been little opportunity for internal mixing with other aerosol components, dust aerosol is present in the atmosphere principally as an external mixture with other common aerosol substances. When dust is advected through a source region for aerosol precursors (e.g., urban emissions, biomass burning) it can adsorb a substantial amount of available condensates onto particle surfaces or can participate in surface reactions (Dentener et al., 1996; Song and Carmichael, 2001; Bauer et al., 2004; Liao and Seinfeld, 2005). Based upon correlation analysis of major ions it has been argued (Song et al., 2005) that dust aerosols with diameters below $1.3 \mu \mathrm{m}$ passing over Asia were $70 \%$ externally mixed and $30 \%$ internally mixed with sulfate. This extent of internal mixing is consistent with microscopic analysis (Zhang et al., 2003b), spectroscopic measurements (Maria et al., 2004, 2003), and volatility studies (Clarke et al., 2004), and recent model studies (Tang et al., 2004) have accurately represented this. Bulk measurements on larger size particles have shown coarse-mode dust associated with organic carbon, nitrate and sometimes sulfate (Bates et al., 2004; Huebert, 2003; Quinn and Bates, 2004), but these species added only about $5 \%$ to the dust mass concentration (Quinn and Bates, 2004). The mass uptake of these species appears to depend on dust surface area (Howell et al., 2004). Because optical properties of coarse- mode aerosols were already dominated by dust, this incremental increase in mass would have little impact on radiative effects. Moreover, the internal mixing of these species with dust appears to have little influence on the change in light scattering with humidity (Carrico et al., 2003), suggesting that the optical properties of dust can be accurately modeled as not being significantly dependent on $R H$. Observed small increases in aerosol light scattering coefficient with $R H$ under dusty conditions are attributed primarily to the presence of accumulation-mode aerosol (Howell et al., 2004). Hence, for radiative purposes the dust mode can be considered to exist as an external mixture with other aerosol modes. However, the increase in soluble properties may reduce the atmospheric lifetime of the dust by enhancing the ability of these particles to serve as cloud condensation nuclei.

Although the effect of various secondary aerosol species accumulating on dust exerts a small effect on the optical properties of the dust, the diversion of these species from the accumulation mode, with its larger mass scattering efficiency, onto the coarse mode may substantially reduce the contribution of these species to aerosol light scattering. This repartitioning of the condensable accumulation mode substantially reduced the single scatter albedo of the accumulation mode during ACE-Asia (Clarke et al., 2004). The repartitioning to coarse sizes also decreased the $f(R H)$ of the accumulation mode compared to values without dust. This loss has been estimated to lead to about a $10 \%$ reduction in accumulation mode $f(R H)$ under elevated dust cases (Howell et al., 2004).

In contrast to electron microscope measurements of particles collected from aircraft (Clarke et al., 2004), such measurements on particles collected near the surface in Southern Japan (Zhang et al., 2003a, b) found $80 \%$ of the dust particles to be internally mixed with sea-salt. It was argued that this mixing had occurred in cloud-free air despite the fact that clear air coagulation rates for particles of these sizes is expected to be negligible. However, a near surface shallow marine inversion in this region was often decoupled from most of the MBL (McNaughton et al., 2004) such that the aircraft and ground based measurements may not be comparable. Also, although supermicrometer dust and sea-salt were both observed in nearby shipboard bulk measurements (Quinn et al., 2004), single-particle mass spectrometer data did not reveal substantial internal mixing (S. A. Guazzotti, personal communication, 2004). Hence, it is unclear if the coastal data are representative. In contrast, measurements in aged air in the Central Pacific found between 2 and $28 \%$ of the coarse sea-salt to be associated with crustal elements; this mixing was attributed to collision and coalescence during cloud passages (Andreae et al., 1986). Although internal mixing of dust and sea salt might impact dust removal efficiencies via precipitation, such mixing would be expected to have little impact on optical effects (Bauer and Koch, 2005). Hence, in general, modeling sea salt and dust as external mixtures appears justifiable, and that is the approach taken here. 


\subsubsection{Secondary marine aerosol}

Secondary particles are formed in the atmosphere from gasto-particle conversion processes. Secondary marine aerosol consists predominantly of nss-sulfate and condensable organic vapors with the sulfur cycle being the more studied and better quantified of the two. Sulfate aerosol can be formed via nucleation and growth processes; however, it is thought that the majority of nss sulfate is formed through heterogeneous processes either on sea-salt and dust aerosol in cloud free conditions or within clouds where they would become associated with the cloud condensation nuclei upon evaporation. Both processes lead to an increase in mass of existing aerosol particles, although the relative contribution to total mass in the supermicrometer mode is negligible. Organic matter associated with submicrometer marine aerosol particulate matter produced by secondary processes is not well quantified relative to primary organic aerosol production, nevertheless, it is expected to lead to substantial internal mixing under certain conditions.

\subsubsection{Primary and secondary combustion aerosol}

Fossil fuel combustion and biomass burning generate aerosols that are major contributors to DRE. Combustion aerosol is extremely complex and variable because of the diverse nature of sources and details of the combustion process. It commonly includes the primary light-absorbing aerosol (black carbon), organic carbon, and coarse particle fly ash. Because black carbon is formed at high temperatures (over $600^{\circ} \mathrm{C}$ ) it is one of the first species to form in combustion plumes and appears to provide a site upon which other condensable or reactive species accumulate (Clarke et al., 2004). However, in biomass and biofuel emissions, particularly under smoldering conditions, organic polymers or so-called "tar-balls" also form (Pósfai et al., 2004). These particles, which are generally much fewer in number, also age to become internally mixed with other aerosol components. In addition, combustion techniques and emission controls vary locally and regionally (Bond et al., 2004). Hence, a brief discussion of combustion emissions and state of mixing is included here.

A major source of primary particulate emissions is mobile sources, including gasoline and diesel-powered vehicles, which introduce large numbers of particles into the atmosphere. Generally most of the particles by number are in the nuclei mode, below $50 \mathrm{~nm}$ diameter (Kittlelson, 1998), whereas the majority of the particle mass is typically between 100 and $200 \mathrm{~nm}$ aerodynamic diameter (Kleeman et al., 2000). Aerosol mass from gasoline fueled vehicles is about $80 \%$ organic carbon, $2 \%$ black carbon with the remainder ash and other compounds; in contrast, for medium-duty diesel vehicles, over $60 \%$ of the emitted mass is black carbon, with most of the rest organic carbon (Kleeman et al., 2000). For a heavy duty diesel under load about $40 \%$ of the emitted mass is black carbon, $30 \%$ organic carbon, dominated by unburned fuel and oil, $15 \%$ sulfate and water and the remaining $15 \%$ ash and other compounds. However, the organic fraction varies widely with engine and operating conditions, from 10 to $90 \%$, being largest for light loads and lower exhaust temperatures (Kittlelson, 1998). About 80\% of the particles exiting the tailpipe are black carbon internally mixed with other components (Kittlelson, 1998). Twostroke engine vehicles constitute a major share of the motor vehicle fleet in Asian countries and contribute substantially to ambient aerosol (Faiz et al., 2004). Particulate emissions consist mainly of unburned or partially oxidized heavy hydrocarbons and sulfates, either originating from the lubricating oil or from the fuel (Canagaratna et al., 2004; Rijkeboer et al., 2005).

Other potentially significant mobile combustion sources of particles are ocean-going ships and aircraft. Ships have primary emissions of $\mathrm{NO}_{\mathrm{x}}, \mathrm{SO}_{2}$, and particles, with the particles being composed of mainly black and organic carbon and lower levels of sulfate (Hobbs et al., 2000; Sinha et al., 2003; Williams et al., 2006 ${ }^{1}$ ). The $\mathrm{SO}_{2}$ emissions from oceangoing ships are estimated to constitute as much 3-4\% of the total global emissions from fossil fuel burning (Sinha et al., 2003). Global aircraft primary emissions of soot and $\mathrm{SO}_{2}$ are significantly less than for ships and comprise a very small fraction of the total fossil fuel emissions (Fahey and Schumann, 1999). These combustions sources generally have a more significant impact on small regional scale cloud formation processes than for global DRE and DCF (Durkee et al., 2000; Minnis et al., 1999).

Fixed sources, including power generation facilities, constitute the major sources of sulfur dioxide, which oxidizes in the atmosphere to form aerosol sulfate. These resulting sulfate aerosols, which can be formed by gas-phase reactions in clear air and by aqueous-phase reactions in clouds, can be present in different size classes depending on the phase in which oxidation takes place and also on the size of the particle on which sulfuric acid formed in the gas phase condenses. Emissions vary substantially with the nature of the fuel, the efficiency of the combustion process, the condition of the equipment and the application of emission controls (if any) (Bond et al., 2004). Point source primary emissions also include fly ash, particles composed of predominantly inorganic oxidized material (like dust) but with a distinct spherical morphology (Mamane et al., 1986; Shi et al., 2003).

A major aerosol source of global significance is biomass burning. Andreae and Merlet (2001) have estimated that $80 \pm 40 \mathrm{Tg} \mathrm{yr}^{-1}$ of total particulate matter are emitted globally by biomass burning though more recent estimates (which vary year by year) range from $50-65 \pm 30 \% \mathrm{Tg} \mathrm{yr}^{-1}$ (Ito and Penner, 2005). This source exhibits a wide range of fuel

\footnotetext{
${ }^{1}$ Williams, E. J., Lerner, B. M., and Middlebrook, A. M.: Measurements of marine vessel emissions, J. Geophys. Res., in preparation, 2006.
} 
types, burning temperatures and conditions (Liousse et al., 1996), with resultant changes in the amount and nature of the aerosol emitted per mass of biomass combusted. Carbonaceous aerosol can be the dominant accumulation-mode constituent comprising on average $80 \%$ of the sub-micrometer mass downwind of African biomass fires (Formenti et al., 2003). Aircraft measurements of lofted biomass combustion aerosols have shown that these particles evolve from a more primary soot-like aerosol to an internally mixed aerosol within an hour or so and that this evolution can involve physical, morphological and chemical changes (Liousse et al., 1996; Pósfai et al., 2003). These changes resulted in the light scattering efficiency initially decreasing with time as the particles underwent rapid modification due to coagulation and condensation. Further downwind the light scattering efficiency increased as the accumulation-mode diameter shifted to larger sizes more efficient in scattering (Formenti et al., 2003).

\subsubsection{Other secondary aerosols}

In general, by the time newly nucleated aerosol particles have grown to diameters approaching $100 \mathrm{~nm}$ where their DRE becomes appreciable, most have become internally mixed with other components, as demonstrated by single-particle mass spectrometry and electron microscopy. This mixing is due primarily to condensation of gas-phase precursors such as sulfuric acid, ammonia, and low-vapor-pressure organic compounds (Maria et al., 2004; Murphy and Thomson, 1997; Zhang et al., 2004). Nitric acid can also partition to the particle phase in the presence of sufficient quantities of ammonia; this partitioning is strongly dependent on temperature (Stelson and Seinfeld, 1982; Neuman et al., 2003). Secondary organic aerosols (SOA) are produced via oxidation of precursor volatile organic compounds (VOCs). Although monoterpenes (from biogenic sources) and aromatic compounds (from anthropogenic sources) oxidize readily to form low volatility products and are thought to be the largest contributors to SOA, other chemistry may be involved on longer time scales to convert additional organic carbon into SOA such as acid-catalyzed reactions, polymer formation, or other post-secondary chemistry (Jang et al., 2002; Limbeck et al., 2003; Claeys et al., 2004; Kalberer et al., 2004; Gao et al., 2004; deGouw et al., 2005). Furthermore, oxidation of biogenic VOCs (e.g., alpha-pinene) could occur by anthropogenic secondary species (e.g., ozone), thereby complicating the distinction between natural and anthropogenic aerosols. Recent analysis of vapor pressure data for various organic carbon compounds identified in tropospheric organic particulate matter, suggests that condensation and repartitioning between gas and condensed aerosol phases appears likely to take place on a time scale of hours or less (Marcolli et al., 2004).

\subsection{Treatment of internal/external mixtures in this study}

While recognizing that most aerosol is internally mixed to some degree, the details of the mixing state can be simplified in order to capture their optical properties with acceptable uncertainty. If species such as sulfates and organics add to dust or sea-salt without appreciably changing their optical properties (within, say, 5\%) from those which would be modeled by assuming they are external mixtures, then these mixtures can be treated as external mixtures for radiative transfer objectives. To be sure, size modes as specified in models will often extend over the nominal $1 \mu \mathrm{m}$ aerodynamic cutpoint often used to separate the measured "coarse" and "fine" aerosol optical scattering properties and this size mode overlap must be considered when comparing model results with actual size-resolved data. However, when the radiative contributions of dust and sea-salt are appreciable, any internal mixing of other species has negligible effects on the radiative properties of the supermicrometer fraction.

In contrast, the mixing state of refractory black carbon/soot exerts a considerable impact on its optical properties. Mass concentrations of refractory black carbon or soot particles peak in the accumulation mode. As these particles provide condensation sites for soluble species, they age rapidly to become internally mixed. Even when comprising $10 \%$ or less of the mass of aerosol particulate matter (e.g., Clarke et al., 2004; Quinn and Bates, 2003; Riemer et al., 2004), black carbon can dominate the light absorbing properties. The nature of the mixing state plays an important role because "coatings" of organic carbon, soluble inorganic species, or water can increase the effective mass absorption coefficient of black carbon by up to a factor of two, depending upon various parameters (Chylek et al., 1995; Fuller et al., 1999; Jacobson, 2001), although typical enhancements are expected to be smaller. This effect has recently been confirmed for laboratory controlled deposits of organic carbon (alpha-pinene) on diesel soot particles of sizes typical of such particles in the ambient atmosphere (Saathoff et al., 2003). The chainlike soot aggregates collapsed to more compact structures, resulting in a $30 \%$ increase in the mass absorption coefficient. Additionally the accompanying increase in hygroscopicity relative to that of hydrophobic fresh soot leads to an increase in scattering efficiency with increasing relative humidity.

Based on the above discussion, the aerosol in the marine atmosphere as treated in this study is categorized into four externally mixed components: sub- $\mu \mathrm{m}$ sulfate/carbonaceous, sub- $\mu \mathrm{m}$ and super- $\mu \mathrm{m}$ dust, and super$\mu \mathrm{m}$ sea salt. The concentrations of these aerosol components calculated by the chemical transport models are compared to measurements, which are categorized in the same way, and the optical properties and radiative effects of the aerosol are likewise calculated for these four components The sulfate/carbonaceous component is treated as a homogeneous internal mixture consisting of sulfate and associated cations, 

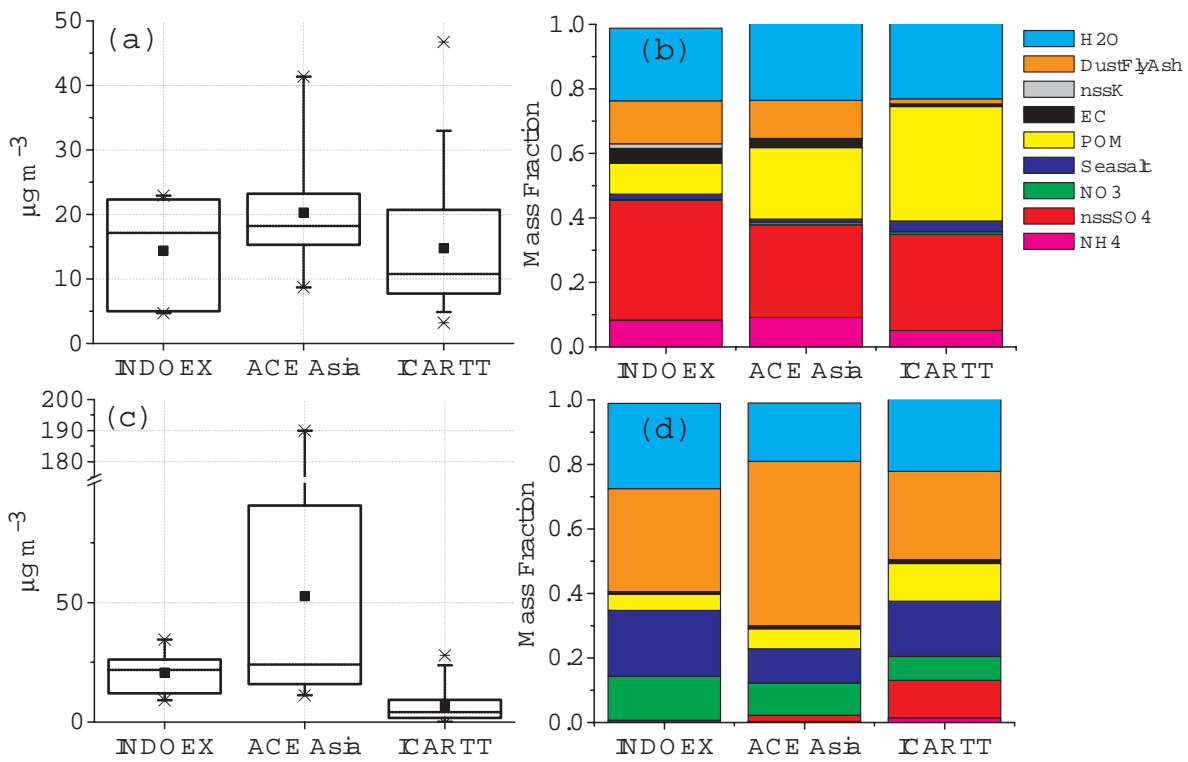

Fig. 5. Submicrometer (a) mass concentrations and (b) mass fractions of the dominant chemical components for the three regions as measured on Ronald H. Brown. Also shown are supermicrometer (c) mass concentrations and (d) mass fractions. The horizontal lines in the boxes denote the 25th, 50th, and 75th percentiles. The whiskers denote the 5th and 95th percentile values. The $\mathrm{x}$ denotes the 1 st and 99 th percentile. The square symbols represent the mean. Mass concentrations and mass fractions are reported at $55 \% \mathrm{RH}$.

principally ammonium, and the carbonaceous component, consisting of organic carbon and black carbon. Non-sea-salt sulfate is calculated from the measurements as total sulfate minus the sea-salt component, as based on the composition of bulk sea-salt (i.e., the sea-salt sulfate concentration equals 0.252 times the sodium concentration). For this work, nitrate is not considered a separate aerosol type as, in the regions considered, nitrate is typically associated with supermicrometer sea-salt and/or dust and therefore contributes minimally to the aerosol optical properties. The proportion of the absorbing, black carbon component relative to that of the nonabsorbing, light scattering material is variable, as calculated by the chemical transport models and as inferred from the measured single scattering albedo. The mass concentrations of the two size components of dust are inferred from measurements using concentrations of aluminum, silicon, and/or iron for an assumed average mineral composition. Sea salt is composed primarily of sodium chloride and additional inorganic ions, with total concentration inferred from measurements of concentrations of sodium or magnesium.

\section{Properties of aerosols over the northwest Atlantic, northwest Pacific, and North Indian Oceans}

This section presents an overview of measurements of aerosol mass loading, composition and microphysical and optical properties in the several regions for which aerosol DRE is evaluated. These measurements have been obtained over an extended period by several long-term monitoring studies and during relatively short intensive field campaigns.
The latter provide a much more detailed characterization of aerosol properties and, as well, provide aircraft measurements to yield vertical distributions of these properties. These quantities provide a basis for calculation of the aerosol optical properties pertinent to these regions and are used to compare, constrain, and further develop the CTMs (Sect. 4).

\subsection{Chemical measurements}

Mass concentrations of aerosol constituents measured during the intensive field campaigns in the three regions selected for this study are summarized in Tables 2, 3 and 4 and Fig. 5. Details on measurement methods and sampling protocols are described in the individual papers referenced in the tables. The data within the several regions are classified according to air mass history to illustrate, for example, differences in the aerosol concentrations over the Indian Ocean when the air had passed over the Indian subcontinent vs. the Arabian Peninsula. The standard deviations serve as a measure of the spatial and temporal variability of these concentrations in the several regions. Much of this variability is attributed to the fact that the sampling intervals varied on the different platforms and between field campaigns. Additionally, because different instrumentation and sampling protocols were used in the several campaigns, the data sets are not directly comparable across the several campaigns. Of the several data sets, the shipboard measurements, recently summarized by Quinn and Bates (2005), having been made on the same research vessel using identical instrumentation and sampling protocols, are the most directly comparable. 
Table 2. Means and standard deviations of measured concentrations $\left(\mu \mathrm{g} \mathrm{m}^{-3}\right)$ over the North Indian Ocean during INDOEX (FebruaryMarch 1999).

\begin{tabular}{|c|c|c|c|c|c|c|c|c|c|c|c|c|}
\hline \multirow[t]{2}{*}{$\begin{array}{l}\text { Air-mass history } \\
\text { or measurement altitude }\end{array}$} & \multicolumn{2}{|c|}{$\begin{array}{c}\text { Sub-1 } \mu \mathrm{m} \\
\mathrm{NH}_{4}+\mathrm{nss} \mathrm{SO}_{4}\end{array}$} & \multicolumn{2}{|c|}{$\begin{array}{l}\text { Sub- } 1 \mu \mathrm{m} \\
\quad \text { OC }\end{array}$} & \multicolumn{2}{|c|}{$\begin{array}{l}\text { Sub-1 } \mu \mathrm{m} \\
\quad \text { EC }\end{array}$} & \multicolumn{2}{|c|}{$\begin{array}{l}\text { Sub-1 } \mu \mathrm{m} \\
\text { sea salt }\end{array}$} & \multicolumn{2}{|c|}{$\begin{array}{c}\text { Total } \\
\text { sea salt }\end{array}$} & \multicolumn{2}{|c|}{$\begin{array}{l}\text { Total } \\
\text { dust }\end{array}$} \\
\hline & mean & std & mean & std & mean & std & mean & std & mean & std & mean & std \\
\hline \multicolumn{13}{|c|}{ Ship } \\
\hline Arabian Peninsula & 1.8 & 0.15 & 0.49 & 0.11 & 0.075 & 0.078 & 0.13 & 0.070 & 7.6 & 3.6 & 8.1 & 2.3 \\
\hline Indian Subcontinent & 9.9 & 3.6 & 0.77 & 0.11 & 1.4 & 0.34 & 0.10 & 0.026 & 3.5 & 2.6 & 9.6 & 3.9 \\
\hline \multicolumn{13}{|c|}{ Aircraft } \\
\hline Below $1.2 \mathrm{~km}$ & 3.9 & & 3.0 & 1.6 & 2.3 & 1.0 & 0.16 & & & & & \\
\hline Above $1.2 \mathrm{~km}$ & & & 4.9 & 2.6 & 3.2 & 2.0 & 0.044 & & & & & \\
\hline \multicolumn{13}{|c|}{ Ground Stations } \\
\hline Kaashidhoo & 7.8 & & 2.7 & & 1.1 & & 0.56 & 0.26 & 2.6 & 1.4 & 9.2 & 6.5 \\
\hline$\left(5^{\circ} \mathrm{N}, 73.5^{\circ} \mathrm{E}\right)$ & 6.6 & 2.9 & & & & & & & & & & \\
\hline
\end{tabular}

Ship data (Quinn and Bates, 2005), aircraft data (Gabriel et al., 2002; Mayol-Bracero et al., 2002), Kaashidhoo ground station data (Chowdhury et al., 2001; D. Savoie, unpublished data). Data are reported in this paper as medians or means with standard deviations. The reported statistics are not meant to imply that the data are normally distributed. Values for extensive properties are generally given as means and standard deviations. Values for intensive properties are given as median values.

Table 3. Means and standard deviations of measured concentrations $\left(\mu \mathrm{g} \mathrm{m}^{-3}\right)$ over the northwestern Pacific Ocean during ACE-Asia (March-April 2001).

\begin{tabular}{|c|c|c|c|c|c|c|c|c|c|c|c|c|c|c|}
\hline \multirow[t]{2}{*}{$\begin{array}{l}\text { Air-mass history } \\
\text { or measurement altitude }\end{array}$} & \multicolumn{2}{|c|}{$\begin{array}{c}\text { Sub-1 } \mu \mathrm{m} \\
\mathrm{NH}_{4}+\mathrm{nss} \mathrm{SO}_{4}\end{array}$} & \multicolumn{2}{|c|}{$\begin{array}{l}\text { Sub-1 } \mu \mathrm{m} \\
\text { OC }\end{array}$} & \multicolumn{2}{|c|}{$\begin{array}{l}\text { Sub-1 } \mu \mathrm{m} \\
\text { EC }\end{array}$} & \multicolumn{2}{|c|}{$\begin{array}{l}\text { Sub-1 } \mu \mathrm{m} \\
\text { sea salt }\end{array}$} & \multicolumn{2}{|c|}{$\begin{array}{c}\text { Total } \\
\text { nss } \mathrm{SO}_{4}\end{array}$} & \multicolumn{2}{|c|}{$\begin{array}{c}\text { Total } \\
\text { sea salt }\end{array}$} & \multicolumn{2}{|c|}{$\begin{array}{l}\text { Total } \\
\text { dust }\end{array}$} \\
\hline & mean & std & mean & std & mean & std & mean & std & mean & std & mean & std & mean & std \\
\hline \multicolumn{15}{|c|}{ Ship } \\
\hline Continental & 7.5 & 2.5 & 2.8 & 0.15 & 0.56 & 0.28 & 0.20 & 0.060 & & & 3.4 & 2.2 & 14 & 18 \\
\hline Continental + Dust & 11 & 5.1 & 3.2 & 0.74 & 0.72 & 0.22 & 0.28 & 0.041 & & & 7.1 & 3.2 & 69 & 47 \\
\hline \multicolumn{15}{|c|}{ Aircraft } \\
\hline Below $2 \mathrm{~km}$ & 5.2 & 3.4 & 5.5 & 3.2 & 1.8 & 1.3 & 0.52 & 0.61 & & & 13 & 25 & & \\
\hline Above $2 \mathrm{~km}$ & 1.1 & 1.6 & 7.4 & 4.7 & 1.0 & 0.72 & 0.17 & 0.34 & & & 2.2 & 4.5 & & \\
\hline \multicolumn{15}{|c|}{ Ground Stations } \\
\hline $\begin{array}{l}\text { Gosan, Korea } \\
\left(33.2^{\circ} \mathrm{N}, 126.2^{\circ} \mathrm{E}\right)\end{array}$ & 6.8 & 5.8 & 3.1 & 1.3 & 0.7 & 0.3 & & & 7.8 & & & & 170 & 340 \\
\hline $\begin{array}{l}\text { Aksu, China } \\
\left(40.2^{\circ} \mathrm{N}, 80.3^{\circ} \mathrm{E}\right)\end{array}$ & & & & & & & & & 9.9 & 5.1 & & & 410 & 410 \\
\hline $\begin{array}{l}\text { Dunhuang, China } \\
\left(40.3^{\circ} \mathrm{N}, 94.5^{\circ} \mathrm{E}\right)\end{array}$ & & & & & & & & & 4.2 & 4.5 & & & 220 & 330 \\
\hline $\begin{array}{l}\text { Changwu, China } \\
\left(35.1^{\circ} \mathrm{N}, 107.4^{\circ} \mathrm{E}\right)\end{array}$ & & & & & & & & & 9.3 & 7.8 & & & 150 & 120 \\
\hline $\begin{array}{l}\text { Zhenbeitai, China } \\
\left(38.2^{\circ} \mathrm{N}, 109.4^{\circ} \mathrm{E}\right)\end{array}$ & & & & & & & & & 4.2 & 3.0 & & & 190 & 200 \\
\hline
\end{tabular}

Ship data (Quinn and Bates, 2005), aircraft data fine-particles (Huebert et al., 2004; Lee et al., 2003) and aircraft data total aerosol (Kline et al., 2004), China ground station data (Zhang et al., 2003), Korea ground station data (Chuang et al., 2003; Arimoto et al., 2004; Quinn et al., unpublished data). 
Table 4. Means and standard deviations of measured concentrations $\left(\mu \mathrm{g} \mathrm{m}^{-3}\right)$ over the northwestern Atlantic Ocean during NEAQS (JulyAugust 2002) and ICARTT (July-August 2004).

\begin{tabular}{|c|c|c|c|c|c|c|c|c|c|c|c|c|}
\hline \multirow[t]{2}{*}{$\begin{array}{l}\text { Air-mass history } \\
\text { or measurement altitude }\end{array}$} & \multicolumn{2}{|c|}{$\begin{array}{c}\text { Sub-1 } \mu \mathrm{m} \\
\mathrm{NH}_{4}+\mathrm{nss} \mathrm{SO}_{4}\end{array}$} & \multicolumn{2}{|c|}{$\begin{array}{l}\text { Sub-1 } \mu \mathrm{m} \\
\quad \text { OC }\end{array}$} & \multicolumn{2}{|c|}{$\begin{array}{l}\text { Sub-1 } \mu \mathrm{m} \\
\quad \mathrm{EC}\end{array}$} & \multicolumn{2}{|c|}{$\begin{array}{l}\text { Sub-1 } \mu \mathrm{m} \\
\text { sea salt }\end{array}$} & \multicolumn{2}{|c|}{$\begin{array}{c}\text { Total } \\
\text { sea salt }\end{array}$} & \multicolumn{2}{|c|}{$\begin{array}{l}\text { Total } \\
\text { dust }\end{array}$} \\
\hline & mean & std & mean & std & mean & std & mean & std & mean & std & mean & std \\
\hline \multicolumn{13}{|c|}{ Ship (NEAQS) } \\
\hline Westerly Flow & 7.5 & 5.8 & 4.5 & 1.6 & 0.38 & 0.15 & 0.062 & 0.10 & 1.2 & 1.0 & 1.6 & 1.0 \\
\hline Winds $190-240^{\circ}$ & 5.4 & 4.9 & 4.5 & 2.6 & & & & & & & & \\
\hline \multicolumn{13}{|c|}{ Ship (ICARTT) } \\
\hline All data & 4.5 & 4.9 & 2.9 & 1.4 & 0.66 & 0.70 & 0.11 & 0.56 & & & & \\
\hline \multicolumn{13}{|c|}{ Aircraft (ICARTT) } \\
\hline Below $2 \mathrm{~km}$ & 5.9 & 6.3 & & & & & 0.17 & 0.033 & 0.74 & 1.4 & & \\
\hline Above $2 \mathrm{~km}$ & 0.88 & 1.7 & & & & & 0.16 & 0.016 & 0.22 & 0.22 & & \\
\hline
\end{tabular}

NEAQS ship data (Quinn and Bates, 2005; A. Middlebrook, unpublished data), ICARTT ship data (Quinn and Bates, unpublished data); ICARTT aircraft data (R. Weber and J. Dibb, unpublished data).

For the INDOEX and ACE-Asia aircraft data sets (both obtained using the NSF/NCAR C-130 but with different aerosol inlets) the averages include all data obtained during the campaigns, as most measurements were made over the oceans. However for ICARTT, in which only some of the data (obtained using the NOAA-WP3 and NASA DC-8) was taken over the ocean, the averages reported here include only measurements over the ocean. The aircraft data are segregated by altitude but not by air-mass history. For most aerosol components the concentrations were greater at lower altitude (typically measurements within the marine boundary layer), with the notable exception of submicrometer carbonaceous aerosol. However, relative standard deviations were generally greater in the free troposphere, indicative of the influence of transport in distinct layers.

Mass concentrations of aerosol constituents have also been determined over multiple-year periods at several sites within the study regions defined in Fig. 2. These data, summarized in Table 5, provide a measure of the inter- and intra-seasonal variability at these stations and an opportunity to compare longer-term measurements with those from the short-term intensive studies. With the exception of the measurements at the Sable Island, Nova Scotia, site, sampling was conducted with large-volume samplers that collected the total aerosol. Consequently these data are not directly comparable to those obtained with the size-selective samplers used on most platforms during the intensive campaigns. Here it is assumed, as a first approximation in such comparisons, that the bulk of the nss sulfate is present in the submicrometer fraction (as supported, for example, by the measurements at Kaashidhoo, Maldive Islands, Table 2) and that the nitrate, sea salt and dust are predominantly in the supermicrometer fraction. These assumptions, which are consistent with the data col- lected during the intensive field campaigns (e.g., Fig. 5), are discussed in more detail in Sect. 2.

As evidenced by the much greater concentrations of aerosol species for air masses that had traveled over the Indian subcontinent versus concentrations in air masses that had traveled over the Arabian peninsula (Table 2), the large differences exhibited by mean concentrations measured on the different platforms must be due in part to differences in air mass flow patterns experienced at the different platforms. Because of such differences it must be concluded that there is no unique "best" data set that characterizes each of these regions. Ground station, ship and aircraft data were collected in each region, and each platform obtained a perspective on the regional properties that reflects the biases toward the air masses sampled by that platform. These and related issues were discussed in papers that compared platform data for INDOEX and ACE-Asia (Clarke et al., 2002; Doherty et al., 2005). Although intensive parameters (e.g., single scattering albedo, mass scattering efficiency) generally agree better than extensive parameters (e.g., mass concentration of any component, light scattering coefficient) they nonetheless can differ substantially on different platforms. As aircraft sample greater spatial scales, data from aircraft may provide a largerscale average for a region. However, aircraft also provide limited temporal averaging for any given location, and because of their large speed, there are generally fewer samples and poorer statistics for a given area. Further, aircraft sampling is often targeted to objectives that can bias representative sampling. Surface sites are biased to local surface properties but can study temporal changes in advected air masses with good statistics. Ships, which also sample at the surface, offer some limited targeting capability as they can move to position themselves in specific flows, which consequently 
Table 5. Means and standard deviations of measured concentrations $\left(\mu \mathrm{g} \mathrm{m}^{-3}\right)$ at long term monitoring stations (and repeated ship cruises in the Indian Ocean) within the regions covered in this study (Fig. 1). Sable Island data (Quinn et al., 2000), and Kaashidhoo, Bermuda, and Miami data (D. Savoie, unpublished data) are daily samples. Gosan, Guam and Okinawa data are weekly samples (D. Savoie, unpublished data). The Indian Ship data are $12 \mathrm{~h}$ samples (D. Savoie, unpublished data).

\begin{tabular}{|c|c|c|c|c|c|c|c|c|c|c|c|c|c|}
\hline \multirow[t]{2}{*}{ Station } & \multirow[t]{2}{*}{$\begin{array}{c}\text { Lat } \\
\mathrm{N}\end{array}$} & \multirow[t]{2}{*}{$\begin{array}{c}\text { Lon } \\
\text { E }\end{array}$} & \multirow[t]{2}{*}{ start } & \multirow[t]{2}{*}{ stop } & \multirow[t]{2}{*}{ season } & \multicolumn{2}{|c|}{$\begin{array}{c}\text { Total } \\
\text { nss sulfate }\end{array}$} & \multicolumn{2}{|c|}{$\begin{array}{c}\text { Total } \\
\text { nitrate }\end{array}$} & \multicolumn{2}{|c|}{$\begin{array}{c}\text { Total } \\
\text { sea salt }\end{array}$} & \multicolumn{2}{|c|}{$\begin{array}{l}\text { Total } \\
\text { dust }\end{array}$} \\
\hline & & & & & & mean & std & mean & std & mean & std & mean & std \\
\hline \multicolumn{14}{|c|}{ North Indian Ocean } \\
\hline \multirow[t]{4}{*}{ Kaashidhoo } & 5.0 & 73.5 & Feb 1998 & Aug 1999 & JJA & 0.72 & 0.40 & 0.41 & 0.26 & 8.8 & 3.8 & 5.9 & 5.1 \\
\hline & & & & & SON & 1.8 & 1.4 & 0.58 & 0.34 & 5.7 & 2.8 & 4.0 & 3.1 \\
\hline & & & & & DJF & 3.5 & 1.8 & 1.2 & 0.60 & 6.6 & 3.7 & 4.3 & 4.7 \\
\hline & & & & & MAM & 3.3 & 1.9 & 1.5 & 0.84 & 5.6 & 3.1 & 7.5 & 7.4 \\
\hline \multirow{3}{*}{ Ships } & & & March 1995 & March 1998 & JJA & 1.5 & 1.6 & 0.84 & 0.91 & 25 & 17 & 8.3 & 12 \\
\hline & & & & & DJF & 3.6 & 1.4 & 2.2 & 1.8 & 7.5 & 3.8 & 5.5 & 6.2 \\
\hline & & & & & MAM & 2.6 & 1.3 & 1.7 & 1.1 & 6.7 & 6.1 & 12 & 13 \\
\hline \multicolumn{14}{|c|}{ NW Pacific Ocean } \\
\hline \multirow[t]{4}{*}{ Gosan } & 33.5 & 126.5 & Sep 1991 & Oct 1995 & JJA & 7.6 & 4.7 & 4.1 & 2.2 & 11 & 9.4 & 8.6 & 10 \\
\hline & & & & & SON & 7.1 & 3.4 & 4.7 & 2.1 & 25 & 30 & 12 & 8.4 \\
\hline & & & & & DJF & 6.8 & 4.1 & 3.6 & 2.1 & 20 & 13 & 20 & 19 \\
\hline & & & & & MAM & 7.7 & 3.9 & 4.7 & 2.4 & 15 & 12 & 28 & 22 \\
\hline \multirow[t]{4}{*}{ Guam } & 17.5 & 144.8 & Jan 1981 & Oct 1982 & JJA & 0.27 & 0.38 & 0.13 & 0.11 & 38 & 20 & 0.41 & 0.38 \\
\hline & & & & & SON & 0.19 & 0.39 & 0.15 & 0.14 & 40 & 22 & 1.3 & 2.3 \\
\hline & & & & & DJF & 0.89 & 1.57 & 0.22 & 0.15 & 46 & 16 & 0.32 & 0.21 \\
\hline & & & & & MAM & 0.54 & 0.21 & 0.33 & 0.13 & 35 & 7.8 & 1.4 & 1.4 \\
\hline \multirow{4}{*}{ Okinawa } & 26.9 & 128.2 & Sep 1991 & March 1994 & JJA & 2.9 & 2.1 & 1.6 & 0.93 & 18 & 22 & 2.6 & 4.5 \\
\hline & & & & & SON & 4.0 & 2.6 & 2.1 & 1.1 & 28 & 14 & 6.3 & 8.4 \\
\hline & & & & & DJF & 4.8 & 2.3 & 1.5 & 0.64 & 26 & 6.7 & 9.4 & 12 \\
\hline & & & & & MAM & 4.8 & 2.7 & 1.9 & 0.89 & 20 & 10 & 22 & 34 \\
\hline \multicolumn{14}{|c|}{ NW Atlantic Ocean } \\
\hline \multirow[t]{4}{*}{ Bermuda } & 32.3 & 64.9 & March 1989 & Aug 1998 & JJA & 2.2 & 2.7 & 0.89 & 0.63 & 8.9 & 4.6 & 8.5 & 16 \\
\hline & & & & & SON & 1.7 & 1.6 & 0.95 & 0.75 & 14 & 9.1 & 3.0 & 4.6 \\
\hline & & & & & DJF & 1.5 & 1.2 & 1.1 & 1.0 & 17 & 11 & 2.3 & 2.4 \\
\hline & & & & & MAM & 2.6 & 2.2 & 1.3 & 0.88 & 14 & 8.0 & 5.2 & 3.6 \\
\hline \multirow[t]{5}{*}{ Miami } & 25.7 & 80.2 & Jan 1989 & Dec 2002 & JJA & 2.0 & 1.6 & 1.8 & 1.4 & 7.1 & 3.3 & 12 & 15 \\
\hline & & & & & SON & 2.0 & 1.6 & 1.6 & 1.4 & 9.1 & 6.6 & 2.7 & 6.3 \\
\hline & & & & & DJF & 1.7 & 1.0 & 1.9 & 1.9 & 10 & 4.6 & 1.3 & 1.8 \\
\hline & & & & & MAM & 3.0 & 1.9 & 2.5 & 1.9 & 9.3 & 4.8 & 2.3 & 2.4 \\
\hline & & & & & & \multicolumn{2}{|c|}{$\begin{array}{l}\text { Sub-1 } \mu \mathrm{m} \\
\text { nss sulfate }\end{array}$} & \multicolumn{2}{|c|}{$\begin{array}{l}\text { Sub-1 } \mu \mathrm{m} \\
\text { nitrate }\end{array}$} & \multicolumn{2}{|c|}{$\begin{array}{c}\text { Sub-1 } \mu \mathrm{m} \\
\text { sea salt }\end{array}$} & & \\
\hline \multirow[t]{4}{*}{ Sable Island } & 43.9 & 60.0 & Aug 1992 & April 2000 & JJA & 1.1 & 1.6 & 0.002 & 0.014 & 0.18 & 0.17 & & \\
\hline & & & & & SON & 1.3 & 1.5 & 0.012 & 0.013 & 0.33 & 0.34 & & \\
\hline & & & & & DJF & 1.4 & 1.1 & 0.017 & 0.016 & 0.63 & 0.59 & & \\
\hline & & & & & MAM & 1.4 & 1.5 & 0.014 & 0.013 & 0.51 & 0.39 & & \\
\hline
\end{tabular}

may not be regionally representative. For all these reasons, although the several types of sampling platforms can provide valid and reliable sampling of a region, they may nonetheless yield different values of aerosol properties of interest.

\subsubsection{North Indian Ocean}

Data from Kaashidhoo and ship cruises in the Indian Ocean (Table 5) show the consequences of monsoonal flow in the area, with generally lower concentrations of sulfate and nitrate in the June to November period and larger concentrations in the December to May period. The dry winter monsoon season is characterized by large-scale subsidence over the Indian subcontinent and northeasterly flow from the continent over the North Indian Ocean. Mean measured concentrations in the December to May period are within the range of values measured during the INDOEX intensive campaign in February-March (Table 2). 
As noted above, concentrations of nss sulfate and elemental carbon (refractory carbon as measured with a combustion organic/elemental carbon analyzer) were appreciably greater in air masses advected off the Indian subcontinent than in air masses advected off the Arabian Peninsula. The elemental carbon concentrations measured during INDOEX were the greatest measured in the three regions included in this study. The large concentrations are apparent in the ship, aircraft (vertical profiles), and ground site data. The large elemental carbon mass fraction (6-11\% at Kaashidhoo - Chowdhury et al., 2001 - and $11 \%$ at the ship when air masses had passed over the Indian subcontinent - Quinn et al., 2002) are reflected in the small values of single scattering albedo measured during INDOEX (Sect. 3.2).

\subsubsection{Northwest Pacific Ocean}

Aerosol chemical measurements have been made for extended periods in the northwest Pacific Ocean at Gosan, Okinawa, and Guam (Table 5). Both Gosan and Okinawa frequently receive continental outflow from eastern Asia, whereas Guam, being located in the easterly trade winds, does not regularly experience such outflow. Consequently, concentrations of nss sulfate and dust are more than an order of magnitude smaller at Guam than at the other two stations. Further, the dust data from Gosan and Okinawa show the strong seasonal cycle of dust coming out of central Asia. Mean concentrations of sulfate, nitrate and dust in MarchMay during 1991-1995 are well within \pm 1 standard deviation of the values measured during ACE-Asia. Not surprisingly, dust concentrations are greatest near the dust source regions (Table 3) while nss sulfate concentrations at these stations are similar to those measured at Gosan and off shore on the ship and aircraft. Dust and sulfate are the dominant components of the aerosol near the surface, whereas organic carbon is dominant aloft.

\subsubsection{Northwest Atlantic Ocean}

Aerosol chemical measurements have been made for extended periods in the northwest Atlantic Ocean at Miami, Bermuda and Sable Island. However, measurements made at Miami and Bermuda are south of the region of intensive in-situ measurements and thus are not directly comparable to those made during the intensive campaigns. Clearly reflected in these measurements (Table 5) is the enhanced dust flow from the Sahara during June-August. Concentrations at Sable Island also do not appear to reflect, in magnitude or seasonality, the continental outflow from the industrial regions along the United States coastline. Sulfate values show no seasonality as opposed to the measurements at Acadia National Park on the coast of Maine where sulfate and organic carbon concentrations peak in the summer months (Malm et al., 1994). It is likely that Sable Island is often isolated in a cold stable marine boundary layer while the continental flow is lofted above the boundary layer out over the Atlantic Ocean (Angevine et al., 2004).

A distinguishing feature in the measurements over the northwestern Atlantic Ocean is the large mass fraction of organic carbon (Fig. 5). Quinn and Bates (2003) showed that particulate organic matter was the dominant component of the submicrometer aerosol mass concentration at the surface during July/August 2002. Large mass fractions of organic carbon were also reported in airborne measurements during TARFOX in July 1996 off the central eastern coast of the United States (Novakov et al., 1997). Although the ICARTT aircraft organic carbon measurements were not obtained by the same methods as the other studies, the available data on water-soluble organic carbon and non-refractory organic mass indicate a substantial influence of biomass burning on the total aerosol mass concentration and organic mass fraction at large altitudes. Additionally, plumes containing large concentrations of sulfate were more commonly observed at lower altitude (R. Weber and A. Middlebrook, unpublished data).

\subsection{Optical measurements during intensive field campaigns} and long term monitoring studies

Optical properties of aerosol constituents measured during the intensive field campaigns in the three regions selected for this study are summarized in Tables 6,7 , and 8 for both accumulation mode and coarse mode size ranges. As with the concentration measurements, the standard deviations serve as a measure of the spatial and temporal variability of these concentrations in the several regions. The data from INDOEX (Clarke et al.,2002; Quinn et al., 2002; Sheridan et al., 2002), ACE-Asia (Anderson et al.,2003; Carrico et al., 2003; Doherty et al., 2005; Quinn et al., 2004), and ACE-1 (Quinn et al., 1998; Quinn and Coffman, 1998; Carrico et al., 1998) have been described in detail previously and interplatform comparisons of optical data for INDOEX and ACEAsia have been discussed in detail in Clarke et al. (2002) and Doherty et al. (2005), respectively. Comparisons between the experimental regions for both long term and intensive data are discussed below.

Long-term in-situ measurements of aerosol optical properties have been made in the three regions discussed here (NOAA aerosol monitoring program; Delene and Ogren, 2002). The measurement protocols are similar to those used during the intensive campaigns, and the measurement periods often encompass the intensive campaign time periods. Also available are ground-based measurements of solar and sky irradiance from which column aerosol properties, including aerosol optical depth, are inferred (NASA AERONET program; Holben et al., 1998; Dubovik and King, 2000). The long-term nature of the NOAA surface in-situ measurements and the NASA ground-based remote sensing measurements provides information on the temporal variability in optical properties. 
Table 6. Median values of measured mass scattering efficiency $\left(\mathrm{m}^{2} \mathrm{~g}^{-1}\right)$ for sub-1 $\mu \mathrm{m}$ and sup-1 $\mu \mathrm{m}$ aerosols derived from measurements made during intensive experiments.

\begin{tabular}{|c|c|c|c|c|c|c|c|}
\hline Air mass history or altitude & Platform & $\begin{array}{l}\text { Sub- } 1 \mu \mathrm{m} \\
450 \mathrm{~nm}\end{array}$ & $\begin{array}{l}\text { Sub-1 } 1 \mu \mathrm{m} \\
550 \mathrm{~nm}\end{array}$ & $\begin{array}{l}\text { Sub- } 1 \mu \mathrm{m} \\
700 \mathrm{~nm}\end{array}$ & $\begin{array}{l}\text { Sup- } 1 \mu \mathrm{m} \\
450 \mathrm{~nm}\end{array}$ & $\begin{array}{l}\text { Sup-1 } \mu \mathrm{m} \\
550 \mathrm{~nm}\end{array}$ & $\begin{array}{c}\text { Sup- } 1 \mu \mathrm{m} \\
700 \mathrm{~nm}\end{array}$ \\
\hline \multicolumn{8}{|c|}{ INDOEX } \\
\hline Arabian Peninsula & RHB & 4.04 & 3.24 & 2.38 & 0.49 & 0.51 & 0.50 \\
\hline Indian Subcontinent & RHB & 5.30 & 3.99 & 2.58 & 0.77 & 0.77 & 0.69 \\
\hline Air mass over ocean for $>5$ days & RHB & 5.79 & 4.73 & 3.65 & 1.25 & 1.26 & 1.22 \\
\hline \multicolumn{8}{|c|}{ ACE-Asia } \\
\hline Continental & RHB & 6.80 & 4.44 & 2.64 & 1.13 & 1.24 & 1.28 \\
\hline Continental + Dust & RHB & 4.36 & 2.97 & 2.02 & 0.97 & 0.99 & 1.01 \\
\hline Continental + Low Dust, Below $2 \mathrm{~km}$ & $\mathrm{C}-130$ & 5.30 & 3.80 & 2.20 & 1.35 & 1.20 & 0.95 \\
\hline All air masses & Gosan & 5.74 & 4.07 & 2.15 & & & \\
\hline Air mass over ocean for $>5$ days & RHB & 4.61 & 3.68 & 2.27 & 1.54 & 1.64 & 1.70 \\
\hline \multicolumn{8}{|c|}{ NEAQS 2002} \\
\hline Westerly Flow (2002) & RHB & 5.37 & 3.66 & 2.28 & 1.41 & 1.15 & 1.02 \\
\hline
\end{tabular}

RHB - NOAA RV Ronald H. Brown, measurements at 55\% RH

C130 - NSF/NCAR C-130, measurements at $<40 \%$ RH

Gosan - Ground Station, South Korea, measurements at $35 \% R H$

Low Dust is defined as supermicrometer mass less than submicrometer mass

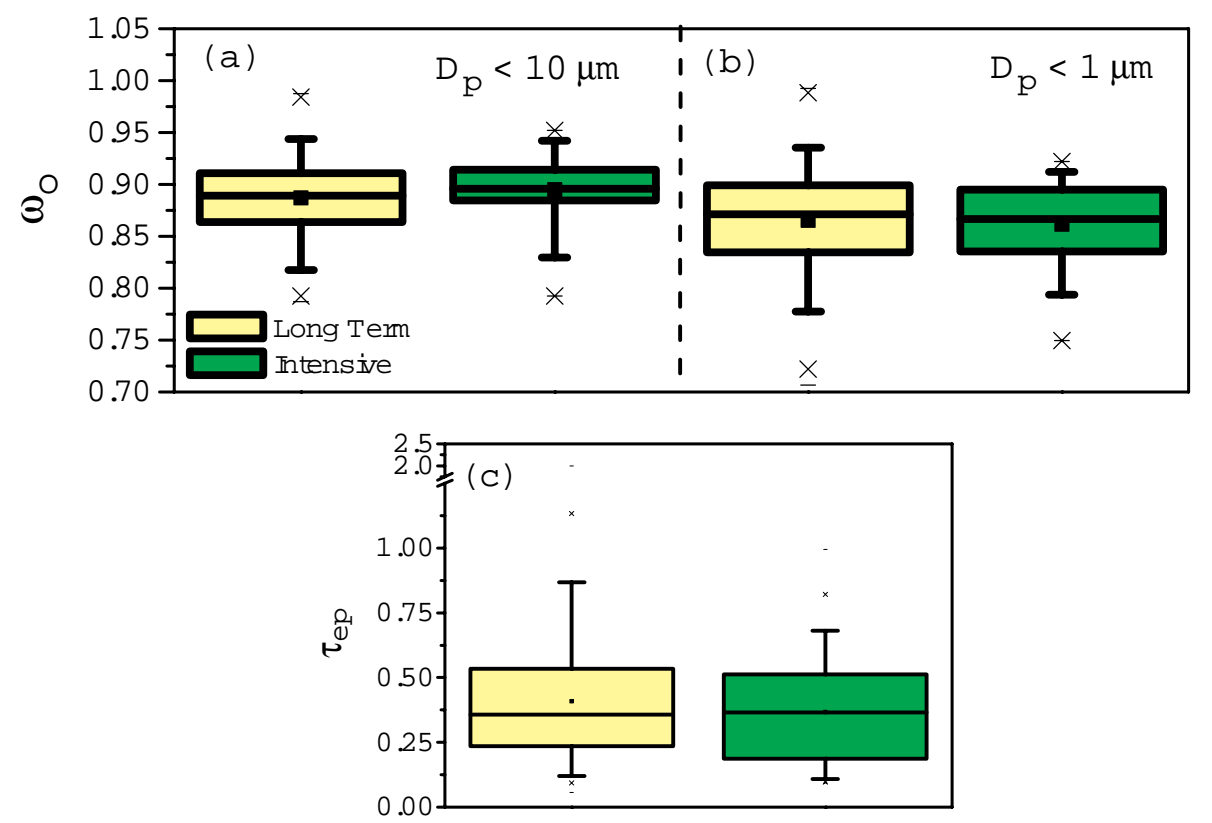

Fig. 6. Mean and variability in (a) sub-10 micrometer single scattering albedo, (b) submicrometer single scattering albedo, and (c) aerosol optical depth for the northwest Pacific (Gosan). Yellow represents long-term measurements and green represents measurements from intensive time periods. Single scattering albedos are from NOAA's in situ measurements and aerosol optical depths are from AERONET. The horizontal lines in the box denote the 25 th, 50th, and 75th percentiles. The whisker denotes the 5th and 95th percentile values. The $x$ denotes the 1st and 99th percentile, the dash the minimum and maximum values, and the square symbol the mean.

Data from the long-term NOAA in-situ measurements $\left(\omega_{0}\right.$ and $b)$ and AERONET remote-sensing measurements $\left(\tau_{e p}\right.$, $\omega_{0}$, and $g$ ) are used to compare these quantities during the in- tensive campaigns with measurements over a longer time period. In Fig. 6, the mean and variability of $\omega_{0}$ and $\tau_{e p}$ for the northwest Pacific Ocean region during the time period of the 


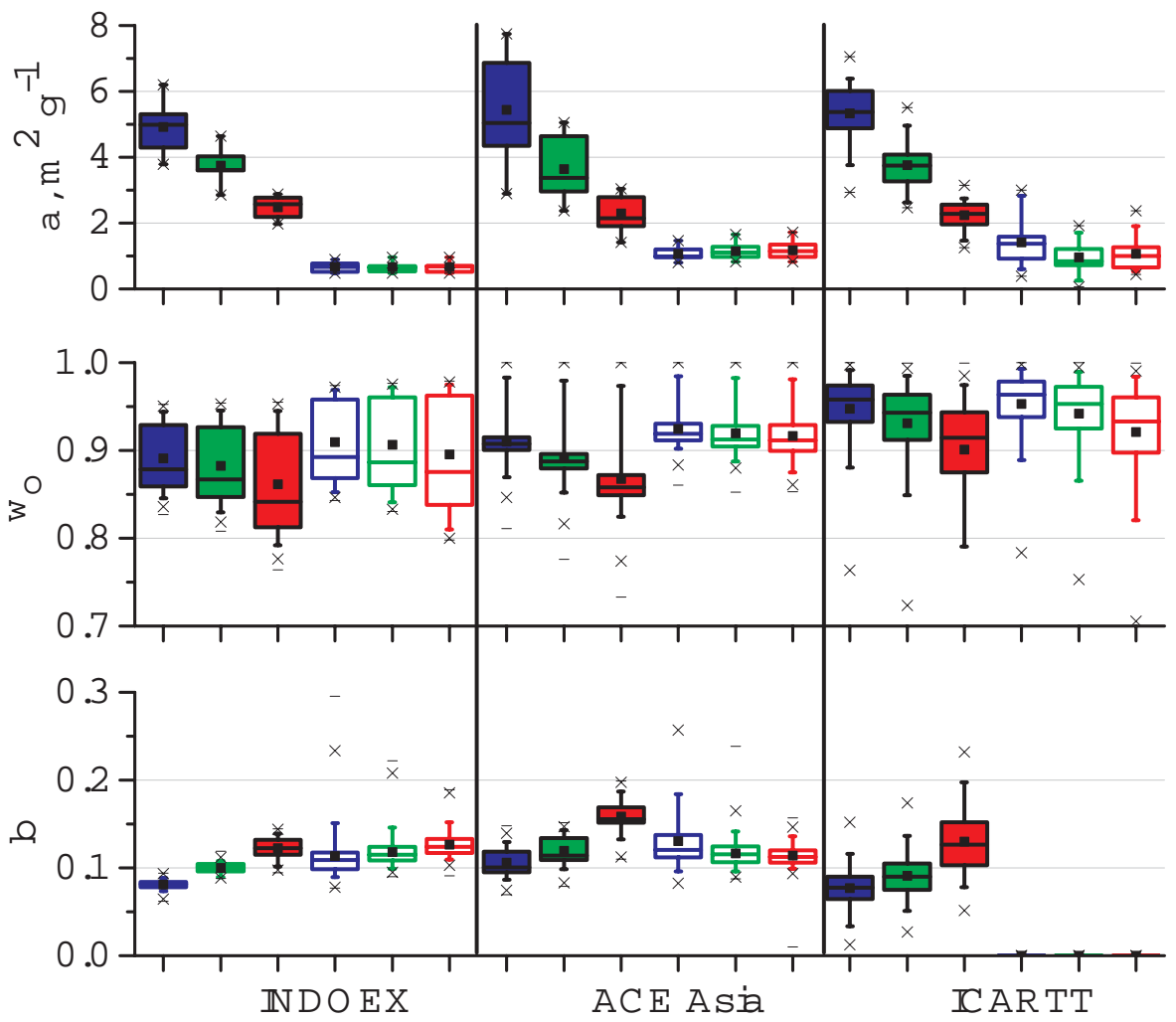

Fig. 7. Mean and variability in mass scattering efficiency $\alpha$, single scattering albedo $\omega_{0}$, and backscattered fraction $b$, for INDOEX, ACEAsia, and ICARTT 2004. Submicrometer values are shown as solid boxes, supermicrometer values as open boxes (except for single scattering albedo for which the open boxes are sub-10 micrometer values). Color represents wavelength: blue, $450 \mathrm{~nm}$; green, $550 \mathrm{~nm}$; and red, $700 \mathrm{~nm}$. The horizontal lines in the box denote the 25th, 50th, and 75th percentiles. The whisker denotes the 5th and 95th percentile values. The $\mathrm{x}$ denotes the 1 st and 99th percentile. The square symbol represents the mean. In calculating $\omega_{0}$ from measurements of absorption and light scattering coefficients at different wavelengths the wavelength dependence of absorption was assumed to be $\lambda^{-1}$ for situations where absorption was dominated by black carbon and $\lambda^{-2}$ for situations where absorption was dominated by dust except for ICARTT 2004 and NEAQS 2002 RHB values which are based on multi-wavelength measurements of absorption.

intensive campaign are compared with available longer-term data. Statistics for all three regions are presented in Table 9. Data for $\omega_{0}$ are available at Gosan (northwestern Pacific ACE Asia) from April 2001 through February 2002; data for $\tau_{e p}$ are available from April 2001 through August 2003. Sable Island, Nova Scotia is used for the comparison of $\omega_{0}$ in the northwestern Atlantic as it is the only NOAA site in the region with long-term measurements (1992-2000). Data for $\tau_{e p}$ for the northwest Atlantic at Chebogue Point, Nova Scotia, are available only from June to August 2004. Data for $\tau_{e p}$ from Kaashidhoo Climate Observatory (KCO) for both the intensive campaign and the period of 1998 to 2000 are used for the northern Indian Ocean - INDOEX comparison. No long term record of $\omega_{0}$ is available for this region.

The mean and variability in single scattering albedo during the campaigns and over the longer time periods are very similar. Hence, the campaign data appear to be representative of the longer term statistics of this intensive property at these sites. The extensive property $\tau_{e p}$ varies more between field campaigns and the longer time periods, especially for the northern Indian Ocean, but the field campaign data still appear to be generally representative of the prevailing conditions at these sites. Angular scattering indicated by observations of $b$ and $g$ are also consistent between the long-term and intensive measurement periods.

In order to determine whether values for properties of interest are similarly representative, long-term and intensivecampaign data for each parameter are presented for each region. Table 9 gives statistical summaries for all measured properties at green wavelengths for the sub- $10 \mu \mathrm{m}$ size cut, except mass scattering efficiency which is for the sub- $1 \mu \mathrm{m}$ size cut. NOAA in-situ measurements were made at $550 \mathrm{~nm}$, $\tau_{e p}$ observations from the NASA AERONET program were also at $550 \mathrm{~nm}$, and all other properties derived from the NASA AERONET data were made at $441 \mathrm{~nm}$. In general, these results indicate that measurements of all properties from the intensive campaigns can be considered representative of broader time-scales within the three regions.

Information concerning the relationships among optical properties, wavelength dependencies within each of the 
Table 7. Median values of single scatter albedo $\omega_{0}$ for sub- $1 \mu \mathrm{m}$ and sup- $1 \mu \mathrm{m}$ aerosols measured during intensive experiments. In calculating $\omega_{0}$ from measurements of absorption and light scattering coefficients at different wavelengths the wavelength dependence of absorption was assumed to be $\lambda^{-1}$ for situations where absorption was dominated by black carbon and $\lambda^{-2}$ for situations where absorption was dominated by dust except for ICARTT 2004 and NEAQS 2002 RHB values which are based on multi-wavelength measurements of absorption.

\begin{tabular}{|c|c|c|c|c|c|c|c|}
\hline Air mass history or altitude & Platform & $\begin{array}{l}\text { Sub-1 } \mu \mathrm{m} \\
450 \mathrm{~nm}\end{array}$ & $\begin{array}{c}\text { Sub-1 } \mu \mathrm{m} \\
550 \mathrm{~nm}\end{array}$ & $\begin{array}{l}\text { Sub-1 } \mu \mathrm{m} \\
700 \mathrm{~nm}\end{array}$ & $\begin{array}{l}\text { Sup-1 } \mu \mathrm{m} \\
450 \mathrm{~nm}\end{array}$ & $\begin{array}{l}\text { Sup-1 } \mu \mathrm{m} \\
550 \mathrm{~nm}\end{array}$ & $\begin{array}{c}\text { Sup-1 } \mu \mathrm{m} \\
700 \mathrm{~nm}\end{array}$ \\
\hline \multicolumn{8}{|c|}{ INDOEX } \\
\hline Arabian Peninsula & RHB & 0.931 & 0.929 & 0.923 & & & \\
\hline Indian Subcontinent & RHB & 0.860 & 0.848 & 0.815 & & & \\
\hline Air mass over ocean for $>5$ days & RHB & 0.951 & 0.950 & 0.947 & & & \\
\hline Below $1 \mathrm{~km}$ altitude & C-130 & & 0.850 & & & & \\
\hline $1-3 \mathrm{~km}$ altitude & C-130 & & 0.850 & & & & \\
\hline All air masses & $\mathrm{KCO}$ & & 0.736 & & & & \\
\hline \multicolumn{8}{|c|}{ ACE-Asia } \\
\hline Continental & RHB & 0.908 & 0.887 & 0.855 & 0.958 & 0.967 & 0.975 \\
\hline Continental + Dust & RHB & 0.905 & 0.888 & 0.869 & 0.964 & 0.971 & 0.978 \\
\hline Continental + Dust, Below $2 \mathrm{~km}$ & C-130 & 0.866 & 0.843 & 0.801 & 0.949 & 0.964 & 0.975 \\
\hline Continental + Dust, Above $2 \mathrm{~km}$ & C-130 & 0.862 & 0.849 & 0.824 & 0.963 & 0.975 & 0.988 \\
\hline All air masses & Gosan & & 0.869 & & & & \\
\hline During dust event (DOY 100.5-104) & Gosan & & 0.814 & & & & \\
\hline Air mass over ocean for $>5$ days & RHB & 0.956 & 0.958 & 0.944 & 0.999 & 0.999 & 0.999 \\
\hline \multicolumn{8}{|c|}{ ICARTT } \\
\hline ICARTT 2004 westerly flow & RHB & 0.964 & 0.951 & 0.926 & & & \\
\hline NEAQS 2002 westerly flow & RHB & 0.957 & 0.951 & 0.941 & 0.971 & 0.985 & 0.995 \\
\hline Below $2 \mathrm{~km}$ altitude & DC-8 & 0.969 & 0.972 & 0.953 & & & \\
\hline Above $2 \mathrm{~km}$ altitude & DC-8 & 0.953 & 0.961 & 0.950 & & & \\
\hline
\end{tabular}

RHB - NOAA RV Ronald H. Brown, measurements at 55\% RH

C130 - NSF/NCAR C-130, measurements at $<40 \%$ RH

$\mathrm{KCO}$ - Kaashidhoo Ground Station, Maldives, measurements at $41 \%$ RH

Gosan - Ground Station, South Korea, measurements at 35\% RH

DC-8 - NASA DC-8, measurements made at $<40 \% R H$

properties, and the effect of particle size range on the average optical properties can be used to improve and simplify modeling of aerosol radiative influences. Figure 7 presents median values and variability for properties relevant to modeling DRE and DCF in all wavelengths and size ranges measured. As the data from the intensive campaigns appear to be representative of the longer term measurements, the figure includes only shipboard measurements from Ronald H. Brown. Evident in the data are strong wavelength dependencies for submicrometer mass scattering efficiency and $b$. These relations are taken into account in the optical properties recommended for climate models (Sect. 3.4).

3.3 Closure experiments to assess understanding of optical properties and radiative effects

\subsubsection{Overview of closure studies}

Closure studies, based on an overdetermined data set of aerosol chemical, microphysical, optical, and radiative prop- erties, consist of comparisons of two or more independent methods of measuring or calculating a single property (Quinn et al., 1996). Closure studies can be used to assess uncertainties in using aerosol chemical and microphysical properties to yield aerosol optical properties, and thus provide a basis for estimating the uncertainties in the properties calculated by RTMs. Similarly closure studies are used to test the ability to determine aerosol optical depth and radiative effects from vertical distributions of extinction coefficient and single scattering albedo. As aerosol properties vary between regions, it is essential that these closure studies be carried out in regions exhibiting a wide variety of aerosol properties.

Several closure studies, summarized in Table 10, illustrate the kinds of closure studies that have been carried out, examine the magnitude of the uncertainties associated with the various techniques used to measure or estimate aerosol optical properties, and assess improvement with time in progressively later studies. The table contains extinction coefficients and aerosol optical depths calculated in several 
Table 8. Median values of the measured hemispheric backscatter fraction $b$ for sub-1 $\mu \mathrm{m}$ and sup-1 $\mu \mathrm{m}$ aerosols measured during intensive campaigns.

\begin{tabular}{|c|c|c|c|c|c|c|c|}
\hline Air mass or altitude & Platform & $\begin{array}{l}\text { Sub-1 } \mu \mathrm{m} \\
450 \mathrm{~nm}\end{array}$ & $\begin{array}{l}\text { Sub-1 } \mu \mathrm{m} \\
550 \mathrm{~nm}\end{array}$ & $\begin{array}{l}\text { Sub-1 } \mu \mathrm{m} \\
700 \mathrm{~nm}\end{array}$ & $\begin{array}{l}\text { Sup-1 } \mu \mathrm{m} \\
450 \mathrm{~nm}\end{array}$ & $\begin{array}{l}\text { Sup-1 } \mu \mathrm{m} \\
550 \mathrm{~nm}\end{array}$ & $\begin{array}{l}\text { Sup-1 } \mu \mathrm{m} \\
700 \mathrm{~nm}\end{array}$ \\
\hline \multicolumn{8}{|c|}{ INDOEX } \\
\hline Arabian Peninsula & RHB & 0.080 & 0.103 & 0.114 & 0.105 & 0.111 & 0.121 \\
\hline Indian Subcontinent & RHB & 0.081 & 0.098 & 0.131 & 0.113 & 0.120 & 0.128 \\
\hline Air mass over ocean for $>5$ days & RHB & 0.087 & 0.104 & 0.113 & 0.076 & 0.088 & 0.100 \\
\hline Below $1 \mathrm{~km}$ altitude & C-130 & & 0.11 & & & & \\
\hline $1-3 \mathrm{~km}$ altitude & C-130 & & 0.11 & & & & \\
\hline All air masses & $\mathrm{KCO}$ & 0.086 & 0.142 & 0.142 & & & \\
\hline \multicolumn{8}{|c|}{ ACE-Asia } \\
\hline Continental & RHB & 0.097 & 0.111 & 0.155 & 0.125 & 0.116 & 0.111 \\
\hline Continental + Dust & RHB & 0.117 & 0.129 & 0.159 & 0.118 & 0.115 & 0.113 \\
\hline Continental + Dust, Below $2 \mathrm{~km}$ & $\mathrm{C}-130$ & 0.100 & 0.117 & 0.153 & 0.097 & 0.102 & 0.109 \\
\hline Continental + Dust, Above $2 \mathrm{~km}$ & C-130 & 0.092 & 0.109 & 0.130 & 0.115 & 0.110 & 0.112 \\
\hline All air masses & Gosan & 0.096 & 0.115 & 0.150 & & & \\
\hline During dust event (DOY 100.5-104) & Gosan & 0.179 & 0.156 & 0.128 & & & \\
\hline Air mass over ocean for $>5$ days & RHB & 0.065 & 0.098 & 0.098 & 0.092 & 0.093 & 0.096 \\
\hline \multicolumn{8}{|c|}{ ICARTT } \\
\hline ICARTT 2004 westerly flow & RHB & 0.079 & 0.089 & 0.121 & 0.069 & 0.076 & 0.066 \\
\hline NEAQS 2002 westerly flow & RHB & 0.092 & 0.107 & 0.154 & 0.118 & 0.106 & 0.110 \\
\hline Below $2 \mathrm{~km}$ altitude & DC-8 & 0.104 & 0.114 & 0.149 & 0.070 & 0.057 & 0.108 \\
\hline Above $2 \mathrm{~km}$ altitude & DC- 8 & 0.106 & 0.115 & 0.156 & 0.078 & 0.087 & 0.101 \\
\hline
\end{tabular}

DOY - Day of year

RHB - NOAA RV Ronald H. Brown, measurements at 55\% RH

C130 - NSF/NCAR C-130, measurements at $<40 \% R H$

$\mathrm{KCO}$ - Kaashidhoo Ground Station, Maldives, measurements at $41 \% R H$

Gosan - Ground Station, South Korea, measurements at 35\% RH

DC-8 - NASA DC-8, measurements made at $<40 \% R H$

ways: 1) from microphysical properties such as size distribution and chemical composition determined by in-situ measurements; 2) from in situ optical measurements of aerosol scattering and absorption coefficients; and 3) from radiometric measurements. Optical depth can be determined: 1) from surface-based radiometric measurements; 2) from airborne radiometric measurements; 3) from surface-based lidar measurements; and 4) from satellite radiometric observations. Comparison of microphysical, optical, and radiometric values yields information about the uncertainties associated with these techniques; comparison among calculated and measured values of optical depth provides an estimate of the uncertainty in calculating optical depth from the optical properties in the radiative transfer model.

An early closure study for the North Atlantic compared aircraft measurements of aerosol optical depth with calculations based on measured aerosol size distribution and absorption coefficient, and chemical composition inferred from thermal volatility (Clarke et al., 1996). The in-situ measurements were adjusted to ambient $R H$ using laboratory growth curves (Tang and Munkelwitz, 1977). For an anthropogenically influenced marine boundary layer, the two methods agreed within $2 \%$, which is well within the uncertainties of both the measurements and the calculations. When a layer of Saharan dust was present above the marine boundary layer, a discrepancy of $50 \%$ was observed, attributed largely to the spatial variability of the dust aerosol.

In a closure study conducted as part of the ACE-2 experiment (Raes et al., 2000) also in the North Atlantic, Collins et al. (2000) found agreement within 3\% between aerosol optical depth determined by an airborne sunphotometer and that calculated from microphysical measurements for clean conditions. The discrepancy was larger when dust and anthropogenic aerosols were present. Sources of uncertainty included uncertainties in particle size, state of mixing, dust optical properties, and hygroscopicity of organic aerosols. Values of $\tau_{e p}$ derived from measurements at the surface and from satellite radiometry agreed within 12\% Durkee et al. (2000). Although the correlation coefficient decreased when dust layers were present the agreement was typically within the 
Table 9. Comparison of optical properties from long-term and intensive campaign measurements. Single scattering albedo $\left(\omega_{0}\right)$ and hemispheric backscatter fraction $(b)$ are derived from in-situ scattering and absorption measurements at NOAA sites; $\omega_{0}$ and the asymmetry parameter $(g)$ are derived from ground-based sun- and sky-photometry measurements at AERONET sites. Measurements of concentrations of particle mass at several NOAA sites allow for the determination of mass scattering efficiency (MSE). A second nephelometer at some sites measured scattering and backscattering at a range of relative humidities, allowing for the computation of $f(R H)$. Data are averaged over the several domains shown in Fig. 1: North Indian Ocean (NIO), northwest Pacific Ocean (NWP), and northwest Atlantic Ocean (NWA). For each measured property, median, mean, standard deviation, and number of observations (n) are reported.

\begin{tabular}{lcccccccc}
\hline & \multicolumn{9}{c}{ Long-Term } & \multicolumn{5}{c}{ Intensive campaigns } \\
& median & mean & std dev & $\mathrm{n}$ & median & mean & std dev & $\mathrm{n}$ \\
\hline MSE & & & & & & & & \\
NWA & 3.0 & 3.2 & 1.1 & 1043 & 3.3 & 3.4 & 1.1 & 120 \\
NWP & 2.4 & 2.4 & 1.2 & 11 & 4.1 & 4.0 & 0.30 & 3 \\
$\omega_{0}$ & & & & & & & & \\
NWA & 0.96 & 0.96 & 0.03 & 1405 & 0.96 & 0.96 & 0.03 & 145 \\
NWA* & 0.96 & 0.96 & 0.02 & 193 & 0.96 & 0.96 & 0.02 & 29 \\
NIO* & 0.91 & 0.91 & 0.03 & 25 & 0.91 & 0.91 & 0.00 & 14 \\
NWP & 0.89 & 0.89 & 0.04 & 220 & 0.90 & 0.90 & 0.03 & 45 \\
NWP* & 0.94 & 0.94 & 0.03 & 157 & 0.94 & 0.93 & 0.02 & 48 \\
$b$ & & & & & & & & \\
NWA & 0.12 & 0.12 & 0.01 & 1504 & 0.11 & 0.11 & 0.02 & 192 \\
NWP & 0.11 & 0.11 & 0.02 & 285 & 0.12 & 0.12 & 0.02 & 46 \\
$g$ & & & & & & & & \\
NWA* & 0.71 & 0.70 & 0.04 & 1346 & 0.71 & 0.70 & 0.04 & 29 \\
NIO* & 0.73 & 0.74 & 0.02 & 149 & 0.73 & 0.73 & 0.02 & 14 \\
NWP* & 0.71 & 0.70 & 0.03 & 353 & 0.68 & 0.69 & 0.03 & 48 \\
$f_{\sigma_{s p}}(R H)$ & & & & & & & & \\
NWP & 2.26 & 2.25 & 0.41 & 42 & 2.38 & 2.34 & 0.40 & 34 \\
$f_{\sigma_{b s p}}(R H)$ & & & & & & & & \\
NWP & 1.65 & 1.69 & 0.23 & 33 & 1.65 & 1.69 & 0.23 & 33 \\
\hline
\end{tabular}

* AERONET sites, ambient humidity; all others NOAA sites, $<40 \% R H$

uncertainty of the satellite measurement, which is estimated as $\pm 20 \%$ (Wagener et al., 1997).

Several closure studies were carried out as part of the ACE-Asia campaign (Huebert et al., 2003). Optical depth from aircraft radiometric measurements and calculated from aircraft sun photometry measurements showed an average agreement within about 13\% (Redemann et al., 2003; Schmid et al., 2003; Kahn et al., 2004), with comparable agreement between measured extinction coefficient and extinction coefficient calculated from microphysical properties (Quinn et al., 2004). Exceptions were clean layers where the absolute error was small but the relative error was large, and a single day with dust aloft for which discrepancies were about $30 \%$ (Kahn et al., 2004). Comparison of optical depth at different relative humidities showed that the discrepancy between radiometric and optical methods was not a simple function of relative humidity (Redemann et al., 2004). A careful error analysis, including the effects of horizontal variability, gave measurement errors in optical depth of around $20 \%$ for radiometric measurements and $15 \%$ for that based on optical measurements (Kahn et al., 2004). Except for the dusty case, all discrepancies were within this range. Comparisons of optical depth between ground-based, ship, and aircraft measurements agreed within $14 \%$ with retrievals from satellite measurements (Wang et al., 2003). Major sources in uncertainty for the retrievals included aerosol absorption, surface reflectance, the calculation of wavelength dependence from aerosol microphysical properties, and sensor calibration.

Few studies are available for the Indian Ocean region. Comparisons from the INDOEX campaign show that in-situ optical measurements and calculations from microphysical properties are in reasonable agreement for submicrometer aerosol $(3 \pm 4 \%)$, but largely variable for supermicrometer aerosol (Quinn et al., 2002). Eldering et al. (2002) compared measurements of $\sigma_{s p}$ and $\omega_{0}$ with values calculated from size-resolved measurements of submicrometer aerosol composition. Light scattering coefficients were predicted to within $5-10 \%$ percent of the measured values over a relative humidity range of $20-90 \%$, for wavelengths of 450,550 , and $700 \mathrm{~nm}$. The calculated single scattering albedo at $550 \mathrm{~nm}$ and $40 \% R H$ had a relative error of $4.0 \%$ when compared to measured values. 
Table 10. Closure studies on aerosol microphysical, optical, and radiative properties in the North Atlantic, North Pacific, and North Indian Ocean atmospheres. Entry in the table denotes reported difference in the indicated quantity as determined by the two approaches; the sign indicates whether the quantity determined by the first named approach is greater $(+)$ or less $(-)$ than that determined by the second approach.

\begin{tabular}{|c|c|c|c|c|c|c|}
\hline \multirow[b]{2}{*}{ Location Study } & \multirow[b]{2}{*}{ Aerosol type } & \multicolumn{3}{|c|}{ Layer extinction coefficient } & \multicolumn{2}{|c|}{ Total optical depth } \\
\hline & & $\begin{array}{c}\text { Microphysical }^{\mathrm{a}} \\
\text { vs. Optical }^{\mathrm{b}}\end{array}$ & $\begin{array}{c}\text { Microphysical }^{\mathrm{a}} \\
\text { vs. Radiometric }^{\mathrm{c}}\end{array}$ & $\begin{array}{c}\text { Optical }^{\mathrm{b}} \\
\text { vs. } \text { Radiometric }^{\mathrm{c}}\end{array}$ & $\begin{array}{c}\text { Layers } \\
\text { vs. Total }\end{array}$ & $\begin{array}{c}\text { Surface } \\
\text { vs. Satellite }\end{array}$ \\
\hline \multicolumn{7}{|l|}{ North Atlantic } \\
\hline \multirow[t]{2}{*}{ Clarke et al. (1996) } & Sulfate layer (soot core) & $-2 \%$ & & & & \\
\hline & Dust & $-50 \%$ & & & & \\
\hline \multirow{4}{*}{ Collins et al. (2000) } & Clean MBL & & $+3 \%$ & & & \\
\hline & Continentally influenced MBL & & $-13 \%$ & & & \\
\hline & Free troposphere - clean & & $-3 \%$ & & & \\
\hline & Free troposphere - dust & & $-17 \%$ & & & \\
\hline Durkee et al. (2000) & East coast, N. America & & & & & $-12 \pm 2 \%$ \\
\hline \multicolumn{7}{|l|}{ North Pacific } \\
\hline \multirow[t]{6}{*}{ Redemann et al. (2003) } & All (28 vertical profiles) & & & & $12 \%$ & \\
\hline & $0-20 \% R H$ & & & $6 \pm 1 \%$ & & \\
\hline & $20-40 \% R H$ & & & $-24 \pm 1 \%$ & & \\
\hline & $40-60 \% R H$ & & & $-2 \pm 2 \%$ & & \\
\hline & $60-80 \% R H$ & & & $4 \pm 2 \%$ & & \\
\hline & $80-100 \% R H$ & & & $27 \pm 7 \%$ & & \\
\hline \multirow[t]{3}{*}{ Wang et al. (2003) } & Land & & & & & $-14 \%$ \\
\hline & Ship & & & & & $-2 \%$ \\
\hline & Aircraft & & & & $-18 \%$ & \\
\hline \multirow[t]{2}{*}{ Kahn et al. (2004) } & Three events excluding cloud & & & $1 \pm 10 \%$ & $\pm 20 \%$ & \\
\hline & One event with dust aloft & & & $30 \pm 45 \%$ & $+17 \%$ & \\
\hline \multirow[t]{2}{*}{ Quinn et al. (2004) } & Submicrometer, surface $*$ & $13 \pm 16 \%$ & & & & \\
\hline & Supermicrometer, surface $*$ & $1 \pm 45 \%$ & & & & \\
\hline \multicolumn{7}{|l|}{ Indian Ocean } \\
\hline \multirow[t]{2}{*}{ Quinn et al. (2002) } & Submicrometer, surface $*$ & $-3 \pm 4 \%$ & & & & \\
\hline & Supermicrometer, surface $*$ & $5 \pm 30 \%$ & & & & \\
\hline
\end{tabular}

* Values given were average comparison over air mass source; standard deviation represents variability among different air masses.

${ }^{a}$ Microphysical denotes quantities calculated from measured size distributions and chemical composition.

${ }^{\mathrm{b}}$ Optical denotes quantities calculated from in situ measurements of scattering and absorption coefficients.

${ }^{\mathrm{c}}$ Radiometric denotes quantities calculated from sunphotometer measurements.

\subsubsection{Summary from closure studies}

For situations in which the aerosol consisted principally of sulfate and carbonaceous material, closure studies on aerosol optical properties and optical depths were generally within $10-15 \%$ and often better. It is difficult to extend these conclusions to studies where aerosol was not segregated by air mass type. Comparisons between aerosol optical depth determined as the vertical integral of in-situ measurements and measurements of extinction coefficient by sun photometry exhibit differences of $10-12 \%$, but these studies are fewer in number. The study by Schmid et al. (2000) suggests that this agreement occurs at the common measurement wavelength of around $550 \mathrm{~nm}$; however, the comparison may not be as well constrained at other wavelengths. Aerosol closure studies show the best agreement when limited to submicrometer sizes and spherical particles that pose the smallest challenges to inlets, measurement techniques, and calculation of aerosol properties (Magi et al., 2003; Redemann et al., 2003).
Comparisons of optical depth for situations where optical depth is dominated by dust aerosol exhibit up to $35 \%$ discrepancy, especially when the dust is present without appreciable sulfate/carbonaceous aerosol. These discrepancies do not decrease in later studies and sometimes cannot be explained by measurement error. Doherty et al. (2005) found discrepancies ranging from $16 \%$ to about $40 \%$ in comparisons between platforms, which may be due to differing inlet efficiencies. A low turbulence inlet, such as that deployed on the NSF/NCAR C-130 during ACE-Asia, has enhanced the passing efficiency of supermicrometer particles into the instrumentation onboard the aircraft (Huebert et al., 2003), but the non spherical shape of dust particles complicates determination of particle size by the optical particle sizers employed as well as calculations of scattering from the reported size distributions (Quinn et al., 2003; Wang et al., 2002). Comparison of measurements on different platforms also is complicated by horizontal and vertical variability in aerosol properties. Horizontal variability in AOD of about $25 \%$ over 
spatial scales of $60 \mathrm{~km}$ has also been reported for sea-salt dominated regions (Shinozuka et al., 2004).

The closure studies suggest that DRE for sulfate/carbonaceous aerosol can be estimated from measurements of the composition and size distribution with an uncertainty of about $25 \%$. This uncertainty arises from the sum, in quadrature, of roughly equal contributions of about $15 \%$ each in translating chemical properties to optical properties, in translating optical properties to extinction coefficient, and in translating in-situ extinction coefficient to column optical depth. For dust aerosol, the respective uncertainties are about $50 \%, 35 \%$ and $15 \%$, resulting in an overall uncertainty of about $60 \%$. This estimate of uncertainty is applicable for the Atlantic and Pacific Oceans; there are no reported column closure studies for the north Indian Ocean.

Closure comparisons for single-scatter albedo are not included in Table 10. Because the present study uses measured values of $\omega_{0}$, uncertainties in the linkage between chemical composition and absorptive properties do not directly affect the uncertainties. However, any discrepancies between modeled and actual single scattering albedo would have an effect in the traditional modeling framework, in which $\omega_{0}$ is calculated based on size distribution and chemical composition. Findings by Quinn et al. (2004) that the measured absorption was systematically greater than calculated by $50-100 \%$ suggest that modeled $\omega_{0}$ may be overestimated.

The studies summarized in Table 10 are examples of recent concerted attempts to perform closure experiments on aerosol optical properties and optical depth. Even given the great deal of care and planning that went into these analyses, limitations remain in the experimental design. Perhaps the largest limitation is that no single study integrated surfaceand satellite-based radiometric measurements of AOD with in situ optical, microphysical and up-looking (surface or aircraft) radiometric measurements. While the studies performed comprehensive and valuable comparisons of some of the techniques, none treated all of them (from the surface via airborne measurements to the satellites) simultaneously. Another limitation is the lack of consistency in comparing results and expressing uncertainties. Comparisons that express the mean difference between two techniques and standard deviation of that mean are most useful in assessing uncertainties. Explicit reporting of these quantities in future studies should enhance the confidence in conclusions drawn from them.

\subsection{Optical properties for radiative transfer calculations}

\subsubsection{Introduction}

Calculation of local aerosol DRE in a RTM requires knowledge of aerosol extinction coefficients $\sigma_{e p}$, single scattering albedos $\omega_{0}$, and asymmetry parameters $g$, all as a function of altitude and all at the ambient relative humidity, also a func- tion of altitude. However, these quantities are not typically reported in field or modeling studies, which generally report the mass concentrations $C_{i}$ of individual aerosol species, the mass scattering efficiency of the aerosol $\alpha$, and the backscatter fraction of the aerosol $b$, again in one or more size ranges. These quantities are typically measured at a low, reference relative humidity; also measured, at least in recent studies, is the relative-humidity dependence of the light scattering coefficient $f_{\sigma_{s p}}\left(R H, R H_{\text {ref }}\right)$. As these properties are not the properties required by the RTMs, it is thus necessary in using aerosol properties calculated by CTMs and as constrained by comparison with field measurements to infer the quantities required by RTMs from those available from the CTMs and field measurements. This section sets forth the approach to doing this and assesses the assumptions and uncertainties associated with this procedure.

A key issue in the present study is relating optical properties of the aerosol as a whole, as measured in field studies, to those of the individual component species that comprise the aerosol. This is necessary to obtain the aerosol optical properties pertinent to the aerosol species that are modeled by the CTM. The approach taken here consists of using field measurements to ascertain the dependence of aerosol properties such as $f(R H)$ on the mix of aerosol composition and then applying these properties to the modeled aerosol.

Median values of aerosol optical properties measured in intensive field studies in the three regions examined here (Tables 6-8) are characteristic of the integral properties of the aerosol present at the measurement locations that in turn is reflective of the diverse sources that give rise to that aerosol. These measurements both provide an opportunity to test the ability of models to calculate how different sources can mix to result in representative regional optical properties and yield the aerosol optical properties required for radiative transfer modeling. It should be stressed that the aerosol optical properties cannot be used without attribution to the individual aerosol constituent species because of the differences that would be expected for differing relative amounts of the several species and also because of the need to attribute DRE and DCF to specific aerosol constituents.

The approach taken here to providing the required aerosol optical properties consists, to the extent possible, of isolating the sulfate/carbonaceous accumulation mode aerosol from dust and sea-salt and determining the properties of this aerosol so that these properties can be used to calculate and mix the optical properties of the aerosol whose individual component concentrations are calculated by the CTMs. Dependences of these properties on composition (e.g., the dependence of $f(R H)$ on organic mass fraction and the dependence of mass scattering efficiency on the ratio of fine-mode to coarse-mode mass) were determined and applied in calculating the aerosol optical properties to be used in the radiative transfer calculations. Values of the properties that were used to constrain the radiative transfer models are discussed below and listed in Tables 11 and 13. Finally, the model output was 
Table 11. Mass scattering efficiency $\alpha\left(\mathrm{m}^{2} \mathrm{~g}^{-1}\right)$ values used in the radiative transfer calculations. For submicrometer sulfate/carbonaceous aerosol, values of $\alpha$ are tabulated for each region; for submicrometer dust, for submicrometer sulfate/carbonaceous aerosol when dust is present (any dust in the submicrometer fraction), and for supermicrometer dust, values of $\alpha$ are evaluated as $\alpha=c_{1} \exp \left(-c_{2} x\right)$ using tabulated values of $c_{1}$ and $c_{2}$, where $x$ is the ratio of the supermicrometer to submicrometer mass concentration. NIO, North Indian Ocean; NWP, Northwest Pacific; NWA, Northwest Atlantic.

\begin{tabular}{lccccccc}
\hline $\begin{array}{l}\text { Aerosol } \\
\text { type }\end{array}$ & \multicolumn{2}{c}{$\begin{array}{l}\text { Submicrometer sulfate/ } \\
\text { carbonaceous }\left(\mathrm{m}^{2} \mathrm{~g}^{-1}\right)\end{array}$} & \multicolumn{2}{c}{$\begin{array}{l}\text { Submicrometer dust and } \\
\text { sulfate/carbonaceous aerosol } \\
\text { when dust is present }\end{array}$} & \multicolumn{2}{c}{ Supermicrometer dust } \\
$\lambda, \mathrm{nm}$ & NIO & NWP & NWA & $c_{1}\left(\mathrm{~m}^{2} \mathrm{~g}^{-1}\right)$ & $c_{2}$ & $c_{1}\left(\mathrm{~m}^{2} \mathrm{~g}^{-1}\right)$ & $c_{2}$ \\
\hline 450 & 4.99 & 5.95 & 5.37 & 5.24 & 0.0406 & 2.22 & 0.115 \\
550 & 3.61 & 4.10 & 3.66 & 3.71 & 0.0420 & 1.74 & 0.0821 \\
700 & 2.58 & 2.33 & 2.28 & 2.12 & 0.0506 & 1.57 & 0.095 \\
\hline
\end{tabular}

Table 12. Single scattering albedo $\omega_{0}$ values at $0 \% R H$ for sub-1 $\mu \mathrm{m}$ and sup- $1 \mu \mathrm{m}$ sulfate/carbonaceous and dust aerosol in each region, as used in the radiative transfer models.

\begin{tabular}{lcccccc}
\hline Aerosol Type & $\begin{array}{c}\text { Sub-1 } \mu \mathrm{m} \\
450 \mathrm{~nm}\end{array}$ & $\begin{array}{c}\text { Sub-1 } \mu \mathrm{m} \\
550 \mathrm{~nm}\end{array}$ & $\begin{array}{c}\text { Sub-1 } \mu \mathrm{m} \\
700 \mathrm{~nm}\end{array}$ & $\begin{array}{c}\text { Sup-1 } \mu \mathrm{m} \\
450 \mathrm{~nm}\end{array}$ & $\begin{array}{c}\text { Sup-1 } \mu \mathrm{m} \\
550 \mathrm{~nm}\end{array}$ & $\begin{array}{c}\text { Sup-1 } \mu \mathrm{m} \\
700 \mathrm{~nm}\end{array}$ \\
\hline Sulfate/carbonaceous & 0.879 & 0.867 & 0.841 & & & \\
Dust & 0.862 & 0.849 & 0.824 & 0.963 & 0.975 & 0.990 \\
& \multicolumn{7}{c}{ North Indian Ocean } \\
Sulfate/carbonaceous & 0.887 & 0.865 & 0.828 & & \\
Dust & 0.862 & 0.849 & 0.824 & 0.963 & 0.975 & 0.990 \\
& \multicolumn{7}{c}{ NW Atlantic Ocean } \\
Sulfate/carbonaceous & 0.966 & 0.961 & 0.949 & & \\
Dust & 0.862 & 0.849 & 0.824 & 0.963 & 0.975 & 0.990 \\
\hline
\end{tabular}

compared to the median properties reported in Tables $6-8$ for accumulation-mode and coarse-mode sizes (Sect. 5.4).

Calculation of the aerosol optical properties discussed below assumes the following aerosol chemical and physical properties (see Sect. 2 for further details):

1. Aerosol mass over the ocean regions examined here is present in two distinct modes, an accumulation mode and a coarse mode. The presence of these two distinct modes is consistent with the great majority of the observations. In both measurements and models the coarse mode is restricted to dry diameter less than $10 \mu \mathrm{m}$.

2. Sea salt and/or dust are present as external mixtures in the coarse mode. Any nitrate carried in the CTM is associated with this mode (Bates et al., 2004). The coarse mode sea salt and/or dust "tails" into the submicrometer mode and is carried in the CTM as submicrometer sea salt and/or dust. Optical properties are given for both the submicrometer and supermicrometer $(1-10 \mu \mathrm{m}$ aerodynamic diameter) dust. The optical properties of sea salt are discussed in the next section.
3. Sulfate, particulate organic matter (POM), black carbon, and ammonium are internally mixed and exist entirely in the submicrometer size range (accumulation mode). Here, the concentration of POM has been either measured directly by an aerosol mass spectrometer or calculated as the measured mass concentration of organic carbon multiplied by 1.4 (ACE-Asia for C130 measurements) or 1.6 (INDOEX, ACE-Asia for Ronald H. Brown and ground station measurements). The factor of 1.4 or 1.6 is consistent with the data analysis on each platform and is a measure of the degree of oxidation of the organic matter; the true factor is not known and uncertainty in this quantity contributes to uncertainty in reported aerosol mass concentrations and derived quantities such as mass scattering efficiency.

4. Aerosol optical properties pertinent to DRE at wavelengths less than $1 \mu \mathrm{m}$ can be accurately obtained by interpolation/extrapolation from the properties measured at wavelengths of 450, 550, and $700 \mathrm{~nm}$. Aerosol DRE at wavelengths greater than $1 \mu \mathrm{m}$, can be accurately calculated using "a priori" values (see Sect. 5.2). 
Table 13. Backscatter fraction at $0 \% R H$ for sub- $1 \mu \mathrm{m}$ and sup- $1 \mu \mathrm{m}$ sulfate/carbonaceous and dust aerosol in each region, as used in the radiative transfer models.

\begin{tabular}{lcccccc}
\hline Aerosol Type & $\begin{array}{c}\text { Sub-1 } \mu \mathrm{m} \\
450 \mathrm{~nm}\end{array}$ & $\begin{array}{c}\text { Sub-1 } \mu \mathrm{m} \\
550 \mathrm{~nm}\end{array}$ & $\begin{array}{c}\text { Sub-1 } \mu \mathrm{m} \\
700 \mathrm{~nm}\end{array}$ & $\begin{array}{c}\text { Sup-1 } \mu \mathrm{m} \\
450 \mathrm{~nm}\end{array}$ & $\begin{array}{c}\text { Sup-1 } \mu \mathrm{m} \\
550 \mathrm{~nm}\end{array}$ & $\begin{array}{c}\text { Sup-1 } \mu \mathrm{m} \\
700 \mathrm{~nm}\end{array}$ \\
\hline \multirow{7}{*}{ North Indian Ocean } \\
Sulfate/carbonaceous & 0.081 & 0.101 & 0.122 & & \\
Dust & 0.092 & 0.109 & 0.130 & 0.115 & 0.110 & 0.112 \\
& \multicolumn{7}{c}{ NW Pacific Ocean } \\
Sulfate/carbonaceous & 0.099 & 0.114 & 0.154 & & \\
Dust & 0.092 & 0.109 & 0.130 & 0.115 & 0.110 & 0.112 \\
& \multicolumn{7}{c}{ NW Atlantic Ocean } \\
Sulfate/carbonaceous & 0.092 & 0.102 & 0.135 & & \\
Dust & 0.092 & 0.109 & 0.130 & 0.115 & 0.110 & 0.112 \\
\hline
\end{tabular}

These assumptions about aerosol chemical and microphysical properties serve as the basis of the approach used here to constrain the calculated aerosol DRE by measurements of the aerosol optical properties.

\subsubsection{Scattering response to changes in $R H$}

A key property of hygroscopic aerosols that must be accurately represented in calculations of aerosol DRE is the increase in aerosol light scattering coefficient $\sigma_{s p}$ with increasing relative humidity and its dependence on the composition and size distribution of the aerosol. Typically this increase in $\sigma_{s p}$ is represented by the quantity $f_{\sigma_{s p}}\left(R H, R H_{\text {ref }}\right)$, the factor by which $\sigma_{s p}$ increases between a reference $R H$ and the $R H$ of interest. Estimates of $f_{\sigma_{s p}}(R H)$ are based on measurements of the scattering coefficient at two or more $R H$ values and calculated according to the relation

$f_{\sigma_{s p}}\left(R H, R H_{\mathrm{ref}}\right) \equiv \frac{\sigma_{s p}(R H)}{\sigma_{s p}\left(R H_{\mathrm{ref}}\right)}=\left[\frac{100-R H_{\mathrm{ref}}}{100-R H}\right]^{\gamma_{s}}$

where $R H_{\text {ref }}$ is the lower, reference $R H$ value, $R H$ is the ambient, larger $R H$ value, and $\gamma_{s}$ describes the steepness of the relationship; the reference $R H$ ( $\left.R H_{\text {ref }}\right)$ in the radiative transfer models is taken as 0 .

As discussed above, the contribution of nitrate and sulfate to $R H$ growth of the light scattering coefficient of dust particles is negligible even when dust contributes substantially to scattering (Carrico et al., 2003; Howell et al., 2004). Consequently, in the radiative transfer calculations reported here, $f_{\sigma_{s p}}(R H)$ for dust has been set to unity (no change in light scattering with changes in $R H$ ).

The sea-spray mode, dominated by sea-salts, is also considered to be externally mixed even though it is recognized that species like nitrate and organic aerosol can be taken up by sea-salt. Again, the influence of these species on overall sea-salt optical properties generally appears to be small, except perhaps in the submicrometer component (Randles et al., 2004). We use a constant value of $f_{\sigma_{s p}}(R H)$ equal to $2.33(R H=80 \%)$ based on measurements of aerosol consisting predominantly of sea spray (Carrico et al., 2003) in all RTM runs. Hence, this approach does not introduce a difference between the "a priori" and constrained optical calculations associated with sea salt. This simplification was added because the emphasis here is on the radiative effects of anthropogenic aerosol and to lesser extent on differences due to differing treatments of the optical properties of natural aerosol components. Optical properties for sea-salt aerosol adjusted to $80 \% R H$ are given in Table 14 .

Organic carbon internally mixed with water soluble salts can reduce deliquescent behavior and decrease the growth of particles under conditions of increasing humidity (Kanakidou et al., 2005; Svenningsson et al., 2005). Measurements during the field campaigns in the three regions examined here revealed a substantial decrease in $f_{\sigma_{s p}}(R H)$ with increasing mass fraction of POM in the accumulation mode (Quinn et al., 2005). These observations indicate that POM can substantially decrease the humidity response of aerosol size and, hence, optical properties and that this effect should be included in model evaluations of aerosol radiative effects.

Values of $\gamma_{s}$ for accumulation mode sulfate/carbonaceous aerosol were derived as a function of the relative amounts of the POM and sulfate in the aerosol from field measurements during INDOEX, ACE Asia, and ICARTT (Quinn et al., 2005).

$\gamma_{s}=0.9( \pm 0.003)-0.6( \pm 0.01) F_{O}$

where

$F_{O}=C_{O} /\left(C_{O}+C_{S}\right)$

$C_{O}$ and $C_{S}$ are the measured mass concentrations of POM and sulfate, respectively. Data obtained at the Chebogue Point ground station and onboard Ronald $\mathrm{H}$. Brown during ICARTT were merged to define the Eq. (4) y-intercept and 
slope for the ICARTT study region. A similar relation was obtained for ACE-Asia using data from the Gosan ground station, Ronald H. Brown, and the C-130. The data were selected for cases when the fine mode scattering fraction exceeded $50 \%$ to minimize the influence of dust on $f(\mathrm{RH})$ (Howell et al., 2004) and to be more representative of the accumulation mode aerosol. Data from Kaashidhoo, Maldives were used to derive a similar relationship for the northern Indian Ocean. Inter-regional variability in the y-intercept and slopes of these relationships most likely is due to differing degrees of acidity of the aerosol $\left(\mathrm{NH}_{4}\right.$ to nss $\mathrm{SO}_{4}^{=}$molar ratios) and hygroscopicity of the organic aerosol (Quinn et al., 2005), although the linear fits were not significantly different when compared to the overall measurement uncertainties. Merging the ACE Asia and ICARTT data sets and normalizing so that they are weighted equally yields the y-intercept and slope in Eq. (4). The relationship is considered to be valid up to $90 \% R H$ as this is the upper limit of the $f(R H)$ measurements.

The radiative transfer calculations reported here used $C_{O}$ as 1.6 times the mass concentration of organic carbon from the CTM output in Eq. (4) to calculate $\gamma_{s}$. For the submicrometer sulfate/carbonaceous aerosol, $f_{\sigma_{s p}}(R H)$ was then calculated using Eq. (3) and $R H_{\mathrm{amb}}$ from the CTM output to obtain the aerosol scattering coefficient and $\omega_{0}$ at ambient $R H$. $R H_{\mathrm{amb}}$ was capped at $95 \%$ because of the large uncertainty in measurements above this $R H$. This somewhat arbitrary cap may result in an underestimation of the scattering coefficient and thus DRE and DCF.

\subsubsection{Mass scattering efficiencies}

Mass scattering efficiency (MSE, $\alpha$ ) the quotient of the light scattering coefficient and the mass concentration of a given aerosol mode, is a key aerosol property required in calculating DRE from modeled mass concentrations of the several aerosol species. While in principle mass scattering efficiencies can be obtained from known or assumed aerosol size distributions, index of refraction, and density, this information is not generally known, so mass scattering efficiencies are commonly determined empirically. In the present study, light scattering coefficients required for the radiative transfer calculations are derived from 1) mass concentrations of the several aerosol components calculated by CTMs and 2) mass scattering efficiencies derived from measurements during INDOEX, ACE Asia, and ICARTT. The mass scattering efficiencies were calculated as the quotient of the measured scattering coefficients at three wavelengths and the mass concentration. Scattering coefficients were measured for sub-1 and sub- $10 \mu \mathrm{m}$ diameter ranges at the reference $R H$; scattering coefficients for the supermicrometer mode were obtained by difference. Aerosol mass concentrations at surface locations and onboard Ronald $\mathrm{H}$. Brown were measured gravimetrically for the sub- $1 \mu \mathrm{m}$ and sub-10 $\mu \mathrm{m}$ diameter ranges at $55-60 \% R H$, and mass concentrations of the super-
Table 14. Optical properties of sub-10 micrometer diameter sea salt aerosol used for all three regions and at all relative humidities ${ }^{\mathrm{a}}$.

\begin{tabular}{lccc}
\hline & $0.45 \mu \mathrm{m}$ & $0.55 \mu \mathrm{m}$ & $0.70 \mu \mathrm{m}$ \\
\hline$\alpha_{s p}$ & 3.4 & 3.4 & 3.6 \\
$\omega_{0}$ & 1.00 & 1.00 & 1.00 \\
$g$ & 0.74 & 0.75 & 0.75 \\
\hline
\end{tabular}

a The given properties apply to $80 \% R H$, which is typical for the marine boundary layer. Properties are based on measurements of aerosol consisting predominantly of sea salt during ACE-1, adjusted from the measurement $R H$ of $55 \%$ to $80 \% R H$ using the parameterization of Carrico et al. (2003).

micrometer mode were likewise obtained by difference. For aircraft measurements volume concentrations were derived from number size distributions at $20-40 \% \mathrm{RH}$ and mass concentrations were calculated with a particle density based on the chemical composition. The mass scattering efficiencies determined by these approaches have been found to be consistent (Clarke et al., 2002).

A concern in application of this approach is that the measurements of light scattering coefficients were made at a low, but not dry, reference $R H$ (e.g., $40 \%$ or $55 \%$ ), at which the aerosol contained appreciable water (Quinn et al., 2004), whereas the CTMs calculate dry mass concentrations. An issue of concern, therefore, is inferring the scattering coefficients pertinent to the $R H$ of the measurements (at 40 to $55 \% R H$ ) and to the ambient atmosphere from the aerosol dry mass concentrations calculated by the CTMs.

For a sulfate/carbonaceous aerosol, which does not exhibit a steep efflorescence markedly below the $R H_{\text {ref }}$, the modeled dry mass concentration $M_{\text {dry }}$ and light scattering coefficient $\sigma_{s p}(R H=0 \%)$, is related to the mass concentration $M_{\text {ref }}$ and scattering coefficient $\sigma_{s p}$ measured at the reference relative humidity $R H_{\text {ref }}$, typically $40 \%$, by:

$$
M_{\mathrm{ref}} / M_{\mathrm{dry}}=\sigma_{s p}(R H=40 \%) / \sigma_{s p}(R H=0 \%)
$$

A justification for this is that the scattering coefficient of particles in the submicrometer size range varies approximately with volume, as noted, for example, by Pinnick et al. (1980). This approach is equivalent to neglecting density changes and assuming the growth function for scattering, $f_{\sigma_{s p}}(R H)$ is related to the growth function for diameter, $f_{D}(R H)^{3}$, as $f_{\sigma_{s p}}(R H) \approx f_{D}(R H)^{3}$. Such a relation is supported also by measurements during INDOEX (Howell et al., 2006 Fig. 11).

Within the approximation of Eq. (6), the measured $\alpha_{\text {ref }}$ can be used directly in the models because upon drying the changes in scattering and mass are compensating to first order. Although a density and refractive index correction would be desirable, such a correction would be of second order, and the error from neglecting this correction appears 


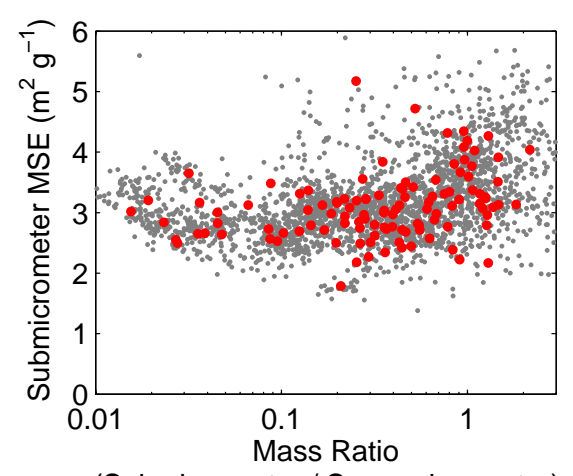

(Submicrometer / Supermicrometer)

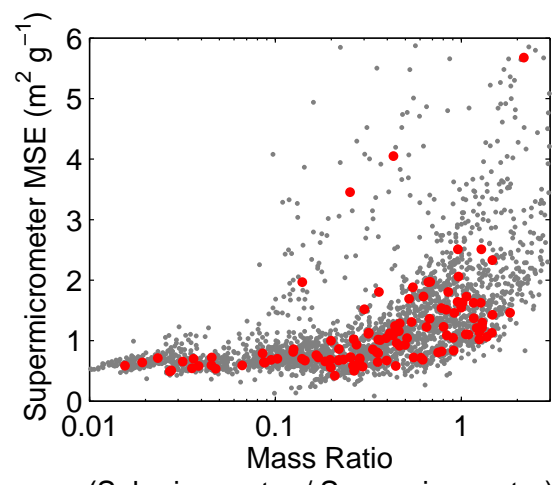

(Submicrometer / Supermicrometer)

Fig. 8. Trends in measured submicrometer mass scattering efficiency vs. log of accumulation mode volume to coarse mass ratio for ACEAsia C-130 data. Values are based upon nephelometer data (Anderson et al., 2003) and size distribution measurements (Clarke et al., 2004) subject to the impactor size cut. Both light scattering coefficient and mass concentration pertain to the dry aerosol. Continuous data and flight-leg-average data (red dots) are indicated. These trends are associated with median values for a submicrometer to supermicrometer mass ratio of 0.39 , a submicrometer mass scattering efficiency of $3.1 \mathrm{~m}^{2} \mathrm{~g}^{-1}$; and a supermicrometer mass scattering efficiency of $0.94 \mathrm{~m}^{2} \mathrm{~g}^{-1}$.

no worse than that which would result from more complicated assumptions. With this assumption Eq. (7) provides a means to calculate $\sigma_{s p}(R H)$ given $M_{\text {dry }}$ from the CTM and measurements of $\alpha_{\text {ref. }}$.

$$
\begin{aligned}
\sigma_{s p}(R H) & =f_{\sigma_{s p}}\left(R H, R H_{\mathrm{ref}}\right) \sigma_{s p}\left(R H, R H_{\mathrm{ref}}\right) \\
& =f_{\sigma_{s p}}\left(R H, R H_{\mathrm{ref}}\right) \alpha\left(R H_{\mathrm{ref}}\right) M_{\mathrm{ref}}
\end{aligned}
$$

Although this approach seems robust for submicrometer aerosol, the relationship is less robust for supermicrometer sea salt. Sea-salt particle mass decreases by a factor of about 2.5 with a decrease in $R H$ from 55\% to dry (Tang et al., 1997), whereas the corresponding humidity dependence $f_{\sigma_{s p}}$ $(55,0)$ for sub- $10 \mu \mathrm{m}$ marine aerosol measured during ACE 1 was about 2 (Carrico et al., 2003). This behavior would imply a $20 \%$ net effect of water on the mass scattering efficiency at 55\% RH under the assumption that changes in scattering and mass compensate each other. Still, this assumption is appropriate given the uncertainty associated with adjusting the scattering and mass measurements made at a reference low $R H$ to a standard "dry" $R H$.

Mass scattering efficiencies can be strongly affected by the size distribution. Evidence for this is given by examination of the dependence of mass scattering efficiencies on the ratio of coarse- to accumulation mode mass concentration, which is a measure of the influence of the tail of the coarse mode distribution on fine mode mass scattering efficiencies and vice versa. Although the measured efficiency curves for the standard Berner-type impactor used in nearly all of the measurements herein are sharp (Fig. 3), the "tails" of the coarse and fine modes typically overlap so that the measured data do not fully resolve the properties of each mode. For the submicrometer data the problem is exacerbated when the coarse mode is dominant and, conversely, the problem for the super $\mu \mathrm{m}$ data is exacerbated when the fine mode is dominant. An example of this effect is reflected in data measured during
ACE-Asia aboard the NSF/NCAR C-130 based upon nephelometry (Anderson et al., 2003) and size distribution (Clarke et al., 2004) measurements, shown in Fig. 8. Values for both submicrometer mass scattering efficiency and supermicrometer mass scattering efficiency decrease as the relative volume of the coarse mode increases. This has important consequences for interpreting measured values of mass scattering efficiency and use of these efficiencies in models. The overall median mass scattering efficiency of $3.1 \mathrm{~m}^{2} \mathrm{~g}^{-1}$ (Fig. 8) is a result of both sulfur/carbonaceous and dust influences. The median value for submicrometer mass scattering efficiency at $550 \mathrm{~nm}\left(\mathrm{C}-130\right.$ data, Table 5) of $3.8 \mathrm{~m}^{2} \mathrm{~g}^{-1}$ was obtained for cases when supermicrometer mass was less than submicrometer mass (low dust). These systematic effects arising from overlapping modes clearly contribute to submicrometer mass scattering efficiencies ranging from about 2 to $5 \mathrm{~m}^{2} \mathrm{~g}^{-1}$ (a factor of more than 2) in Fig. 8. This range of variability is not an uncertainty but a consequence of mixing aerosol components with very different submicrometer mass scattering efficiency values. Hence, the variance in campaign measured values must not be used as an indicator of observed uncertainty by the models but only to bound the range of values generated by the models after mixing diverse regional sources. A similar conclusion is evident for the coarse mode where a median value of $1.0 \mathrm{~m}^{2} \mathrm{~g}^{-1}(550 \mathrm{~nm})$ in Fig. 8 also results from a range of measured leg-average values between about 0.5 and $3.0 \mathrm{~m}^{2} \mathrm{~g}^{-1}$. For the low-dust cases (Table 6) the measured value was $1.2 \mathrm{~m}^{2} \mathrm{~g}^{-1}$. Large values are a result of both artifacts in the measured dust distribution (loss of larger particles) and the influence of the sulfur/carbonaceous submicrometer mode tailing into the supermicrometer mode.

These observations pose some concern in assigning aerosol properties to aerosol constituents whose mass concentrations are specified by the CTMs for diameters above and below $1 \mu \mathrm{m}$. Equations that describe the dependence of 
these mass scattering efficiency values on the relative coarse and fine volumes are included in Table 11 as a guide for interpreting model results. The implications of the above for the submicrometer mass scattering efficiency is that the sulfate/carbonaceous accumulation mode without any dust has a value near $4 \pm 1 \mathrm{~m}^{2} \mathrm{~g}^{-1}$. The values observed under larger dust conditions are near $3 \pm 0.5 \mathrm{~m}^{2} \mathrm{~g}^{-1}$.

Another consideration is that as the concentration of accumulation mode aerosol increases, the peak mass-mean diameter has been found to increase slightly. During INDOEX the mass-mean diameter for medium scattering $\left(25-55 \mathrm{Mm}^{-1}\right)$ and large scattering $\left(55-100 \mathrm{Mm}^{-1}\right)$ accumulation-mode cases increased by about $10 \%$ for C-130 data and about $6 \%$ for Ronald H. Brown data (Clarke et al., 2002). For mass mean diameter increasing from 0.25 to $0.35 \mu \mathrm{m}$ the size dependent mass scattering efficiency increases from values near $3 \mathrm{~m}^{2} \mathrm{~g}^{-1}$ to near $4 \mathrm{~m}^{2} \mathrm{~g}^{-1}$, depending upon the width of the distribution. Hence, under increasing accumulation mode concentrations the mass scattering efficiency for the accumulation mode can increase with increasing concentration. However, even though these trends were evident on both platforms, they were also comparable to the differences in mass mean diameter for the different platforms (i.e., about $0.32 \mu \mathrm{m}$ for the $\mathrm{C}-130$ and about $0.35 \mu \mathrm{m}$ for Ronald H. Brown) and to estimated measurement uncertainty in mass scattering efficiency, about $10 \%$. For this reason this effect is not represented in the modeling, but it should be noted that it is an additional source of error or bias in the calculations.

\subsubsection{Single-scattering albedo $\left(\omega_{0}\right)$}

As discussed previously, aerosol scattering coefficients were reported for all experiments at three wavelengths (450, 550, $700 \mathrm{~nm}$ ) for sub-1 and sub-10 $\mu \mathrm{m}$ size ranges. Aerosol absorption coefficients were reported at a single wavelength of $550 \mathrm{~nm}$ with the exception of NEAQS 2002 and ICARTT 2004 on Ronald H. Brown where measurements were made at 467, 530, and $660 \mathrm{~nm}$. The single wavelength measurements of absorption were converted from $550 \mathrm{~nm}$ to 450 and $700 \mathrm{~nm}$ assuming a $\lambda^{-1}$ dependency for accumulation mode sulfate/carbonaceous aerosol (Virkkula et al., 2005; Quinn et al., unpublished data) and a $\lambda^{-2}$ dependency for coarse mode dust aerosol. The absorption coefficients measured at 467, 530 , and $660 \mathrm{~nm}$ were converted to the nephelometer wavelengths with the Angstrom exponent for absorption. These measurements and assumed absorption spectral dependencies have been used to generate wavelength-dependent values of $\omega_{0}$ (Tables 6 and 11) for each of the three regions examined here. The absorption coefficient is assumed to be independent of relative humidity. Although a recent modeling study of this effect (Nessler et al., 2004) found the absorption to be altered by a factor of 0.9 to 1.6 for $R H$ increasing from 0 to $99 \%$, the effect on $\omega_{0}$ was only $0.2 \%$ because the enhancement of absorption is much smaller than the increase in

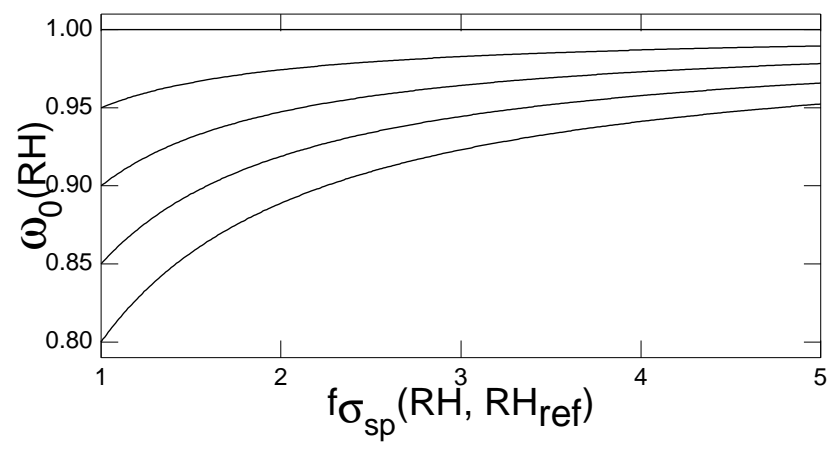

Fig. 9. Dependence of single scattering albedo on the enhancement of light scattering coefficient relative to that at a reference relative humidity, $f_{\sigma_{s p}}\left(R H, R H_{\text {ref }}\right)$, for values of the single scattering albedo at that reference relative humidity as given by the intercepts of the several curves on the left axis. These calculations are correct with the assumption that only aerosol scattering coefficients and not absorption coefficients are a function of $R H$.

scattering. Under the assumption that only aerosol scattering coefficients and not absorption coefficients are functions of $R H$, the dependence of $\omega_{0}$ on $R H$ can be expressed in terms only of $f_{\sigma_{s p}}\left(R H, R H_{\text {ref }}\right)$ as:

$$
\begin{aligned}
& \omega_{0}(R H)=\omega_{0, \text { ref }} f_{\sigma_{s p}} \\
& \quad\left(R H, R H_{\mathrm{ref}}\right) /\left[1+\omega_{0, \mathrm{ref}}\left(f_{\sigma_{s p}}\left(R H, R H_{\mathrm{ref}}\right)-1\right)\right]
\end{aligned}
$$

where $\omega_{0}(R H)$ is the single scattering albedo at ambient humidity and $\omega_{0, \text { ref }}$ is the single scattering albedo at the low reference humidity, as given in Tables 6 and 11. This relation, shown in Fig. 9 for several values of $\omega_{0 \text {,ref, increases }}$ monotonically with increasing relative humidity from the initial value at the reference relative humidity toward unity as the scattering component of the extinction aerosol becomes increasingly greater.

For supermicrometer aerosol consisting of dust only $\omega_{0, \text { ref }}$ is based upon ACE-Asia measurements that yield a value near $0.97(550 \mathrm{~nm})$ (Anderson et al., 2003), with a slight wavelength dependency. Dust optical properties based upon asymptotic behavior under large dust concentrations imply a

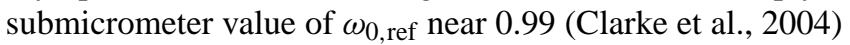
assuming a mineral composition that is size independent. However, even under dust cases with small concentrations of sulfate/carbonaceous aerosol, the submicrometer value of $\omega_{0, \text { ref }}$ is near 0.9 , consistent with a possibly different mineralogy in the smaller sizes (Lafon et al., 2004). Regardless of the reason, the ubiquitously small values of $\omega_{0}$ for submicrometer aerosol dominated by dust suggest a submicrometer dust $\omega_{0, \text { ref }}$ of $0.89(550 \mathrm{~nm})$ is adequate for modeling purposes.

For sea salt the observed value of $\omega_{0 \text {, ref }}$ at larger sizes is 1.0 (Quinn et al., 1998). For submicrometer aerosol the value would be expected also to be 1.0 , but it often is measured slightly lower in clean marine regions. It is not known 
whether this is indicative of a larger amount of absorbing material present in the sea salt itself, perhaps associated with material in organic surface films, or whether this is due to trace amounts of soot or other substances often present in submicrometer aerosol, even in clean marine regions (Pósfai et al., 1999; Lewis and Schwartz, 2004). The values given in Table 14 are from shipboard measurements during ACE-1 in the remote Southern Ocean (Quinn et al., 1998).

\subsubsection{Hemispheric backscattered fraction, $b$}

The asymmetry parameter $g$, the intensity-weighted average of the cosine of the scattering angle, and a critical input for forcing estimates, is inferred here from the measured backscatter fraction $b$. The backscatter fraction was measured on most platforms at three wavelengths (Tables 8 and 13) with variability typically about $10-20 \%$.

The relationship between the backscattered fraction measured at the surface at a U.S. continental site and the derived asymmetry parameter has been examined by Andrews et al. (2005, Fig. 7). The asymmetry parameter was derived in two ways, from Mie theory using a measured size distribution and from the Henyey-Greenstein approximation (Wiscombe and Grams, 1976), which is commonly (e.g., Haltrin, 2002) used to convert the backscatter fraction, $b$, to the asymmetry parameter, $g$. The analytical relationship of $b$ to $g$ obtained by the integration of the Henyey-Greenstein function is:

$b=\frac{1-g^{2}}{2 g}\left\lfloor\frac{1}{\left(1+g^{2}\right)^{1 / 2}}-\frac{1}{1+g}\right\rfloor$

Comparisons of the two methods showed that, for smaller values of $b(\leq 0.12)$, values of $g$ derived using the HenyeyGreenstein approximation are 5-15\% larger than those obtained using Mie theory. As the value of $b$ increases, the two methods converge and, for the median value of the measured $b$ (0.13), corresponding to $g=0.94$, the two methods agree to within $1 \%$. This comparison indicates that using the HenyeyGreenstein approximation yields an estimate of $g$ that is acceptable for radiative transfer calculations and supports use of the expression (9) here to obtain values of $g$ for the RT calculations from measured values of $b$, which are widely available from nephelometry measurements.

The asymmetry parameter also depends on $R H$. This dependence, $f_{g}(R H)$, was expressed in terms of an exponent $\gamma_{\text {asym }}$ in the same manner as that of the scattering coefficient, $f_{\sigma_{s p}}(R H)$ (Eq. 3). Based upon the wavelength dependence of the backscatter fraction and its variation with humidity measured during INDOEX and ACE-Asia (Andrews et al., unpublished data, 2005) two parameters were calculated: $\gamma_{s}$ and $\gamma_{\text {asym }}$. Although both Mie theory and the empirical data indicate a relationship between $\gamma_{\text {asym }}$ and $\gamma_{s}$, the relationship calculated with the data exhibits appreciable scatter and is substantially different from that obtained by Mie calculations. It was thus concluded that there are insufficient data to permit separate functional relationships to be determined for each wavelength and size category. For the radiative transfer calculations presented here, the following relationship was used to parameterize $\gamma_{\text {asym }}$ based on an empirical fit to the data:

$\gamma_{\text {asym }}=0.2833 \gamma_{s}-0.2222 \gamma_{s}^{2}$

While this humidity dependence of $g$ appears to hold up to $R H=85 \%$, there are no data to support an increasing $f_{g}(R H)$ above this $R H$. As the value of $g$ pertinent to large drops such as cloud drops is 0.85 , values of $g$ have been capped at 0.85 in the RTM calculations reported here.

\subsubsection{Comparison of normalized "a priori" and constrained optical properties}

A key question examined here is the extent of the difference in DRE and DCF as calculated for a given aerosol field using either "a priori" aerosol optical properties, specifically those incorporated into the GFDL AM2 radiation transfer model, or optical properties constrained by measurements in specific geographical regions and times. In calculating the constrained optical properties and their $R H$ dependence, sulfate, black carbon, and organic carbon were treated as internally mixed as sulfate/carbonaceous aerosol and as such were all hygroscopic. The humidity dependences of the optical properties of the sulfate/carbonaceous aerosol were parameterized as functions of the organic mass fraction. Finally, the seven size categories of dust reported in the measurements were reduced to only two, submicrometer and supermicrometer, with the optical properties based on regional-average values and measurements of the ratio of supermicrometer to submicrometer mass concentrations.

Radiation transfer models such as AM2 calculate aerosol radiative effects using vertical distributions of three aerosol optical properties: the extinction coefficient, the single scattering albedo, and the asymmetry parameter, all of which depend on wavelength and all of which must be known at ambient $R H$. The constrained sets of these properties, were calculated from the aerosol properties observed in each of the domains (Tables 11-13) according to the following procedure:

(1) The ratio of supermicrometer to submicrometer aerosol mass concentration was calculated assuming the sulfate/carbonaceous aerosol to be entirely submicrometer and sea salt to be $6 \%$ submicrometer and $94 \%$ supermicrometer.

(2) The mass scattering coefficients, single scattering albedos, and backscatter fractions at wavelengths $0.45 \mu \mathrm{m}$, $0.55 \mu \mathrm{m}$, and $0.70 \mu \mathrm{m}$ for submicrometer and supermicrometer dust were assigned according to Tables 11-13 using the supermicrometer to submicrometer mass ratio.

(3) The organic mass fraction was computed (Eq. 5) and used to calculate exponents $\gamma_{s}$ (Eq. 4) and $\gamma_{\text {asym }}$ 
(Eq. 10), describing the $R H$ dependence of the light scattering coefficient $\sigma_{s p}$ and the asymmetry parameter $g$, respectively.

(4) The mass scattering efficiency of dry sulfate/carbonaceous aerosol at $0.45 \mu \mathrm{m}, 0.55 \mu \mathrm{m}$, and $0.70 \mu \mathrm{m}$ was assigned according to Table 11 ; this is done both for situations when dust is present and dust is absent. The mass scattering efficiency of the dry aerosol was then converted to the mass scattering efficiency of the aerosol at ambient $R H$ relative to the dry mass using $\gamma_{s}$ (Eq. 3).

(5) The single scattering albedo of dry sulfate/carbonaceous aerosol at $0.45 \mu \mathrm{m}, 0.55 \mu \mathrm{m}$, and $0.70 \mu \mathrm{m}$ was assigned according to Table 12 and converted to single scattering albedo at ambient $R H$ using Eq. (8).

(6) The mass extinction efficiency at each wavelength was calculated as the mass scattering efficiency divided by single scattering albedo (all at ambient $R H$ ).

(7) The backscatter fraction of dry sulfate/carbonaceous aerosol at $0.45 \mu \mathrm{m}, 0.55 \mu \mathrm{m}$, and $0.70 \mu \mathrm{m}$ was assigned according to Table 13 and converted to the asymmetry parameter of the dry aerosol using Eq. (10), which was in turn converted to the asymmetry parameter of the aerosol at ambient $R H$ using $\gamma_{\text {asym }}$ and an equation analogous to Eq. (3).

(8) The scattering coefficient, single scattering albedo, and asymmetry parameter at ambient $R H$ were interpolated/extrapolated to the AM2 solar bands out to $1 \mu \mathrm{m}$ wavelength.

(9) For sea salt the mass scattering coefficient, single scattering albedo, and asymmetry parameter at $0.45 \mu \mathrm{m}$, $0.55 \mu \mathrm{m}$, and $0.70 \mu \mathrm{m}$ were assigned according to Table 14 and interpolated/extrapolated in log-log space (based on the Ångström exponent dependence) to the central wavelength in each of the AM2 solar bands. The extrapolation was performed out to $1 \mu \mathrm{m}$ wavelength.

The "a priori" shortwave aerosol optical properties incorporated in the GFDL AM2 model followed Haywood et al. (1999). Optical properties were specified for sea salt (with mass extinction efficiency that accounted for the submicrometer and supermicrometer categories together), natural sulfate, anthropogenic sulfate, black carbon, organic carbon, seven size categories of natural dust (the eighth and largest size category was over the $10-\mu \mathrm{m}$ aerodynamic diameter measurement limit and was not included in these calculations), and seven size categories of anthropogenic dust. Black carbon, organic carbon, and mineral dust were assumed not to exhibit any $R H$ growth; the optical properties of sulfate (assumed to be in the form of ammonium sulfate) were determined as a function of relative humidity using look-up tables (values tabulated at 26 relative humidities in the range of $30-95 \% R H$ ). All of the "a priori" optical properties were derived from Mie scattering calculations at 40 wavelengths assuming lognormal size distributions, tabulated refractive indices (Shettle and Fenn, 1979; Toon and Pollack, 1976; Toon et al., 1976; WCP, 1986) and external mixtures. The values were then band-averaged to the AM2 wavelength grid.

The "a priori" aerosol optical properties in the University of Michigan (UMich) RTM follow those described in Liu et al. $(2006)^{2}$. The properties are first calculated based on the Mie theory at 168 wavelengths. Fossil fuel sulfate, POM, and black carbon are assumed to be internally mixed with the "polluted" aerosol size distribution reported in Penner et al. (2001), with hydrophilic growth associated with the sulfate (assumed to be ammonium sulfate) portion of the mixture. A 4.4 to 1 ratio for POM to black carbon is assumed based on averages from fossil fuel emission inventories and observations in polluted regions. Tabulated refractive indices (Toon et al., 1976; Shettle and Fenn, 1979) are volume-weighted for the Mie calculations where the refractive index for POM is assumed to be the same as that for ammonium sulfate. Excess POM (that in excess of 4.4 $\mathrm{x}$ black carbon, Penner et al., 2001) is treated as externally mixed dry sulfate aerosol. Natural sulfate is treated as externally mixed with hygroscopic growth $\left(\right.$ as $\left.\left.\left(\mathrm{NH}_{4}\right)_{2} \mathrm{SO}_{4}\right)\right)$ and sea salt is treated at $80 \% R H$ for consistency with the GFDL RTM. For dust and sea salt, the optical properties were calculated separately for the size bins reported by the MOZART and STEM models. The refractive index for dust was that reported by d'Almeida (1991) except that the imaginary part of the refractive index was decreased to reflect recent measurements of dust single scattering albedo (Dubovnik et al., 2002). Look-up tables for the optical property changes with $R H$ are calculated for the hydrophilic aerosols.

Comparisons between the "a priori" and constrained optical properties (mass extinction efficiency, single scattering albedo, and asymmetry parameter) for mixed sulfate/carbonaceous aerosols are shown in Fig. 10 for the NIO (North Indian Ocean) for indicated values of relative humidity, supermicrometer to submicrometer fraction, and organic mass fraction. The black carbon mass fraction in the GFDL AM2 model was chosen to give the same single scattering albedo at $0.55 \mu \mathrm{m}$ as in the measurements for a given relative humidity and organic mass fraction, while the black carbon mass fraction in the UMich model is determined from the "a priori" internally mixed POM to black carbon ratio and by adding externally mixed POM to match the specified POM fraction. The constrained mass extinction efficiency is generally similar to the "a priori" though the UMich extinction efficiency at $85 \% R H$ tends to be higher than the

\footnotetext{
${ }^{2}$ Liu, X., Penner, J. E., Das, B., Bergmann, D., Rodriguez, J. M., Strahan, S., Wang, M., and Feng, Y.: Uncertainties in global aerosol simulations: Assessment using three meteorological datasets, J. Geophys. Res., submitted, 2006.
} 

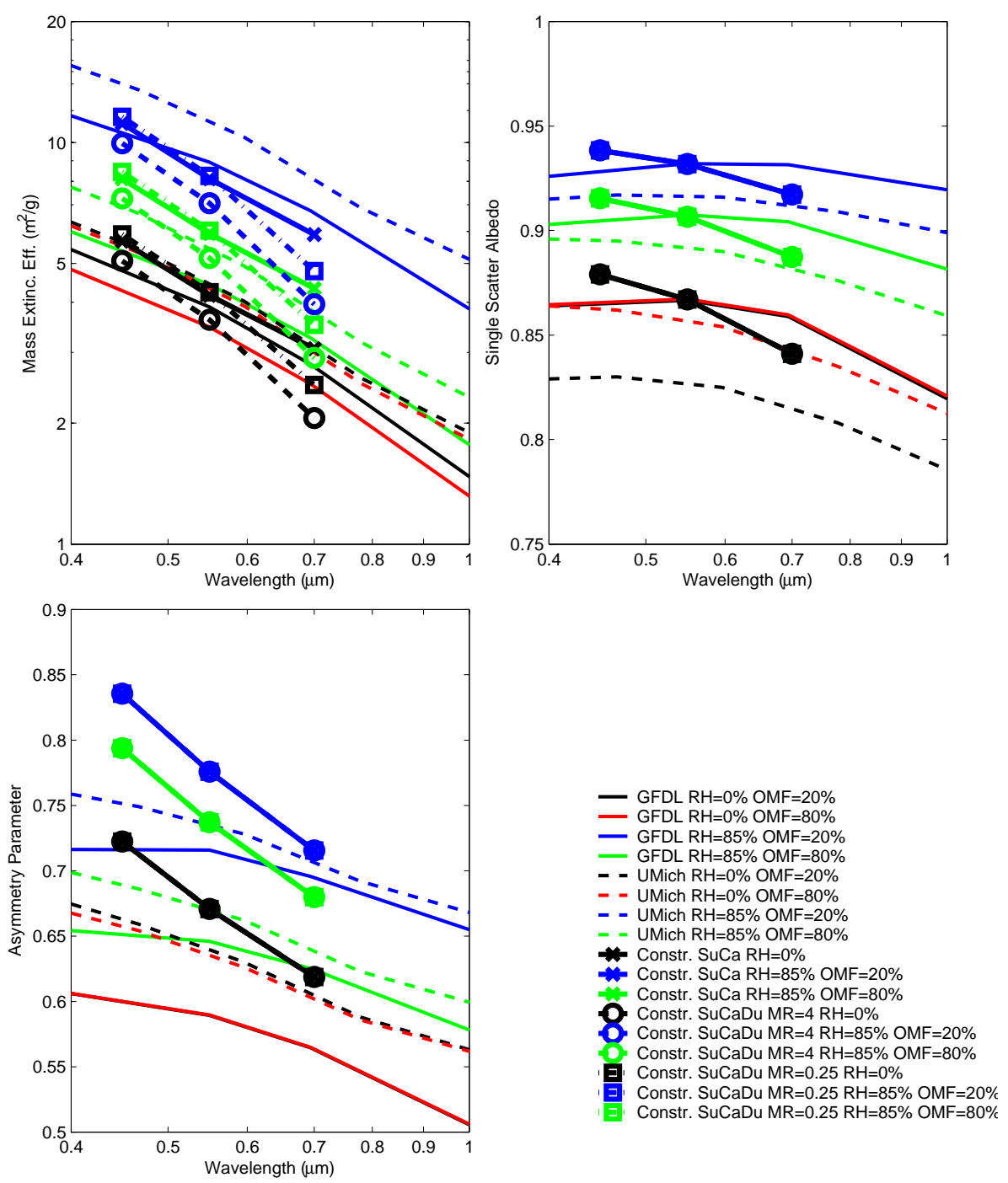

Fig. 10. Comparison of "a priori" and constrained optical properties of sulfur/carbonaceous aerosol. The "a priori" properties are from the GFDL AM2 and University of Michigan radiation transfer models and the constrained properties are based on measurements in the NIO domain during the INDOEX campaign. MR denotes ratio of super- $\mu \mathrm{m}$ to sub- $\mu \mathrm{m}$ dry aerosol mass concentration (which, in the constrained optical scheme, affects mass extinction efficiency only); $R H$ denotes relative humidity; OMF denotes organic mass fraction; SuCa refers to sulfate-carbonaceous aerosol, and SuCaDu refers to sulfate carbonaceous aerosol when dust is present. Mass extinction efficiency is defined as extinction at ambient $R H$ divided by dry aerosol mass. For the GFDL model, black carbon mass fraction was set such that the single scatter albedo at $0.55 \mu \mathrm{m}$ matched that of the constrained optical properties.

constrained. The constrained single scattering albedo varies more strongly with wavelength than the "a priori". The constrained asymmetry parameter also exhibits a steeper wavelength dependence than the "a priori" with larger values particularly at the shorter wavelengths. Given this, in portions of the NIO with a large sulfate/carbonaceous aerosol loading, the difference between the estimated extinction and forcing from the constrained runs and the "a priori" runs is expected to be slight, with the asymmetry parameter contributing to a larger forcing in the constrained runs. For the NWP (Northwest Pacific), the constrained mass extinction efficiency at large relative humidity is greater by $20-40 \%$ than the "a priori". As in the NIO, the constrained single scattering albedo and asymmetry parameter in the NWP exhibit stronger wavelength dependences than the "a priori", with a larger asymmetry parameter particularly at the shorter wavelengths. Given this, in portions of the NWP with a large sulfate/carbonaceous aerosol loading, the estimated extinction and forcing from the constrained runs are expected to be larger than from the "a priori" runs, but by less than a factor of 2. For the NWA (Northwest Atlantic), the constrained mass extinction efficiency is greater than the GFDL 

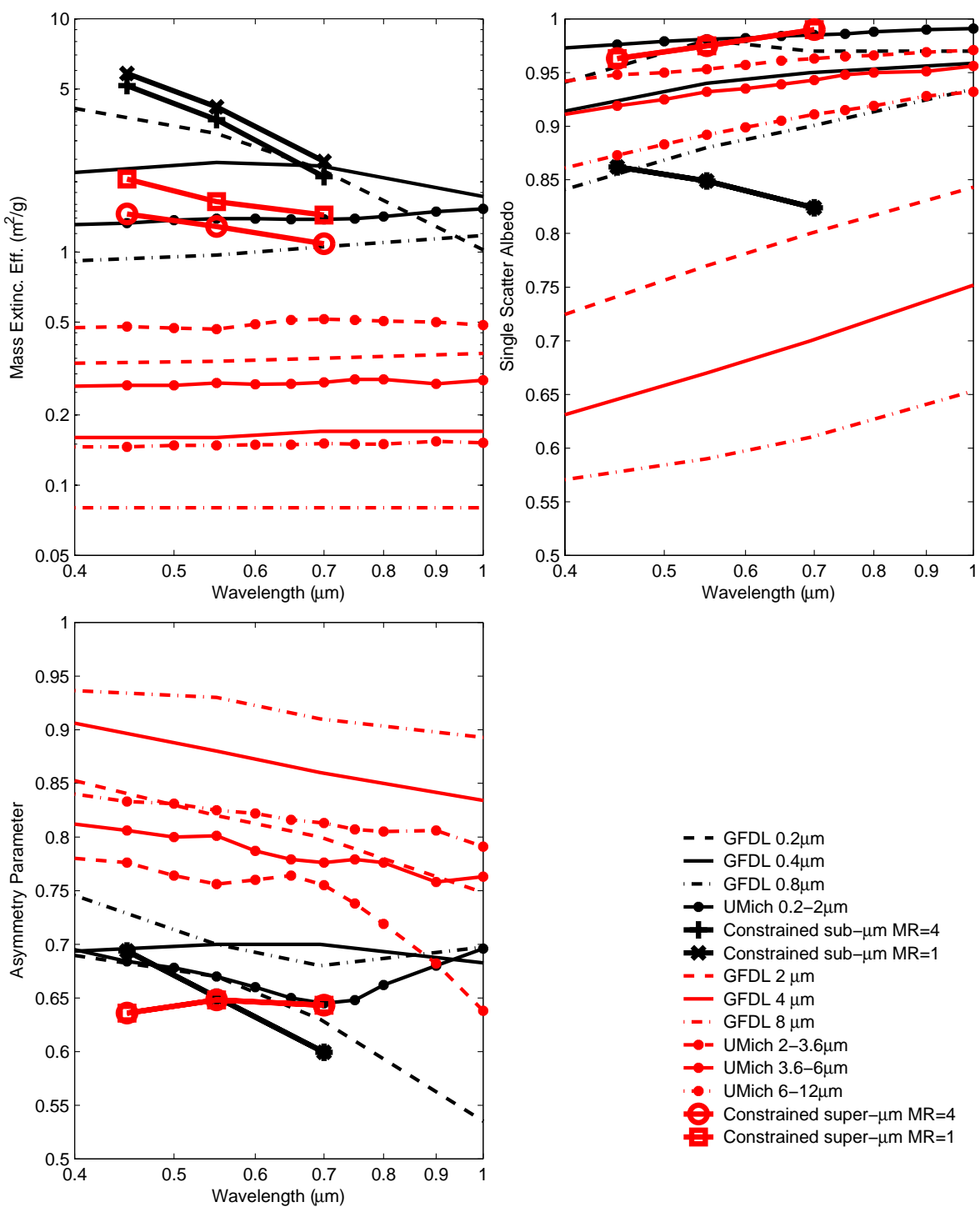

Fig. 11. Comparison of "a priori" and constrained optical properties of dust aerosol. The "a priori" properties are from the GFDL AM2 and University of Michigan radiation transfer models and the constrained properties are based on in situ measurements during the ACE-Asia field campaign. MR denotes ratio of super- $\mu \mathrm{m}$ to sub- $\mu \mathrm{m}$ dry aerosol mass concentration (which, in the constrained optical scheme, affects mass extinction efficiency only). All indicated sizes refer to dry particle diameter.

"a priori" extinction efficiency when the relative humidity and organic mass fraction is high, but is well represented in the UMich "a priori" model. However the UMich "a priori" extinction efficiency is greater than the constrained extinction efficiency when the relative humidity is high and the organic mass fraction is low while the constrained value is well represented in the GFDL "a priori" model. The constrained single scattering albedo and asymmetry parameter again exhibit stronger wavelength dependences than the "a priori" and the constrained asymmetry parameter is somewhat higher. Therefore, in portions of NWA with a large sulfate/carbonaceous aerosol loading and with large organic mass fraction (as was generally the case), extinction would be expected to be greater in the constrained than in the GFDL "a priori" runs by $20-40 \%$ and forcing would be expected to be greater by a somewhat smaller amount.

For dust aerosols (Fig. 11), the constrained mass extinction efficiency is substantially greater than the "a priori". The constrained single scattering albedo is also significantly larger than the GFDL "a priori", indicating that the measured dust was much less absorbing than that assumed in the GFDL AM2 model but is better represented in the UMich model. While the constrained asymmetry parameter for submicrometer dust is not far off from the "a priori" models, the constrained asymmetry parameter for supermicrometer dust is substantially smaller than the "a priori" models, indicating 
Table 15. Estimated total uncertainties (accuracy and natural variability) for measured aerosol optical properties $\left(\alpha_{s p}, 1-\omega_{0}, g\right)$ and their $R H$ dependence expressed as an uncertainty in $\gamma_{s}$. Using Eq. (12), examples of resulting percent uncertainties are given for 80 and $90 \% R H$.

\begin{tabular}{lcccc}
\hline Parameter & base & gamma & $80 \% R H$ & $90 \% R H$ \\
\hline$\alpha_{s p}$ & 0.1 & 0.4 & $19 \%$ & $25 \%$ \\
$1-\omega_{0}$ & 0.2 & 0.4 & $38 \%$ & $50 \%$ \\
$g$ & 0.15 & 0.4 & $29 \%$ & $38 \%$ \\
\hline
\end{tabular}

that the measured supermicrometer dust did not have as sharp a forward scattering peak as assumed in the "a priori" models, and raising concerns with the values employed in the model. Considering all of these factors, we expect that regions with a large dust loading will have a larger estimated extinction and DRE from the constrained runs than from the a priori runs, with the majority of the contribution from scattering rather than absorption for the GFDL model. The differences in single scattering albedo would also be expected to be manifested in differences between TOA and surface DRE that are greater in the "a priori" runs.

For sea salt aerosols, the constrained mass extinction efficiency (3-4 $\mathrm{m}^{2} \mathrm{~g}^{-1}$, increasing with increasing wavelength) is somewhat greater than the "a priori" $\left(2.5-2.6 \mathrm{~m}^{2} \mathrm{~g}^{-1}\right)$ and the constrained asymmetry parameter is slightly smaller than the "a priori" ( 0.75 vs. 0.78$)$ There is virtually no difference between the "a priori" and constrained single scattering albedo, both of which are nearly identically 1.0. Given this, we would expect that regions with a greater than average sea salt loading will again have a somewhat greater estimated extinction and DRE from the constrained runs than from the "a priori" runs, with all of the contribution from scattering.

3.4.7 Variability, accuracy and uncertainties in aerosol optical properties

The total uncertainty associated with the median value of a given optical property $\left(\Delta_{t} P\right)$ was evaluated as the sum, taken in quadratures, of the natural variation about the median value $\left(\Delta_{v} P\right)$ and the accuracy $\left(\Delta_{a} P\right)$ :

$\Delta_{t} P=\left[\left(\Delta_{v} P\right)^{2}+\left(\Delta_{v} P\right)^{2}\right]^{1 / 2}$

As it is difficult to separate these two sources of uncertainty, they are set equal, and hence $\Delta_{t} P=1.4 \Delta_{v} P$. It is also assumed that the uncertainties at all three visible wavelengths of the measurements are equal. For a property $P$ (mass scattering efficiency, co-albedo $\left(1-\omega_{0}\right)$, or backscatter fraction) at ambient $R H, R H_{\mathrm{amb}}$, evaluated according to the relative humidity dependence

$P=\left.P\right|_{R H_{\mathrm{ref}}}\left(\frac{100-R H_{\mathrm{ref}}}{100-R H_{\mathrm{amb}}}\right)^{\gamma}$ the overall fractional uncertainty $\triangle P / P$ exhibits a dependence on $R H$ as:

$$
\begin{aligned}
\left.\frac{\Delta P}{P}\right|_{R H_{\mathrm{amb}}}= & \left\{\left[\left.\frac{\Delta P}{P}\right|_{R H_{\mathrm{ref}}}\right]^{2}+\left[\ln \left(\frac{100-R H_{\mathrm{ref}}}{100-R H_{\mathrm{amb}}}\right) \Delta \gamma_{s}\right]^{2}\right. \\
& \left.+\left[\gamma \frac{\left(100-\Delta R H_{\mathrm{amb}}\right)}{100-R H_{\mathrm{amb}}}\right]^{2}\right\}^{1 / 2}
\end{aligned}
$$

Uncertainties for mass scattering efficiency, co-albedo $\left(1-\omega_{0}\right)$, and backscatter fraction, calculated from the above equations, are given in Table 15. In addition, an estimated uncertainty is given for $\gamma_{s}$. Note that the effect of uncertainty in $\gamma_{s}$ becomes increasingly large near $100 \% \mathrm{RH}$. These uncertainties contribute to the uncertainty in model-based estimates of AOD, DRE and DCF as discussed in Sect. 5.2.

\section{CTM calculations of the distributions of natural and anthropogenic aerosols}

\subsection{Introduction}

Chemical transport models provide a means to estimate 4dimensional distributions of aerosol species concentrations and properties, based on a distribution of emissions of particulate matter and gaseous precursors that is also a function of location and time. The aerosol mass and composition distributions in turn can be used as input to radiative transfer models to estimate DRE and DCF. Linking emissions to aerosol distributions is essential to attribute aerosol radiative effects to specific aerosol components and ultimately to provide policy makers with the information needed for adaptive management of atmospheric composition. The results presented in this section lead to an assessment of the uncertainty in the calculated regional aerosol composition fields by comparing aerosol calculations by two models - the regional chemical transport model STEM-2K3, and global chemical transport model MOZART version 2.5 - with each other and with observations. The discussion presented here is not intended as a comprehensive model intercomparison study, or a detailed review of uncertainty. There are important on-going studies that are designed to provide systematic and more comprehensive aerosol model intercomparisons. For example, the AEROCOM study is comparing several global aerosol models (Kinne et al., 2005; Textor et al., 2005), various dust models are being evaluated under the DMIPS project (Uno et al., 2006), and regional models are being compared for East Asia applications in the MICS study (Carmichael et al., 2002). Furthermore, there are also recent reviews focused on specific aerosols, for example, the review of secondary organic aerosol modeling by Kanakidou et al. (2005). The results of the comparison of modeled aerosol quantities from a regional and a global model presented and discussed in this section, provide insights into the uncertainties in the representation of the processes that link emissions to ambient aerosol distributions. 


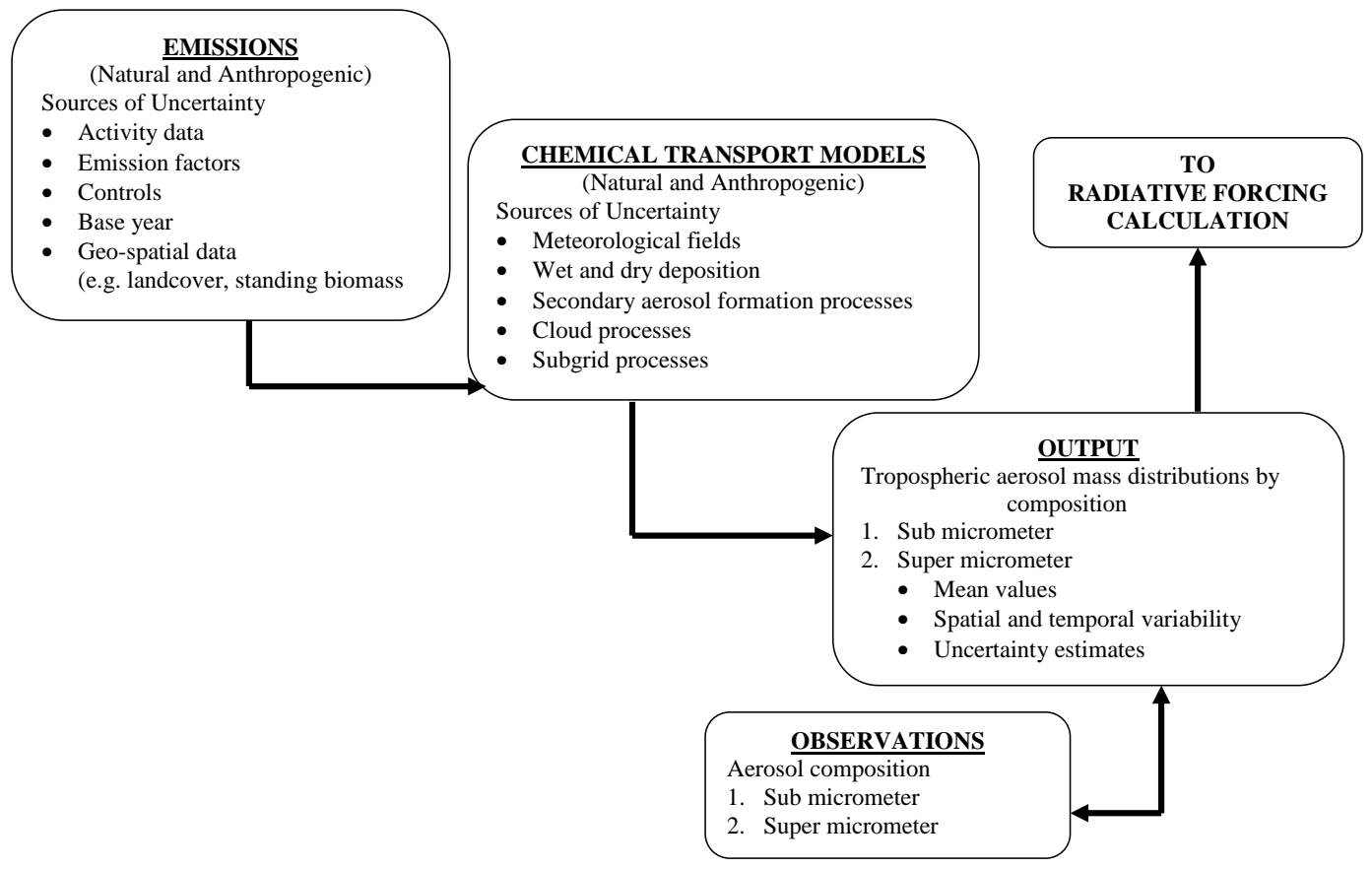

Fig. 12. Schematic of the calculation chain linking emissions to aerosol distributions discussed in this section.

The analysis chain presented in this section is illustrated in Fig. 12. The analysis starts by examining estimates of emissions, which are large sources of uncertainty. The chemical transport models calculate the 4-dimensional aerosol distributions, taking into account governing transport, transformation and removal processes. Uncertainties in the rates of these processes are an additional contribution to overall uncertainty. Calculated mass loadings for sub- and super- micrometer nss sulfate, ammonium, nitrate, black carbon, organic carbon, sea salt, and mineral dust are analyzed, along with their spatial and temporal variation for the three domains and time periods of interest. As all aspects of this analysis chain are uncertain, a comparison of distributions determined by the two models provides an estimate of the overall consequences of these uncertainties on the modeled aerosol distributions. Finally the modeled aerosol chemical compositions are compared with observations from the intensive field campaigns to assess the predictive capabilities of the models. These comparisons are then discussed in the context of the estimated uncertainties.

\subsection{Calculation details}

\subsubsection{Model descriptions}

The University of Iowa STEM-2K3 (Sulfur Transport and dEposition Model, Version 2003) is a regional air quality model (Tang et al., 2003, 2004; Carmichael et al., 2003; Uno et al., 2004). STEM employs the SAPRC-99 gaseous mechanism (Carter, 2000), the aerosol thermodynamics module
SCAPE II (Simulating Composition of Atmospheric Particles at Equilibrium) (Kim et al., 1993a, b; Kim and Seinfeld, 1995) and the NCAR Tropospheric Ultraviolet-Visible (TUV) radiation model (Madronich and Flocke, 1999). The aerosol species simulated here include inorganic salts (sulfate, nitrate, and associated cations), black carbon, primary organic carbon, sea salt and mineral dust aerosol in 4 size bins: $0.1-0.3 \mu \mathrm{m}, 0.3-1.0 \mu \mathrm{m}, 1.0-2.5 \mu \mathrm{m}$, and $2.5-10 \mu \mathrm{m}$ dry geometric diameter (Tang et al., 2004). The 30 photolysis frequencies for the SAPRC-99 mechanism, which take into account the influence of aerosols and clouds, are explicitly treated on-line (Tang et al., 2003). The NIO and NWP simulations used fixed observational based boundary conditions (lowest 5th percentile values of aircraft data from INDOEX and ACE-Asia), while the NWA simulations used boundary conditions provided by MOZART fields. Five-day spin-up times were used in all cases.

MOZART (Model for OZone And Related chemical Tracers) is a global chemical transport model. The basic structure and gas-phase chemistry in MOZART are described in Horowitz et al. (2003). The implementation of aerosols in MOZART is based on that of Tie et al. (2005), with mineral dust based on Ginoux et al. (2001). The simulations presented here utilize MOZART version 2.5. In this version, MOZART includes 82 species to simulate the gas-phase chemistry, plus an additional 20 aerosol and aerosol precursor species. Sulfate (from both anthropogenic and biogenic sources, i.e., DMS), nitrate, ammonium, black carbon, organic carbon are treated as submicrometer aerosol 

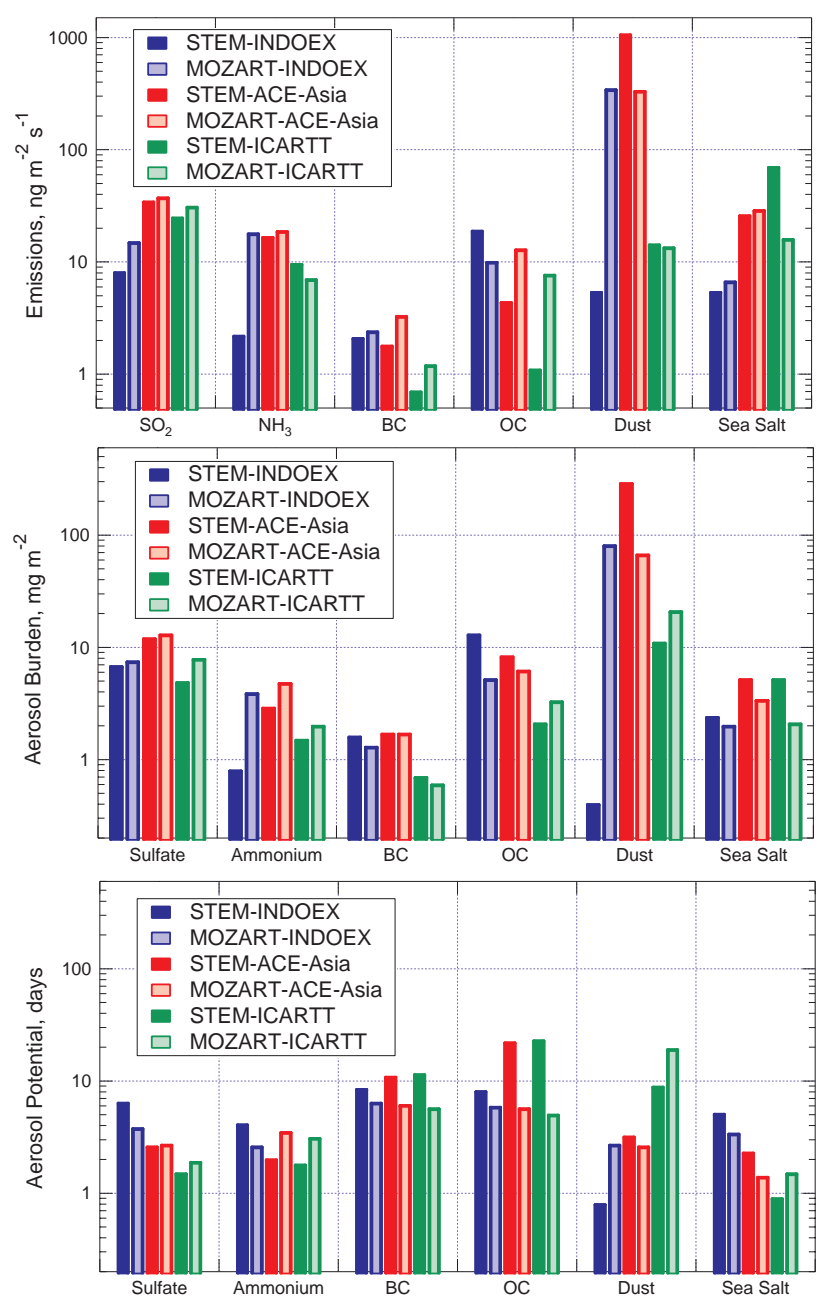

Fig. 13. Time- and space average mass emission fluxes, burdens and aerosol potentials for the key aerosol and precursor species for the three domains.

(geometric dry diameter); sea salt is treated in 4 size bins, $0.2-1.0 \mu \mathrm{m}, 1.0-3.0 \mu \mathrm{m}, 3.0-10.0 \mu \mathrm{m}, 10.0-29.0 \mu \mathrm{m}$ dry geometric diameter), and mineral dust in 5 size bins, $0.2-2.0 \mu \mathrm{m}, 2.0-3.6 \mu \mathrm{m}, 3.6-6.0 \mu \mathrm{m}, 6.0-12.0 \mu \mathrm{m}, 12.0-$ $20.0 \mu \mathrm{m}$ geometric diameter). Model simulations used a December 1994 start date.

Each model was run with meteorological fields that were specific to the periods of the field campaigns. MOZART meteorological fields were based on NCEP products. STEM meteorological fields were calculated using a mesoscale model (RAMS and MM5), which used NCEP or ECMWF meteorological fields for initialization. MOZART runs begin with a start date of December 1994. STEM simulation for TRACE-P and ACE-Asia period was driven by RAMS simulation with ECMWF $1^{\circ} \times 1^{\circ}$ reanalysis data; STEM simulation for NIO was driven by RAMS simulation with NCEP $2.5^{\circ} \times 2.5^{\circ}$ reanalysis data; STEM simulation for ICARTT was driven by MM5 simulation with NCEP final analysis (FNL) $1^{\circ} \times 1^{\circ}$ data.

MOZART was run with $1.88^{\circ} \times 1.88^{\circ}$ resolution $(209 \mathrm{~km}$ in latitude, $120-209 \mathrm{~km}$ in longitude, depending on latitude); STEM horizontal resolution varied from 60 to $80 \mathrm{~km}$. In order to facilitate a direct comparison, the MOZART results were spatially interpolated onto the STEM grid. MOZART output was daily-average concentrations, whereas STEM output was 3-h instantaneous concentrations. Both outputs were temporally averaged for each region before being compared. Concentrations of nss sulfate, sea salt, dust, black carbon, organic carbon and ammonium were analyzed. Tropospheric column amounts as well as concentrations at specific altitudes were compared.

\subsubsection{Emissions}

The emissions used in the two models are summarized in Table 16 and Fig. 13. The use of different emission inventories by STEM and MOZART accounts for some differences in the model results, as discussed below. For MOZART, the emissions used in this paper are based on "climatological emissions". That is, the emissions did not vary from year to year, and did not reflect the actual biomass burning during the time periods of the campaigns. Also, they were not updated to the "official" emissions inventories for the campaign (e.g., TRACE-P or ICARTT). The emissions from fossil fuel sources were from EDGAR v2.0 (Olivier et al., 1996), except for black carbon and organic carbon, which were based on Cooke et al. (1996) (organic carbon emissions were doubled from the Cooke et al., 1996, value - IPCC, 2001). Biomass burning emissions were based on Hao and Liu (1994) in the tropics, and Müller (1992) in the extratropics, with emission ratios from Andreae and Merlet (2001). Isoprene and monoterpene emissions were from GEIA (Guenther et al., $1995)$, with a $25 \%$ reduction in tropical isoprene emissions. Soil $\mathrm{NO}_{\mathrm{x}}$ emission was from Yienger and Levy (1995). Sea salt and dust emissions were calculated interactively, as described in Tie et al. (2005) and Ginoux et al. (2001), respectively.

For STEM, anthropogenic emissions used in this study for NIO and NWP were based on Streets et al. (2003), and the biomass burning emissions (specific to Spring 2001) were from Woo et al. (2003). Dust and sea salt emissions were calculated interactively using the meteorological fields. Dust emissions were estimated using a modified form of the method of Liu and Westphal (2001). Seasalt emissions were calculated online following Monahan et al. (1986) and Song and Carmichael (2001). Further details are presented in Tang et al. (2004). Isoprene and monoterpene emissions were from GEIA (Guenther et al., 1995) and soil $\mathrm{NO}_{\mathrm{x}}$ emission was from Yienger and Levy (1995). For the ICARTT experiment the anthropogenic emissions were from the US EPA 1999 National Emission Inventory (2003). The biomass burning emissions included in this inventory 

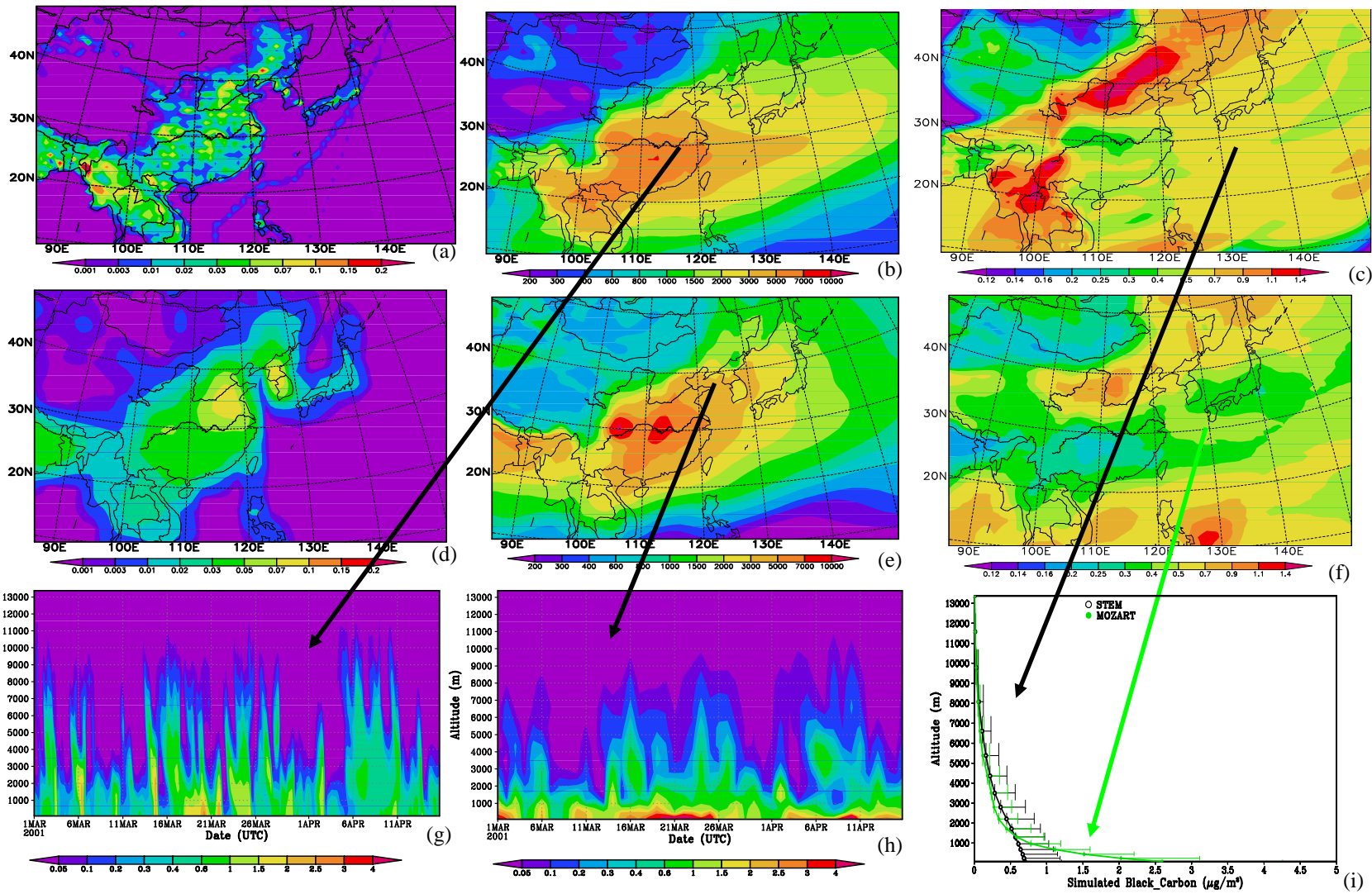

Fig. 14. Illustrative results of the analysis of the modeled quantities from STEM and MOZART. Shown are results for black carbon for the NWP during the ACE-Asia period 2 March-15 April, 2001. The black carbon emissions used by STEM (a) and MOZART (d), and modeled campaign-mean column amounts for STEM (b) and MOZART (e) in $\mu \mathrm{g} \mathrm{m}^{-2}$. Temporal variability is plotted as the relative standard deviation (defined as the temporal standard deviation of the column amount divided by the mean column amount) for STEM (c) and MOZART (f). STEM (g) and MOZART (h) time height profiles at Gosan, S. Korea $\left(\mu \mathrm{g} \mathrm{m}^{-3}\right)$, and time averaged profiles at Gosan (i) along with the standard deviation of the time variation (shown as +1 standard deviation above the mean). Note highly nonlinear scale bars.

represent a climatological value and thus do not reflect the enhanced emissions associated with the Alaskan fires in the summer of 2004.

The ratios of the emissions used in STEM to those used in the MOZART analysis are shown in Table 16. The emissions of $\mathrm{SO}_{2}$ and black carbon agree within a factor of 2 . The emissions of organic carbon differ by more than a factor of 2 , while the largest differences are for dust. The magnitude of the differences between the emissions used by the various models is reflective of the large uncertainties associated with current emission inventories. This will be addressed in more detail in Sect. 4.4.

The horizontal distributions of black carbon emissions used by STEM and MOZART at the resolution of the model calculations are shown in Figs. 14a, d. Qualitatively, the emissions show similar geographical features, reflecting regional population distributions. Differences in regional distributions (e.g., over SE Asia) arise largely through estimates of emissions from open biomass burning. The higher resolution emissions show more heterogeneous distributions, with larger peak emissions. These differences have a clear impact on model results at locations proximate to the major emission regions. The impacts of resolution on modeled aerosol distributions are discussed below. Further discussions of uncertainties in emissions inventories are presented in Sect. 4.4.1.

In order to estimate direct climate forcing by anthropogenic aerosols (Sect. 5) it is necessary to distinguish anthropogenic and natural aerosols. This was done with the MOZART model by carrying out additional simulations using natural emissions only, following Horowitz (2006) $)^{3}$. Natural emissions included DMS, mineral dust, and sea salt. Biomass burning emissions were assumed to be natural in the extratropics and 90\% anthropogenic (i.e., 10\% natural) in the tropics. All fossil fuel and biofuel emission sources were considered anthropogenic. Secondary organic aerosols were classified as natural or anthropogenic depending on

\footnotetext{
${ }^{3}$ Horowitz, L. W.: Simulation of past, present, and future concentrations and radiative forcings of ozone and aerosols, Part I: Methodology, ozone evaluation, and sensitivity to aerosol wet removal, J. Geophys. Res., submitted, 2006.
} 
their precursor hydrocarbon emission sources. In particular, secondary organic aerosols produced from monoterpene oxidation are considered to be natural. The choice of which sources to include in the "natural" simulations is of course somewhat subjective. This choice adds an additional uncertainty to the present calculation of aerosol DCF. No differentiation of natural and anthropogenic aerosol was made in the STEM model runs.

\subsubsection{Chemical conversion}

In both models sulfate consisted of secondary aerosol produced from the gas-phase oxidation of $\mathrm{SO}_{2}$ (or DMS) by $\mathrm{OH}$ and aqueous-phase oxidation by $\mathrm{H}_{2} \mathrm{O}_{2}$ and $\mathrm{O}_{3}$. Oxidant concentrations were calculated by the photochemical model. $\mathrm{O}_{3}$ and $\mathrm{H}_{2} \mathrm{O}_{2}$ are sufficiently long-lived that they were advected in the model; $\mathrm{OH}$ was treated in rapid local steady state. MOZART included a small fraction of primary sulfate. In MOZART, organic carbon aerosol consisted of primary and secondary aerosol (treated as separate species in the model); oxidation of primary emitted hydrocarbons was initiated mainly by $\mathrm{OH}$ and $\mathrm{O}_{3}$ reactions. STEM included only primary organic carbon.

In STEM coagulation was not included, and thus black carbon and organic carbon were not modeled in the super micrometer mode.

\subsubsection{Wet and dry removal}

In MOZART OC was initially emitted as 50\% hydrophobic and 50\% hydrophilic. The hydrophobic component was converted to hydrophilic with an e-folding lifetime of 1.6 days (Cooke and Wilson, 1996). Hydrophobic organic carbon was not removed by wet deposition; hydrophilic organic carbon was removed at the same rate as sulfate. Wet deposition of black carbon was treated similarly to organic carbon, but the initial distribution was $80 \%$ hydrophobic and $20 \%$ hydrophilic. Dust was treated as a hydrophilic component. Dry deposition of dust and sulfate were modeled at the geometric mean of the diameter ranges of the several components.

In STEM a first-order wet removal constant for soluble particulate matter was employed that was assumed to depend on the precipitation rate via the following empirical relation (Uno et al., 2004),

$k_{w}=10^{-5} h^{0.88}$

where $k_{w}$ is the first-order removal rate constant $\left(\mathrm{s}^{-1}\right)$, and $h$ is the precipitation rate, in $\mathrm{mm} \mathrm{h}^{-1}$ (Uno et al., 2004). Black carbon and organic carbon were treated as insoluble with no wet deposition.

4.3 How robust are the model simulations of different types of aerosols?

The 4-dimensional aerosol distributions for the three domains and study time periods were calculated and analyzed.
The calculated column distributions of aerosols were determined by the underlying emissions inventory (magnitude and distribution), and by the transport and removal processes represented in the models. Each model used different emissions and different representations of removal processes. Although each model represented the same meteorological periods, and started with the same large scale flow conditions (as determined by NCEP), the STEM calculations were carried out at higher spatial resolution. Consequently, the flow details differ because of differences in model resolution and model-specific meteorological treatments (e.g., mixing heights, cloud fields, etc.).

Results illustrating the analysis chain are shown in Fig. 14 which presents the calculated values of black carbon for the NWP. Monthly mean column amounts were calculated for each species and domain. Temporal variations also were analyzed at each grid point. An example is shown for the vertical distributions of black carbon as a function of time at the Gosan, South Korea site (Figs. 14g, h). To help quantify the model comparisons, the temporal averaged vertical profiles were calculated along with the standard deviation for each $1 \mathrm{~km}$ in elevation for each grid point. The mean and standard deviation of the MOZART and STEM modeled profiles for Gosan are also shown (Fig. 14i). Finally, the relative temporal standard deviation of the aerosol column amounts is shown in Figs. 14c, $\mathrm{f}$ and discussed in further detail below; a similar analysis was conducted for all aerosol species and the three domains shown in Fig. 2. There were substantial differences in the geographical distribution and magnitudes of the modeled column burdens of some of the substances modeled, particularly so for sea salt and dust, for which the emissions were generated internally in the models. These differences are reflected in calculated AOD and DRE of the total aerosols using the outputs from the two models.

\subsubsection{Modeled black carbon for the NWP}

The campaign-mean column amounts of black carbon calculated by the STEM and MOZART models are qualitatively similar (Figs. 14b, e). For example, both models show largest values over central China. The peak values calculated with MOZART are larger than those with STEM, as are the averaged column amounts. This reflects the larger black carbon emissions (MOZART/STEM emission ratio = 2) used in MOZART for the NWP. However even when this is accounted for, important differences remain. For example, the STEM calculations show larger values over SE Asia (due to differences in biomass burning emissions) and a stronger zonal outflow along $30^{\circ} \mathrm{N}$ than those shown in the MOZART calculations.

The modeled time-height profiles of black carbon in both models exhibit similar temporal variability, driven largely by the temporal (synoptic) variations in the meteorological fields, and by spatial and temporal variations in emissions (biomass burning and dust have the largest temporal 
Table 16. Time- and space average mass emission fluxes of key aerosol and precursor species for the three domains in $n g \mathrm{~m}^{-2} \mathrm{~s}^{-1}(\mathrm{see}$ Table 1 for CTM domains and time periods).

\begin{tabular}{lccccccccc}
\hline & \multicolumn{3}{c}{ NIO } & & \multicolumn{3}{c}{ NWP } & \multicolumn{3}{c}{ NWA } \\
& STEM & MOZART & Ratio* & STEM & MOZART & Ratio* & STEM & MOZART & Ratio* \\
\hline $\mathrm{SO}_{2}^{\mathrm{X}}$ & 8.1 & 15 & 0.53 & 35 & 38 & 0.92 & 25 & 31 & 0.81 \\
$\mathrm{BC}_{\text {Primary OC }}$ & 2.1 & 2.4 & 0.88 & 1.8 & 3.2 & 0.56 & 0.7 & 1.2 & 0.58 \\
$\mathrm{NH}_{3}$ & 19 & 10 & 1.81 & 4.4 & 13 & 0.34 & 1.1 & 7.7 & 0.14 \\
Dust & 2.2 & 18 & 0.12 & 17 & 19 & 0.89 & 9.6 & 7.0 & 1.4 \\
Sea Salt & 5.4 & 350 & 0.016 & 1100 & 300 & 3.7 & 14 & 13 & 1.1 \\
\hline
\end{tabular}

* Ratio is STEM/MOZART

${ }^{x} \mathrm{SO}_{2}$ does not include volcanic emissions except for NWP. $\mathrm{SO}_{2}$ volcanic emissions during TRACE-P/ACE-Asia $=9.5 \mathrm{ng} \mathrm{SO}_{2} \mathrm{~m}^{-2} \mathrm{~s}^{-1}$ (STEM) and $0.1 \mathrm{ng} \mathrm{SO} \mathrm{m}^{-2} \mathrm{~s}^{-1}$ (MOZART).

variations). Qualitatively, the temporal variability in the two models was similar, as shown in the example for black carbon at $126^{\circ} \mathrm{E}, 33.5^{\circ} \mathrm{N}$ (Figs. $14 \mathrm{~g}, \mathrm{~h}$ ). The STEM model has higher spatial and temporal resolution and the time series of the calculated values reflect this. The mean modeled vertical profiles and the standard deviation representing the temporal variability are shown in Fig. 14i. The impact of this temporal variability on the aerosol DRE is discussed in Sect. 5. At this location the black carbon profiles are qualitatively similar, with the largest values occurring near the surface. The two models show similar temporal variability, with the STEM results for altitudes above $1 \mathrm{~km}$ showing greater variability. The main difference between the black carbon simulated by the two models is near the surface (below $1 \mathrm{~km}$ ), where MOZART exhibits much greater black carbon concentrations. The near surface differences reflect differences in mixed layer heights and dry deposition.

The temporal variability of the column amounts are shown in Fig. 14c, $\mathrm{f}$ in terms of the relative standard deviation. The general patterns are similar for STEM and MOZART, with largest values over Northeast China being due to the frontal transport associated with the major dust storms caused by the traveling low pressure systems, and along the southern domain boundary, a region outside of the main outflow zone during March and April. STEM results also show large variability over SE Asia associated with the temporal variations in biomass burning emissions; the lower temporal variability of the MOZART column amounts is attributed to the fact that MOZART used monthly mean climatological biomass burning emissions, whereas STEM used emissions specific to the modeling period.

The time-averaged vertical mass concentration profiles for each aerosol component, were spatially averaged to produce domain-averaged vertical profiles shown in Fig. 15 for the NWP. While there is substantial spatial variability within the domain, caused by spatial variability in sources, transport and removal processes, the mean values are similar. For example the mean black carbon and sulfate profiles generally agree within $\sim 30 \%$.
The largest differences between the two models occur for dust and sea salt. Sea salt and dust contribute substantially to aerosol optical depth and play an important role in the DRE. Although sea salt is natural and dust predominantly so, these substances can substantially influence the anthropogenic component of the aerosol by providing reaction pathways that impact the amount and size distributions of aerosol sulfate, nitrate and ammonia. Modeling sea salt and dust (emissions and removal) is difficult. As emissions of both species depend, among other thing, on surface wind speeds, the modeled emissions and resultant concentrations are sensitive to surface meteorological inputs. Their emissions are computed within the models, using parameterizations that are tightly coupled to the surface meteorology. During the TRACE-P and ACE-Asia period, modeled sea salt aerosol concentrations over the western Pacific were similar for MOZART and STEM, whereas over the South China Sea STEM showed substantially greater sea salt concentrations than MOZART. The vertical profiles were qualitatively similar, but MOZART had more sea salt at higher altitudes (and less near the surface).

Of the modeled aerosol species, dust exhibited the largest difference between the two models. Dust emissions in STEM were higher by a factor of 4 than those used in MOZART and the time and domain average concentration at the surface in the STEM simulations showed much larger values and more temporal and spatial variability than MOZART. This reflects differences in the size dependent emissions models, and differences in removal processes (gravitational settling and wet removal). As dust could play an important role in DRE and most radiation calculations are based on model-simulated dust loadings, the difference between modeled dust abundances is noteworthy. The uncertainties associated with dust calculations are discussed in more detail in the following section. 
Table 17. Time- and space-average aerosol mass column amounts $\left(\mathrm{mg} \mathrm{m}^{-2}\right)$ of key aerosol species in the three CTM domains and the spatial variability within the domain expressed as the relative standard deviation of the time-average column amount. The ratios of the mean column loadings are also shown.

\begin{tabular}{|c|c|c|c|c|c|}
\hline \multicolumn{6}{|c|}{ NIO } \\
\hline \multirow[t]{2}{*}{ Species } & \multicolumn{2}{|c|}{ STEM } & \multicolumn{2}{|c|}{ MOZART } & \multirow{2}{*}{$\begin{array}{c}\text { STEM/MOZART } \\
\text { Ratio }\end{array}$} \\
\hline & Mean & Rel Std Dev & Mean & Rel Std Dev & \\
\hline Sulfate & 6.8 & 0.5 & 7.5 & 0.8 & 0.91 \\
\hline Sea Salt & 2.4 & 1.0 & 2.0 & 0.3 & 1.20 \\
\hline Ammonium & 0.8 & 0.4 & 3.9 & 1.1 & 0.21 \\
\hline Dust & 0.4 & 5.5 & 81 & 1.1 & 0.0049 \\
\hline $\mathrm{BC}$ & 1.6 & 0.8 & 1.3 & 0.9 & 1.23 \\
\hline Primary OC & 13 & 0.8 & 5.2 & 0.9 & 2.50 \\
\hline \multirow{3}{*}{ Species } & \multicolumn{4}{|c|}{ NWP } & \\
\hline & \multicolumn{2}{|c|}{ STEM } & \multicolumn{2}{|c|}{ MOZART } & STEM/MOZART \\
\hline & Mean & Rel Std Dev & Mean & Rel Std Dev & Ratio \\
\hline Sulfate & 12 & 0.7 & 13 & 0.9 & 0.90 \\
\hline Sea Salt & 5.2 & 0.8 & 3.4 & 0.4 & 1.53 \\
\hline Ammonium & 2.9 & 1.0 & 6.0 & 1.0 & 0.48 \\
\hline Dust & 290 & 1.3 & 67 & 0.9 & 4.33 \\
\hline $\mathrm{BC}$ & 1.7 & 0.9 & 1.7 & 0.8 & 1.00 \\
\hline Primary OC & 8.3 & 1.0 & 6.2 & 0.8 & 1.34 \\
\hline \multirow{3}{*}{ Species } & \multicolumn{4}{|c|}{ NWA } & \\
\hline & \multicolumn{2}{|c|}{ STEM } & \multicolumn{2}{|c|}{ MOZART } & STEM/MOZART \\
\hline & Mean & Rel Std Dev & Mean & Rel Std Dev & Ratio \\
\hline Sulfate & 4.9 & 0.8 & 7.9 & 0.6 & 0.62 \\
\hline Sea Salt & 5.2 & 0.5 & 2.1 & 0.4 & 2.48 \\
\hline Ammonium & 1.5 & 0.9 & 2.0 & 0.5 & 0.75 \\
\hline Dust & 11 & 1.9 & 21 & 0.4 & 0.52 \\
\hline $\mathrm{BC}$ & 0.7 & 0.6 & 0.6 & 0.5 & 1.17 \\
\hline Primary OC & 2.1 & 0.4 & 3.3 & 0.6 & 0.64 \\
\hline
\end{tabular}

\subsubsection{Summary of calculated column amounts}

Time- and domain-averaged column mass loadings of various aerosol components simulated by the two models are compared in Table 17 and Fig. 13. When aggregated to domain-average column mass loading, the MOZART and STEM models yield mean column amounts for most substances and domains, that differ by less than $50 \%$, although in some instances they differ by a factor of 4 or more. Furthermore, the models show similar variability. Relative standard deviations range from $\sim 0.4$ to $\sim 1.2$ for sulfate, black carbon, organic carbon and sea salt. The relative standard deviations are larger for dust, as the emissions of these primary particles exhibit large spatial and temporal variation. The variability of nitrate (not shown) is also large, reflecting the fact that the partitioning of nitrate to the aerosol phase is strongly dependent on the availability of base cations (associated with sea salt and dust).

Comparisons of the various regions (Fig. 13) show that dust and sea salt columns were greatest over the NWP, re- flective of the large wind speeds and large production of these aerosols at the time of that study. Sulfate columns were greater than black carbon and organic carbon (and nitrate not shown) during every campaign. The largest differences between the modeled values were for dust, organic carbon and sea salt. The relative magnitude of these columns is a direct reflection of the emissions and removal processes in the regions.

4.4 Factors leading to differences in modeled aerosol amounts - uncertainty analysis

As suggested in Fig. 12 several large sources of uncertainties are associated with the calculation of the aerosol composition and size distributions. The basis for these uncertainty estimates are discussed here. 

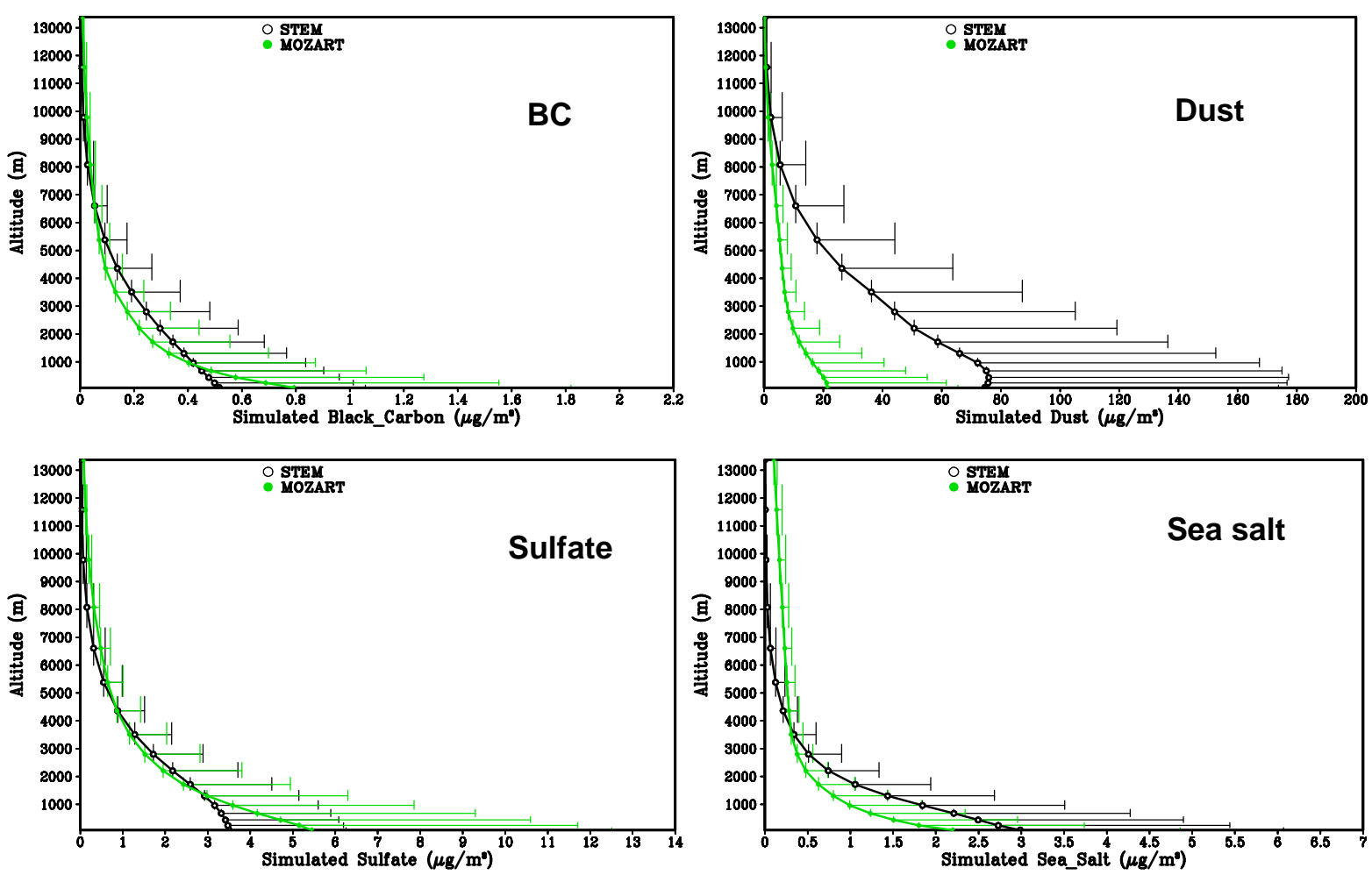

Fig. 15. Time and domain average column profiles of concentrations of selected aerosol substances for the NWP. Horizontal bars indicate + 1 standard deviation.

\subsubsection{Emissions}

Emissions play a critical role in both actual and modeled aerosol distributions, and uncertainties in emissions are a large source of uncertainty in model based estimates of aerosol concentrations. For some species (i.e., black carbon, $\mathrm{SO}_{2}$, volatile organic carbon, $\mathrm{NO}_{\mathrm{x}}$ ) the emission estimates are derived from complex models that take into account fuel properties, fuel usage, combustion conditions, and sociological factors (Streets et al., 2003). For other species (i.e., sea salt and dust), emissions are estimated within the CTM using parameterizations of factors that influence primary particle generation such as wind speed for sea salt (Woodcock, 1953; Lewis and Schwartz, 2004) and wind speed and agricultural practices for dust (Gillette and Hanson, 1989). Dust generation models rely on maps of soil types and vegetative cover, which may change seasonally or become outdated because of land-use changes. Some sources are largely variable in time (i.e., volcanoes and biomass burning), making it a challenge for models to accurately describe the emissions that may have affected the air observed on any particular day.

One approach to estimating uncertainties in emissions is comparison of the emissions employed by the two models, to the extent that these emissions are independently derived. The emissions used by MOZART and STEM came from different sources, some of which differed substantially, even when averaged over the entire domain and modeling period (Table 16). For example the $\mathrm{SO}_{2}$ and black carbon emissions varied by up to a factor of 2 , and organic carbon by up to a factor of 8 ; moreover the sense of the ratio differed from domain to domain. Such large differences reflect the uncertainties in the inventories employed. For example, an estimate of uncertainties associated with the Asian emissions has been provided by Streets et al. (2003) who estimated the overall uncertainties in their emissions (expressed as $95 \%$ confidence intervals) as: $\pm 16 \%\left(\mathrm{SO}_{2}\right), \pm 360 \%$ (black carbon), $\pm 450 \%$ (organic carbon), $\pm 500 \%$ (primary particles with $\left.D_{p}<2.5 \mu \mathrm{m}\right)$, and $\pm 80 \%\left(\mathrm{NH}_{3}\right)$. For comparison, for Asia the uncertainty for $\mathrm{CO}_{2}$ emissions is $\pm 31 \%$. The uncertainties in emissions of the aerosol species are clearly very large.

Difficulties arise in estimating emissions not only in developing areas but also in developed regions. Current analysis of the ICARTT data set suggests that emissions of sulfur oxides and nitrogen oxides from power plants in the eastern United States may be $\sim 20 \%$ and $50 \%$ lower than reported in the 1999 EPA inventory (the inventory used in the STEM model), respectively. These lower emissions are associated with improved control technologies on power plants.

Further insight into the sources of uncertainty in modeled aerosol amounts can be gained from model intercomparison studies. Recently such an intercomparison of eight regional 
and global CTMs for the East Asia region for Spring 2002 (Uno et al., 2006) examined mass emissions and concentrations of dust $\left(D_{p}<20 \mu \mathrm{m}\right)$. Substantial differences in emissions (factor of 15) were attributed to uncertainties in the land use category data and to differences in the calculated nearsurface meteorological parameters (such as friction velocity) responsible for dust generation.

Some of the differences between the aerosol burdens calculated by MOZART and STEM can be accounted for by the differences in emissions used by the models. For example, for the NWP and NIO, the black carbon emissions used by MOZART were larger than those used by STEM (by factors of 1.5 and 2, respectively, Table 16) and correspondingly the black carbon column burdens calculated with MOZART were greater than those calculated with STEM by a factor of 2 . For dust emissions, which were generated internally within the models, the differences between the emissions in the two models were substantially greater, with STEM emissions a factor of 3.2 greater than MOZART emissions in NWP but a factor of 64 smaller than MOZART emissions in NIO. For NWP the burden of dust aerosol calculated by STEM was a factor of 4 greater than that calculated by MOZART, consistent with the ratio in emissions between the two models.

\subsubsection{Wet removal}

Another major source of uncertainty in calculating aerosol distributions is aerosol removal by wet deposition. This is true in general, but especially so for black carbon and organic carbon, which exhibit physical properties ranging from hydrophilic to hydrophobic, depending on poorly understood conditions - including chemical processing. The lifetime of black carbon against wet removal and the resultant concentrations can differ greatly depending on whether the black carbon is internally mixed with soluble species. The differences in the MOZART and STEM results reflect in part these differences. In general MOZART results appear to have stronger wet removal of aerosols (sulfate, black carbon, organic carbon and dust) than STEM. As a consequence of lack of observational data on wet deposition of black carbon, the wet removal rates are uncertain to a factor of 3-4. The sensitivity of modeled black carbon concentrations to wet removal was examined by rerunning the STEM model with wet removal turned off. These runs were compared with a firstorder wet removal constant that was assumed to depend on the precipitation rate (Eq. 14). The effect of wet removal on surface concentrations of black carbon for East Asia during ACE Asia ranged from negligible to as large as $\sim 0.5 \mu \mathrm{g} \mathrm{m}^{-3}$ (dependent on frequency, location and timing of precipitation events). Column burdens of black carbon were reduced by up to $\sim 30 \%$ by wet removal processes in this region.

In the case of wet removal of organic carbon, recent results from AEROCOM comparing results from 13 global models found that the removal rate differs by a factor of 3-4 (Kanaki- dou et al., 2005). Differences in removal processes were also identified as a major source of uncertainty in the calculated dust column amounts (Uno et al., 2006).

Although dry deposition also plays a role in determining the ambient aerosol loadings, from a long term and global perspective, wet removal processes play the most substantial role in removing aerosols from the atmosphere. In the case of sulfate, model studies indicate that wet removal accounts for greater than $80 \%$ of sulfate removal (Carmichael et al., 2002). However during specific periods (e.g., the dry season during INDOEX, or dust storms, which are associated with dry cold fronts), dry deposition of aerosols is important. As discussed previously, the removal of dust by settling and dry deposition is largely uncertain. Results from eight CTMs for the TRACE-P/ACE-Asia time period differ by a factor of 10 in modeled total amounts of sulfate dry deposited (Carmichael et al., 2002; Uno et al., 2006). Very little is known about dry deposition of $\mathrm{BC}$ and organic carbon, and there is a lack of observational deposition (dry or wet) data to test and constrain models.

\subsubsection{Aerosol potentials}

The reasons for the differences between the models are examined further by means of the aerosol potentials for the several different species, evaluated as the time and space average column burden over the domain divided by the time and space average emission flux of the material or its precursor. For a closed domain and for a conservative substance the aerosol potential is a measure of the turnover time of the material in the atmosphere and would thus be equal to the inverse of the rate of removal from the atmosphere by wet and dry deposition processes, typically a few days. For a domain of limited extent such as those examined here, the aerosol potential is influenced as well by the amount of material that is transported into and out of the domain; any material that is imported into the domain from emissions outside the domain would lead to an increase in the aerosol potential, whereas the export of material from the domain results in an aerosol potential, when calculated in this way, that is less than the inverse of the removal rate. Also, for materials such as secondary sulfate that are formed by reaction in the atmosphere, the aerosol potential also incorporates the fraction of the emitted material $\left(\mathrm{SO}_{2}\right)$ that is converted to sulfate ("yield") (Rasch et al., 2000). These aerosol potentials are presented in Table 18 and Fig. 13. For sulfate, the values are $\sim 3$ days for NWP and $\sim 2$ days for NWA, and $\sim 4$ to 6 days for NIO. The larger values for NIO reflect the longer lifetimes associated with the experimental period (i.e., the dry season and thus minimal removal by precipitation). For black carbon, values range from $\sim 6$ to $\sim 11$ days. Organic carbon shows a large difference between MOZART and STEM. MOZART estimates a uniform value of $\sim 5$ days, whereas STEM calculations yield values ranging from $\sim 8$ to 23 days. These STEM organic carbon potentials 
Table 18. Domain-average potentials for the several aerosol species, evaluated as mean column mass loadings divided by mean emission fluxes.

\begin{tabular}{lcccccc}
\hline & \multicolumn{3}{c}{ Aerosol potential, days } & \multicolumn{2}{c}{ NWP } & \multicolumn{2}{c}{ NWA } \\
& STEM & MOZART & STEM & MOZART & STEM & MOZART \\
\hline nss-Sulfate $^{\mathrm{a}}$ & 6.4 & 3.8 & 2.6 & 2.7 & 1.5 & 1.9 \\
BC & 8.5 & 6.4 & 11 & 6.1 & 11.5 & 5.7 \\
primary OC $^{\mathrm{b}}$ & 8.1 & 5.9 & 22 & 5.7 & 23 & 5.0 \\
Ammonium $^{\mathrm{c}}$ & 4.1 & 2.6 & 2.0 & 3.5 & 1.8 & 3.1 \\
Dust $_{\text {Sea Salt }}$ & 0.8 & 2.7 & 3.2 & 2.6 & 8.9 & 19 \\
& 5.1 & 3.4 & 2.3 & 1.4 & 0.9 & 1.5 \\
\hline
\end{tabular}

a nss sulfate column loading and $\mathrm{SO}_{2}$ emissions were expressed in units of sulfur mass.

$\mathrm{b}$ Organic carbon values are for primary OC. The STEM results are for a simulation without wet removal.

c Ammonium $\left(\mathrm{NH}_{4}^{+}\right)$column loading and ammonia $\left(\mathrm{NH}_{3}\right)$ emissions were expressed in units of nitrogen mass.

Table 19. Summary of estimated multiplicative uncertainties in time- and space average column amounts of the several aerosol species in the three domains, based on model intercomparisons, sensitivity studies, and expert opinion. The total uncertainty associated with the column amount was evaluated as $U=\exp \left\{\left[\left(\sum\left(\ln u_{i}\right)\right)^{2}\right]^{1 / 2}\right\}$ where the $u_{i}$ denote the uncertainties associated with the several factors. Also shown are the normalized low and high differences associated with the several column amounts, as defined in the Appendix.

\begin{tabular}{|c|c|c|c|c|c|c|c|}
\hline & Emissions & $\begin{array}{c}\text { Wet } \\
\text { removal }\end{array}$ & $\begin{array}{l}\text { Vertical } \\
\text { Transport }\end{array}$ & $\begin{array}{l}\text { Chemical } \\
\text { Formation }\end{array}$ & $\begin{array}{c}\text { Total } \\
\text { Multiplicative } \\
\text { Uncertainty }\end{array}$ & $\begin{array}{c}\text { Normalized } \\
\text { Low } \\
\text { Difference }\end{array}$ & $\begin{array}{l}\text { Normalized } \\
\text { High } \\
\text { Difference }\end{array}$ \\
\hline \multicolumn{8}{|c|}{ NIO } \\
\hline nss $\mathrm{SO}_{4}^{=}$ & 1.3 & 1.3 & 1.5 & 1.3 & 1.8 & 0.44 & 0.8 \\
\hline $\mathrm{BC}$ & 3 & 2 & 1.5 & & 3.9 & 0.74 & 2.9 \\
\hline OC & 3.5 & 2 & 1.5 & 3 & 6.4 & 0.84 & 5.4 \\
\hline Dust & 5 & 2 & 1.5 & & 6.0 & 0.83 & 5.0 \\
\hline Sea Salt & 5 & 1.3 & 1.5 & & 5.4 & 0.81 & 4.4 \\
\hline \multicolumn{8}{|c|}{ NWP } \\
\hline nss $\mathrm{SO}_{4}^{=}$ & 1.3 & 1.3 & 1.5 & 1.3 & 1.8 & 0.44 & 0.8 \\
\hline $\mathrm{BC}$ & 3 & 2 & 1.5 & & 3.9 & 0.74 & 2.9 \\
\hline $\mathrm{OC}$ & 3.5 & 2 & 1.5 & 3 & 6.4 & 0.84 & 5.4 \\
\hline Dust & 5 & 2 & 1.5 & & 6.0 & 0.83 & 5.0 \\
\hline Sea Salt & 5 & 1.3 & 1.5 & & 5.4 & 0.81 & 4.4 \\
\hline \multicolumn{8}{|c|}{ NWA } \\
\hline nss $\mathrm{SO}_{4}^{=}$ & 1.3 & 1.3 & 1.5 & 1.3 & 1.8 & 0.44 & 0.8 \\
\hline $\mathrm{BC}$ & 2 & 2 & 1.5 & & 2.9 & 0.66 & 1.9 \\
\hline $\mathrm{OC}$ & 2 & 2 & 1.5 & 3 & 4.6 & 0.78 & 3.6 \\
\hline Dust & 5 & 2 & 1.5 & & 6.0 & 0.83 & 5.0 \\
\hline Sea Salt & 5 & 1.3 & 1.5 & & 5.4 & 0.81 & 4.4 \\
\hline
\end{tabular}

reflect the fact that these simulations did not include wet removal, and thus may result in a substantial overestime of organic carbon burdens. Aerosol potentials for dust are quite variable, with values for the two models varying from 1 to 20 days. As these aerosol potentials are calculated for regional and episodic (non-steady) conditions, with significant fluxes of material through the boundaries, they do not re- flect geophysical residence times and thus cannot be directly compared to residence times calculated with global models. For example, the large value for dust for NWA calculated by MOZART is caused by a significant influx of dust from Africa into the eastern boundary of the region. The general consistency between the models for sulfur is reflected in the lower estimated uncertainties in transformation and removal 
processes as shown in Table 19. The large differences for dust and organic carbon reflect the larger uncertainties associated mainly with the removal processes.

\subsubsection{Additional factors}

Meteorological fields also play a critical role in the aerosol distributions calculated in the models. In the case of wet removal, the timing and amount of precipitation, and the formation of clouds are critical factors, and these are quantities that remain difficult to accurately represent in models. Relative humidity plays an important role in radiative transfer calculations as it controls the aerosol size distribution (see Sect. 3.4). STEM and MOZART use the same global reanalysis meteorological fields (i.e., NCEP) and thus start with the same large scale $R H$ fields. The $R H$ fields used in STEM are those subsequently calculated by the mesoscale meteorological model (either MM5 or RAMS). Monthly mean differences between those used in MOZART and STEM at $3 \mathrm{~km}$ during NIO, for example, differ by $\pm 10 \%$, with large (30$40 \%$ ) differences over the Tibet Plateau albeit at fairly low $R H$, where the consequences of differences in $R H$ on aerosol optical properties are relatively small.

There remain substantial uncertainties in CTMs associated with transport processes. An inter-comparison of four global scale and three regional scale chemical transport models using common emissions with TRACE-P CO observations found substantial differences in spatial distributions and column amounts due to meteorological processes (Kiley et al., 2003). Model differences in treatment of planetary boundary layer dynamics, vertical convection, and lifting in frontal zones were found to result in differences of a factor of 2 in modeled column amounts along specific flight paths.

For secondary aerosols (e.g., sulfate and the secondary component of organic aerosols), there are additional uncertainties associated with their chemical production. A recent review of secondary organic aerosol and global modeling (Kanakidou et al., 2005) reports uncertainties in modeled global distributions of secondary organic aerosol to be a factor of $* 6$. As secondary organic aerosol comprises typically 10 to $50 \%$ of global organic aerosols, this is a large source of uncertainty. The contributions of secondary organic aerosol to total organic aerosol modeled in this study were roughly $10 \%$ for the NIO and NWP and $25 \%$ for the NWA. For sulfates, for which the formation processes are better understood and constrained by long-term observations, the factional uncertainty in column burden is estimated to be $\sim 30 \%$. The uncertainties in the emissions differ by region; those for the other processes are assumed to be independent of region.

\subsubsection{Summary of uncertainties in CTM results}

The contributions of the uncertainties of the various processes to the uncertainties in time- and space-average column amounts of selected species in the three domains are summarized in Table 19 (the uncertainties associated with modeling the aerosol composition and size at a specific time and location are greater than those for the column quantities when averaged over time and space). These uncertainty estimates, expressed as multiplicative uncertainties (see Appendix), allow for a qualitative comparison of the sources of uncertainty in the analysis chain. Although the relative sources of uncertainty vary from species to species, in general the uncertainties are ranked as follows: emissions $>$ wet removal $>$ chemical formation $>$ vertical transport.

The estimated uncertainties in the modeled average column burdens of the several substances, are quite large, up to a factor of $* 6$, with the exception of sulfate, for which the multiplicative uncertainty is estimated as $* 1.8$. These estimated uncertainties are much larger than the inter-model differences, and are larger also than the spatial variation in the modeled aerosol column burdens (see Table 17). The relatively small inter-model differences may be due in part to compensating errors in the various models, as indicated by the comparison of aerosol potentials. However, this is unlikely to be the entire explantation, as the models exhibit more skill than indicated by the uncertainties, when evaluated against observational data, as discussed below.

\subsection{Comparisons of CTM results with observations}

The large uncertainties in the calculated aerosol distributions discussed above clearly have a great impact on the ability to calculate the radiative effects of aerosols. However, these modeled aerosol distributions are "a priori" estimates of aerosol loadings and of associated uncertainties. An alternative to relying solely on these "a priori" estimates is comparison of modeled and observed loadings, particularly with observations obtained during the intensive field experiments. These measurements provide a means to compare observations with modeled values at the surface and at discrete points above the surface. The radiative transfer calculations are sensitive to first order to the column loadings, with the vertical distribution of the material being of secondary importance. Although data are not available that would permit a direct comparison of column mass loadings, the surface comparisons and the information provided by the aircraft data provide valuable information both to assess the accuracy of CTM estimates of aerosol mass concentration and composition and to provide an alternative estimate of aerosol loadings for radiative transfer calculations that is constrained by the observations. STEM has been extensively compared against the TRACE-P and ACE-Asia data, and is being tested against the ICARTT and INDOEX data. Detailed comparisons can be found in Carmichael et al. (2003a, b), Horowitz et al. (2003), Tang et al. (2003, 2004), Bates et al. (2004) and Streets et al. (2006), and these results are summarized but not repeated in detail here. In this section we focus on a few key points. 

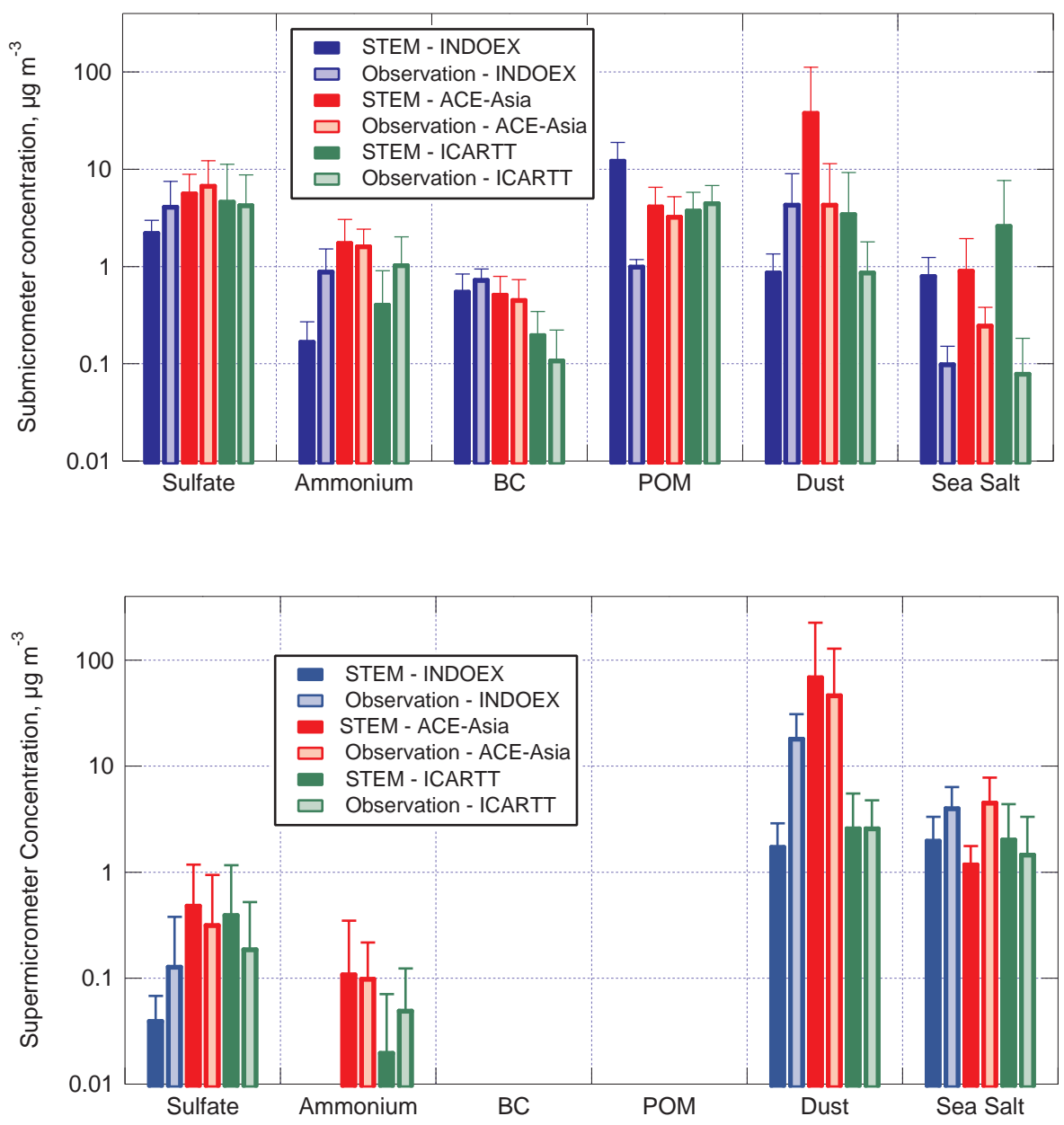

Fig. 16. Comparison of the mean concentration $\left(\mu \mathrm{g} \mathrm{m}^{-3}\right)$ and standard deviation of the observed (RV Ronald H. Brown) and modeled (STEM) aerosol components during INDOEX, ACE-Asia, and ICARTT. The model was sampled at the times and locations of the measurements. Error bars denote +1 standard deviation. Supermicrometer (and total) BC and POM were not measured (and also not modeled).

The STEM modeled aerosol quantities are compared to observations made aboard the NOAA RV Ronald H. Brown in Table 20. Here the model has been sampled at the times and locations of the shipboard measurements (every $30 \mathrm{~min}$ along the cruise track). The results are summarized in Fig. 16 which presents the observed and modeled mass concentrations of the several constituents for the sub-micrometer and super-micrometer aerosol during INDOEX, ACE-Asia and ICARTT. The average mass concentrations of the submicrometer aerosol species are modeled within $\sim 30 \%$, and exhibit variability similar to that observed in the field measurements. The super-micrometer fraction is substantially under-estimated by the model by a factor of 3. Also shown (Fig. 17) are the mass fractions of the several aerosol components $(i)$ evaluated as $\sum c_{i} / \sum C$, where the summation is taken over the individual measurements. The model calculations capture the observed sub-micrometer concentrations better than the super-micrometer concentrations.
In terms of chemical composition, there is general consistency between the observed and modeled aerosol composition, with the fine mode dominated by sulfate, organic carbon and black carbon, and the super-micrometer mode dominated by sea salt (as represented by Na, Tang et al., 2004, and dust as represented by Ca, Tang et al., 2004). Aerosol nitrate is found in the super-micrometer fraction in the model and observations and is associated with the dust and sea salt. The concentrations of organic carbon are overestimated for INDOEX. However, in contrast, the model underestimates organic carbon concentration when compared to the INDOEX aircraft data (as discussed below). The modeled sub-micrometer mode concentrations of the several species are generally consistent with the observations and moreover exhibit a variability that is similar to that of the observations. In the model the largest variations are found for nitrate, sea salt and calcium, reflecting the large uncertainties in the emission models used for sea salt and dust and the 
Table 20. Comparison of the mean concentration $\left(\mu \mathrm{g} \mathrm{m}^{-3}\right)$ and relative standard deviation (RSD) of the observed (RV Ronald H. Brown) and modeled (STEM) aerosol components during INDOEX, ACE-Asia, and ICARTT.

\begin{tabular}{|c|c|c|c|c|c|c|c|c|c|c|c|c|c|c|c|}
\hline \multicolumn{6}{|c|}{ INDOEX } & \multicolumn{5}{|c|}{ ACE-Asia } & \multicolumn{5}{|c|}{ ICARTT } \\
\hline & \multicolumn{2}{|c|}{ Observation } & \multicolumn{2}{|c|}{ Model } & \multirow{2}{*}{$\begin{array}{l}\text { Obs Model } \\
\text { Ratio }\end{array}$} & \multicolumn{2}{|c|}{ Observation } & \multicolumn{2}{|c|}{ Model } & \multirow{2}{*}{$\begin{array}{l}\text { Obs Model } \\
\text { Ratio }\end{array}$} & \multicolumn{2}{|c|}{ Observation } & \multicolumn{2}{|c|}{ Model } & \multirow{2}{*}{$\begin{array}{l}\text { Obs Model } \\
\text { Ratio }\end{array}$} \\
\hline & Mean & RSD & Mean & RSD & & Mean & RSD & Mean & RSD & & Mean & RSD & Mean & RSD & \\
\hline $\mathrm{subNO}_{3}$ & 0.02 & 0.77 & 0.26 & 0.83 & 0.1 & 0.1 & 1.56 & 0.75 & 2.17 & 0.1 & 0.06 & 0.68 & 0.56 & 2.35 & 0.1 \\
\hline $\operatorname{supNO} 3$ & 1.65 & 0.6 & 0.32 & 0.61 & 5.1 & 2.4 & 0.74 & 0.91 & 1.12 & 2.6 & 0.61 & 1.28 & 0.83 & 1.43 & 0.7 \\
\hline totNO & 1.64 & 0.61 & 0.58 & 0.43 & 2.8 & 2.5 & 0.73 & 1.66 & 1.3 & 1.5 & 0.66 & 1.18 & 1.39 & 1.35 & 0.5 \\
\hline subnssSO $_{4}$ & 4.19 & 0.8 & 2.24 & 0.33 & 1.9 & 6.84 & 0.79 & 5.71 & 0.55 & 1.2 & 4.32 & 1.03 & 4.69 & 1.39 & 0.9 \\
\hline supnssSO $_{4}$ & 0.13 & 1.92 & 0.04 & 0.7 & 3.1 & 0.32 & 1.93 & 0.49 & 1.4 & 0.5 & 0.19 & 1.76 & 0.4 & 1.92 & 0.5 \\
\hline totnssSO & 4.2 & 0.85 & 2.28 & 0.32 & 1.8 & 7.16 & 0.8 & 6.19 & 0.56 & 1.1 & 4.51 & 1.03 & 5.09 & 1.4 & 0.9 \\
\hline subNa & 0.04 & 0.5 & 0.32 & 0.53 & 0.1 & 0.1 & 0.51 & 0.36 & 1.12 & 0.3 & 0.03 & 1.35 & 1.04 & 1.89 & 0 \\
\hline supNa & 1.6 & 0.57 & 0.79 & 0.66 & 2 & 1.81 & 0.7 & 0.47 & 1.1 & 3.8 & 0.58 & 1.25 & 0.81 & 1.13 & 0.7 \\
\hline totNa & 1.63 & 0.58 & 1.11 & 0.61 & 1.5 & 1.92 & 0.68 & 0.84 & 1.04 & 2.3 & 0.61 & 1.22 & 1.85 & 1.32 & 0.3 \\
\hline subCa & 0.05 & 1.05 & 0.01 & 0.53 & 4.4 & 0.05 & 1.6 & 0.44 & 1.92 & 0.1 & 0.01 & 1.05 & 0.04 & 1.64 & 0.3 \\
\hline supCa & 0.21 & 0.68 & 0.02 & 0.65 & 9.3 & 0.54 & 1.72 & 0.8 & 2.23 & 0.7 & 0.03 & 0.82 & 0.03 & 1.1 & 1 \\
\hline totCa & 0.25 & 0.65 & 0.03 & 0.6 & 7.1 & 0.58 & 1.63 & 1.24 & 2.11 & 0.5 & 0.04 & 0.68 & 0.06 & 1.19 & 0.6 \\
\hline subOC & 0.63 & 0.17 & 7.77 & 0.52 & 0.1 & 2.06 & 0.59 & 2.63 & 0.55 & 0.8 & 2.83 & 0.5 & 2.38 & 0.52 & 1.9 \\
\hline supOC & & & & & & 0.87 & 0.73 & & & & 0.3 & 1.9 & & & \\
\hline TotOC & & & & & & 4.76 & 0.54 & & & & 3.14 & 0.54 & & & \\
\hline subEC & 0.74 & 0.28 & 0.56 & 0.5 & 1.3 & 0.46 & 0.6 & 0.52 & 0.52 & 0.9 & 0.11 & 1.02 & 0.2 & 0.72 & 0.5 \\
\hline supEC & & & & & & 0.28 & 0.84 & & & & 0.02 & 2.28 & & & \\
\hline totEC & & & & & & 0.77 & 0.57 & & & & 0.12 & 0.98 & & & \\
\hline $\mathrm{subNH}_{4}$ & 0.9 & 0.69 & 0.17 & 0.59 & 5.3 & 1.64 & 0.48 & 1.77 & 0.72 & 0.9 & 1.05 & 0.93 & 0.41 & 1.2 & 2.6 \\
\hline $\operatorname{supNH}_{4}$ & 0 & 3.91 & 0 & 7.03 & & 0.1 & 1.17 & 0.11 & 2.17 & 0.9 & 0.05 & 1.47 & 0.02 & 2.54 & 2 \\
\hline totNH 4 & 0.92 & 0.68 & 0.17 & 0.59 & 5.4 & 1.74 & 0.5 & 1.88 & 0.73 & 0.9 & 1.1 & 0.92 & 0.43 & 1.19 & 2.6 \\
\hline
\end{tabular}

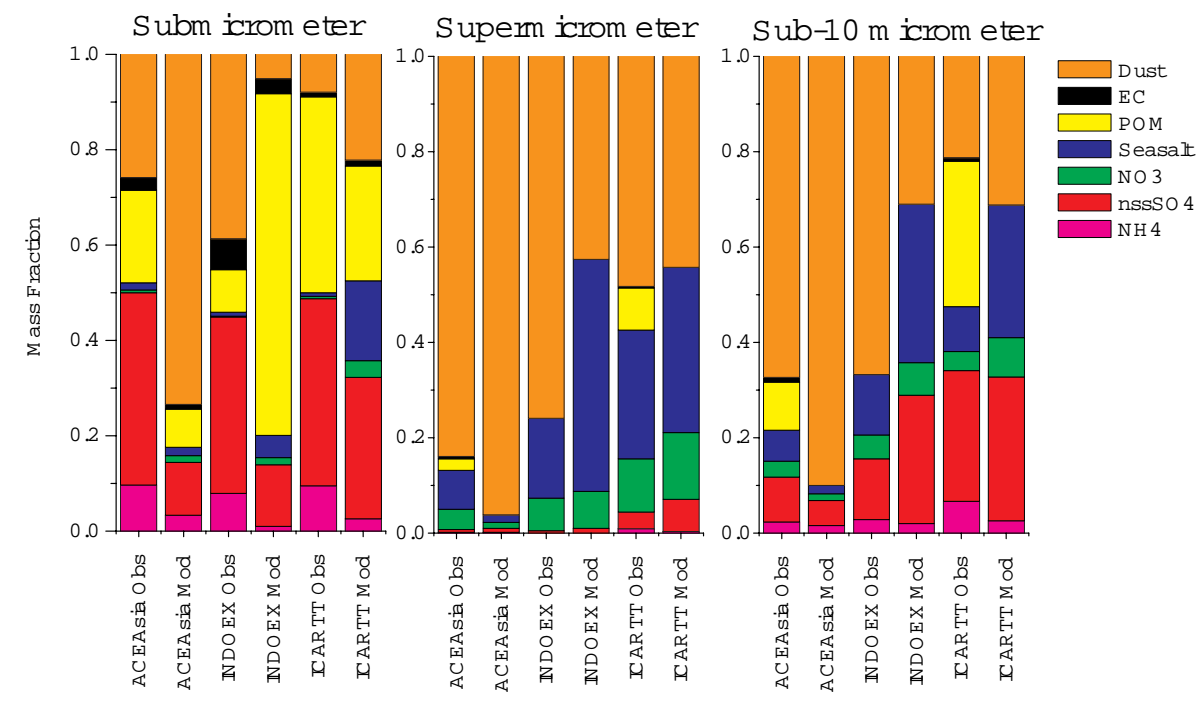

Fig. 17. Modeled (STEM) and observed (RV Ronald H. Brown) dry mass fractions of the aerosol components in the three domains for the submicrometer (left), supermicrometer (center), and total sub-10 micrometer (right) aerosol.

strong dependency of the nitrate partitioning on these quantities. The models also tend to put too large a fraction of these substances into the sub-micrometer mode compared to the observations. Larger relative differences between modeled and observed concentrations of individual species are found in the super-micrometer mode, although the modeled variability is similar to that observed. The biggest discrepancy between model and observations is the underestimation of modeled sea salt (as reflected in the $\mathrm{Na}$ concentrations).
Comparison of the modeled species concentrations with the aircraft data (model values are extracted along the flight paths) provides further insights (Table 21). In general the model results are better below $2 \mathrm{~km}$ than at higher altitudes, reflecting the uncertainties in modeling vertical transport and removal processes (as discussed previously). Dust and sea salt are underestimated (evidently reflecting errors in emissions modeling). Sulfate again is modeled with the best skill (reflecting the greater accuracy in the emissions and 
Table 21. Comparison of concentrations of aerosol constituents $\left(\mu \mathrm{g} \mathrm{m}^{-3}\right)$ determined by aircraft observations and modeled by STEM for the INDOEX, TRACE-P/ACE-Asia and ICARTT campaigns.

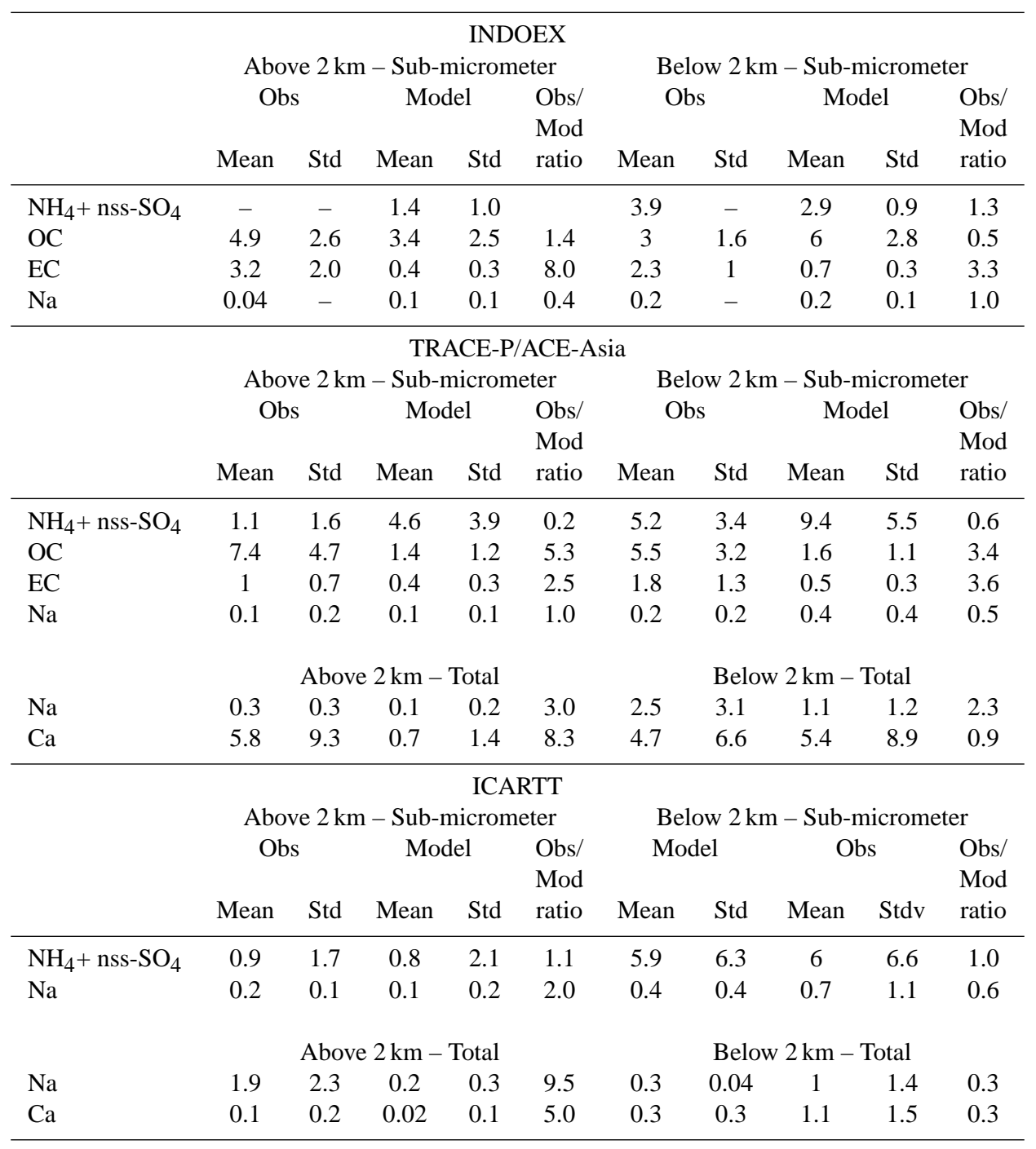

See Tables 2-4 for sources of observational data.

model representation of chemical conversion and removal processes). Black carbon and organic carbon differences illustrate larger uncertainties (e.g., errors in the emissions and in the representation of secondary organic aerosol formation).

The calculations of aerosol mass also enter into the radiative forcing calculations through the parameterization of the optical properties. For example, as discussed in Sect. 3, the observed optical properties can be used to constrain the radiative transfer calculations. Parameterizations of optical properties were developed that depend on the fine aerosol mass fraction, the anthropogenic fraction of the fine mode aerosol mass, and the organic aerosol mass fraction. In the radiative transfer calculations the optical properties are calculated using the modeled values of these quantities.
The modeled values of these factors are compared to the observation-derived values in Table 22 . The modeled values generally agree with the observations within $20 \%$. The calculation of the submicrometer dust mass is also important in the radiation forcing calculation. As discussed above, estimating dust emissions as a function of size is highly uncertain. Based on the comparison of calculated aerosol calcium (as a surrogate for dust) with observations (Tables 20 and 21), the STEM model appears to overestimate the amount of dust in the sub-micrometer fraction in the high dust conditions of the NWP. The sensitivity of radiative forcing calculations to the concentration of submicrometer dust is discussed in Sect. 5 . 
Table 22. Comparison of the observation-based (RV Ronald H. Brown) and modeled (STEM) fine mode parameters used in optical property functions calculated using the mean values in Table 20.

\begin{tabular}{lccccccccc}
\hline & Obs & $\begin{array}{c}\text { NIO } \\
\text { Model }\end{array}$ & $\begin{array}{c}\text { Obs/ } \\
\text { Mod }\end{array}$ & Obs & $\begin{array}{c}\text { NWP } \\
\text { Model }\end{array}$ & $\begin{array}{c}\text { Obs/ } \\
\text { Mod }\end{array}$ & Obs & $\begin{array}{c}\text { NWA } \\
\text { Model }\end{array}$ & $\begin{array}{c}\text { Obs/ } \\
\text { Mod }\end{array}$ \\
\hline $\begin{array}{l}\text { Fine Aerosol } \\
\text { Mass Fraction }\left(F_{f}\right)\end{array}$ & 0.66 & 0.89 & 0.74 & 0.59 & 0.80 & 0.74 & 0.83 & 0.80 & 1.04 \\
$\begin{array}{l}\text { Fine Aerosol } \\
\text { Anthropogenic Mass Fraction }\left(F_{f a}\right)\end{array}$ & 0.98 & 0.96 & 1.02 & 0.99 & 0.93 & 1.06 & 0.99 & 0.87 & 1.14 \\
Organic Fine Mass Fraction $\left(F_{o^{*}}\right)$ & 0.13 & 0.68 & 0.19 & 0.23 & 0.22 & 1.05 & 0.40 & 0.34 & 1.18 \\
\hline
\end{tabular}

* $F_{O}$ is calculated as organic carbon/(organic carbon + nss sulfate) in sub micrometer mode

\subsection{Summary of CTM results}

As discussed throughout this section, the uncertainties in modeling tropospheric aerosol concentration and composition as a function of size are quite large. Differences in mean column amounts calculated with the two models were usually less than a factor of 2 for most species and domains. The exception was dust for NWP (a factor of 3). When the model results were compared to measured values the differences were found to lie well within the estimated uncertainties associated with the calculations, which, however, are quite large. These results illustrate that the relative error of the models is much lower than the estimated uncertainties as inferred by propagation of the uncertainties in the model parameterizations. Despite the large uncertainties associated with emissions and the processes within the CTMs, the CTMs estimate, in these study areas, the regional average surface aerosol concentrations with much greater skill than might be expected from the uncertainties. This is due in part to compensating errors and the model-specific parameterizations. Models are developed over time and are evaluated against available observations, and parameterizations may be selected to produce the best results rather than for physical consistency with the meteorological and thermodynamic fields. For example, a model with large emission rates may use a parameterization for wet removal that is very efficient; in order to best match the observations. A major benefit of the model/measurement comparisons is a reassessment of the uncertainties associated with deriving aerosol distributions from CTMs.

Comparison of the sources of uncertainty in the CTMs suggests that improvements in emission inventories are essential to improving the accuracy of CTM calculations. The largest differences between model results and observations were found for low-altitude flights over the Yellow Sea, close to the large emission sources in China. A similar tendency was found in certain gas phase species; for example, $\mathrm{CO}$ was also underestimated at low altitudes over the Yellow Sea. Recent inverse model studies have shown a need to increase the representation of $\mathrm{CO}$ emissions from China in the model (Kasibhatla et al., 2002; Palmer et al., 2003); such inverse modeling can be done with confidence for a low-reactivity gas such as CO. These observation-based studies have in turn stimulated development of a new bottom-up CO inventory (Streets et al., 2006), resulting in an increase of $\sim 40 \%$ over the emissions given earlier (Streets et al., 2003); this increase is due largely to the industrial sector. These new estimates have implications for black carbon emissions, as the observed ratios of black carbon/CO are reasonably well represented by the Streets et al. (2003) emissions inventory. Thus an increase in $\mathrm{CO}$ emissions suggests that the black carbon emissions will also need to be revised upwards.

Enhanced observations are also needed to develop better removal parameterizations for aerosols. Wet deposition measurements provide a valuable constraint on wet removal rates. While measurements of wet deposition are available for the key inorganic species, analogous necessary measurements of wet deposition of black carbon and organic carbon are lacking.

Finally, although the observations obtained during the intensive field experiments provide critical data to test and improve the process treatments and the accuracy of model calculations, they are not commonly being integrated into the models to produce 4-dimensional observation-constrained distributions (as is done in the field of meteorology, where global reanalysis products that integrate in-situ and remotely sensed data with models are produced operationally). In view of the large uncertainties in the calculation chain leading to aerosol mass distributions, it would seem useful in developing more accurate model aerosol distributions to incorporate aerosol assimilation methods where observational data are available, such as from intensive field campaigns or from satellite observations (Collins et al., 2001). 


\section{Radiative transfer calculations}

\subsection{Radiative transfer models}

\subsubsection{Overview}

Total solar clear sky aerosol optical depth (AOD), DRE and DCF were computed from the 4-D fields of aerosol mass concentrations calculated in the CTM runs described in Sect. 4 using the radiation transfer model (RTM) of the Geophysical Fluid Dynamics Laboratory (GFDL) global atmosphere model AM2 (GAMDT, 2004) at a spatial resolution of $2^{\circ}$ latitude $\times 2.5^{\circ}$ longitude and a temporal resolution of $3 \mathrm{~h}$ and by the University of Michigan (UMich) RTM (e.g., Liu et al., $2006^{2}$ ) at the resolution of the CTM grid boxes. Ambient $R H$ and temperature were generated in the GFDL RTM, based on NCEP reanalysis, every three hours in order both to account for water vapor absorption and, more importantly in the present context, to calculate aerosol optical properties as a function of $R H$. (As discussed in Sect. 3, sea salt optical properties were held constant at the values corresponding to $80 \%$ relative humidity.) Ambient $R H$ and temperature were provided to the UMich RTM from the CTM at the time resolution of the aerosol data. Aerosol input to the RTM calculations consisted of daily mean aerosol fields (dry mass concentrations of sea salt, sulfate, black carbon, organic carbon, and dust as a function of location, altitude and date) from each of the two CTMs (MOZART and STEM) for the times and locations of the three measurement campaigns (Table 1, Fig. 2). For the MOZART calculations, two aerosol fields were provided for each campaign - total aerosol (natural plus anthropogenic) and natural aerosol (no anthropogenic emissions of aerosols or gases). For the STEM calculations, only a single, total aerosol field was provided for each campaign. Aerosol optical depth was calculated as the vertical integral of aerosol extinction coefficient. The radiative flux calculations were made with no aerosols, total aerosols, and in the MOZART runs, natural aerosols. Aerosol direct radiative effect (DRE) was calculated as the difference in the pertinent flux component (surface downwelling irradiance or top-of-atmosphere net irradiance) for the total aerosol calculation minus that for the aerosol-free calculation. Aerosol direct climate forcing (DCF) was calculated similarly in the MOZART runs as the difference for the total aerosol calculation minus that for the natural aerosol calculation. The calculations were conducted over the domains shown in Fig. 2 (shaded areas) using an ocean-only mask. Clear sky was implemented in the model by removing clouds from the column; thus the calculated aerosol DRE and DCF are pertinent to a cloud-free planet and do not account for the masking of aerosol effects by clouds above the aerosol or for the decrease in aerosol scattering influences, and increase in aerosol absorption influences, for clouds below the aerosol. For this reason these calculations are expected to overestimate regional DRE and DRF. However the calculations do corre- spond closely to measurements of aerosol direct influences that are restricted to situations of no cloud or very little cloud.

In order to examine the consequences of using aerosol optical properties constrained by observations versus the optical properties incorporated into the GFDL AM2 model or UMich model, DRE (MOZART and STEM) and DCF (MOZART only) were calculated once using the aerosol optical properties built in to the radiation code (the "a priori" runs) and once using the aerosol optical properties based on observations calculated as described in Sect. 3.4.6 (the constrained runs). As the measurements of aerosol optical properties were limited to the visible spectral range the use of constrained optical properties was limited to wavelengths shorter than $1 \mu \mathrm{m}$, with the "a priori" values, including their $R H$ dependence, used at longer wavelengths.

\subsubsection{Description of the radiative transfer model}

The radiation component of AM2 performed a full radiation calculation every $3 \mathrm{~h}$, including the effects of molecular scattering, absorption by $\mathrm{H}_{2} \mathrm{O}$ vapor, $\mathrm{CO}_{2}, \mathrm{O}_{3}, \mathrm{O}_{2}, \mathrm{~N}_{2} \mathrm{O}, \mathrm{CH}_{4}$, CFC-11, CFC-12, CFC-113, and HCFC-22, and absorption and scattering by clouds and aerosols. The shortwave scheme used the delta-Eddington exponential-sum-fit technique (a two-stream style calculation) with 18 bands from 0.175 to $4.0 \mu \mathrm{m}$ (Freidenreich and Ramaswamy, 1999) and computed total shortwave fluxes using the adding method (Ramaswamy and Bowen, 1994). Climatological ozone profiles followed Fortuin and Kelder (1998). The ocean surface was treated as Lambertian with the albedo varying with solar zenith angle according to Taylor et al. (1996). Sea surface temperatures and sea-ice were represented according to a prescription by J. Hurrell at NCAR (personal communication) for the year 2000. While the aerosols in the model also exerted a direct radiative effect in the longwave (calculated using nongray absorption coefficients specified in eight spectral bands following Ramachandran et al., 2000), only shortwave effects $(\lambda<4.0 \mu \mathrm{m})$ were analyzed here.

The radiation component of the University of Michigan RTM performed a shortwave radiation calculation every hour, including the effects of molecular scattering, absorption by $\mathrm{H}_{2} \mathrm{O}$ vapor, $\mathrm{CO}_{2}, \mathrm{O}_{3}, \mathrm{O}_{2}$, and absorption and scattering by clouds and aerosols (Grant et al., 1998, 1999). The radiative scheme used a two-stream delta-Eddington solution and had 9 bands covering the Ultra-Visible (UV) and visible region from $0.175 \mu \mathrm{m}$ to $0.700 \mu \mathrm{m}$ and 3 bands resolving water vapor absorption in the near Infra-Red (IR) between 0.700 and $4.000 \mu \mathrm{m}$. In order to gain computational efficiency, the model computed the solar fluxes at each waveband by solving a penta-diagonal matrix with Gaussian elimination instead of the adding method (Langmann et al., 1998). The current version of the UMich RTM used a broadband average surface albedo, which only depends on the underlying surface type. 
All radiative properties for both models were output as UTC diurnal means, one value per day during the period of each measurement campaign (Table 1), and were further processed into time-mean (over the time period of each campaign) latitude-longitude maps, area-mean time series, and area-mean time-mean values with standard deviation of the time-mean.

5.2 Uncertainties in the calculation of direct aerosol radiative effect and forcing

\subsubsection{Introduction}

As discussed in Sect. 5.1, calculation of aerosol DRE and DCF, requires solution of the radiative transfer equation for a specified vertical distribution of aerosol optical properties and boundary conditions (surface and top of atmosphere). Contributions to uncertainties in aerosol influences on radiative fluxes calculated with RTMs include uncertainties in the mass concentration of the aerosol and its vertical distribution (discussed above), uncertainties in the mass extinction efficiency of the aerosol (which, together with the vertical distribution of the mass concentration results in the aerosol optical depth), and uncertainties in other optical properties of the aerosol (single scattering albedo and asymmetry parameter) together with uncertainties resulting from the model-based representation of the radiation transfer and uncertainties resulting from averaging over spatial and/or temporal inhomogeneities in carrying out the radiation transfer calculations in a particular application of the model. This section examines these several contributions to uncertainty in the calculation of aerosol DRE and DCF, focusing mainly on uncertainties associated with the aerosol properties themselves.

Conceptually these several contributions to uncertainty in DRE (or DCF) might be represented as follows:

$$
\Delta \mathrm{DRE}=\sum^{\oplus} \frac{\delta \mathrm{DRE}}{\delta Q_{i}} \Delta Q_{i} \oplus \sum^{\oplus} \Delta \mathrm{DRE}_{\mathrm{RTM}_{j}}
$$

where the $\Delta Q$ represent uncertainties in aerosol properties $Q_{i}$ and the $\triangle \mathrm{DRE}_{\mathrm{RTM}_{j}}$ represent uncertainties in DRE introduced by application of the RTM; the notation $\sum^{\oplus}$ and $\oplus$ denote addition in quadrature (see Appendix) for uncorrelated uncertainties. The discussion in this section focuses on the uncertainties in aerosol properties and their consequences. Additional uncertainties in the radiation transfer modeling, which are generally small relative to the uncertainties resulting from uncertainties in aerosol properties are briefly discussed.

Although the theory of atmospheric radiative transfer in a horizontally homogeneous clear-sky atmosphere is relatively well established, its implementation can introduce biases or uncertainties in estimating DRE. In particular, solving the radiative transfer equation to derive a shortwave flux requires an integration of atmospheric radiances over the zenith and azimuthal angles as well as integration over wavelength. The angular integrations were done here using a twostream delta-Eddington calculation. The spectral integration was done by breaking the shortwave spectrum into a discrete number of spectral bands, with the gas and aerosol scattering and absorbing properties properly represented over each spectral band. RTM intercomparison studies (e.g., Boucher et al., 1997; Halthore et al., 2004) have shown that for a well specified aerosol and other pertinent inputs to the calculation such as surface reflectance and solar zenith angle, calculations of instantaneous aerosol forcing by a suite of models agree quite closely, with standard deviations generally less than $10 \%$.

In addition to uncertainties associated with calculation of local and instantaneous aerosol DRE, uncertainties also arise in calculating temporal and spatial averages, which require spatial and temporal integration. The latter integrations were carried out at the spatial and temporal resolution of the GFDL RTM. Each of these integrations (angular, spectral, spatial, and temporal) can introduce biases or uncertainties, for example if the spectral bands are not sufficiently fine or if correlative variations in the input variables with respect to one of the variable of integrations are not accounted for. We review below the correlations that need to be accounted for in calculations of the DRE. These are not always considered in calculations published in the literature, either because of constraints on computer time or by lack of knowledge of the variations in the input variables. The resultant uncertainties are examined below.

\subsubsection{Uncertainties and correlations related to the angular integrations}

The angular distribution of aerosol light scattering was represented here by the asymmetry parameter (the mean of the cosine of the phase function). This quantity was characterized in field studies from the backscatter fraction of the aerosol (nominally the fraction of scattered radiation that is scattered into the back hemisphere) as measured with an integrating nephelometer. The aerosol phase function was reconstructed from the asymmetry parameter assuming a delta-Eddington phase function rather than the full series of Legendre moments. Depending on solar zenith angle this approach could lead to underestimation or overestimation of the DRE for phase functions typical of accumulation- and coarse-mode aerosols as computed from Mie theory (Boucher, 1988). Because the bias in DRE is sometimes positive and sometimes negative, the error in the daily integrated DRE is less than at any given solar zenith angle (Bellouin et al., 2004).

As water surfaces reflect radiation non-isotropically, the angular distribution of surface reflectance is characterized by a bi-directional reflectance distribution function (BRDF). However, for simplicity it is assumed in DRE calculations here that surfaces are Lambertian. The oceanic surface is largely anisotropic, especially under calm conditions, for 
which there is a sharp specular (Fresnel) reflection. Nonetheless, because of the diffuse nature of aerosol scattering the anisotropy of the oceanic surface results in DRE errors of at most $5 \%$ for instantaneous DRE, and the effect turns out to be negligible when the DRE is averaged over daytime (Bellouin et al., 2004).

Unlike the surface BRDF, the surface albedo is not an intrinsic property of the surface but depends on the aerosol loading through changes in the ratio of direct and diffuse solar radiation reaching the surface. The sensitivity of the surface albedo to the aerosol loading can be substantial over the ocean because the albedos for direct and diffuse radiation can be very different at small and large solar zenith angles. Bellouin et al. (2004) showed that using a no-aerosol (Lambertian) surface albedo instead of the actual albedo could result in a DRE error as large as $25 \%$ for an aerosol optical depth of 0.05 at $865 \mathrm{~nm}$. The daily-integrated DRE, while smaller, can be biased by about $2 \%\left(45^{\circ} \mathrm{N}\right.$ summer) or up to $13 \%\left(45^{\circ} \mathrm{N}\right.$ winter) for the same aerosol optical depth. The effects get smaller at larger aerosol optical depths.

\subsubsection{Uncertainties and correlations related to the spectral integration}

Aerosol optical properties vary spectrally. The scattering coefficient varies with the wavelength, $\lambda$, typically as $\lambda^{-\mathscr{a}}$ where $a$ is the Ångström exponent. The Ångström exponent is close to 0 for coarse-mode aerosols and can be as large as 2 for accumulation-mode aerosols. The aerosol single scattering albedo also varies with wavelength. There is stronger absorption at UV wavelengths for dust (e.g., Dubovik et al., 2001) and for some, but not all, organic aerosols (e.g., Jacobson, 2001; Lund Myhre and Nielsen, 2004; Kirchstetter et al., 2004). The optical depth due to molecular (Rayleigh) scattering varies as $\lambda^{-4}$ with extra features due to absorption. Surface albedo can also exhibit strong spectral features, especially over vegetated areas.

Although the effect is not included in the results reported here, aerosols also exert a DRE in the longwave spectrum. For anthropogenic aerosols this longwave effect is typically $10 \%$ of the shortwave DRE (Vogelmann et al., 2003; Reddy et al., 2005a, b). Dufresne et al. (2002) showed that it was important to consider scattering of longwave radiation (in addition to absorption and emission) in order to accurately estimate aerosol DRE both at the surface and top-of-atmosphere. As most radiative transfer schemes used in global models consider only absorption and emission of longwave radiation, it is appropriate to neglect aerosol scattering in the longwave spectrum (and prescribe the aerosol absorption optical depth) to estimate reasonably well the top-of-atmosphere fluxes (albeit at the expense of surface fluxes).
5.2.4 Uncertainties and correlations related to the spatial integration

The aerosol DRE is computed at a spatial resolution defined by GFDL RTM grid boxes and at the resolution of the CTM grid boxes in the Umich RTM. Sub-grid scale variations in various parameters may result in uncertainties if they are correlated or if non-linear effects are present. Such correlations might certainly be expected between aerosol concentration and relative humidity. Myhre et al. (2002) showed that neglecting sub-grid scale variations in relative humidity in global models with a coarse resolution would cause an underestimate of the sulfate DRE of $30-40 \%$, at least over certain regions, because the scattering coefficient increases superlinearly with increasing $R H$.

\subsubsection{Conclusions regarding uncertainties in RTM calcula- tions}

The foregoing considerations point to the necessity of evaluating aerosol DRE and DCF by explicit integration over three dimensions and time. Even when such explicit integration is carried out, as in this study, resultant errors may arise from sub-grid correlations (e.g., relative humidity). Also in the present study a 24-h average aerosol concentration field is employed (albeit with time-dependent $R H$ fields in the GFDL model); the use of such a daily average aerosol concentration might lead to error for aerosol components such as secondary sulfates and organics whose production and concentration might be correlated with time of day.

\subsection{Comparison of "a priori” and constrained model runs}

The approach to assessing the consequences of aerosol properties on calculated AOD, DRE, and DCF was to carry out two sets of radiation transfer calculations for each of the two sets of aerosol concentration fields, as obtained from the CTM calculations by STEM and MOZART using two different RTMs (GFDL and UMich). Here the two sets of optical properties are denoted "a priori" properties, referring to the optical properties that are built into the GFDL AM2 and UMich radiation transfer codes, and constrained properties, referring to the optical properties derived from measurements during the three field campaigns.

For the purposes of comparison, four separate quantities are calculated from each model run as described in Sect. 1: (1) the aerosol extinction optical depth (AOD) at $0.55 \mu \mathrm{m}$ wavelength for total (natural plus anthropogenic) aerosols and in the MOZART calculations also for natural aerosols only; (2) the total solar direct radiative effect (DRE) at the top of atmosphere (TOA) and surface (SFC), defined as the net flux with aerosols minus the net flux without aerosols, for total (natural plus anthropogenic) aerosols; (3) the normalized direct radiative effect (DRE divided by AOD) or "radiative efficiency" $(\varepsilon)$ (Anderson et al., 2005) at the TOA and SFC, 

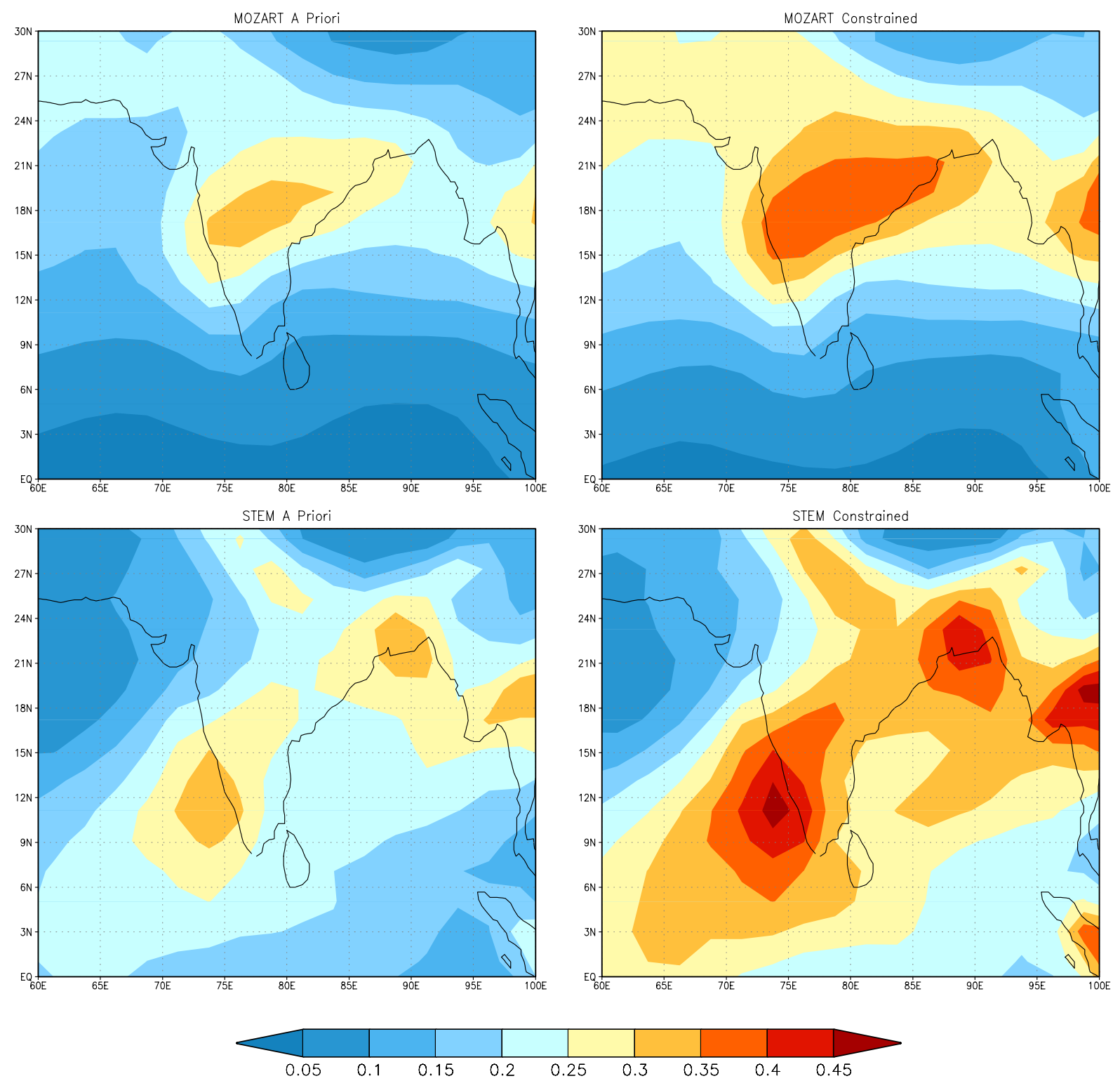

Fig. 18. NIO AOD at $0.55 \mu \mathrm{m}$ with MOZART aerosols (top panel) and STEM aerosols (bottom panel). First column is with the "a priori" aerosol optical properties; second column is with the constrained optical properties.

for total (natural plus anthropogenic) aerosols; and (4) the total solar direct climate forcing (DCF) at the TOA and SFC, defined as the net flux with total aerosols minus the net flux with natural aerosols, in the MOZART calculations only. As stated in Sect. 5.1.1, all of these are clear sky (cloud free) calculations. The DRE, radiative efficiency, and DCF are all affected by the aerosol mass concentration, size distribution, and chemical composition, as well as the surface reflectivity and solar irradiance.

\subsubsection{Comparison of "a priori" and constrained model runs $-\mathrm{NIO}$}

A map of the time-mean AOD for total aerosols in the NIO is shown in Fig. 18 over both land and water to depict aerosols in the source regions as well as aerosols transported to the ocean. The difference over the ocean between the runs using the aerosol loadings from the MOZART CTM and those using the aerosol loadings from the STEM CTM are much greater than the difference between the runs using the "a priori" optical properties and those using the constrained optical properties. With the MOZART aerosols, the AOD is less than 0.2 over the majority of the ocean, except for 

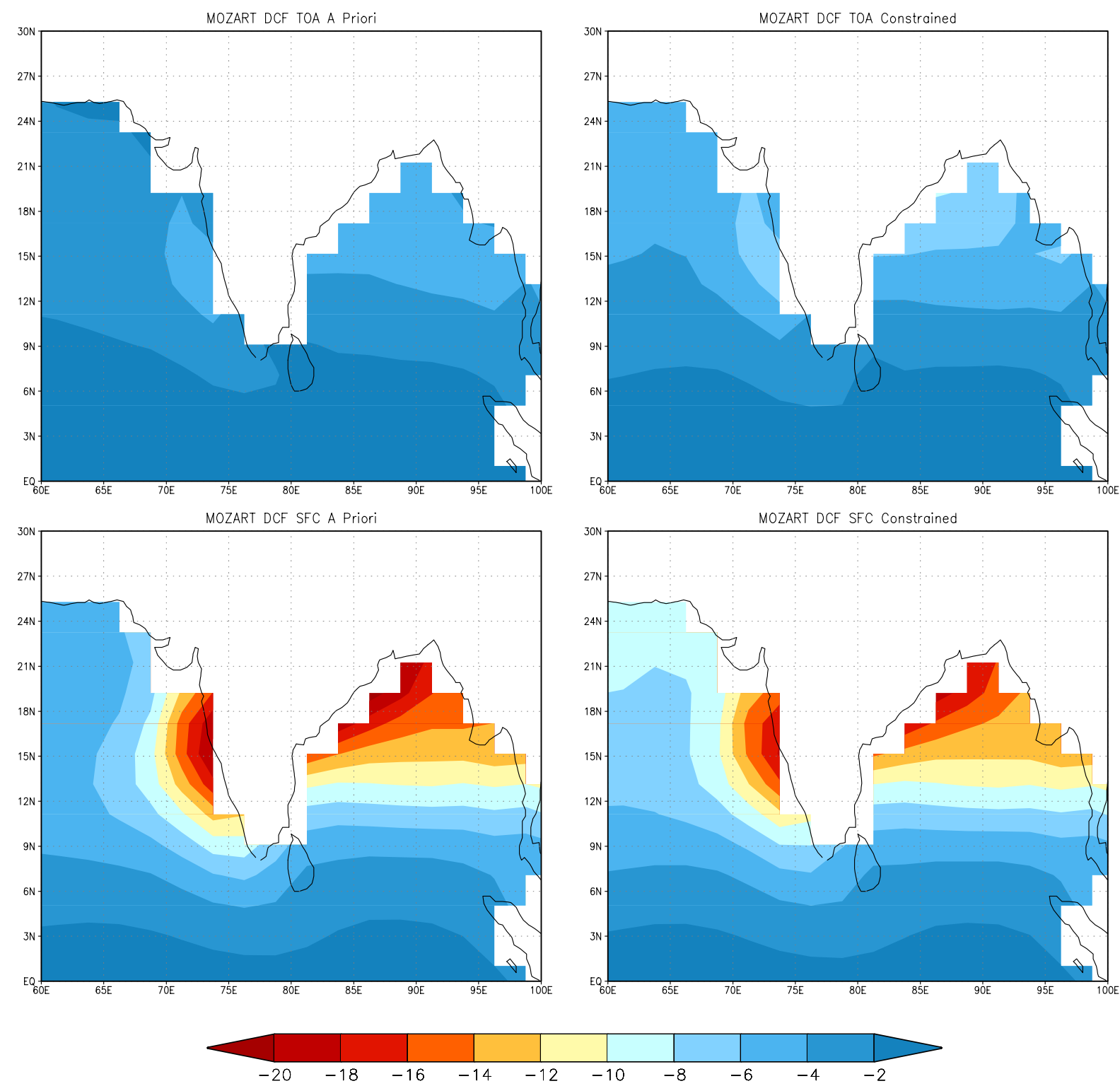

Fig. 19. NIO DCF at the top-of-atmosphere (top panel) and surface (bottom panel). First column is with the "a priori" aerosol optical properties; second column is with the constrained optical properties.

the immediate proximity of the continent. With the STEM aerosols, the GFDL RTM estimates a substantially greater AOD over the ocean (up to 0.45 ), with a particularly large AOD off the southwest coast of India. The difference is attributed to differences in the column burden of black carbon and organic carbon near the Indian coast and sea salt in the southwest corner of the plotted domain, with STEM having much more outflow to the southwest than MOZART. Although MOZART has a much larger dust burden in this region than STEM (Table 17), the dust is not transported out over the ocean. The differences in AOD are also influenced by the choice of optical properties. With the MOZART aerosols, the relative difference between the constrained and "a priori" AOD is generally between 20 and $40 \%$, with the entire domain exhibiting larger values of AOD with the optical properties constrained by the observations than with the "a priori" optical properties. With STEM aerosols, the relative difference reaches $70 \%$ in the southwest corner of the domain. The larger values of AOD with the constrained optical properties are in agreement with the relatively larger values of the constrained versus "a priori" mass extinction efficiencies presented in Sect. 3.4.6. The time-mean and standard deviation of the ocean-area-average AOD, DRE, radiative efficiency, and DCF for the NIO domain are given in Table 23 for both the GFDL and UMich RTMs. The availability of calculated concentrations of natural aerosol 

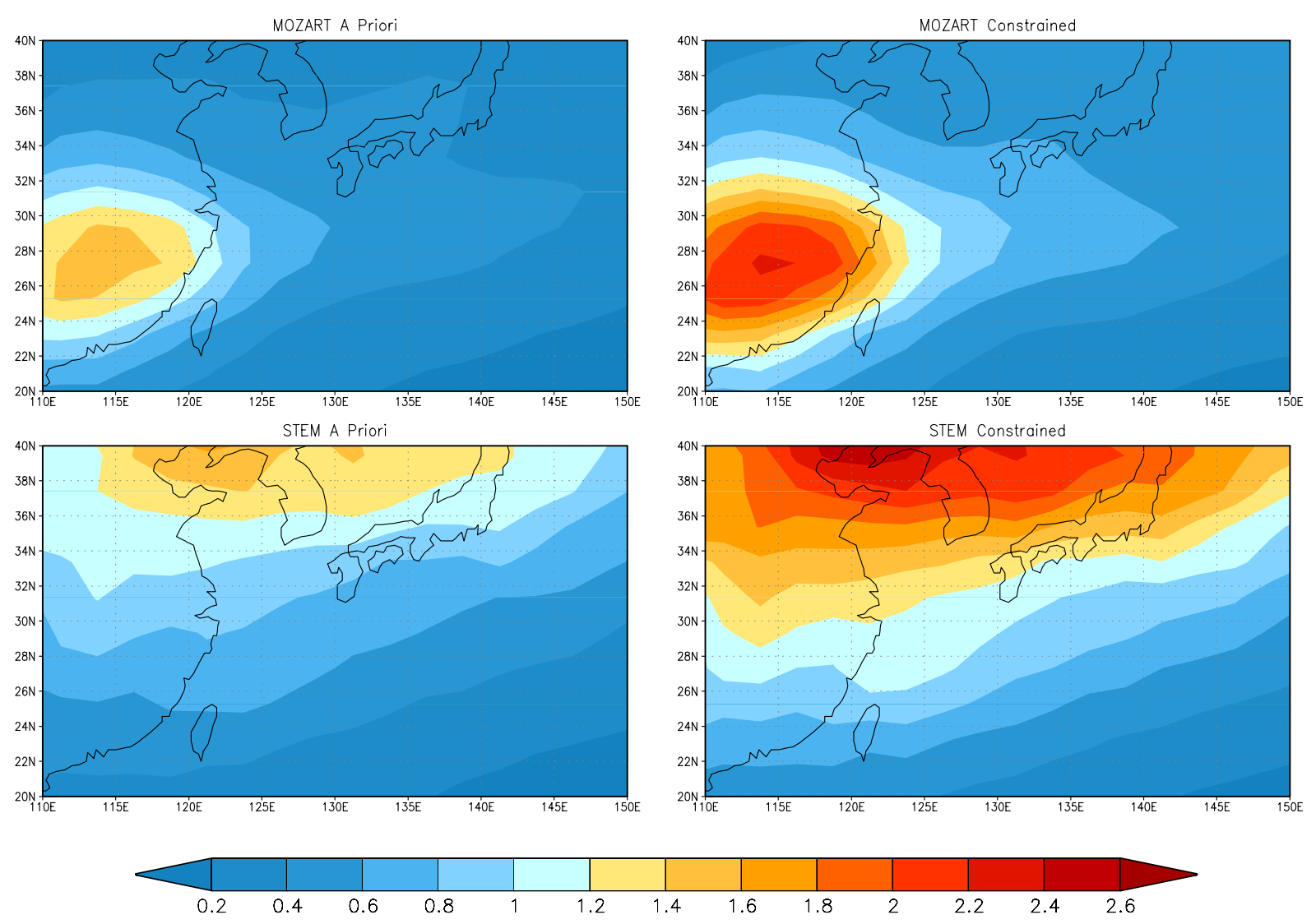

Fig. 20. NWP AOD at $0.55 \mu \mathrm{m}$ with MOZART aerosols (top panel) and STEM aerosols (bottom panel). First column is with the "a priori" aerosol optical properties; second column is with the constrained optical properties.

species in the MOZART runs permits presentation of natural AOD and of DCF for MOZART only. The area-mean timemean AOD over the ocean is smaller using the aerosol burdens from the MOZART CTM $(0.13 \pm 0.020,0.11 \pm 0.017$, $0.16 \pm 0.024$, and $0.16 \pm 0.024$ from the GFDL "a priori", UMich "a priori", GFDL constrained and UMich constrained runs, respectively) than using the aerosol burdens from the STEM CTM $(0.20 \pm 0.044,0.19 \pm 0.043,0.27 \pm 0.061$, and $0.24 \pm 0.052$ from the GFDL "a priori", UMich "a priori", GFDL constrained and UMich constrained runs, respectively). The standard deviation of the time series of AOD is 2 to 3 times larger using the STEM CTM than using the MOZART CTM, indicating somewhat more time variability in the STEM aerosol fields than in the MOZART aerosol fields.

The relative difference between the constrained and "a priori" area-mean time-mean AOD is $27 \%$ using the MOZART CTM and 34\% using the STEM CTM in the GFDL modle runs, while it is $47 \%$ and $24 \%$, respectively for the UMich model runs. Given the larger area-mean time-mean AOD using the STEM CTM, the DRE using the STEM CTM is also greater than the DRE using the MOZART CTM for both the SFC and TOA (Table 23). The relative difference between the constrained and "a priori" area-mean time-mean DRE is generally smaller than the relative difference between the constrained and "a priori" AOD. The time-mean DRE at the SFC and TOA over the ocean using the MOZART CTM is consistent with the pattern of AOD over the ocean using the MOZART CTM in Fig. 18, with the largest DRE near the central coast of the Indian subcontinent. The radiative efficiency for NIO is generally larger using the MOZART CTM than using the STEM CTM for both the SFC and TOA, although the values are similar given the standard deviations (Table 23). The relative difference between the constrained and "a priori" radiative efficiency reaches $27 \%$.

Because natural aerosols were not generated using the STEM CTM, the DCF is calculated using the MOZART CTM only (Fig. 19). As with the AOD and DRE, the constrained DCF is generally larger than the "a priori" DCF (Table 23). The relative differences are $3.2 \%$ and $-0.16 \%$ for GFDL and UMich at the SFC, respectively, and 39\% and $41 \%$ at the TOA, respectively. The larger AOD in the constrained runs, which is due to a greater mass scattering efficiency as the mass loading is the same, is offset by the much higher forcing efficiency in the a priori runs which result in similar values of forcing at the surface. 

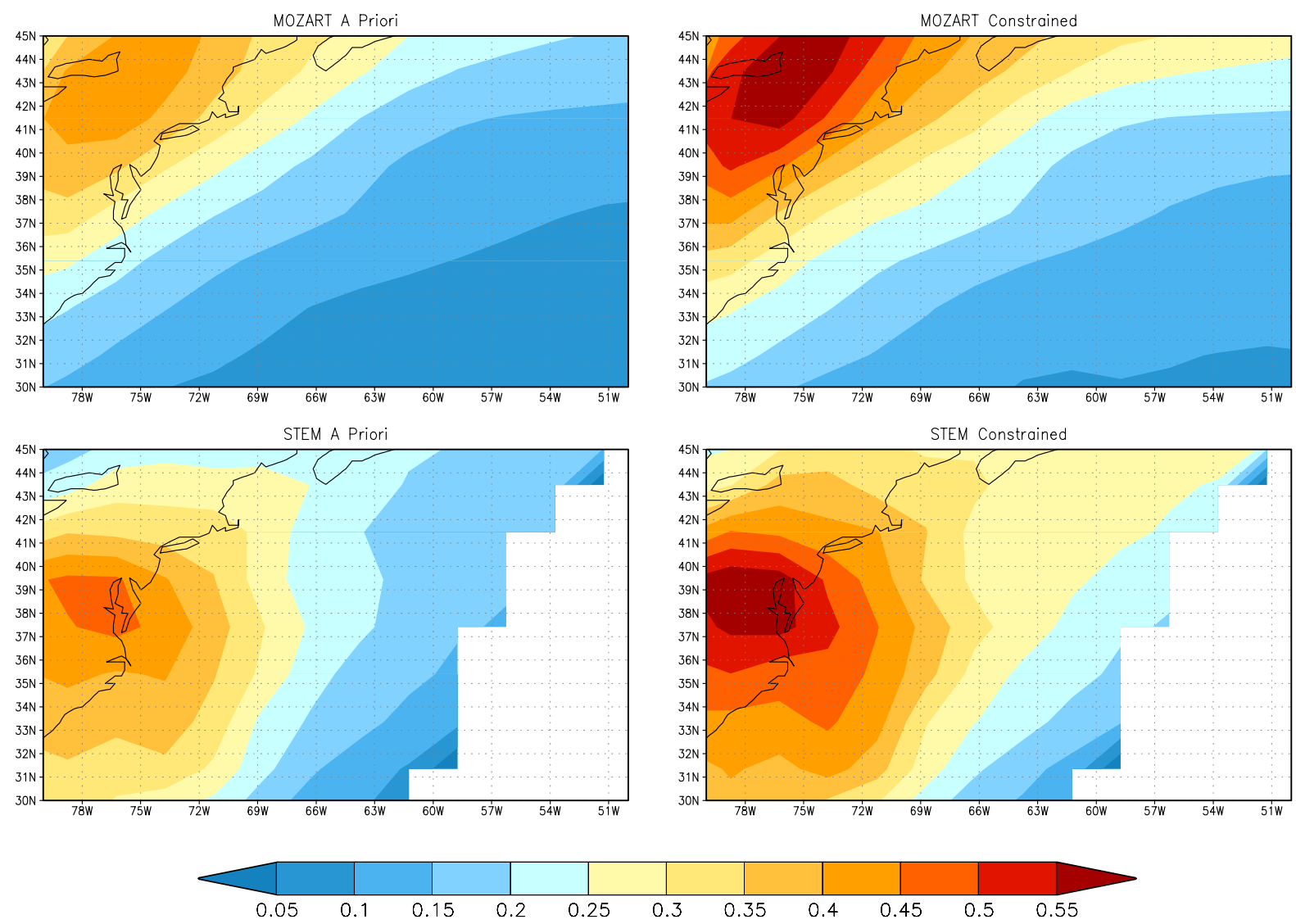

Fig. 21. NWA AOD at $0.55 \mu \mathrm{m}$ with MOZART aerosols (top panel) and STEM aerosols (bottom panel). First column is with the "a priori" aerosol optical properties; second column is with the constrained optical properties. Note that the STEM simulation in NWA does not cover the whole domain.

\subsubsection{Comparison of "a priori" and constrained model runs - NWP and NWA}

The time-mean and standard deviation of the ocean-areaaverage AOD, DRE, radiative efficiency, and DCF for the NWP and NWA domains are given in Tables 24 and 25. Some features of the results in the NIO are common to the NWP and the NWA, although others are not. As in the NIO, in the NWP, the standard deviation of the time series of AOD is generally larger using the STEM CTM than using the MOZART CTM, indicating more time variability in the STEM aerosol fields than in the MOZART aerosol fields. In the NWA, the standard deviation of the time series of AOD is quite small using both CTMs, suggesting little variability in aerosol composition and burden in this region. For both the GFDL and UMich models, the NWP (Fig. 20) and NWA (Fig. 21) domains exhibit a larger constrained AOD than "a priori" AOD. The relative difference varies between 10 and $30 \%$ in the NWA and 30 and 50\% in the NWP for the GFDL model, and varies between 45 and $50 \%$ in the NWA and 30 and $50 \%$ and in the NWP for the UMich model. The magnitude of the relative difference is again in agreement with the relative values of the constrained versus "a priori" mass extinction coefficients presented in Sect. 3.4.6.

In the NWP, the GFDL RTM calculates a larger AOD with STEM aerosols particularly in the northern half of the domain. This is attributed to the much larger dust loading in STEM (Table 17), particularly the loading of dust aerosols with diameters less than $3.6 \mu \mathrm{m}$. Again STEM exhibits much more outflow to the east than MOZART. In the NWA, the GFDL RTM estimates a larger AOD with STEM aerosols particularly off of the eastern coast of the continent. This is mostly attributed to sulfate with some contribution from sea salt, as well as farther off-shore flow in the STEM CTM. Although sulfate burdens in the MOZART and STEM CTMs are similar, MOZART tends to have more sulfate over land, while STEM tends to have more sulfate over the ocean (not shown).

The values of AOD calculated by the UMich RTM are generally smaller than those by the GFDL RTM, especially in the prior runs. The main reason is due to the mass extinction efficiency of the dust, which is smaller in the UMich RTM than in the GFDL RTM (see Fig. 11). A comparison of the values of AOD calculated by the GFDL RTM and by Conant 
Table 23. Time-mean and standard deviation of the ocean area average optical depth, DRE, radiative efficiency $\varepsilon$, and DCF for the NIO with MOZART and STEM aerosols as calculated by the GFDL AM2 RTM and the University of Michigan $($ UMich $)$ RTM. Relative difference = (constrained minus "a priori”)/“a priori”.

\begin{tabular}{|c|c|c|c|c|c|c|c|c|c|c|c|c|c|c|c|c|}
\hline & \multicolumn{2}{|c|}{$\begin{array}{c}\text { Natural } \\
\text { AOD }\end{array}$} & \multicolumn{2}{|c|}{$\begin{array}{l}\text { Total } \\
\text { AOD }\end{array}$} & \multicolumn{2}{|c|}{$\begin{array}{c}\text { Total } \\
\text { DRE SFC } \\
\left(\mathrm{Wm}^{-2}\right)\end{array}$} & \multicolumn{2}{|c|}{$\begin{array}{c}\text { Total } \\
\varepsilon \mathrm{SFC} \\
\left(\mathrm{Wm}^{-2}\right)\end{array}$} & \multicolumn{2}{|c|}{$\begin{array}{c}\text { Total } \\
\text { DCF SFC } \\
\left(\mathrm{Wm}^{-2}\right)\end{array}$} & \multicolumn{2}{|c|}{$\begin{array}{c}\text { Total } \\
\text { DRE TOA } \\
\left(\mathrm{Wm}^{-2}\right)\end{array}$} & \multicolumn{2}{|c|}{$\begin{array}{c}\text { Total } \\
\varepsilon \text { TOA } \\
\left(\mathrm{Wm}^{-2}\right)\end{array}$} & \multicolumn{2}{|c|}{$\begin{array}{c}\text { Total } \\
\text { DCF TOA } \\
\left(\mathrm{Wm}^{-2}\right)\end{array}$} \\
\hline & Value & std & Value & std & Value & std & Value & std & Value & std & Value & std & Value & std & Value & std \\
\hline $\begin{array}{l}\text { MOZART } \\
\text { (GFDL) } \\
\text { "a priori" }\end{array}$ & 0.041 & 0.0085 & 0.13 & 0.020 & -10 & 1.4 & -78 & 4.2 & -6.7 & 1.2 & -4.1 & 0.61 & -35 & 0.68 & -2.4 & 0.58 \\
\hline $\begin{array}{l}\text { MOZART } \\
\text { (GFDL) } \\
\text { constrained }\end{array}$ & 0.049 & 0.0088 & 0.16 & 0.024 & -10 & 1.4 & -62 & 2.3 & -6.8 & 1.1 & -5.5 & 0.77 & -35 & 1.8 & -3.3 & 0.48 \\
\hline $\begin{array}{l}\text { MOZART } \\
\text { relative } \\
\text { difference }\end{array}$ & 0.19 & & 0.27 & & -0.019 & & -0.20 & & 0.032 & & 0.34 & & 0.0054 & & 0.39 & \\
\hline $\begin{array}{l}\text { MOZART } \\
\text { (UMich) } \\
\text { "a priori" }\end{array}$ & 0.032 & 0.006 & 0.11 & 0.017 & -8.2 & 1.3 & -71 & 1.9 & -6.3 & 1.2 & -3.3 & 0.5 & -31 & 0.80 & -1.8 & 0.40 \\
\hline $\begin{array}{l}\text { MOZART } \\
\text { (UMich) } \\
\text { constrained }\end{array}$ & 0.049 & 0.009 & 0.16 & 0.024 & -9.2 & 1.3 & -54 & 1.9 & -6.3 & 1.0 & -4.5 & 0.70 & -27 & 1.1 & -2.6 & 0.40 \\
\hline $\begin{array}{l}\text { MOZART } \\
\text { relative } \\
\text { difference }\end{array}$ & 0.52 & & 0.47 & & 0.13 & & -0.23 & & -0.00 & & 0.35 & & -0.13 & & 0.41 & \\
\hline $\begin{array}{l}\text { STEM } \\
\text { (GFDL) } \\
\text { "a priori", }\end{array}$ & & & 0.20 & 0.044 & -15 & 3.6 & -74 & 3.8 & & & -6.4 & 1.4 & -33 & 0.52 & & \\
\hline $\begin{array}{l}\text { STEM } \\
\text { (GFDL) } \\
\text { constrained }\end{array}$ & & & 0.27 & 0.061 & -17 & 4.1 & -63 & 3.0 & & & -6.9 & 1.5 & -26 & 0.48 & & \\
\hline $\begin{array}{l}\text { STEM } \\
\text { relative } \\
\text { difference }\end{array}$ & & & 0.34 & & 0.12 & & -0.15 & & & & 0.071 & & -0.20 & & & \\
\hline $\begin{array}{l}\text { STEM } \\
\text { (UMich) } \\
\text { "a priori", }\end{array}$ & & & 0.19 & 0.043 & -15 & 3.4 & -77 & 1.4 & & & -6.2 & 1.3 & -34 & 1.4 & & \\
\hline $\begin{array}{l}\text { STEM } \\
\text { (UMich) } \\
\text { constrained }\end{array}$ & & & 0.24 & 0.052 & -15 & 3.4 & -65 & 2.2 & & & -5.7 & 1.1 & -25 & 1.3 & & \\
\hline $\begin{array}{l}\text { STEM } \\
\text { relative } \\
\text { difference }\end{array}$ & & & 0.24 & & 0.04 & & -0.16 & & & & -0.07 & & 0.25 & & & \\
\hline
\end{tabular}

et al. (2003, Fig. 8a) reveals a difference of a factor of 2 to 3 even though both approaches use the same STEM aerosol loadings. This difference is mainly due to the optical properties of dust. The mass scattering/extinction efficiency for supermicrometer dust used by Conant et al. (2003) is similar to the "a priori" and constrained efficiency used in the GFDL RTM (Fig. 11) but the submicrometer mass scattering/extinction efficiency used by Conant et al. (2003) lies between the "a priori" and constrained efficiency used by the GFDL RTM. For a low super- to submicrometer dust ratio $(\sim 2)$, this difference in submicrometer dust scattering efficiency can make a factor of two difference in the calculated optical depth. If half of the submicrometer dust mass is transferred to the supermicrometer dust in the GFDL RTM, the total dust AOD decreases from 0.30 to 0.18 . This sensitivity of the calculated optical depth to relative amounts of super and submicrometer dust is substantial given the large uncertainty associated with CTM simulations of dust concentrations as a function of size. Another source of uncertainty in dust optical properties is associated with the choice of single scattering albedo. Both Conant et al. (2003) and the UMich "a priori" RTM assume a less absorbing dust than the "a priori" dust used in the GFDL RTM which results in a relatively higher mass scattering efficiency. In addition, the mass scattering efficiencies of sulfate and black carbon in the GFDL AM2 and UMich RTM are much higher than those used by Conant et al. (2003). 
Table 24. Time-mean and standard deviation of the ocean area average optical depth, DRE, radiative efficiency $\varepsilon$, and DCF for the NWP with MOZART and STEM aerosols as calculated by the GFDL AM2 RTM and the University of Michigan (UMich) RTM. Relative difference = (constrained minus "a priori”)/“a priori”.

\begin{tabular}{|c|c|c|c|c|c|c|c|c|c|c|c|c|c|c|c|c|}
\hline & \multicolumn{2}{|c|}{$\begin{array}{c}\text { Natural } \\
\text { AOD }\end{array}$} & \multicolumn{2}{|c|}{$\begin{array}{l}\text { Total } \\
\text { AOD }\end{array}$} & \multicolumn{2}{|c|}{$\begin{array}{c}\text { Total } \\
\text { DRE SFC } \\
\left(\mathrm{Wm}^{-2}\right)\end{array}$} & \multicolumn{2}{|c|}{$\begin{array}{c}\text { Total } \\
\varepsilon \mathrm{SFC} \\
\left(\mathrm{Wm}^{-2}\right)\end{array}$} & \multicolumn{2}{|c|}{$\begin{array}{c}\text { Total } \\
\text { DCF SFC } \\
\left(\mathrm{Wm}^{-2}\right)\end{array}$} & \multicolumn{2}{|c|}{$\begin{array}{c}\text { Total } \\
\text { DRE TOA } \\
\left(\mathrm{Wm}^{-2}\right)\end{array}$} & \multicolumn{2}{|c|}{$\begin{array}{c}\text { Total } \\
\varepsilon \text { TOA } \\
\left(\mathrm{Wm}^{-2}\right)\end{array}$} & \multicolumn{2}{|c|}{$\begin{array}{c}\text { Total } \\
\text { DCF TOA } \\
\left(\mathrm{Wm}^{-2}\right)\end{array}$} \\
\hline & Value & std & Value & std & Value & std & Value & std & Value & std & Value & std & Value & std & Value & std \\
\hline $\begin{array}{l}\text { MOZART } \\
\text { (GFDL) } \\
\text { "a priori" }\end{array}$ & 0.076 & 0.011 & 0.43 & 0.084 & -24 & 3.3 & -63 & 4.5 & -18 & 2.7 & -13 & 2.0 & -33 & 1.4 & -9.9 & 1.9 \\
\hline $\begin{array}{l}\text { MOZART } \\
\text { (GFDL) } \\
\text { constrained }\end{array}$ & 0.088 & 0.0091 & 0.60 & 0.13 & -28 & 4.1 & -54 & 3.9 & -23 & 3.8 & -18 & 2.7 & -34 & 2.1 & -14 & 2.6 \\
\hline $\begin{array}{l}\text { MOZART } \\
\text { relative } \\
\text { difference }\end{array}$ & 0.17 & & 0.40 & & 0.18 & & -0.14 & & 0.29 & & 0.40 & & 0.042 & & 0.43 & \\
\hline $\begin{array}{l}\text { MOZART } \\
\text { (UMich) } \\
\text { A priori }\end{array}$ & 0.07 & 0.012 & 0.44 & 0.14 & -22 & 4.2 & -61 & 5.5 & -18 & 4.0 & -12 & 2.9 & -32 & 1.8 & -8.9 & 2.7 \\
\hline $\begin{array}{l}\text { MOZART } \\
\text { (UMich) } \\
\text { constrained }\end{array}$ & 0.09 & 0.011 & 0.66 & 0.20 & -27 & 5.0 & -50 & 4.4 & -22 & 4.6 & -17 & 3.2 & -30 & 2.1 & 12 & 3.0 \\
\hline $\begin{array}{l}\text { MOZART } \\
\text { relative } \\
\text { difference }\end{array}$ & 0.33 & & 0.5 & & 0.23 & & -0.19 & & 0.19 & & 0.36 & & -0.07 & & 0.40 & \\
\hline $\begin{array}{l}\text { STEM } \\
\text { (GFDL) } \\
\text { "a priori" }\end{array}$ & & & 0.66 & 0.25 & -40 & 14 & -66 & 4.0 & & & -18 & 5.4 & -31 & 1.9 & & \\
\hline $\begin{array}{l}\text { STEM } \\
\text { (GFDL) } \\
\text { constrained }\end{array}$ & & & 0.98 & 0.42 & -48 & 18 & -56 & 3.6 & & & -25 & 7.8 & -30 & 2.1 & & \\
\hline $\begin{array}{l}\text { STEM } \\
\text { relative } \\
\text { difference }\end{array}$ & & & 0.46 & & 0.21 & & -0.15 & & & & 0.36 & & -0.029 & & & \\
\hline $\begin{array}{l}\text { STEM } \\
\text { (UMich) } \\
\text { "a priori", }\end{array}$ & & & 0.58 & 0.20 & -33 & 8.4 & -63 & 4.1 & & & -19 & 6.5 & -33 & 2.3 & & \\
\hline $\begin{array}{l}\text { STEM } \\
\text { (UMich) } \\
\text { constrained }\end{array}$ & & & 0.91 & 0.36 & -44 & 14 & -53 & 2.9 & & & -23 & 7.0 & -29 & 1.7 & & \\
\hline $\begin{array}{l}\text { STEM } \\
\text { relative } \\
\text { difference }\end{array}$ & & & 0.57 & & 0.32 & & -0.16 & & & & 0.22 & & -0.14 & & & \\
\hline
\end{tabular}

As in the NIO, in the NWP, the DRE using the STEM CTM is greater than the DRE using the MOZART CTM, while in the NWA, the DRE using the STEM CTM is within the standard deviation of the DRE using the MOZART CTM. In the NWP, the radiative efficiency using the MOZART CTM is similar to that using the STEM CTM. In the NWA, however, the constrained radiative efficiency at the SFC for the NWA is larger using the STEM CTM than using the MOZART CTM, while the constrained and "a priori" radiative efficiency at the TOA is larger using the MOZART CTM. As in the NIO, in both the NWP (Fig. 22) and the NWA (Fig. 23) the GFDL constrained DCF is generally larger than the "a priori" DCF.

\subsubsection{Conclusions from the "a priori" and constrained com- parisons}

The constrained optical properties derived from measurements have a substantial influence on the estimated AOD and other radiative quantities, increasing the AOD (34 $\pm 8 \%)$, TOA DRE $(32 \pm 12 \%)$, and TOA DCF $(37 \pm 7 \%)$ relative to values obtained with "a priori" parameterizations of aerosol loadings and properties (GFDL RTM). However, the above comparison demonstrates that differences in the aerosol burden, as estimated in this study using two CTMs, has a large effect on the magnitude of the radiative quantities. 
Table 25. Time-mean and standard deviation of the ocean area average optical depth, DRE, radiative efficiency $\varepsilon$, and DCF for the NWA with MOZART and STEM aerosols as calculated by the GFDL AM2 RTM and the University of Michigan (UMich) RTM. Relative difference = (constrained minus "a priori”)/“a priori”.

\begin{tabular}{|c|c|c|c|c|c|c|c|c|c|c|c|c|c|c|c|c|}
\hline & \multicolumn{2}{|c|}{$\begin{array}{c}\text { Natural } \\
\text { AOD }\end{array}$} & \multicolumn{2}{|c|}{$\begin{array}{l}\text { Total } \\
\text { AOD }\end{array}$} & \multicolumn{2}{|c|}{$\begin{array}{c}\text { Total } \\
\text { DRE SFC } \\
\left(\mathrm{Wm}^{-2}\right)\end{array}$} & \multicolumn{2}{|c|}{$\begin{array}{c}\text { Total } \\
\varepsilon \mathrm{SFC} \\
\left(\mathrm{Wm}^{-2}\right)\end{array}$} & \multicolumn{2}{|c|}{$\begin{array}{c}\text { Total } \\
\text { DCF SFC } \\
\left(\mathrm{Wm}^{-2}\right)\end{array}$} & \multicolumn{2}{|c|}{$\begin{array}{c}\text { Total } \\
\text { DRE TOA } \\
\left(\mathrm{Wm}^{-2}\right)\end{array}$} & \multicolumn{2}{|c|}{$\begin{array}{c}\text { Total } \\
\varepsilon \text { TOA } \\
\left(\mathrm{Wm}^{-2}\right)\end{array}$} & \multicolumn{2}{|c|}{$\begin{array}{c}\text { Total } \\
\text { DCF TOA } \\
\left(\mathrm{Wm}^{-2}\right)\end{array}$} \\
\hline & Value & std & Value & std & Value & std & Value & std & Value & std & Value & std & Value & std & Value & Std \\
\hline $\begin{array}{l}\text { MOZART } \\
\text { (GFDL) } \\
\text { "a priori" }\end{array}$ & 0.037 & 0.0044 & 0.16 & 0.046 & -10 & 2.5 & -65 & 4.7 & -6.8 & 2.4 & -6.8 & 1.8 & -43 & 2.0 & -5.0 & 1.8 \\
\hline $\begin{array}{l}\text { MOZART } \\
\text { (GFDL) } \\
\text { constrained }\end{array}$ & 0.055 & 0.0072 & 0.22 & 0.059 & -11 & 2.6 & -53 & 3.4 & -7.2 & 2.4 & -9.3 & 2.2 & -46 & 2.7 & -6.4 & 2.1 \\
\hline $\begin{array}{l}\text { MOZART } \\
\text { relative } \\
\text { difference }\end{array}$ & 0.48 & & 0.32 & & 0.068 & & -0.19 & & 0.059 & & 0.38 & & 0.055 & & 0.29 & \\
\hline $\begin{array}{l}\text { MOZART } \\
\text { (UMich) } \\
\text { "a priori" }\end{array}$ & 0.037 & 0.007 & 0.14 & 0.04 & -8.8 & 2.7 & -63 & 3.1 & -6.3 & 2.4 & -5.6 & 1.5 & -42 & 2.1 & -3.7 & 1.4 \\
\hline $\begin{array}{l}\text { MOZART } \\
\text { (UMich) } \\
\text { constrained }\end{array}$ & 0.055 & 0.008 & 0.20 & 0.06 & -9.6 & 2.6 & -49 & 3.1 & -6.2 & 2.3 & -7.7 & 2.0 & -39 & 2.1 & -5.0 & 1.8 \\
\hline $\begin{array}{l}\text { MOZART } \\
\text { relative } \\
\text { difference }\end{array}$ & 0.49 & & 0.45 & & 0.106 & & -0.22 & & -0.01 & & 0.36 & & -0.06 & & 0.35 & \\
\hline $\begin{array}{l}\text { STEM } \\
\text { (GFDL) } \\
\text { "a priori", }\end{array}$ & & & 0.24 & 0.076 & -12 & 3.0 & -54 & 4.8 & & & -9.7 & 2.7 & -41 & 1.6 & & \\
\hline $\begin{array}{l}\text { STEM } \\
\text { (GFDL) } \\
\text { constrained }\end{array}$ & & & 0.30 & 0.093 & -15 & 3.9 & -54 & 18 & & & -13 & 3.2 & -44 & 2.1 & & \\
\hline $\begin{array}{l}\text { STEM } \\
\text { relative } \\
\text { difference }\end{array}$ & & & 0.27 & & 0.23 & & -0.0047 & & & & 0.34 & & 0.066 & & & \\
\hline $\begin{array}{l}\text { STEM } \\
\text { (UMich) } \\
\text { "a priori", }\end{array}$ & & & 0.24 & 0.08 & -13 & 3.3 & -56 & 4.2 & & & -9.7 & 2.9 & -41 & 1.3 & & \\
\hline $\begin{array}{l}\text { STEM } \\
\text { (UMich) } \\
\text { constrained }\end{array}$ & & & 0.31 & 0.10 & -14 & 4.0 & -48 & 1.9 & & & -12 & 3.3 & -40 & 1.3 & & \\
\hline $\begin{array}{l}\text { STEM } \\
\text { relative } \\
\text { difference }\end{array}$ & & & 0.29 & & 0.14 & & -0.13 & & & & 0.22 & & -0.02 & & & \\
\hline
\end{tabular}

5.4 Comparison of AOD and DRE from model and measurements

Model evaluation by comparison of measured and modeled mass concentrations of aerosol constituents is restricted primarily to the surface, where the vast majority of measurements are made. In contrast, model evaluation by comparison of measured and modeled aerosol optical depth involve the entire atmospheric column and benefit greatly from the availability of data from the global network of intercalibrated monitoring stations operated under the AERONET program (Holben et al., 2001). The latter comparisons, however, do not distinguish individual aerosol species and thus do not immediately pertain to the issue of anthropogenic forcing and, as well, are subject to the large uncertainties in modeled loadings of dust and sea salt, for which the source terms are particularly uncertain. In evaluating models by comparison with measurements, discrepancies beyond measurement uncertainty indicate model error, which could be in the component mass burdens and/or the assigned optical properties (primarily, mass extinction efficiency as a function of $R H$ for each component). To help distinguish these causes, two CTMs (STEM and MOZART) and two sets of optical properties ("a priori" and constrained) were used to calculate AOD and DRE using the GFDL RTM as described above. For each campaign, three AERONET stations were identified for AOD comparison, all located either on islands or at coastal locations consistent with the focus in this paper on 
Table 26. Comparison of measured and modeled aerosol optical depth at $550 \mathrm{~nm}\left(\tau_{550}\right)$ using the GFDL RTM. The comparison is based on diurnal-mean data at nine AERONET stations (three from each campaign, all located on either islands or coasts) and for the model grid cells containing those stations. Results from each campaign have been aggregated. Four model types are compared in terms of (a) correlation, (b) root-mean-square error, and (c) campaign-mean. Further details on the analysis method and test results are given in the text, Sect. 5.4, and Fig. 24.

\begin{tabular}{|c|c|c|c|c|}
\hline & $\begin{array}{l}\text { STEM } \\
\text { a priori }\end{array}$ & $\begin{array}{l}\text { STEM } \\
\text { constr. }\end{array}$ & $\begin{array}{l}\text { MOZART } \\
\text { a priori }\end{array}$ & $\begin{array}{l}\text { MOZART } \\
\text { constr. }\end{array}$ \\
\hline \multicolumn{5}{|c|}{ a. Model vs. AERONET correlation coefficient, $r$, for diurnal-mean $\tau_{550}$} \\
\hline NIO & 0.45 & 0.42 & 0.53 & 0.53 \\
\hline NWP & 0.25 & 0.23 & 0.49 & 0.46 \\
\hline NWA & 0.47 & 0.41 & 0.21 & 0.19 \\
\hline \multicolumn{5}{|c|}{ b. Normalized, root-mean-square model error for diurnal-mean $\tau_{550}$} \\
\hline $\mathrm{NIO}$ & $49 \%$ & $38 \%$ & $66 \%$ & $58 \%$ \\
\hline NWP & $190 \%$ & $330 \%$ & $56 \%$ & $69 \%$ \\
\hline NWA & $64 \%$ & $76 \%$ & $65 \%$ & $66 \%$ \\
\hline \multicolumn{5}{|c|}{ c. Normalized model error for regional mean $\tau_{550}$} \\
\hline $\mathrm{NIO}$ & $-37 \%$ & $-14 \%$ & $-58 \%$ & $-48 \%$ \\
\hline NWP & $110 \%$ & $200 \%$ & $-7 \%$ & $23 \%$ \\
\hline NWA & $12 \%$ & $30 \%$ & $-14 \%$ & $2 \%$ \\
\hline
\end{tabular}
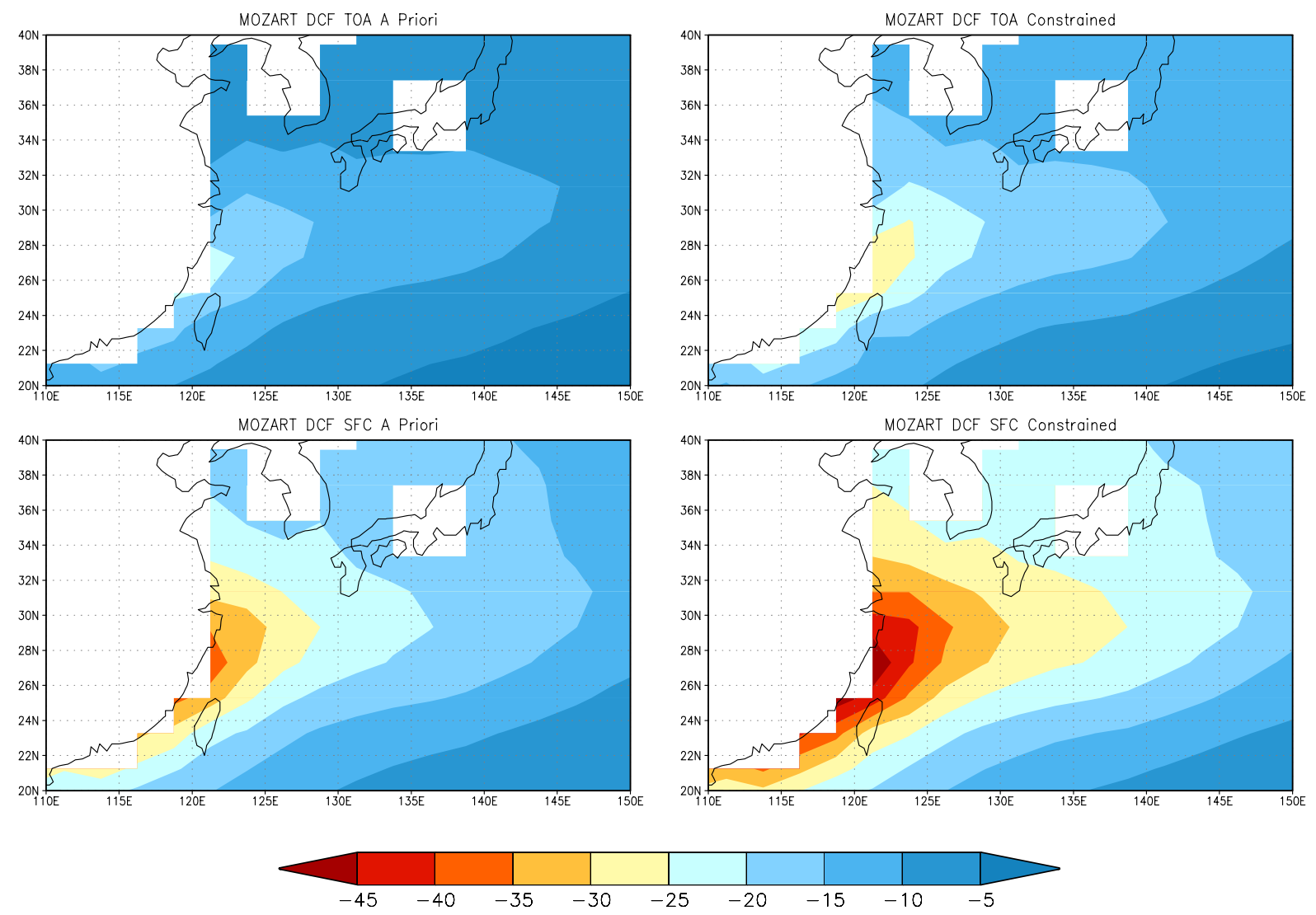

Fig. 22. NWP DCF at the top-of-atmosphere (top panel) and surface (bottom panel). First column is with the "a priori" aerosol optical properties; second column is with the constrained optical properties. 

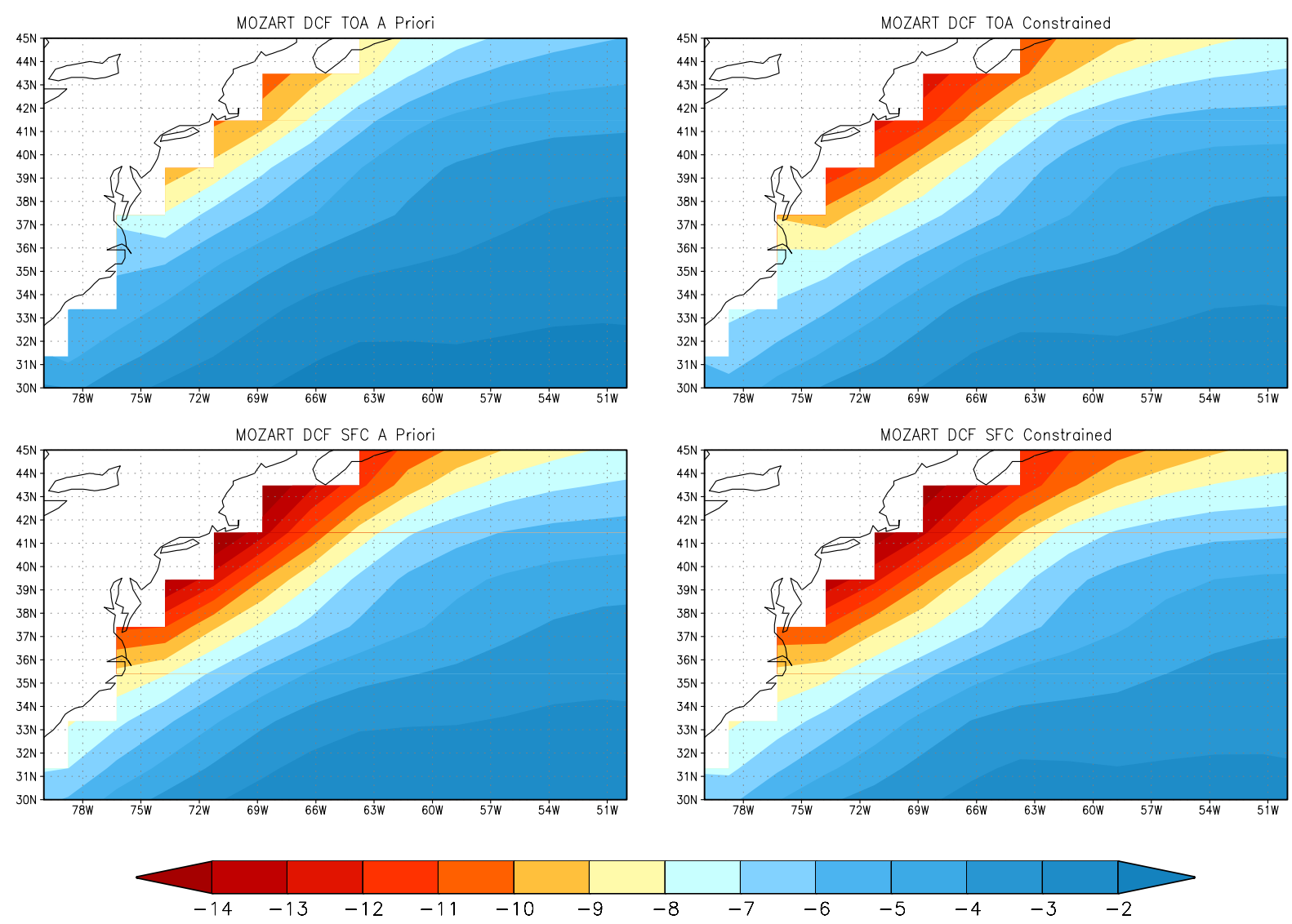

Fig. 23. NWA DCF at the top-of-atmosphere (top panel) and surface (bottom panel). First column is with the "a priori" aerosol optical properties; second column is with the constrained optical properties.

aerosol properties over the ocean. DRE comparisons come from ground sites, ship and aircraft measurements.

\subsubsection{AOD comparison details}

Diurnal-mean (00:00-24:00 UTC) optical depths at $550 \mathrm{~nm}$ $\left(\tau_{550}\right)$ were calculated as described below. Model data encompass the entire 24-h period, whereas AERONET level2 (quality assured) sun photometer data exist only for daylight and cloud-free times. AERONET cloud-screening procedures are described by Smirnov et al. (2000). Because the intent of the present study is to examine aerosol DRE and DCF in cloud-free conditions, in modeling aerosol optical depth the aerosol is allowed to hydrate only up to a maximum $R H$ of $95 \%$. (When ambient $R H$ in the model exceeds $95 \%$, hydration is set to the $95 \% R H$ value.) Model data for the comparison are extracted from the single grid box in which the AERONET station is located. As $550 \mathrm{~nm}$, the wavelength for which aerosol optical depth is modeled, is not a wavelength at which optical depth is measured, $\tau_{550}$ was calculated from the measurements by performing a regression of $\log (\tau)$ upon $\log$ (wavelength), using values of $\tau$ (at least three and usually four) reported from $440 \mathrm{~nm}$ to $870 \mathrm{~nm}$. Optical depths at each wavelength were diurnally averaged prior to performing this regression. Comparison plots and statistics consider only those days for which calculated AOD's from both models (STEM and MOZART) and measurements from AERONET were available.

\subsubsection{AOD results}

Campaign-mean values and standard deviations of $\tau_{550}$ at each of the nine stations are shown in Fig. 24. Separate bars are shown for each of the four model runs (STEM and MOZART, constrained and "a priori" properties) and for the AERONET measurements. The bar height represents the mean of the daily averages and the thin line segment extending upward from each bar indicates one standard deviation above the mean. Also indicated on the figure is the number of days used at each station in calculating the means. The data are summarized from three perspectives in Table 26. Parts $\mathrm{a}$ and $\mathrm{b}$ examine the ability of the models to reproduce the day-to-day variability seen in the AERONET measurements. Part a presents the correlation coefficient, $r$, evaluated using all daily comparisons for all the sites in each of the domains. Part $b$ presents the root-mean-square difference between 


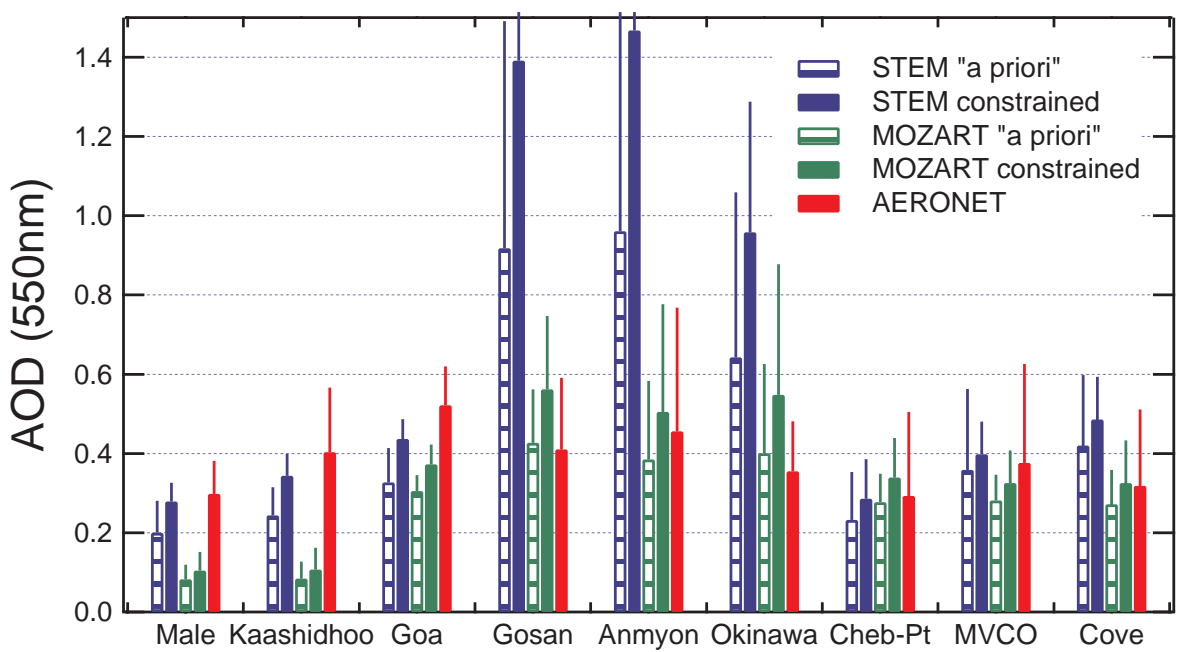

Fig. 24. Test of model ability to reproduce measured aerosol optical depth at $550 \mathrm{~nm}\left(\tau_{550}\right)$. The test is based on diurnal-mean data at nine AERONET stations (three from each region, all located on either islands or coasts) and for the model grid cells containing those stations. NIO stations include: Male $\left(4.2^{\circ} \mathrm{N}, 73.5^{\circ} \mathrm{E}, 2 \mathrm{~m}\right.$ elevation), Kaashidoo $\left(5.0^{\circ} \mathrm{N}, 73.5^{\circ} \mathrm{E}, 0 \mathrm{~m}\right)$, and Goa, India $\left(15.5^{\circ} \mathrm{N}, 73.8^{\circ} \mathrm{E}, 20 \mathrm{~m}\right) . \mathrm{NWP}^{\circ}$ stations include: Gosan $\left(33.3^{\circ} \mathrm{N}, 126.2^{\circ} \mathrm{E}, 0 \mathrm{~m}\right)$, Anmyon $\left(36.3^{\circ} \mathrm{N}, 126.2^{\circ} \mathrm{E}, 47 \mathrm{~m}\right)$, and Okinawa $\left(26.4^{\circ} \mathrm{N}, 127.8^{\circ} \mathrm{E}, 46 \mathrm{~m}\right) . \mathrm{NWA}^{\circ}$ stations include: Chebogue Pt. $\left(43.7^{\circ} \mathrm{N}, 66.1^{\circ} \mathrm{W}, 0 \mathrm{~m}\right)$, Martha's Vineyard Coastal Observatory $\left(41.3^{\circ} \mathrm{N}, 70.6^{\circ} \mathrm{W}, 10 \mathrm{~m}\right)$, and Cove Lighthouse $\left(36.9^{\circ} \mathrm{N}, 75.7^{\circ} \mathrm{W}, 37 \mathrm{~m}\right)$. Bar height denotes campaign-wide means and whisker standard deviations at each station for the four types of model and for the AERONET measurements. The number of days with STEM and MOZART data at each station $\mathrm{N}$ is indicated below the station name. Further details on the analysis method and test results are given in the text, Sect. 5.4, and Table 26. Note that sea salt hygroscopic growth was held at $80 \% \mathrm{RH}$ in the model runs.

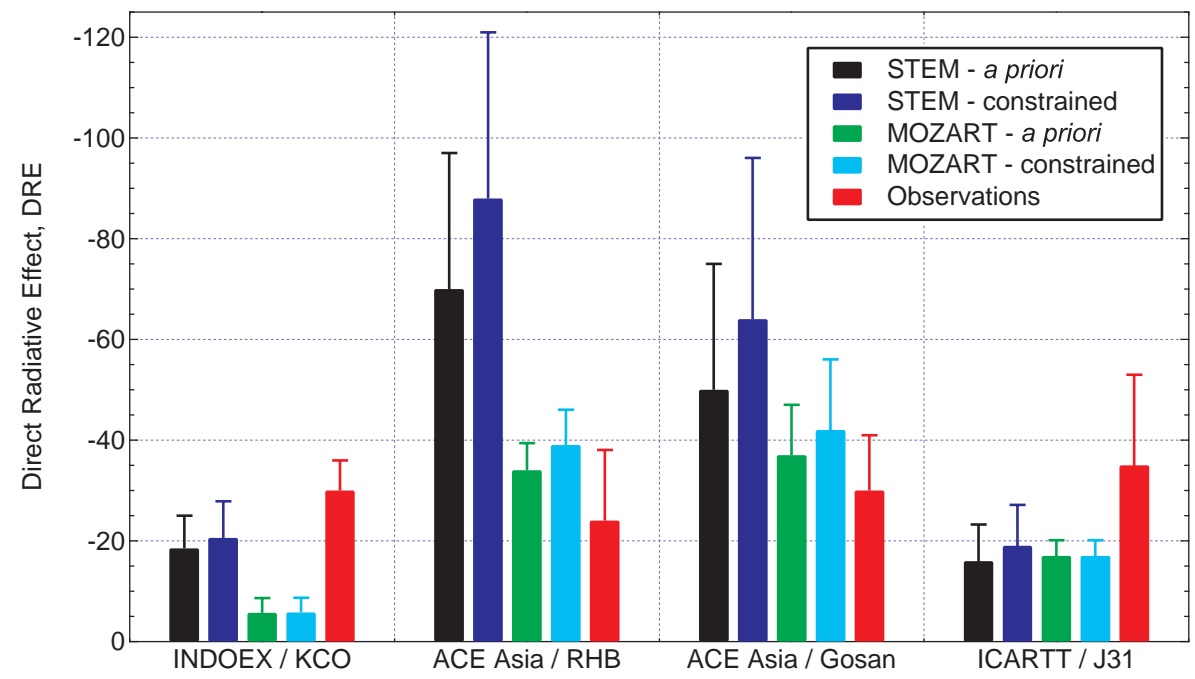

Fig. 25. Comparison of surface DRE measured during field campaigns and that calculated using the STEM and MOZART aerosol distributions. Model results are from the grid box(s) of the measurements for the Kaashidhoo (KCO) ground station during INDOEX, the RV Ronald H. Brown and Gosan ground station during ACE-Asia and the J31 aircraft during ICARTT (see Table 27 for time periods and references). Note that sea salt hygroscopic growth was held at $80 \% \mathrm{RH}$ in the model runs.

measured and modeled AOD, normalized by the AERONET campaign-mean, $\left[\sum\left(\tau_{\text {model }}-\tau_{\text {AERONET }}\right)^{2} / n\right]^{1 / 2} / \overline{\tau_{\text {AERONET }}}$, where the overscore denotes averages over time and measurement sites in each of the domains. Part c presents the campaign-mean relative model error in $\tau_{550}$, calculated as $\left(\overline{\tau_{\text {model }}}-\overline{\tau_{\text {AERONET }}}\right) / \overline{\tau_{\text {AERONET }}}$.

\subsubsection{DRE comparison details}

Diurnal-mean (00:00-24:00 UTC), clear sky, total solar surface DRE have been reported for INDOEX at KCO, ACE 
Table 27. (a) Normalized GFDL model error for regional mean DRE in percent ((DRE model $\left.\left._{-}-D_{\text {meas }}\right) / D R E_{\text {meas }}\right)$ and (b) normalized "a priori"/constrained difference for regional mean DRE in percent ((DRE $\left.\left.\mathrm{APriori}-\mathrm{DRE}_{\mathrm{cons}}\right) / \mathrm{DRE}_{\mathrm{const}}\right)$.

\begin{tabular}{|c|c|c|c|c|}
\hline \multicolumn{5}{|c|}{ a. Normalized model error for regional mean DRE (\%) } \\
\hline Intensive/Platform & STEM & STEM & MOZART & MOZART \\
\hline & "A Priori"a & Constrained $^{\mathrm{a}}$ & "A Priori" & Constrained \\
\hline INDOEX/KCO ${ }^{\mathrm{b}, \mathrm{c}}$ & -38 & -31 & -81 & -81 \\
\hline ACE Asia/RHB ${ }^{d}$ & 190 & 260 & 41 & 60 \\
\hline ACE Asia/Gosan ${ }^{\mathrm{e}}$ & 68 & 110 & 23 & 40 \\
\hline ICARTT/J31 ${ }^{\mathrm{f}}$ & -55 & -48 & -51 & -51 \\
\hline \multicolumn{5}{|c|}{ b. Normalized "A Priori" - Constrained Difference for regional mean DRE (\%) } \\
\hline Intensive/Platform & STEM & & MOZART & \\
\hline INDOEX/KCO ${ }^{\mathrm{b}, \mathrm{c}}$ & -10 & & -1.8 & \\
\hline ACE Asia/RHB ${ }^{d}$ & -20 & & -12 & \\
\hline ACE Asia/Gosan ${ }^{\mathrm{e}}$ & -20 & & -12 & \\
\hline ICARTT/J31 ${ }^{\mathrm{f}}$ & -13 & & -0.58 & \\
\hline
\end{tabular}

a Wavelength range 0.175 to $4.0 \mu \mathrm{m}$

b Sateesh and Ramanathan (2000), 0.2 to $4 \mu \mathrm{m}$, January to March 1999.

c Bush and Valero (2002), 0.3 to $3.81 \mu \mathrm{m}, 12$ February to 28 March 1999.

d Markowicz et al. (2003), 0.28-2.8 $\mu \mathrm{m}, 7$ April to 15 April 2001.

e Bush and Valero (2003), 0.3 to $3.81 \mu \mathrm{m}, 25$ March to 4 May 2001.

f J. Redemann, personal communication, 2005, 0.35 to $1.7 \mu \mathrm{m}, 21$ July to 3 August 2004.

Asia on RHB and at Gosan, and ICARTT on the J31 aircraft. Mean values were calculated over the measurement period at each platform and compared to regional mean values calculated for the same time periods using the GFDL RTM with STEM and MOZART input. The wavelength range of the measurements varied but were all within 0.2 to $4 \mu \mathrm{m}$ (see Table 27) while the modeled wavelengths spanned 0.175 to $4.0 \mu \mathrm{m}$. The mean values based on the measurements are for a fixed ground site or a moving platform while the modeled values are based on the mean for the entire region.

\subsubsection{DRE results}

Figure 25 shows a comparison of the measured and modeled values. As with the AOD comparison, separate bars are shown for each of the four model runs (STEM and MOZART, constrained and a priori properties) and for the measurements. The normalized model error for regional mean DRE ((DRE $\left.\left.E_{\text {model }}-\mathrm{DRE}_{\text {meas }}\right) / \mathrm{DRE}_{\text {meas }}\right)$ is shown in Table 27 and compared to the normalized difference that results from the use of a priori versus constrained optical properties $\left(\left(\mathrm{DRE}_{\mathrm{A} \text { priori }}-\mathrm{DRE} \mathrm{E}_{\text {const }}\right) / \mathrm{DRE}_{\text {const }}\right)$. For INDOEX and ACE Asia, the model error in DRE is similar to that in AOD with underprediction of DRE during INDOEX by MOZART and overprediction during ACE Asia by STEM. Both STEM and MOZART underpredict the values measured onboard the J31 aircraft during ICARTT. This difference is most likely a result of the model values reflecting the regional mean while the aircraft was targeting pollution plumes. For all experi- ments, the regional mean model error is greater than the difference imposed by using the a priori versus constrained optical properties.

\subsubsection{Implications}

In general, the skill of the models in capturing the day-to-day variations in the AERONET measurements is quite poor (Table $26 a, b)$. The models capture only $1-28 \%$ of the day-today variations in $\tau_{550}$ (squaring the numbers in Table 26a); typical daily-mean errors are $40-70 \%$ (Table 26b). On the other hand, with two exceptions, the models are reasonably successful at capturing the campaign-mean values and standard deviations of AOD (Fig. 24 and Table 26c). The exceptions are substantial underprediction during INDOEX (stations Male, Kaashidhoo, and Goa, India) by MOZART and substantial overprediction during ACE-Asia (stations Gosan, Anmyon, and Okinawa) by STEM. Collins et al. (2001) and Reddy et al. (2004) also underestimated the AOD over the Indian Ocean, which Reddy et al. (2004) related to an underestimation of sources, associated with poorly constrained ECMWF winds in the region. Collins et al. (2001) were able to improve their estimated AOD using satellite assimilation. Part of the reason for the collective difficulty in modeling the AOD during INDOEX in comparison to ground based measurements and why Collins et al. (2001) benefited from satellite assimilation may be the existence of separate upper level aerosol plumes (independent of the surface plumes from coastal India), which according to aircraft data carried 
Table 28. Global and annual average direct TOA forcing by aerosol species and associated multiplicative uncertainties as estimated by IPCC TAR (Ramaswamy et al., 2001). "Low limit" denotes the most negative (or least positive) limit to the range of the forcing estimate and "High limit" denotes least negative (or most positive) limit. "Low difference" $\left(\Delta^{-}\right)$and "High difference" $\left(\Delta^{+}\right)$denote the difference between the estimated forcing and the low or high limit, respectively; "Normalized low difference" $\left(\delta^{-}\right)$and "Normalized high difference" $\left(\delta^{+}\right)$denote the corresponding normalized differences. The total forcing (not given by IPCC) was evaluated as the algebraic sum of the forcings of the several species; the associated uncertainties were calculated according to Eq. (A5). The normalized low difference in the total forcing greater than unity indicates that the uncertainty limit encompasses a value that is opposite in sign to the best estimate of the forcing.

\begin{tabular}{lcccccccc}
\hline $\begin{array}{l}\text { Aerosol } \\
\text { species }\end{array}$ & $\begin{array}{c}\text { Forcing } \\
\mathrm{Wm}^{-2}\end{array}$ & $\begin{array}{c}\text { Multiplicative } \\
\text { Uncertainty }\end{array}$ & $\begin{array}{c}\text { Low } \\
\text { limit } \\
\mathrm{Wm}^{-2}\end{array}$ & $\begin{array}{c}\text { High } \\
\text { Limit } \\
\mathrm{Wm}^{-2}\end{array}$ & $\begin{array}{c}\text { Low } \\
\text { Difference } \\
\mathrm{Wm}^{-2}\end{array}$ & $\begin{array}{c}\text { High } \\
\text { Difference } \\
\mathrm{Wm}^{-2}\end{array}$ & $\begin{array}{c}\text { Normalized } \\
\text { Low } \\
\text { Difference }\end{array}$ & $\begin{array}{c}\text { Normalized } \\
\text { High } \\
\text { Difference }\end{array}$ \\
\hline Sulfate & -0.40 & 2 & -0.80 & -0.20 & 0.40 & 0.20 & 0.50 & 1 \\
Biomass BC & 0.20 & 3 & 0.067 & 0.60 & 0.13 & 0.40 & 0.65 & 2 \\
Biomass OC & -0.40 & 3 & -1.2 & -0.13 & 0.80 & 0.27 & 0.68 & 2 \\
Fossil BC & 0.20 & 2 & 0.10 & 0.40 & 0.10 & 0.20 & 0.50 & 1 \\
Fossil OC & -0.06 & 3 & -0.18 & -0.020 & 0.12 & 0.04 & 0.67 & 2 \\
Total & -0.46 & - & -1.38 & 0.10 & 0.92 & 0.56 & 1.22 & 2 \\
\hline
\end{tabular}

about half of the total AOD. Model resolution is also a factor, as STEM, which was run at higher spatial resolution, was able to transport significantly more aerosol mass to Male and Kaashidoo. In the case of the overestimation of AOD by STEM for Ace-Asia, this appears to be due largely to the submicrometer dust fraction. As discussed in Sect. 4.5, STEM appears to overestimate the amount of dust in the submicrometer fraction in the high dust conditions of the NWP.

The fact that the models do rather well in reproducing the aerosol optical depth as averaged over time and over the several stations suggests the utility of the model calculations in estimating aerosol DRE and DCF over such large domains, despite the poor correlation in the day-to-day measurements. Another general result of this comparison is that the choice of aerosol optical properties ("a priori" vs. constrained) is of second-order importance compared to the choice of chemical transport model, which controls the mass burden of the various aerosol components. It would appear, therefore, that the factor-of-two or more discrepancies identified in INDOEX/MOZART and ACE-Asia/STEM cannot be explained by uncertainties in optical properties but, instead, must be attributed to errors in modeled aerosol mass burden. There is no clear indication from this test that the constrained optical properties represent an improvement over the "a priori" optical properties. However, this absence of evidence is not surprising given the evident errors in aerosol mass burden and the secondary importance of optical properties in determining aerosol optical depth.

5.5 Comparison of derived values and uncertainties with previous IPCC estimates

Aerosol DCF calculated here might usefully be compared to the global mean estimates of such forcing presented by IPCC (Ramaswamy et al., 2001). However such comparison is sub- ject to the caveat that the previous estimates were for global average total-sky direct radiative forcing, whereas the present estimates are clear-sky direct radiative forcing for specific oceanic domains and during specific periods that are unlikely to be representative of the global mean. Nonetheless it may be useful to compare the estimates of both the forcings and, even more useful to compare the associated uncertainties.

IPCC TAR (Ramaswamy et al., 2001) reported the direct global and annual average TOA forcings for several aerosol substances, e.g., for sulfate $-0.4 \mathrm{Wm}^{-2}$, together with the associated multiplicative uncertainties, which for sulfate was given as $* 2$, where the notation $Q * u$ denotes $Q$ times or divided by $u$; the range of uncertainty in forcing corresponding to this multiplicative uncertainty is -0.2 to $-0.8 \mathrm{Wm}^{-2}$. Here, as is conventional, a negative forcing denotes a cooling influence. The estimates presented by IPCC TAR are summarized in Table 28; IPCC also presented a range for direct forcing by mineral dust, not shown here, but did not present an estimate of the forcing itself. IPCC TAR did not sum the several aerosol forcings, nor did it propagate the associated uncertainties. Here total direct aerosol forcing is obtained by algebraically adding the positive and negative forcings of the individual species. The uncertainty associated with the total forcing is obtained according to Eq. (A5) in the Appendix, as was done also by Schwartz (2004). Also presented in the table are the high and low limits of the uncertainty ranges associated with the several forcings, the differences between these large and low limits and the corresponding best estimates, and these differences normalized to the best estimates. The normalized uncertainties (high and low limits of range divided by the forcing) associated with the several forcings are shown in Fig. 26. An alternative means of evaluating the uncertainty associated with the total forcing has been given by Boucher and Haywood (2001) on the basis of Monte Carlo calculations for assumed probability distribution functions 


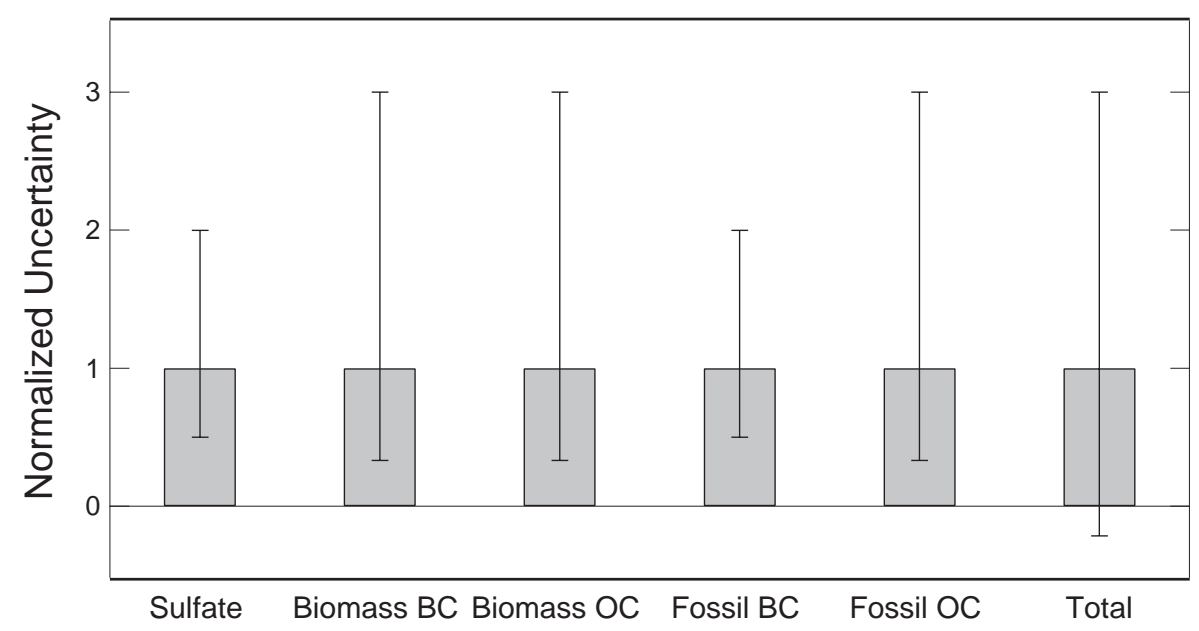

Fig. 26. Normalized uncertainties (uncertainty range of the indicated quantity divided by the value of the quantity) associated with the global and annual mean direct TOA forcing by the several aerosol species for which such forcings were estimated by IPCC TAR (Ramaswamy et al., 2001). Also shown is the range of normalized uncertainty for the total direct aerosol forcing calculated according to Eq. (A5) and presented in Table 28, normalized by the total direct aerosol forcing; negative value indicates that the uncertainty range of this forcing (for which the best estimate is negative) encompasses values of opposite sign (i.e., positive).

for the several forcings. Because the total forcing is a sum of positive and negative forcings by the several aerosol species, the uncertainty range associated with the best estimate of the total aerosol direct forcing (which is negative) is quite large relative to the estimated total forcing, encompassing positive as well as negative values.

A similar uncertainty analysis was carried out here for each of the three domains examined. For each domain the normalized uncertainties in the time- and space-average total aerosol burden and anthropogenic aerosol burden were calculated from the estimated multiplicative uncertainties in the burdens of the individual aerosol species summarized in Table 19 and the time- and space-average aerosol mass column amounts summarized in Table 17. The largest normalized uncertainties are a result of the large uncertainties associated with the chemical transport models, the greatest contributions to which are uncertainties in emissions and chemical transformation (Table 19, Fig. 27a). These uncertainties were then propagated to obtain uncertainties in AOD, DRE, and DCF, by taking into account the additional uncertainties estimated for the optical properties summarized in Table 15 and the time and space-average values summarized in Tables 20 and 21. The results for the NWP are shown in Fig. 28. The uncertainties calculated for DCF in this analysis expressed as normalized uncertainties (i.e., ratioed to the best estimate of the quantity, $\delta^{-}=0.72, \delta^{+}=2.6$ ) are similar to those calculated from the estimates given by IPCC-TAR for the uncertainties in global mean anthropogenic aerosol forcing $\left(\delta^{-}=1.2\right.$, $\delta^{+}=2.0$; Table 28). Despite the large uncertainties associated with emissions and other processes represented in the CTMs, the CTMs, at least in the study areas examined here, calculate regional average surface aerosol concentrations with much greater skill than might be expected based on the estimated uncertainties (Fig. 27b). Using the mean model/observation ratios (Tables 20 and 21) as a measure of the factor uncertainty to constrain RTM calculations results in a reduction of the normalized uncertainty for DCF to $\delta^{-}=0.64$ and $\delta^{+}=1.8$. These reductions are shown in Fig. 28 for the NWP domain.

\section{Summary}

This study has examined the shortwave radiative effects of aerosols in three oceanic regions downwind of major urban population centers with the intent of developing and applying a methodology to incorporate understanding gained from field observations of aerosol loading and optical properties into refined estimates of the radiative effects. Radiative effects examined were aerosol optical depth AOD; aerosol direct radiative effect DRE in cloud free sky, the difference in shortwave radiative flux (at the surface or top of atmosphere) due the total aerosol (anthropogenic plus natural); and aerosol direct climate forcing DCF in cloud free sky, the difference in shortwave radiative flux (at the surface or top of atmosphere) due the anthropogenic aerosol. The two major contributions to uncertainty in calculations of aerosol radiative effects are uncertainty in the aerosol burden, the total amount of aerosol per unit area, which is conventionally calculated by use of chemical transport models, and uncertainty in the aerosol optical properties that are inputs to the radiative transfer calculations. Measurements of these quantities in major field campaigns have provided data which constrain estimates of aerosol amounts and properties thereby leading to refined estimates of the magnitudes of aerosol radiative effects and to substantial reductions in uncertainty of these 

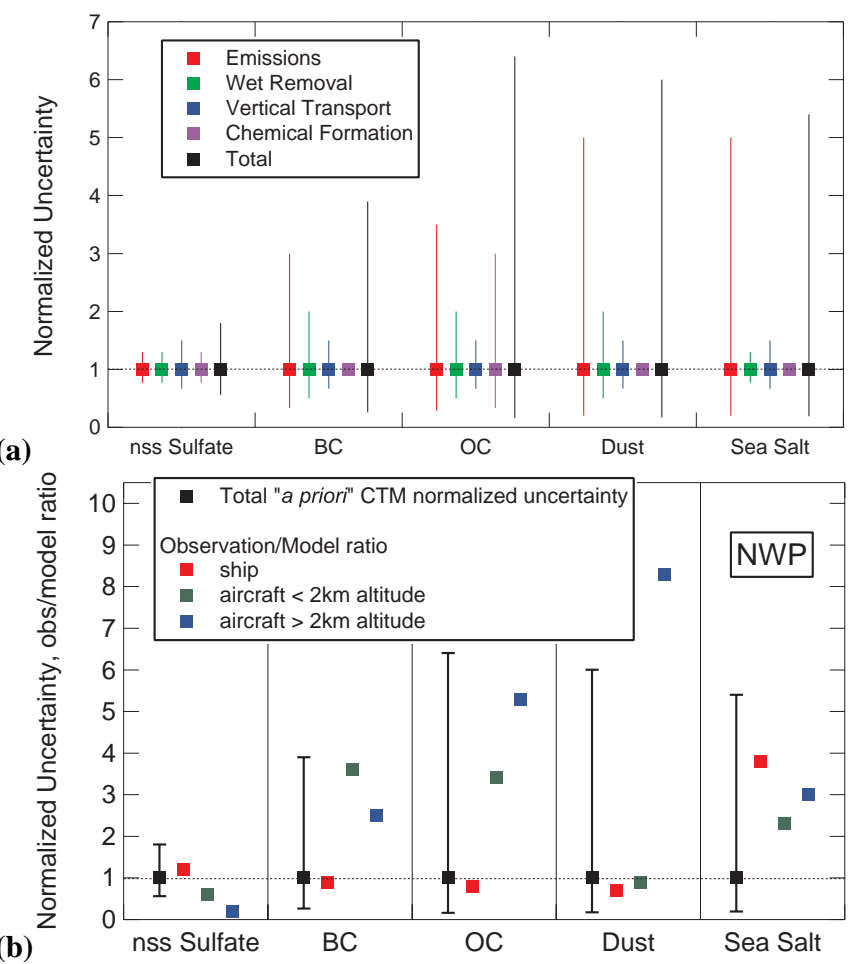

Fig. 27. (a) Normalized uncertainties (uncertainty range of the indicated quantity divided by the value of the quantity) associated with the CTM (Table 19) in the NWP. (b) Total normalized uncertainty in the "a priori" CTM calculations (from Fig. 27a) compared with the ratio of the mean CTM calculated concentration to the measured concentration along the Ronald $\mathrm{H}$. Brown cruise track during ACEAsia (Table 20) and the C-130 flight track during ACE-Asia.

effects, albeit directly pertinent only to the times and locations of the field campaigns.

Measurements of aerosol composition, mixing state, size distribution, and optical properties permitted development of the following generalizations and parameterizations:

a) Mixing state. AOD, DRE and DCF, can be accurately calculated by categorizing aerosols into four externallymixed subgroups: submicrometer sulfate/carbonaceous aerosol, submicrometer mineral dust, supermicrometer mineral dust, and supermicrometer sea salt. Internal mixing of these subgroups, which appears to be slight, has little impact on the radiative effects of these aerosols and can therefore be neglected in estimating aerosol influences on shortwave radiative fluxes and the associated uncertainties.

b) Hygroscopic growth. The hygroscopic growth factor for the sulfate/carbonaceous aerosol can be parameterized as a function of the organic mass fraction.

c) Optical properties. Observed wavelength-dependent mass scattering efficiencies, single scatter albedo, and

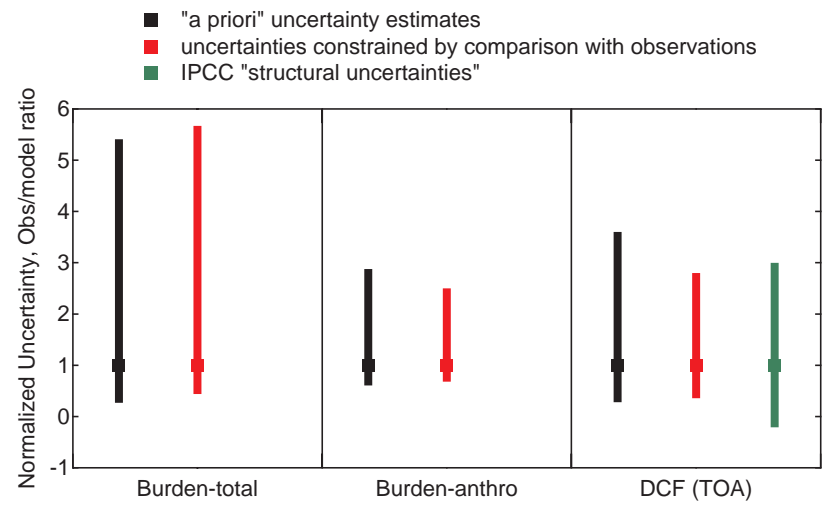

Fig. 28. Normalized uncertainties (uncertainty range of the indicated quantity divided by the value of the quantity) associated with the mean total aerosol column burden, the mean anthropogenic aerosol column burder, and the aerosol direct climate forcing (DCF), for the northwest Pacific region during ACE-Asia. Also shown for comparison is the normalized uncertainty associated with the global mean aerosol direct climate forcing calculated (Table 28; Fig. 26) from IPCC (Ramaswamy et al., 2001) estimates of the uncertainties in the forcings by the several aerosol species; negative value indicates that the uncertainty range of this (negative) forcing encompasses values of opposite sign (i.e., positive).

asymmetry parameter for the various aerosol subgroups in the three regions can be applied in RTMs in lieu of "a priori" optical properties. The mass scattering efficiency of sulfate/carbonaceous and dust aerosol can be parameterized as a function of the supermicrometer to submicrometer mass concentration.

The observationally-constrained TOA DCF over the NIO, NWP, and NWA during the time periods of INDOEX, ACE-Asia, and ICARTT was $-3.3 \pm 0.47,-14 \pm 2.6$, $-6.4 \pm 2.1 \mathrm{Wm}^{-2}$, respectively, considerably greater in magnitude than the globally averaged forcing due to enhanced greenhouse gas concentrations. However it must be stressed that such forcings are overestimates of the actual aerosol forcings because they do not take into account the fraction of the domain that is covered by clouds, for which aerosol direct effects will be minimal. Constraining the aerosol properties employed in the radiative transfer calculations based on measurements resulted in AODs that were, on average, $34 \pm 8 \%$ larger than those obtained using the "a priori" optical properties. The effects of constraining the aerosol properties on calculated TOA DRE and DCF were similar $(32 \pm 12 \%$ and $37 \pm 7 \%$ increase, respectively) but were less for SFC DRE and DCF ( $14 \pm 8 \%$ and $12 \pm 14 \%$ increase, respectively). These results imply that AOD and TOA DRE and DCF in these areas may be greater than previously estimated.

The uncertainties in CTM estimated aerosol burdens and RTM optical properties were determined. With the use of constrained quantities (extensive and intensive parameters) the calculated uncertainty in DCF during ACE-Asia was $25 \%$ 
less than the structural uncertainties used in the IPCC 2001 estimates of global clear-sky DCF (Fig. 28). The uncertainties in AOD and DRE, however, are much greater because of the large discrepancies between modeled and measured dust and sea salt burdens that arise mainly from uncertainties in emissions of these materials. This assessment of uncertainties applies to clear sky, no cloud conditions and thus does not take into account uncertainties associated with fractional cloudiness. It also relies on measurements that are specific to the time and locations of the field campaigns and is thus restricted to these times and locations.

"A priori" modeling of DCF, as has been employed in previous estimates, is subject to large uncertainties that result from uncertainties in modeled burdens of the several aerosol species and of associated intensive properties. In assessing DCF it is essential that these uncertainties be reduced. While measurements of AOD and radiative fluxes provide a valuable constraint on DRE as shown here, the use of these measurements to reduce uncertainties in DRE or DCF is limited due to the large uncertainties in the burdens of dust and sea salt aerosol, constituents that contribute substantially in many situations to AOD but are not associated with DCF. Measurement campaigns that determine the amounts and intensive properties of natural and anthropogenic constituents are essential to constrain calculations of DRE and DCF. Improving estimates at both regional and global scales requires improvement in the ability of CTMs to model aerosol burdens. This will require: 1) verification and more frequent updating of emission data bases, 2) verification and improved parameterization of wet deposition, sea salt and dust source functions and processes controlling organic aerosol formation and transformation and 3) vertical measurements of aerosol distributions for comparison with CTM estimates.

In conclusion, intensive in-situ measurements of the loading, distribution, and chemical, microphysical, and optical properties of atmospheric aerosols over several regions of the globe during the past decade are contributing to an enhanced understanding of these properties and improved quantitative estimation of the effects of these aerosols on shortwave radiative fluxes resulting from scattering and absorption of solar radiation. Such quantitative understanding is essential for accurate representation of these aerosol effects in climate models.

\section{Appendix A}

\section{Uncertainties and uncertainty propagation}

Many of the quantities reported in this paper are characterized by large spatial or temporal variability which must be propagated into estimates of uncertainties of derived quantities. The situation of large variability is commonplace in air pollution meteorology, in which it is found that distributions of concentrations are often skewed to larger values and for which the standard deviation not uncommonly exceeds the mean (e.g., Zimmer and Larsen, 1965). This Appendix sets forth how these large and asymmetric uncertainties have been expressed and propagated into derived quantities as used in this study.

In general the uncertainty associated with a quantity of interest $Q$ denoted as $\pm \Delta Q$ refers to the uncertainty range $(Q-\delta Q, Q+\Delta Q)$ or equivalently $Q(1-\delta Q, 1-\delta Q)$, where $\delta Q \equiv \Delta Q / Q$ is the relative uncertainty associated with $Q$. However for a situation in which the standard deviation is comparable to or exceeds the mean of a nonnegative quantity such as a concentration, the standard deviation or other symmetric measure of uncertainty or variability is not suitable for characterizing the spread of the distribution, and some asymmetric measure is required. Frequently it is found that the logarithm of the concentration of an atmospheric constituent is roughly normally distributed (Zimmer and Larsen, 1965), i.e., the lognormal distribution, for which the breadth of the distribution is typically characterized by the geometric standard deviation $s$, the standard deviation of the distribution of values of the logarithm of the quantity of interest $Q$. Such a measure of variability results in a multiplicative uncertainty associated with the quantity itself, denoted here $Q * u$ ( $Q$ times or divided by $u$ ), where $u=\exp s$. The corresponding uncertainty associated with the quantity itself is asymmetric, the uncertainty on the large side, the positive uncertainty $\Delta Q^{+}$, being greater than that on the low side, the negative uncertainty $\Delta Q^{-}$:

$$
\begin{aligned}
& \Delta Q^{+}=u Q-Q=Q(u-1) \quad \text { and } \\
& \Delta Q^{-}=Q-Q / u=Q(1-1 / u) .
\end{aligned}
$$

The uncertainty range associated with $Q$ is thus $\left(Q-\Delta Q^{-}, Q+\Delta Q\right) \quad$ or $\quad Q\left(1-\delta Q^{-}, 1+\delta Q\right), \quad$ where $\delta Q^{-} \equiv \Delta Q^{-} / Q$ and $\delta Q^{+} \equiv \Delta Q^{+} / Q$ are denoted the negative and positive relative uncertainties associated with the quantity $Q$, respectively. These relative uncertainties are especially useful in comparing the uncertainties associated with different types of quantities, e.g., the uncertainty associated with the emission flux of a substance versus that associated with the atmospheric burden of this substance. Not uncommonly the uncertainty on the large side exceeds the magnitude of the quantity itself; that is, the positive relative uncertainty $\delta Q^{+}=u-1$ exceeds unity.

In general, in evaluating the uncertainty associated with a product of two or more factors characterized by uncorrelated uncertainties, the fractional uncertainty associated with the product is evaluated as the sum, taken in quadratures, of the fractional uncertainties associated with each of the factors (e.g., Bevington, 1969). That is, for the product $z=x y$ of two quantities $x$ and $y$ characterized by uncorrelated uncertainties $\Delta x$ and $\Delta y$, respectively, the multiplicative uncertainty 
in the product is estimated as

$$
\frac{\Delta z}{z}=\left[\left(\frac{\Delta x}{x}\right)^{2}+\left(\frac{\Delta y}{y}\right)^{2}\right]^{1 / 2}=\frac{\Delta x}{x} \oplus \frac{\Delta y}{y},
$$

where the notation $a \oplus b$ is introduced to denote a sum taken in quadratures, $\left(a^{2}+b^{2}\right)^{1 / 2}$. Equivalently, Eq. (A2) may be expressed in terms of the uncertainties associated with the logarithms of the several quantities:

$\Delta \ln z=\Delta \ln x \oplus \Delta \ln y$,

from which it may be seen that for multiplicative uncertainties associated with the factors $x$ and $y, u_{x}$ and $u_{y}$, respectively, the multiplicative uncertainty associated with the product $z$ is given by

$u_{z}=\exp \left(\ln u_{x} \oplus \ln u_{y}\right)$

This expression has previously been used to evaluate the uncertainty associated with global mean radiative forcing by sulfate aerosol, evaluated as the product of estimates of several global-mean factors, in terms of the uncertainties associated with the several factors (Penner et al., 1994).

When quantities characterized by multiplicative uncertainties (or other asymmetric measures of uncertainty) are to be added, the positive and negative uncertainties need to be propagated separately. Consider the uncertainty associated with a quantity evaluated as the sum of several terms, $X=\sum x_{i}$, with multiplicative uncertainties characterizing the several terms $x_{i}$. For the uncertainties in the several terms taken as uncorrelated, the positive and negative uncertainty ranges associated with the sum are

$\Delta X^{+}=\sum^{\oplus} \Delta x_{i}^{+}$and $\Delta X^{-}=\sum^{\oplus} \Delta x_{i}^{-}$,

respectively, where the positive and negative uncertainties associated with the several terms $x_{i}, \Delta x_{i}^{+}$and $\Delta x_{i}^{-}$, respectively, are evaluated by Eq. (A1) and where the notation $\sum^{\oplus}$ denotes a sum taken in quadrature.

The multiplicative uncertainties associated with such a sum, which are generally not symmetric, are given as

$u^{\times}=\left(X+\Delta X^{+}\right) / X=1+\delta X^{+}$and

$u^{\div}=X /\left(X-\Delta X^{-}\right)=1 /\left(1-\delta X^{-}\right)$,

respectively, and expressed in terms of these multiplicative uncertainties the range associated with the quantity $X$ is $\left(X u^{\times}, X / u^{\div}\right)$.

In some situations, especially when some of the terms comprising a sum $x_{i}$ are of opposite sign, the negative uncertainty $\Delta X^{-}$associated with a given quantity $X$ may exceed the magnitude of the quantity itself; equivalently the negative relative uncertainty exceeds unity. In such situations the lower limit of the uncertainty range associated with the quantity is of opposite sign to the quantity itself; that is, even the sign of the quantity is uncertain. In these situations

it is no longer meaningful to define a multiplicative uncertainty associated with the quantity by Eq. (A6). An example of such a situation is the uncertainty associated with total anthropogenic radiative forcing of climate change over the industrial period evaluated (Schwartz, 2004) as the algebraic sum of positive greenhouse gas forcing and mainly negative shortwave aerosol forcing.

The expressions presented here serve as the basis for calculation of the uncertainties associated with the several quantities reported in the text.

\section{Appendix B}

\section{Nomenclature, subscripts and acronyms}

Nomenclature
$\stackrel{\circ}{b}$
$b$
$c$
C

$D_{p}$

$f_{\sigma_{s p}}\left(R H, R H_{\text {ref }}\right)$

$F$

$F_{O}$

$g$

$g$

$h$

$t$

$\alpha_{s p}$

$\gamma$
Ångstrom exponent

Hemispheric backscattered fraction (in nephelometry)

Constant in expression relating $f(R H)$ to relative humidity

Concentration of particulate matter, typically in units $\mu \mathrm{g} \mathrm{m}^{-3}$;

often expressed as a mixing ratio, i.e., mass per standard cubic meter, taken as 1 atmosphere (101325 Pa) and $25^{\circ} \mathrm{C}$.

Particle diameter

Dependence of aerosol light scattering coefficient on relative humidity relative to that at a low reference relative humidity

Radiative flux

Fraction of particulate matter that is organic

Exponent in expression relating $f(R H)$ to relative humidity

Asymmetry parameter (in light scattering; mean of cosine of scattering

phase function

Precipitation rate

Significance variable in Student's $t$ test

Mass scattering efficiency of aerosol particulate matter

Exponent describing steepness of dependence of light scattering coefficient or asymmetry parameter on relative humidity 
$\delta Q \quad$ Relative uncertainty in quantity $Q$

$\Delta Q \quad$ Absolute uncertainty in quantity $Q$

$\varepsilon \quad$ Radiative efficiency $(\Delta F / \tau)$

$\sigma_{a p}$ Light absorption coefficient of aerosol particulate matter

$\sigma_{s p} \quad$ Light scattering coefficient of aerosol particulate matter

$\tau_{e p} \quad$ Aerosol optical depth

$\omega_{0} \quad$ Single-scattering albedo

$\begin{array}{ll}\begin{array}{l}\text { Subscripts } \\ \text { amb } \\ \text { asym }\end{array} & \begin{array}{l}\text { ambient } \\ \text { asymmetry (refers to asymmetry } \\ \text { parameter) } \\ \text { back (refers to scattering into back- } \\ \text { ward hemisphere) } \\ \text { b }\end{array} \\ \text { absorption } \\ \text { a } & \text { diameter } \\ \text { refers to dry particle properties (at } \\ \text { dry } & \text { low } R H \text { ) } \\ \text { e } & \text { extinction } \\ \mathrm{O} & \text { organic } \\ \text { p } & \text { particle, particulate } \\ \text { ref } & \text { reference } \\ \mathrm{s} & \text { scattering } \\ \mathrm{S} & \text { sulfate }\end{array}$

\section{Acronyms}

ACE

AEROCOM AEROsol model COMparison (http://nansen.ipsl.jussieu.fr/ AEROCOM/)

AERONET AErosol RObotic NETwork

AM2 GFDL Atmospheric Model, Version 2

AOD (AOT) Aerosol Optical Depth (Thickness)

BC Black Carbon

BRDF Bidirectional Reflectance Distribution Function

CCRI Climate Change Research Initiative

CCSP Climate Change Science Program

CIRPAS Center for Interdisciplinary

Remotely-Piloted Aircraft Studies

CMDL Climate Modeling and Diagnostic Laboratory (NOAA)

CTM Chemical Transport Model

DCF Direct Climate Forcing by anthropogenic aerosol

DMIPS Dust Modeling IntercomParison Study

\begin{tabular}{|c|c|}
\hline DMS & Dimethyl sulfide \\
\hline DOY & Day of Year (UTC; January 1=1) \\
\hline DRE & $\begin{array}{l}\text { Direct Radiative Effect of the total } \\
\text { aerosol }\end{array}$ \\
\hline EC & Elemental Carbon \\
\hline ECMWF & $\begin{array}{l}\text { European Centre for Medium- } \\
\text { Range Weather Forecasts }\end{array}$ \\
\hline EDGAR & $\begin{array}{l}\text { Emissions Database for Global At- } \\
\text { mospheric Research }\end{array}$ \\
\hline EPA & $\begin{array}{l}\text { Environmental Protection Agency } \\
\text { (US) }\end{array}$ \\
\hline NL & Final analysis \\
\hline $\mathrm{AM}$ & $\begin{array}{l}\text { Itmospheric Model Devel- } \\
\text { Team (GFDL) }\end{array}$ \\
\hline $\mathrm{CM}$ & rculation Model \\
\hline EIA & $\begin{array}{l}\text { Global Emissions Inventory Activ- } \\
\text { ity }\end{array}$ \\
\hline FDL & $\begin{array}{l}\text { Geophysical Fluid Dynamics Labo- } \\
\text { ratory (NOAA) }\end{array}$ \\
\hline INDOEX & $\begin{array}{l}\text { INDian Ocean EXperiment (http:// } \\
\text { www-indoex.ucsd.edu/) }\end{array}$ \\
\hline IPCC & $\begin{array}{l}\text { Intergovernmental Panel on Cli- } \\
\text { mate Change }\end{array}$ \\
\hline ICARTT & $\begin{array}{l}\text { International Consortium for Atmo- } \\
\text { spheric Research on Transport and } \\
\text { Transformation (http://www.al. } \\
\text { noaa.gov/ICARTT/) }\end{array}$ \\
\hline INTEX & $\begin{array}{l}\text { INtercontinental chemical Trans- } \\
\text { port EXperiment }\end{array}$ \\
\hline $\mathrm{CO}$ & oo Climate Observatory \\
\hline MICS & terComparison Study \\
\hline MISR & $\begin{array}{l}\text { Multi-angle Imaging SpectroRa- } \\
\text { diometer }\end{array}$ \\
\hline MM5 & $\begin{array}{l}\text { Mesoscale Model, Version } 5 \text { (http: } \\
\text { //www.mmm.ucar.edu/mm5) }\end{array}$ \\
\hline MODIS & $\begin{array}{l}\text { MODerate resolution Imaging } \\
\text { Spectroradiometer }\end{array}$ \\
\hline MOZART & $\begin{array}{l}\text { Model of OZone And Related } \\
\text { chemical Tracers }\end{array}$ \\
\hline SE & Mass Scattering Efficiency \\
\hline NASA & $\begin{array}{l}\text { National Aeronautics and Space } \\
\text { Administration }\end{array}$ \\
\hline NCAR & $\begin{array}{l}\text { National Center for Atmospheric } \\
\text { Research }\end{array}$ \\
\hline NCEP & $\begin{array}{l}\text { National Centers for Environmental } \\
\text { Prediction }\end{array}$ \\
\hline NEAC & New England Air Quality Study \\
\hline NIO & \\
\hline NOAA & $\begin{array}{l}\text { National Oceanic and Atmospheric } \\
\text { Administration }\end{array}$ \\
\hline $\mathrm{NO}_{\mathrm{x}}$ & Nitrogen oxides \\
\hline NSF & National Science Foundation \\
\hline $110 \mathrm{~S}$ & \\
\hline & vest Atlantic \\
\hline
\end{tabular}




\begin{tabular}{|c|c|}
\hline $\mathrm{P}$ & Northwest Pacific \\
\hline $\mathrm{OC}$ & Organic Carbon \\
\hline OMF & Organic Mass Fraction \\
\hline NR & Office of Naval Research \\
\hline ILS & Particle Into Liquid Sampler \\
\hline $\mathrm{DM}$ & Particulate Organic Matter \\
\hline AMS & $\begin{array}{l}\text { Regional Atmospheric Modelling } \\
\text { System }\end{array}$ \\
\hline $2 H$ & Relative Humidity \\
\hline $\mathrm{V}$ & Research Vessel \\
\hline HB & Ronald H. Brown (research vessel) \\
\hline SD & Relative Standard Deviation \\
\hline T, RTM & $\begin{array}{l}\text { Radiative Transfer, Radiative } \\
\text { Transfer Model }\end{array}$ \\
\hline APRAC & $\begin{array}{l}\text { Statewide Air Pollution Research } \\
\text { Center } \\
\text { (http://pah.cert.ucr.edu } / \sim \text { carter/ } \\
\text { reactdat.htm) }\end{array}$ \\
\hline CAPE & $\begin{array}{l}\text { Simulating Composition of Atmo- } \\
\text { spheric Particles at Equilibrium } \\
\text { (model) }\end{array}$ \\
\hline$d$ & standard deviation \\
\hline TEM & $\begin{array}{l}\text { Sulfur Transport and dEposition } \\
\text { Model }\end{array}$ \\
\hline TAR & Third Assessment Report (IPCC) \\
\hline TARFOX & $\begin{array}{l}\text { Tropospheric Aerosol Radiative } \\
\text { Forcing Observational eXperiment }\end{array}$ \\
\hline $\mathrm{OA}$ & Top-Of-Atmosphere \\
\hline TUV & Tropospheric Ultraviolet-Visible \\
\hline TRACE-P & $\begin{array}{l}\text { Transport And Chemical Evolution } \\
\text { Over The Pacific } \\
\text { (http://www-gte.larc.nasa.gov/ } \\
\text { trace/tracep.html) }\end{array}$ \\
\hline & University Of Michigan \\
\hline & Universal Time Coordinated \\
\hline
\end{tabular}

Acknowledgements. We thank B. Andrews for assistance with data and comments on sections of this paper; D. Schwarzkopf for assistance with the GFDL AM2 radiation code; K. Duckenfield for comments on this manuscript. The contributing investigators acknowledge support from their respective sponsoring agencies. This manuscript is a CCSP Phase 1 product and was funded by the NOAA Climate Program and the NASA Radiation Science Program. This is PMEL contribution number 2857.

Edited by: U. Lohmann

\section{References}

Allan, J. D., Bower, K. N., Coe, H., Boudries, H., Jayne, J. T., Canagaratna, M. R., Millet, D. B., Goldstein, A. H., Quinn, P. K., Weber, R. J., and Worsnop, D. R.: Submicron aerosol composition at Trinidad Head, California, during ITCT 2K2: Its relationship with gas phase volatile organic carbon and assessment of instrument performance, J. Geophys. Res., 109(D23), 1-16, doi:10.1029/2003JD004208, 2004.
Anderson, T. L., Charlson, R. J., Bellouin, N., et al.: An "A-Train" strategy for quantifying direct aerosol forcing of climate, Bull. Am. Met. Soc., 86(12), 1795-1809, doi:10.1175/BAMS-86-121795, 2005.

Anderson, T. L., Masonis, S. J., Covert, D. S., Ahlquist, N. C., Howell, S. G., Clarke, A. D., and McNaughton, C. S.: Variability of aerosol optical properties derived from in situ aircraft measurements during ACE-Asia, J. Geophys. Res., 108(D23), 8647, doi:10.1029/2002JD003247, 2003.

Andreae, M. O., Charlson, R. J., Bruynseels, F., Storms, H., Vangrieken, R., and Maenhaut, W.: Internal mixture of sea salt, silicates, and excess sulfate in marine aerosols, Science, 232(4758), 1620-1623, 1986.

Andreae, M. O. and Merlet, P.: Emission of trace gases and aerosols from biomass burning, Global Biogeochem. Cycles, 15(4), 955966, 2001.

Andrews, E., Sheridan, P. J., Fiebig, M., McComiskey, A., Ogren, J. A., Arnott, P., Covert, D., Elleman, R., Gasparini, R., Collins, D., Jonsson, H., Schmid, B., and Wang, J.: Comparison of methods for deriving aerosol asymmetry parameter. J. Geophys. Res., 111, D05S04, doi:10.1029/2004JD005734, 2006.

Angevine, W. M., Senff, C. J., White, A. B., Williams, E. J., Koermer, J., Miller, S. T. K., Talbot, R., Johnston, P. E., McKeen, S. A., and Downs, T.: Coastal boundary layer influence on pollutant transport in New England, J. Appl. Meteorol., 43, 1425-1437, 2004.

Arimoto, R., Zhang, X. Y., Huebert, B. J., Kang, C. H., Savoie, D. L., Prospero, J. M., Sage, S. K., Schloesslin, C. A., Khaing, H. M., and Oh, S. N.: Chemical composition of atmospheric aerosols from Zhenbeitai, China and Gosan, South Korea, during ACE-Asia, J. Geophys. Res., 109(D19S04), doi:10.1029/2003JD004323, 2004.

Bates, T. S., Huebert, B. J., Gras, J. L., Griffiths, F. B., and Durkee, P. A.: The International Global Atmospheric Chemistry (IGAC) Project's First Aerosol Characterization Experiment (ACE-1) Overview. J. Geophys. Res., 103, 16 297-16318, 1998.

Bates, T. S., Quinn, P. K., Coffman, D. J., Covert, D. S., Miller, T. L., Johnson, J. E., Carmichael, G. R., Guazzotti, S. A., Sodeman, D. A., Prather, K. A., Rivera, M., Russell, L. M., and Merrill, J. T.: Marine boundary layer dust and pollution transport associated with the passage of a frontal system over eastern Asia, J. Geophys. Res., 109(D19), doi:10.1029/2003JD004094, 2004.

Bates, T. S., Quinn, P. K., Coffman, D. J., Johnson, J. E., and Middlebrook, A. M.: The dominance of organic aerosols over the Gulf of Maine during NEAQS 2002. J. Geophys. Res., 110(D18202), doi:10.1029/2005JD005797, 2005.

Bauer S. E., Balkanski, Y., Schulz, M., Hauglustaine, D. A., and Dentener, F.: Global modeling of heterogeneous chemistry on mineral aerosol surfaces: Influence on tropospheric ozone chemistry and comparison to observations, J. Geophys. Res., 109, D02304, doi:10.1029/2003JD003868, 2004.

Bauer, S. E. and Koch, D.: Impact of heterogeneous sulfate formation at mineral dust surfaces on aerosol loads and radiative forcing in the GISS GCM, J. Geophys. Res., 110(D17202), doi10.1029/2005JD005870, 2005.

Bellouin, N., Boucher, O., Vesperini, M., and Tanré, D.: Estimating the aerosol direct radiative perturbation: impact of the ocean surface representation and aerosol non-sphericity, Q. J. R. Meteorol. Soc., 130, 2217-2232, 2004. 
Bevington, P. R.: Data reduction and error analysis for the physical sciences, McGraw Hill, 1969.

Bond, T. C., Charlson, R. J., and Heintzenberg, J.: Quantifying the emission of light-absorbing particles: Measurements tailored to climate studies, Geophys. Res. Lett., 25(3), 337-340, 1998.

Bond, T. C., Streets, D. G., Yarber, K. F., Nelson, S. M., Woo, J. H., and Klimont, Z.: A technology based inventory of black and organic carbon emissions from combustion, J. Geophys. Res., 109(D14203), doi:10.1029/2003JD003697, 2004.

Boucher, O.: On Aerosol direct shortwave forcing and the HenyeyGreenstein phase function, J. Atmos. Sci., 55, 128-134, 1998.

Boucher, O. and Anderson, T. L.: GCM assessment of the sensitivity of direct climate forcing by anthropogenic sulfate aerosols to aerosol size and chemistry, J. Geophys. Res., 100, $26117-$ $26134,1995$.

Boucher O. and Haywood, J.: On summing the components of radiative forcing of climate change, Climate Dynamics, 18, 297302, 2001.

Boucher, O., Schwartz, S. E., Ackerman, T. P., Anderson, T. L., Bergstrom, B., Bonnel, B., Chylek, P., Dahlback, A., Fouquart, Y., Fu, Q., Halthore, R. N., Haywood, J., Iversen, T., Kato, S., Kinne, S., Kirkevåg, A., Knapp, E., Lacis, A., Laszlo, I., Mishchenko, M. I., Nemesure, S., Ramaswamy, V., Roberts, D., Russell, P., Schlesinger, M., Stephens, G. L., Wagener, R., Wang, M., Wong, J., Yang, F.: Intercomparison of models representing shortwave radiative forcing by sulfate aerosols, J. Geophys. Res., 103, 16979-16998, 1998.

Brock, C. A., Hudson, P. K., Lovejoy, E. R., Sullivan, A., Nowak, J. B., Huey, L. G., Cooper, O. R., Cziczo, D. J., de Gouw, J., Fehsenfeld, F. C., Holloway, J. S., Hübler, G., Lafleur, B. G., Murphy, D. M., Neuman, J. A., Nicks, J. D. K., Orsini, D. A., Parrish, D. D., Ryerson, T. B., Tanner, D. J., Warneke, C., Weber, R. J., and Wilson, J. C.: Particle characteristics following cloud- modified transport from Asia to North America, J. Geophys. Res., 109(D23S26), doi:10.1029/2003JD004198, 2004.

Burtscher, H., Baltensperger, U., Bukowiecki, N., Cohn, P., Huglin, C., Mohr, M., Matter, U., Nyeki, S., Schmatloch, V., Streit, N., and Weingartner, E.: Separation of volatile and non-volatile aerosol fractions by thermodesorption: instrumental development and applications, J. Aerosol Sci., 32, 427-442, 2001.

Bush, B. C. and Valero, F. P. J.: Spectral aerosol radiative forcing at the surface during the Indian Ocean Experiment (INDOEX), J. Geophys. Res., 107(D19), 4307, doi:10.1029/2000JD000020, 2002.

Bush, B. C. and Valero, F. P. J.: Surface aerosol radiative forcing at Gosan during the ACE-Asia campaign, J. Geophys. Res., 108(D23), 8660, doi:10.1029/2002JD003233, 2003.

Canagaratna, M. R., Jayne, J. T., Ghertner, D. A., Herndon, S., Shi, Q., Jimenez, J. L., Silva, P. J., Williams, P., Lanni, T., Drewnick, F., Demerjian, K. L., Kolb, C. E., and Worsnop, D. R.: Chase studies of particulate emissions from in-use New York City vehicles, Aerosol Sci. Technol., 38, 555-573, 2004.

Carmichael, G. R., Calori, G., Hayami, H., Uno, I., Cho, S. Y., Engardt, M., Kim, S. B., Ichikawa, Y., Ikeda, Y., Woo, J. H., Ueda, H., and Amann, M.: The Mics-Asia study: Model intercomparison of long-range transport and sulfur deposition in East Asia, Atmos. Environ., 36(2), 175-199, 2002.

Carmichael, G. R., Tang, Y., Kurata, G., Uno, I., Streets, D., Woo, J. H., Huang, H., Yienger, J., Lefer, B., Shetter, R., Blake,
D., Atlas, E., Fried, A., Apel, E., Eisele, F., Cantrell, C., Avery, M., Barrick, J., Sachse, G., Brune, W., Sandholm, S., Kondo, Y., Singh, H., Talbot, R., Bandy, A., Thorton, D., Clarke, A., and Heikes, B.: Regional-scale chemical transport modeling in support of the analysis of observations obtained during the TRACE-P Experiment, J. Geophys. Res., 108(D21), 8823, doi:10.1029/2002JD003117, 2003a.

Carmichael, G. R., Tang, Y., Kurata, G., Uno, I., Streets, D. G., Thongboonchoo, N., Woo, J. H., Guttikunda, S., White, A., Wang, T., Blake, D. R., Atlas, E., Fried, A., Potter, B., Avery, M. A., Sachse, G. W., Sandholm, S. T., Kondo, Y., Talbot, R. W., Bandy, A., Thorton, D., and Clarke, A. D.: Evaluating regional emission estimates using the TRACE-P observations, J. Geophys. Res., 108(D21), 8810, doi:10.1029/2002JD003116, 2003b.

Carrico, C. M, Rood, M. J., and Ogren, J. A.: Aerosol light scattering properties at Cape Grim, Tasmania, during the first Aerosol Characterization Experiment (ACE 1), J. Geophys. Res., 103, 16 565-16 574, 1998.

Carrico, C. M., Kus, P., Rood, M. J., Quinn, P. K., and Bates, T. S.: Mixtures of pollution, dust, sea salt, and volcanic aerosol during ACE-Asia: Radiative properties as a function of relative humidity, J. Geophys. Res., 108(D23), 8650, doi:10.1029/2003JD003405, 2003.

Carter, T. R., Hulme, M., Crossley, J. F., Malyshev, S., New, M. G., Schlesinger, M. E., and Uomenvirta, H.: Climate change in the 21st century: Interim characterizations based on the new IPCC emissions scenarios, The Finnish Environment, 433, 148, 2000.

Cavalli, F., Facchini, M. C., Decesari, S., Mircea, M., Emblico, L., Fuzzi, S., Ceburnis, D., Yoon, Y. J., O’Dowd, C., Putaud, J. P., Dell'Acqua, A.: Advances in characterization of size-resolved organic matter in marine aerosol over the North Atlantic, J. Geophys. Res., 109(D24215), doi:10.1029/2004JD005137, 2004.

Chameides, W. L. and Stelson, A. W., Aqueous-phase chemical processes in deliquescent sea-salt aerosols: A mechanism that couples the atmospheric cycles of S and sea salt, J. Geophys. Res., 97(D18), 20 565-20 580, 1992.

Charlson, R. J., Anderson, T. L., and Rodhe, H.: Direct climate forcing by anthropogenic aerosols: Quantifying the link between atmospheric sulfate and radiation, Contr. Atmos. Phys., 72, 7994, 1999.

Charlson R. J., Langner, J., Rodhe, H., Leovy, C. B., and Warren, S. G.: Perturbation of the Northern Hemisphere radiative balance by backscattering from anthropogenic aerosols, Tellus, 43AB, 152-163, 1991.

Charlson, R. J., Schwartz, S. E., Hales, J. M., Cess, R. D., Coakley, Jr., J. A., Hansen, J. E., and Hofmann, D. J.: Climate forcing by anthropogenic aerosols, Science, 255, 423-430, 1992.

Chowdhury, Z., Hughes, L. S., Salmon, L. G., and Cass, G. R.: Atmospheric particle size and composition measurements to support light extinction calculations over the Indian Ocean, J. Geophys. Res., 106, 28 597-28 605, 2001.

Chylek, P., Videen, G., Ngo, D., Pinnick, R. G., and Klett, J. D.: Effect of black carbon on the optical properties and climate forcing of sulfate aerosols, J. Geophys. Res., 100, 16325-16332, 1995.

Chylek, P. and Wong, J.: Effect of absorbing aerosol on global radiation budget, Geophys. Res. Lett., 22, 929-931, 1995.

Chuang, P. Y., Duvall, R. M., Bae, M. S., Jefferson, A., Schauer, J. J., Yang, H., Yu, J. Z., and Kim, J.: Observations of elemental carbon and absorption during ACE-Asia and implications 
for aerosol radiative properties and climate forcing, J. Geophys. Res., 108(D23), 8634, doi:10.1029/2002JD003254, 2003.

Claeys, M., Graham, B., Vas, G., Wang, W., Vermeylen, R., Pashynska, V., Cafmeyer, J., Guyon, P., Andreae, M. O., Artaxo, P., and Maenhaut, W.: Formation of secondary organic aerosols through photooxidation of isoprene, Science, 303, 1173-1176, 2004.

Clarke, A. D., Collins, W. G., Rasch, P. J., Kapustin, V. N., Moore, K., Howell, S., and Fuelberg, H.E.: Dust and pollution transport on global scales: Aerosol measurements and model predictions, J. Geophys. Res., 106(D23), 32 555-32 569, 2001.

Clarke, A. D., Howell, S., Quinn, P. K., Bates, T. S., Ogren, J. A., Andrews, E., Jefferson, A., Massling, A., Mayol-Bracero, O., Maring, H., Savoie, D., and Cass, G.: INDOEX aerosol: A comparison and summary of chemical, microphysical, and optical properties observed from land, ship, and aircraft, J. Geophys. Res., 107(D19), 8033, doi:10.1029/2001JD000572, 2002.

Clarke, A. D. and Kapustin, V. N.: A pacific aerosol survey. Part I: A decade of data on particle production, transport, evolution, and mixing in the troposphere, J. Atmos. Sci., 59(3), 363-382, 2002.

Clarke, A., Kapustin, V., Howell, S., Moore, K., Lienert, B., Masonis, S., Anderson, T., and Covert, D.: Sea-salt size distributions from breaking waves: Implications for marine aerosol production and optical extinction measurements during SEAS, J. Atmos. Ocean. Technol., 20(10), 1362-1374, 2003.

Clarke, A. D. and Porter, J. N.: Pacific marine aerosol 2. equatorial gradients in chlorophyll, ammonium, and excess sulfate during SAGAA-3, J. Geophys. Res., 98(D9), 16 997-17 010, 1993.

Clarke, A. D., Porter, J. N., Valero, F. P. J., and Pilewskie, P.: Vertical profiles, aerosol microphysics, and optical closure during the Atlantic Stratocumulus Transition Experiment: Measured and modeled column optical properties, J. Geophys. Res., 101(D2), 4443-4453, 1996.

Clarke, A. D., Shinozuka, Y., Kapustin, V. N., Howell, S., Huebert, B., Doherty, S., Anderson, T., Covert, D., Anderson, J., Hua, X., Moore, I. K. G., McNaughton, C., Carmichael, G., and Weber, R.: Size distributions and mixtures of dust and black carbon aerosol in Asian outflow: Physiochemistry and optical properties, J. Geophys. Res., 109(D15), doi:10.1029/2003JD004378, 2004.

CCSP (Climate Change Science Program): Our Changing Planet. The U.S. Climate Change Science Program for FY 2004 and 2005, 150 p., 2004.

Collins, D. R., Jonsson, H. H., Seinfeld, J. H., Flagan, R. C., Gassó, S., Hegg, D. A., Russell, P. B., Schmid, B., Livingston, J. M., Öström, E., Noone, K. J., Russell, L. M., and Putaud, J. P.: In Situ Aerosol Size Distributions and Clear Column Radiative Closure During ACE-2, Tellus, 52B, 498-525, 2000.

Collins, W. D., Rasch, P. J., Eaton, B. E., Khattatov, B. V., Lamarque, J.-F., and Zender, C. S.: Simulating aerosols using a chemical transport model with assimilation of satellite aerosol retrievals: Methodology for INDOEX, J. Geophys. Res., 106(D7), 7313-7336, 2001.

Conant, W. C., Seinfeld, J. H., Wang, J., Carmichael, G. R., Tang, Y., Uno, I., Flatau, P. J., Markowicz, K. M., and Quinn, P. K.: A model for the radiative forcing during ACE-Asia derived from CIRPAS Twin Otter and R/V Ronald H. Brown data and comparison with observations, J. Geophys. Res., 108(D23), 8661, doi:10.1029/2002JD003260, 2003.
Cooke, W. F. and Wilson, J. J. N.: A global black carbon aerosol model. J. Geophys. Res., 101(D14), 19395-19409, 1996.

Cruz, C. N. and Pandis, S. N.: Deliquescence and hygroscopic growth of mixed inorganic-organic atmospheric aerosol, Environ. Sci. Technol., 38, 4797-4809, 2000.

Cziczo, D. J., DeMott, P. J., Brooks, S. D., Prenni, A. J., Thomson, D. S., Baumgardner, D., Wilson, J. C., Kreidenweis, S. M., and Murphy, D. M.: Observations of organic species and atmospheric ice formation, Geophys. Res. Lett., 31(12), doi:10.1029/2004GL019822, 2004.

d'Almeida, G., Koepke, P., and Shettle, E. P.: Atmospheric aerosols: Global climatology and radiative characteristics, A. Deepak Pub., Hampton, VA, 561 p., 1991.

deGouw, J. A., Middlebrook, A. M., Warneke, C., Goldan, P. D., Kuster, W. C., Roberts, J. M., Fehsenfeld, F. C., Worsnop, D. R., Canagaratna, M. R., Pszenny, A. A. P., Keene, W. C., Marchewka, M., and Bertman, S. B.: The budget of organic carbon in a polluted atmosphere: Results from the New England Air Quality Study in 2002, J. Geophys. Res., 110(D16), doi:10.1029/2004JD004662, 2005.

Delene, D. and Ogren, J. A.: Variability of aerosol optical properties at four North American surface monitoring sites, J. Atmos. Sci., 59, 1135-1150, 2002

Dentener, F. J., Carmichael, G. R., Zhang, Y., Lelieveld, J., and Crutzen, P. J.: Role of mineral aerosol as a reactive surface in the global troposphere, J. Geophys. Res., 101, 22 869-22 889, 1996.

Doherty, S. J., Quinn, P., Jefferson, A., Carrico, C., Anderson, T. L., and Hegg, D.: A comparison and summary of aerosol optical properties as observed in- situ from aircraft, ship and land during ACE-Asia, J. Geophys. Res., 110(D4), doi:10.1029/2004JD004964, 2005.

Dubovik, O., Holben, B. N., Eck, T. F., Smirnov, A., Kaufman, Y. J., King, M. D., Tanre, D., and Slutsker, I.: Variability of absorption and optical properties of key aerosol types observed in worldwide locations, J. Atmos. Sci., 59, 590-608, 2002.

Dubovik, O. and King, M. D.: A flexible inversion algorithm for retrieval of aerosol optical properties from Sun and sky radiance measurements, J. Geophys. Res., 105(D16), 20 673-20 696, 2000.

Dufresne, J.-L., Gautier, C., Ricchiazzi, P., and Fouquart, Y.: Longwave Scattering Effects of Mineral Aerosols, J. Atmos. Sci., 59, 1959-1966, 2002

Durkee, P. A., Nielsen, K. E., Smith, P. J., Russell, P. B., Schmid, B., Livingston, J. M., Holben, B. N., Tomasi, C., Vitale, V., Collins, D., Flagan, R. C., Seinfeld, J. H., Noone, K. J., Ostrom, E., Gasso, S., Hegg, D., and Russell, L.M.: Regional aerosol optical depth characteristics from satellite observations: ACE-1, TARFOX and ACE-2 results, Tellus, 52(2), 484-497, 2000.

Durkee, P. A., Noone, K. J., and Bluth, R. T.: The Monterey area ship track experiment, J. Atmos. Sci., 57, 2523-2541, 2000.

Eldering, A., Ogren, J. A., Chowdhury, Z., Hughes, L. S., and Cass, G. R.: Aerosol optical properties during INDOEX based on measured aerosol particle size and composition. J. Geophys. Res., 107(D22), 8001, doi:10.1029/2001JD001572, 2002.

Fahey, D. W. and Schumann, U.: Aviation-produced aerosols and cloudiness, in Aviation and the Global Atmosphere, Intergovernmental Panel on Climate Change, (IPCC), Cambridge Univ. Press, Cambridge, UK, 1999. 
Faiz, A., Gautam, S., and Gwilliam, K. M.: Technical and policy options for reducing emissions from 2-stroke engine vehicles in Asia, Int. J. Vehicle Design, 34, 1-11, 2004.

Formenti, P., Elbert, W., Maenhaut, W., Haywood, J., Osborne, S., and Andreae, M.O.: Inorganic and carbonaceous aerosols during the Southern African Regional Science Initiative (SAFARI 2000) experiment: Chemical characteristics, physical properties, and emission data for smoke from African biomass burning, J. Geophys. Res., 108(D13), 8488, doi:10.1029/2002JD002408, 2003.

Fortuin, P. and Kelder, H.: An ozone climatology based on ozonesonde and satellite measurements, J. Geophys. Res., 103, $31709-31734,1998$.

Freidenreich, S. M. and Ramaswamy, V.: A new multiple-band solar radiative parameterization for general circulation models, J. Geophys. Res., 104, 31 389-31 409, 1999.

Fuller, K. A., Malm, W. C., and Kreidenweis, S. M.: Effects of mixing on extinction by carbonaceous particles, J. Geophys. Res., 104(D13), 15 941-15 954, doi:10.1029/1998JD100069, 1999.

Gabriel, R., Mayol-Bracero, O. L., and Andreae, M. O.: Chemical characterization of submicron aerosol particles collected over the Indian Ocean, J. Geophys. Res., 107, 8005, doi:10.1029/2000JD000034, 2002.

Gao, S., Keywood, M., Ng, N. L., Surratt, J., Varutbangkul, V., Bahreini, R., Flagan, R. C., and Seinfeld, J. H.: Low-molecularweight and oligomeric components in secondary organic aerosol from the ozonolysis of cycloalkenes and alpha-pinene, J. Phys. Chem., 108(46), 10 147-10 164, doi:10.1021/jp047466e, 2004.

GAMDT - Geophysical Fluid Dynamics Laboratory (GFDL) Global Atmospheric Model Development Team: The new GFDL global atmosphere and land model AM2-LM2: Evaluation with prescribed SST simulations, J. Climate, 17, 4641-4673, 2004.

Gillette, D. A. and Hanson, K. J.: Spatial and temporal variability of dust production caused by wind erosion in the United States, J. Geophys. Res., 94(D2), 2197-2206, 1989.

Ginoux, P., Chin, M., Tegen, I., Prospero, J. M., Holben, B., Dubovik O., and Lin, S. J.: Sources and distributions of dust aerosols simulated with the GOCART model, J. Geophys. Res., 106(D17), 20 255-20 273, 2001.

Grant, K., Grossman, A., Chuang, C., and Penner, J. E.: Description of a solar radiative transfer model for use in LLNL climate and atmospheric chemistry studies, Lawrance Livermore National Laboratory (LLNL) Report UCID-ID-129949. Available online as a PDF file under http://www.llnl.gov/tid/lof/documents/pdf/ 233048.pdf, 1998.

Grant, K. E., Chuang, C. C., Grossman, A. S., and Penner, J. E.: Modeling the spectral optical properties of ammonium sulfate and biomass burning aerosols: parameterization of relative humidity effects and model results, Atmos. Environ., 33, 26032620, 1999.

Guazzotti, S. A., Suess, D. T., Coffee, K. R., Quinn, P. K., Bates, T. S., Wisthaler, A., Hansel, A., Ball, W. P., Dickerson, R. R., Neusüß, C., Crutzen, P. J., and Prather, K. A.: Characterization of carbonaceous aerosols outflow from India and Arabia: Biomass/biofuel burning and fossil fuel combustion, J. Geophys. Res., 108(D15), 4485, doi:10.1029/2002JD003277, 2003.

Guenther, A., Hewitt, C. N., Erickson, D., Fall, R., Geron, C., Graedel, T., Harley, P., Klinger, L., Lerdau, M., McKay, W. A., Pierce, T., Scholes, B., Steinbrecher, R., Tallamraju, R., Taylor, J., and Zimmerman, P.: A global model of natural volatile organic compound emissions, J. Geophys. Res., 100(D5), 88738892, 1995.

Haltrin, V. I.: One-parameter two-term Henyey-Greenstein phase function for light scattering in seawater, Appl. Optics, 4, 10221028, 2002.

Halthore, R. N., Crisp, D., Schwartz, S. E., Anderson, G. P., Berk, A., Bonnel, B., Boucher, O., Chang, F.-L., Chou, M.-D., Clothiaux, E. E., Dubuisson, P., Fomin, B., Fouquart, Y., Freidenreich, S., Gautier, C., Kato, S., Laszlo, I., Li, Z., Mather, J. H., Plana-Fattori, A., Ramaswamy, V., Ricchiazzi, P., Shiren, Y., Trishchenko, A., and Wiscombe, W.: Intercomparison of shortwave radiative transfer codes and measurements. J. Geophys. Res., 110(D11206), doi:10.1029/2004JD005293, 2005.

Hao, W. M. and Liu, M. H.: Spatial and temporal distribution of tropical biomass burning, Global Biogeochem. Cycles, 8, 495503, 1994.

Haywood, J. M., Ramaswamy, V., and Soden, B. J.: Tropospheric aerosol climate forcing in clear-sky satellite observations over the oceans, Science, 283, 1299-1303, 1999.

Haywood, J. M. and Shine, K. P.: The effect of anthropogenic sulfate and soot aerosol on the clear sky planetary radiation budget, Geophys. Res. Lett., 22, 603-606. 1995.

Hobbs, P. V., Garrett, T. J., Ferek, R. J., Strader, S. R., Hegg, D. A., Frick, G. M., Hoppel, W. A., Gasparovic, R. F., Russell, L. M., Johnson, D. W., O'Dowd, C., Durkee, P. A., Nielsen, K. E., and Innes, G.: Emissions from ships with respect to their effects on clouds, J. Atmos. Sci., 57, 2570-2590, 2000.

Holben B. N., Eck, T. F., Slutsker, I., Tanre, D., Buis, J. P., Setzer, A., Vermote, E., Reagan, J. A., Kaufman, Y. J., Nakajima, T., Lavenu, F., Jankowiak, I., and Smirnov, A.: AERONET - A federated instrument network and data archive for aerosol characterization, Remote Sens. Environ., 66, 1-16, 1998.

Holben, B. N., Tanré, D., Smirnov, A., Eck., T. F., Slutsker, I., Abuhasan, N., Newcomb, W. W., Schafer, J. S., Chatenet, B., Lavenu, F., Kaufman, Y. J., Vande Castle, J., Setzer, A., Markham, B., Clark, D., Frouin, R., Halthore, R., Karneli, A., O’Neill, N. T., Pietras, C., Pinker, R. T., Voss, K., and Zibordi, G.: An emerging ground-based aerosol climatology: Aerosol optical depth from AERONET, J. Geophys. Res., 106, $12067-$ $12097,2001$.

Horowitz, L. W., Walters, S., Mauzerall, D. L., Emmons, L. K., Rasch, P. J., Granier, C., Tie, X., Lamarque, J.-F., Schultz, M. G., Tyndall, G. S., Orlando, J. J., and Brasseur, G. P.: A global simulation of tropospheric ozone and related tracers: Description and evaluation of Mozart, version 2, J. Geophys. Res., 108(D24), 4784, doi:10.1029/2002JD002853, 2003.

Howell, S. G., Clarke, A. D., Shinozuka, Y., Kapustin, V. N., McNaughton, C. S., Doherty, S., and Anderson, T.: The influence of relative humidity upon pollution and dust during ACE-Asia: size distributions and implications for optical properties, J. Geophys. Res., 111, D06205, doi:10.1029/2004JD005759, 2006.

Hudson, P. K., Murphy, D. M., Cziczo, D. J., Thomson, D. S., de Gouw, J. A., Warneke, C., Holloway, J., Jost, H. J., and Hübler, G.: Biomass-burning particle measurements: Characteristic composition and chemical processing, J. Geophys. Res., 109(D23), doi:10.1029/2003JD004398, 2004.

Huebert, B. J.: Reactive gases and aerosols: What we did (and didn't) learn from ACE-Asia, Geochim. Cosmochim. Acta, 67(18), A162-A162, 2003. 
Huebert, B. J., Bates, T. S., Russell, P. B., Shi, G., Kim, Y. J., Kawamura, K., Carmichael, G., and Nakajima, T.: An overview of ACE-Asia: strategies for quantifying the relationships between Asian aerosols and their climatic impacts. J. Geophys. Res., 108(D23), 8633, doi:10.1029/2003JD003550, 2003.

Huebert, B., Bertram, T., Howell, S. G., Eatough, D., Kline, J., and Blomquist, B.: Measurements of organic and elemental carbon in Asian outflow during ACE- ASIA from the NSF/NCAR-C130, J. Geophys. Res., 109, doi:10.1029/2004JD004700, 2004.

Huebert, B., Bertram, T., Kline, J., Howell, S., Eatough, D., and Blomquist, B.: Measurements of organic and elemental carbon in Asian outflow during ACE-Asia from the NSF/NCAR C-130, J. Geophys. Res., 109(D19S11), doi:10.1029/2004JD004700, 2004

IPCC (Intergovernmental Panel on Climate Change): Radiative forcing of climate change, in: Climate Change 2001, Cambridge Univ. Press, New York, 2001.

Jacob, D. J., Crawford, J. H., Kleb, M. M., Connors, V. S., Bendura, R. J., Raper, J. L., Sachse, G. W., Gille, J. C., Emmons, L., and Heald, C. L.: The Transport and Chemical Evolution over the Pacific (TRACE-P) aircraft mission: design, execution, and first results, J. Geophys. Res., 108, 9000, doi:10.1029/2002JD003276, 2003.

Jacobson, M. Z.: Global direct radiative forcing due to multicomponent anthropogenic and natural aerosols, J. Geophys. Res., 106, 1551-1568, 2001.

Jaffe, D., Bertschi, I., Jaeglé, L., Novelli, P., Reid, J. S., Tanimoto, H., Vingarzan, R., and Westphal, D. L.: Long-range transport of Siberian biomass burning emissions and impact on surface ozone in western North America, Geophys. Res. Lett., 31(16), doi:10.1029/2004GL020093, 2004.

Jang, M., Czoschke, N. M., Lee, S., and Kamens, R. M.: Heterogeneous atmospheric aerosol production by acid-catalyzed particlephase reactions, Science, 298, 814-817, 2002.

Johnson, G. R., Ristovski, Z., and Morawska, L.: Method for measuring the hygroscopic behavior of lower volatility fractions of an internally mixed aerosol., J. Aerosol Sci., 35, 443-455, 2004.

Kahn, R., Anderson, J., Anderson, T.L., Bates, T., Brechtel, F., Carrico, C. M., Clarke, A., Doherty, S. J., Dutton, E., Flagan, R., Frouin, R., Fukushima, H., Holben, B., Howell, S., Huebert, B., Jefferson, A., Jonsson, H., Kalashnikova, O., Kim, J., Kim, S.W., Kus, P., Li, W.-H., Livingston, J. M., McNaughton, C., Merrill, J., Mukai, S., Murayama, T., Nakajima, T., Quinn, P., Redemann, J., Rood, M., Russell, P., Sano, I., Schmid, B., Seinfeld, J., Sugimoto, N., Wang, J., Welton, E. J., Won, J.-G., and Yoon, S.C.: Environmental snapshots from ACE-Asia, J. Geophys. Res., 109(D19), doi:10.1029/2003JD004339, 2004.

Kalberer, M., Paulsen, D., Sax, M., Steinbacher, M., Dommen, J., Prevot, A. S. H., Fisseha, R., Weingartner, E., Frankevich, V., Zenobi, R., and Baltensperger, U.: Identification of polymers as major components of atmospheric organic aerosols, Science, 303, 1659-1662, 2004.

Kasibhatla, P., Arellano, A., Logan, J. A., Palmer P. I., and Novelli, P.: Top- down estimate of a large source of atmospheric carbon monoxide associated with fuel combustion in Asia, Geophys. Res. Lett., 29(19), 1900, doi:10.1029/2002GL015581, 2002.

Kanakidou, M., Seinfeld, J. H., Pandis, S. N., Barnes, I., Dentener, F. J., Faccini, M. C., Van Dingenen, R., Ervens, B., Nenes, A., Nielsen, C. J., Swietliki, E., Putaud, J. P., Balkanski, Y., Fuzzi,
S., Horth, J., Moortgat, G. K., Winterhalter, R., Meyhr, C., Tsigaridis, K., Vignati, E., Stephanou, E. G., and Wilson, J.: Organic aerosol and global climate modeling: a review, Atmos. Chem. Phys., 5, 1053-1123, 2005.

Kiley, C. M., Fuelberg, H. E., Palmer, P. I., Allen, D. J., Carmichael, G. R., Jacob, D. J., Mari, C., Pierce, R. B., Pickering, K. E., Tang, Y. H., Wild, O., Fairlie, T. D., Logan, J. A., Sachse, G. W., Shaack, T. K., and Streets, D. G.: An intercomparison and evaluation of aircraft-derived and simulated $\mathrm{CO}$ from seven chemical transport models during the TRACE-P experiment, J. Geophys. Res., 108(D21), 8819, doi:10.1029/2002JD003089, 2003.

Kim, Y. P. and Seinfeld, J. H.: Atmospheric gas aerosol equilibrium 3: Thermodynamics of crustal elements $\mathrm{Ca}^{2+}, \mathrm{K}^{+}$, and $\mathrm{Mg}^{2+}$, Aerosol Sci. Technol., 22(1), 93-110, 1995.

Kim, Y. P., Seinfeld, J. H., and Saxena, P.: Atmospheric gas aerosol equilibrium 2: Analysis of common approximations and activitycoefficient calculation methods, Aerosol Sci. Technol., 19(2), 182-198, 1993b.

Kim, Y. P., Seinfeld, J. H., and Saxena, P.: Atmospheric gas aerosol equilibrium 1: Thermodynamic model, Aerosol Sci. Technol., 19(2), 157-181, 1993a.

Kinne, S., Schulz, M., Textor, C., Guibert, S., Balkanski, Y., Bauer, S., Berntsen, T., Berglen, T., Boucher, O., Chin, M., Collins, W., Dentener, F., Diehl, T., Easter, R., Feichter, H., Fillmore, D., Ghan, S., Ginoux, P., Gong, S., Grini, A., Hendricks, J., Herzog, M., Horrowitz, L., Isaksen, I., Iversen, T., Jones, A., Kloster, S., Koch, D., Krol, M., Lauer, A., Lamarque, J.-F., Lesins, G., Liu, X., Lohmann, U., Montanaro, V., Myhre, G., Penner, J., Pitari, G., Reddy, S., Roberts, D., Seland, O., Stier, P., Takemura, T., and Tie, X.: An AeroCom initial assessment optical properties in aerosol component modules of global models, Atmos. Chem. Phys. Discuss., 5, 8285-8330, 2005.

Kirchstetter, T. W., Novakov, T., and Hobbs, P. V.: Evidence that the spectral dependence of light absorption by aerosols is affected by organic carbon, J. Geophys. Res., 109(D21208), doi:10.1029/2004JD004999, 2004.

Kittlelson, D. B.: Engines and nanoparticles, J. Aerosol Sci. 29(5/6), 575-588, 1998.

Kleeman, M. J., Schauer, J. J., and Cass, G. R.: Size and composition distribution of fine particulate matter from motor vehicles, Environ. Sci. Technol., 34(7), 1132-1142, 2000.

Kline, J., Huebert, B., Howell, S., Blomquist, B., Zhuang, J., Bertram, T., and Carrillo, J.: Aerosol composition and size vs altitude measured from the C-130 during ACE-Asia, J. Geophys. Res., 109(D19508), doi:10.1029/2004JD004540, 2004.

Lafon, S., Rajot, J., Sokolik, I., Caquineau, S., Alfaro, S. C., Formenti, P., Maille, M., and Gaudichet, A.: Comprehensive Characterization of Size-resolved Composition and Morphology of Mineral Dust Particles for Radiative Forcing Studies, AGU annual meeting, San Francisco, A23C-0815, 2004.

Langmann, B., Herzog, M., and Graf, H.: Radiative forcing of climate by sulfate aerosols as determined by a regional circulation chemistry transport model, Atmos. Environ., 32, $2757-$ 2768, 1998.

Lee, Y.-N., Weber, R. J., Ma, Y., Orsini, D., Maxwell, K., Blake, D., Meinardi, S., Sachse, G., Harward, C., Clarke, A. D., Moore, K., Kapustin, V. N., Chen, T.-Y., Thornton, D. C., Tu, F. H., and Bandy, A. R.: Airborne measurement of inorganic ionic components of fine aerosol particles using the PILS-IC technique during 
ACE-ASIA and TRACE-P, J. Geophys. Res., 108(D23), 8646, doi:10.1029/2002JD003265, 2003.

Lewis, E. R. and Schwartz, S. E.: Sea Salt Aerosol Production Mechanisms, Methods, Measurements, and Models. Geophysical Monograph Series Vol. 152, American Geophysical Union, Washington, 413 pp. ISBN: 0-87590-417-3, 2004.

Liao, H. and Seinfeld, J. H.: Global impacts of gas-phase chemistry-aerosol interactions on direct radiative forcing by anthropogenic aerosols and ozone, J. Geophys. Res.,110, D18208, doi:10.1029/2005JD005907, 2005.

Limbeck, A., Kulmala, M., and Puxbaum, H.: Secondary organic aerosol formation in the atmosphere via heterogeneous reaction of gaseous isoprene on acidic particles, Geophys. Res. Lett., 30(19), 1996, doi:10.1029/2003GL017738, 2003.

Liousse, C., Penner, J. E., Chuang, J., Walton, J. J., Eddleman, H., and Cachier, H.: A global three-dimensional model study of carbonaceous aerosols, J. Geophys. Res.. 101, 19411-19432, 1996.

Liu, M. and Westphal, D. L.: A study of the sensitivity of simulated mineral dust production to model resolution, J. Geophys. Res., 106(D16), 18 099-18 112, doi:10.1029/2000JD900711, 2001.

Lohmann, U., Feichter, J., Chuang, C. C., and Penner, J. E.: Prediction of the number of cloud droplets in the ECHAM GCM, J. Geophys. Res., 104(D8), 9169-9198, 1999.

Lund Myhre, C. E. and Nielsen, C. J.: Optical properties in the UV and visible spectral region of organic acids relevant to tropospheric aerosols, Atmos. Chem. Phys., 4, 1759-1769, 2004.

Madronich, S. and Flocke, S.: The role of solar radiation in atmospheric chemistry, Handbook of Environmental Chemistry, Vol. 2, Part I. Environmental Photochemistry, P. Boule, Springer Verlag, 1999.

Magi, B. I., Hobbs, P. V., Schmid, B., and Redemann, J.: Vertical profiles of light scattering, light absorption and single scattering albedo during the dry, biomass burning season in southern Africa and comparisons of in-situ and remote sensing measurements of aerosol optical depths, J. Geophys. Res., 108(D13), 8504, doi:10,1029/2002JD002361, 2003.

Malm, W. C., Sisler, J. F., Huffman, D., Eldred, R. A., and Cahill, T. A.: Spatial and seasonal trends in particle concentration and optical extinction in the United States, J. Geophys. Res., 99, 13471370, 1994.

Mamane, Y., Miller, J. L., and Dzubay, T. G.: Characterization of individual fly ash particles emitted from coal- and oil-fired power plants, Atmos. Environ., 20, 2125-2135, 1986.

Marcolli, C., Lou, B., Peter, T., and Weingold, F. G.: Internal mixing of the organic aerosol by gas phase diffusion of semivolatile organic compounds, Atmos. Chem. Phys., 4, 2593-2599, 2004.

Markowicz, K. M., Flatau, P. J., Quinn, P. K., Carrico, C. M., Flatau, M. K., Vogelmann, A. M., Bates, D., Liu, M., and Rood, M.: Influence of relative humidity on aerosol radiative forcing: An ACE-Asia experiment perspective, J. Geophys. Res., 108(D23), 8662, doi:10.1029/2002JD003066, 2003.

Maria, S. F., Russell, L. M., Gilles, M. K., and Myneni, S. C. B.: Organic aerosol growth mechanisms and their climate forcing implications, Science, 306, 1921-1924, 2004.

Maria, S. F., Russell, L. M., Turpin, B. J., Porcja, R. J., Campos, T. L., Weber, R. J., and Huebert, B. J.: Source signatures of carbon monoxide and organic functional groups in Asian Pacific Regional Aerosol Characterization Experiment (ACE-Asia) submicron aerosol types, J. Geophys. Res., 108(D23), 8637,
doi:10.1029/2003JD003703, 2003.

Martin, S. T.: Phase transitions of aqueous atmospheric particles, Chem. Rev. 100, 3403-3453, 2000.

Martin, S. T., Schlenker, J. C., Malinowski, A., Hung, H.-M., and Rudich, Y.: Crystallization of atmospheric sulfate-nitrateammonium particles, Geophys. Res. Lett., 30, 2102-2105, doi:10.1029/2003GL017930, 2003.

Mayol-Bracero, O. L., Gabriel, R., Andreae, M. O., Kirchstetter, T.W., Novakov, T., Ogren, J., Sheridan, P., and Streets, D. G.: Carbonaceous aerosols over the Indian Ocean during the Indian Ocean Experiment (INDOEX): Chemical characterization, optical properties, and probable sources, J. Geophys. Res., 107, 8030, doi:10.1029/2000JD000039, 2002.

McNaughton, C. S., Clarke, A. D., Howell, S. G., Moore, K. G., Brekhovskikh, V. L., Weber, R. J., Orsini, D. A., Covert, D. S., Buzorius, G., Brechtel, F. J., Carmichael, G. R., Tang, Y., Eisele, F. L., Mauldin, R. L., Bandy, A. R., Thornton, D. C., and Blomquist, B.: Spatial distribution and size evolution of particles in Asian outflow: Significance of primary and secondary aerosols during ACE-Asia and TRACE-P, J. Geophys. Res., 109, doi:10.1029/2003JD003528, 2004.

Middlebrook, A. M., Murphy, D. M., and Thomson, D. S.: Observations of organic material in individual marine particles at Cape Grim during the first Aerosol Characterization Experiment (ACE 1), J. Geophys. Res., 103, 16475-16483, 1998.

Ming, Y. and Russell, L. M.: Predicted hygroscopic growth of sea salt aerosol, J. Geophys. Res., 106(D22), 28 259-28 274, 2001.

Minnis, P., Schumann, U., Doelling, D. R., Gierens, K. M., and Fahey, D. W.: Global distribution of contrail radiative forcing, Geophys. Res. Lett., 26, 1853-1856, 1999.

Mishchenko, M. I., Liu, L., Travis, L. D., and Lacis, A. A.: Scattering and radiative properties of semi-external versus external mixtures of different aerosol types, J. Quant. Spectrosc. Radiat. Transfer, 88, 139-147, 2004a.

Mishchenko, M. I., Cairns, B., Hansen, J. E., Travis, L.D., Burg, R., Kaufman, Y. J., Vanderlei, M. J., and Shettle, E. P.: Monitoring of aerosol forcing of climate from space: analysis of measurement requirements, J. Quant. Spectrosc. Radiat. Trans., 88, 149-161, 2004 b.

Monahan, E. C.: The ocean as a source of atmospheric particles, The Role of Air- Sea Exchange in Geochemical Cycling, P. Buat-Menard, Kluwer Academic Publishers, Dordrecht, Holland, 129-163, 1986.

Moore, K. G., Clarke, A. D., Kapustin, V. N., and Howell, S. G.: Long-range transport of continental plumes over the $\mathrm{Pa}$ cific Basin: Aerosol physiochemistry and optical properties during PEM-Tropics A and B, J. Geophys. Res., 108(D2), 8236, doi:10.1029/2001JD001451, 2003.

Müller, J. F.: Geographical-distribution and seasonal-variation of surface emissions and deposition velocities of atmospheric trace gases, J. Geophys. Res., 97(D4), 3787-3804, 1992.

Murphy, D. M., Anderson, J. R., Quinn, P. K., McInnes, L. M., Brechtel, F. J., Kreidenweis, S. M., Middlebrook, A. M., Posfai, M., Thomson, D. S., and Buseck, P. R.: Influence of sea-salt on aerosol radiative properties in the Southern Ocean marine boundary layer, Nature, 392(6671), 62-65, 1998a.

Murphy, D. M., Thomson, D. S., and Mahoney, M. J.: In situ measurements of organics, meteoritic material, mercury, and other elements in aerosols at 5 to 19 kilometers, Science, 282, 1664- 
1669, 1998b.

Murphy, D. M. and Thomson, D. S.: Chemical composition of single aerosol particles at Idaho Hill, J. Geophys. Res., 102, 6341$6368,1997$.

Myhre, G., Jonson, J. E., Bartnicki, J., Stordal, F., and Shine, K. P.: Role of spatial and temporal variations in the computation of radiative forcing due to sulphate aerosols: A regional study, Q. J. R. Meteorol. Soc., 128, 973-989, 2002.

Nemesure S., Wagener, R., and Schwartz, S. E.: Direct shortwave forcing of climate by anthropogenic sulfate aerosol: Sensitivity to particle size, composition, and relative humidity, J. Geophys. Res., 100, 26 105-26116, 1995.

Nessler, R., Wintergartner, E., and Baltensberger, U.: Effect of humidity on aerosol light absorption and its implication for extinction and the single scatter albedo illustrated for a site in the lower free troposphere., J. Aerosol Sci., 36(8), 958-972, doi:10.1016/j/aerosolsci.2004.11.012, 2004.

Novakov, T., Hegg, D. A., and Hobbs, P. V.: Airborne measurements of carbonaceous aerosols on the East Coast of the United States, J. Geophys. Res., 102(D25), 30 023-30 030, 1997.

O'Dowd, C. D., Facchini, M. C., Ceburnis, D., Mircea, M., Decesari, S., Fuzzi, S., Yoon, Y. J., and Putaud, J. P.: Biogenically driven organic contribution to marine aerosol, Nature, 431(7009), 676-680, 2004.

Olivier, J. G. J., Bouwman, A. F., van der Maas, C. W. M., Berdowski, J. J. M., Veldt, C., Bloos, J. P. J., Visschedijk, A. J. H., Zanfeld, P. Y. J., and Haverlag, J. L.: Description of Edgar Version 2.0: A set of global emission inventories of greenhouse gases and ozone depleting substances for all anthropogenic and most natural sources on a per country basis and on a $1^{\circ} \times 1^{\circ}$ grid, RIVM Report 771060 002, 1996.

Palmer, P. I., Jacob, D. J., Jones, D. B. A., Heald, C. L., Yantosca, R. M., Logan, J. A., Sachse, G. W., and Streets, D. G.: Inverting for emissions of carbon monoxide from Asia using aircraft observations over the western Pacific, J. Geophys. Res., 108(D21), 8828, doi:10.1029/2003JD003397, 2003.

Penner, J. E., Andreae, M., Annegarn, H., Barrie, L., Feichter, J., Hegg, D., Jayaraman, A., Leaitch, R., Murphy, D., Nganga, J., and Pitari, G.: Chapter 5: Aerosols, their Direct and Indirect Effects, in: Climate Change 2001: The Scientific Basis, edited by: Houghton, J. T., Ding, Y., Griggs, D. J., Noguer, M., van der Linden, P. J., Dai, X., Maskell, K., Johnson, C. A., Report to Intergovernmental Panel on Climate Change from the Scientific Assessment Working Group (WGI), 289-348, Cambridge University Press, 2001.

Penner, J. E., Charlson, R. J., Hales, J. M., Laulainen, N. S., Leifer, R., Novakov, T., Ogren, J., Radke, L. F., Schwartz, S. E., and Travis, L.: Quantifying and minimizing uncertainty of climate forcing by anthropogenic aerosols, Bull. Amer. Meteorol. Soc., 75, 375-400, 1994.

Philippin, S., Wiedensholer, A., and Stratman, F.: Measurements of non-volatile fractions of pollution aerosols with an eight tube volatility tandem differential mobility analyzer (VTDMA-8), J. Aerosol Sci., 35(2), 185-203, 2004.

Phinney, L. A., Leaitch, R., Lohmann, U., Boudries, H., Worsnop, D., Toom- Sauntry, J., Wadleigh, M., Sharma, S., and Schantz, N.: Characterization of aerosol over the sub-arctic NE Pacific During SERIES, Deep Sea Res., in press, 2004.

Pinnick, R. G., Jennings, S. G., and Chylek, P.: Relationships be- tween extinction, absorption, backscattering and mass content of sulfuric acid aerosols. J. Geophys. Res., 85, 4059-4066, 1980.

Podzimek, J.: Physical properties of coarse aerosol particles and haze elements in a polluted urban-marine environment, J. Aerosol Sci., 21, 299-308, 1990.

Pósfai, M., Anderson, J. R., Buseck, P. R., and Sievering, H.: Soot and sulfate aerosol particles in the remote marine troposphere, $\mathrm{J}$. Geophys. Res., 104(D17), 21 685-21 693, 1999.

Pósfai, M., Gelencsér, A., Simonics, R., Arató, K., Li, J., Hobbs, P. V., and Buseck, P. R.: Atmospheric tar balls: Particles from biomass and biofuel burning, J. Geophys. Res., 109(D6), 1-9, doi:10.1029/2003JD004169, 2004.

Pósfai, M., Simonics, R., Li, J., Hobbs, P. V., and Buseck, P. R.: Individual aerosol particles from biomass burning in southern Africa: 1. Compositions and size distributions of carbonaceous particles, J. Geophys. Res., 108(D13), 8483, doi:10.1029/2002JD002291, 2003.

Quinn, P. K., Anderson, T. L., Bates, T. S., Dlugi, R., Heintzenberg, J., von Hoyingen-Huene, W., Kulmala, M., Russell, P. B., and Sweitlicki, E.: Closure in tropospheric research: a review and future needs, Contr. Atmos. Phys. Beitr., 69, 547-577, 1996.

Quinn, P. K. and Bates, T. S.: North American, Asian, and Indian haze: Similar regional impacts on climate?, Geophys. Res. Lett., 30(11), 1555, doi:10.1029/2003GL016934, 2003.

Quinn, P. K. and Bates, T. S.: Regional aerosol properties: Comparisons from ACE 1, ACE 2, Aerosols99, INDOEX, ACE Asia, TARFOX, and NEAQS, J. Geophys. Res., 110(D14), doi:10.1029/2004JD004755, 2005.

Quinn, P. K., Bates, T. S., Baynard, T., Clarke, A. D., Onasch, T. B., Wang, W., Rood, M., Andrews, E., Allan, J., Carrico, C. M., Coffman, D., and Worsnop, D.: Impact of particulate organic matter on the relative humidity dependence of light scattering: A simplified parameterization, Geophys. Res. Lett., 32(L22809), doi:101029/2005GL024322, 2005.

Quinn, P. K., Bates, T. S., Miller, T. L., Coffman, D. J., Johnson, J. E., Harris, J. M., Ogren, J. A., Forbes, G., Anderson, T. L., Covert, D. S., and Rood, M. J.: Surface submicron aerosol chemical composition: What fraction is not sulfate?, J. Geophys. Res., 105, 6785-6806, 2000.

Quinn, P. K. and Coffman, D. J.: Local closure during ACE 1: Aerosol mass concentration and scattering and backscattering coefficients, J. Geophys. Res., 103, 16575-16596, 1998.

Quinn, P. K., Coffman, D. J., Kapustin, V. N., Bates, T. S., and Covert, D. S.: Aerosol optical properties in the marine boundary layer during ACE 1 and the underlying chemical and physical aerosol properties, J. Geophys. Res., 103, 16547-16 563, 1998.

Quinn, P. K., Coffman, D. J., Bates, T. S., Miller, T. L., Johnson, J. E., Welton, E. J., Neusüss, C., Miller, M., and Sheridan, P. J.: Aerosol optical properties during INDOEX 1999, J. Geophys. Res., 107(D19), 8020, doi:10.1029/2000JD000037, 2002.

Quinn, P. K., Coffman, D. J., Bates, T. S., Welton, E. J., Covert, D. S., Miller, T. L., Johnson, J. E., Maria, S., Russell, L., Arimoto, R., Carrico, C. M., Rood, M. J., and Anderson, J.: Aerosol optical properties measured aboard the Ronald $\mathrm{H}$. Brown during ACE-Asia as a function of aerosol chemical composition and source region, J. Geophys. Res., 109(D19), doi:10.1029/2003JD004010, 2004.

Raes, F., Bates, T., McGovern, F., and van Liedekerke, M.: The 2nd Aerosol Characterization Experiment (ACE-2): General 
overview and main results, Tellus, 52B, 111-125, 2000.

Ramachandran, S., Ramaswamy, V., Stenchikov, G. L., and Robock, A.: Radiative impact of the Mount Pinatubo volcanic eruption: Lower stratospheric response, J. Geophys. Res., 105, 24 409-24 429, 2000.

Ramanathan, V. and Vogelmann, A. M.: Greenhouse Effect, Atmospheric Solar Absorption, and the Earth's Radiation Budget: From the Arrhenius-Langely Era to the 1990's, Ambio, 26(1), 38-46, 1997.

Ramanathan, V., Crutzen, P. J., Kiehl, J. T., and Rosenfeld, D.: Aerosols, climate, and the hydrological cycle, Science, 294, 2119-2124, 2001a.

Ramanathan, V., Crutzen, P. J., Lelieveld, J., et al.: Indian Ocean Experiment: An integrated analysis of the climate forcing and effects of the great Indo- Asian haze, J. Geophys. Res., 106, 28371-28 398, 2001b.

Ramaswamy, V. and Bowen, M. M.: Effect of changes in radiatively active species upon the lower stratospheric temperatures, J. Geophys. Res., 99, 18 909-18 921, 1994.

Randles, C. A., Russell, L. M., and Ramaswamy, V.: Hygroscopic and optical properties of organic sea salt aerosol and consequences for climate forcing, Geophys. Res. Lett., 31(L16108), doi:10.1029/2004GL020628, 2004.

Rasch, P. J., Barth, M. C., Kiehl, J. T., Schwartz, S. E., and Benkovitz, C. M.: A description of the global sulfur cycle and its controlling processes in the National Center for Atmospheric Research Community Climate Model, Version 3, J. Geophys. Res., 105, 1367-1385, 2000.

Reddy, M. S., Boucher, O., Bellouin, N., Schulz, M., Balkanski, Y., Dufresne, J.-L., and Pham, M.: Estimates of global multi-component aerosol optical depth and direct radiative perturbation in the Laboratoire de Météorologie Dynamique general circulation model, J. Geophys. Res., 110(D10S16), doi:10.1029/2004JD004757, 2005a.

Reddy, M. S., Boucher, O., Schulz, M., and Balkanski, Y.: Aerosol optical depths and direct radiative perturbations by species and source type, Geophys. Res. Lett., 32(L12803), doi:10.1029/2004GL021743, 2005b.

Reddy, M. S., Boucher, O., Venkataraman, C., Verma, S., León, J.-F., Bellouin, N., and Pham, M.: General circulation model estimates of aerosol transport and radiative forcing during the Indian Ocean Experiment, J. Geophys. Res., 109(D16205), doi:10.1029/2004JD004557, 2004.

Redemann, J., Masonis, S. J., Schmid, B., Anderson, T. L., Russell, P. B., Livingston, J. M., Dubovik, O., and Clarke, A. D.: Clear-column closure studies of aerosols and water vapor aboard the NCAR C-130 during ACE-Asia, 2001, J. Geophys. Res., 108(D23), 8655, doi:10.1029/2003JD003442, 2003.

Riemer, N., Vogel, H., Vogel, B., and Fiedler, F.: Modeling aerosols on the mesoscale: Treatment for soot aerosol and radiative effects, J. Geophys. Res., 108(D19), doi:10.1029/2003JD003448, 2004.

Rijkeboer, R., Bremmers, D., Samaras, Z., and Ntziachristos, L.: Particulate matter regulation for two-stroke two wheelers: Necessity or haphazard legislation? Atmos. Environ., 39, 24832490, 2005.

Russell, L. M., Maria, S. F., and Myneni, S. C. B.: Mapping organic coatings on atmospheric particles, Geophys. Res. Lett., 29(16), 1029, doi:10.1029/2002GL014874, 2002.
Russell, P. B., Livingston, J. M., Hignett, P., Kinne, S., Wong, J., Chien, A., Bergstrom, R., Durkee, P., and Hobbs, P. V.: Aerosolinduced radiative flux changes off the United States mid-Atlantic coast: Comparison of values calculated from sunphotometer and in situ data with those measured by airborne pyranometer, J. Geophys. Res., 104, 2289-2307, 1999.

Saathoff, H., Naumann, K. H., Schnaiter, M., Schöck, W., Möhler, O., Schurath, U., Weingartner, E., Gysel, M., and Baltensperger, $\mathrm{U}$ : Coating of soot and $\left(\mathrm{NH}_{4}\right)_{2} \mathrm{SO}_{4}$-particles by ozonolysis of a-pinene, J. Aerosol Sci., 34, 1297, doi:10.1016/S00218502(03)00364-1, 2003.

Satheesh, S. K. and Ramanathan, V.: Large differences in tropical aerosol forcing at the top of the atmosphere and the Earth's surface, Nature, 304, 60-62, 2000.

Schmid, B., Hegg, D. A., Wang, J., Bates, D., Redemann, J., Russell, P. B., Livingston, J. M., Jonsson, H. H., Welton, E. J., Seinfeld, J. H., Flagan, R. C., Covert, D. S., Dubovik, O., and Jefferson, A.: Column closure studies of lower tropospheric aerosol and water vapor during ACE-Asia using airborne Sun photometer and airborne in situ and ship-based lidar measurements, J. Geophys. Res., 108(D23), 8656, doi:10.1029/2002JD003361, 2003.

Schmid, B., Livingston, J. M., Russell, P. B., Durkee, P. A., Jonsson, H. H., Collins, D. R., Flagan, R. C., Seinfeld, J. H., Gasso, S., Hegg, D. A., Ostrom, E., Noone, K. J., Welton, E. J., Voss, K. J., Gordon, H. R., Formenti, P., and Andreae, M. O.: Clear-sky closure studies of lower tropospheric aerosol and water vapor during ACE-2 using airborne sunphotometer, airborne in-situ, spaceborne, and ground-based measurements, Tellus, 52(2), 568-593, 2000.

Schwartz, S. E.: Uncertainty requirements in radiative forcing of climate change, J. Air Waste Management Assoc., 54, 13511559, 2004.

Sellegri, K., Laj, P., Peron, F., Dupuy, R., Legrand, M., Preunkert, S., Putaud, J., Cachier, H., and Ghermandi, G.: Mass balance of free tropospheric aerosol at the Puy de Dôme (France) in winter, J. Geophys. Res., 108(D11), 4333, doi:10.1029/2002JD002747, 2003.

Sheridan, P. J., Brock, C. A., and Wilson, J. C.: Aerosol particles in the upper troposphere and lower stratosphere: Elemental composition and morphology of individual particles in northern midlatitudes, Geophys. Res. Lett., 21, 2587-2590, 1994.

Sheridan, P., Jefferson, A., and Ogren, J.: Spatial variability of submicrometer aerosol radiative properties over the Indian Ocean during INDOEX, J. Geophys. Res., 107(D19), 8011, doi:10.1029/2000JD000166, 2002.

Shettle, E. P. and Fenn, R. W.: Models for the aerosols of the lower atmosphere and the effects of humidity variations on their optical properties, Technical Paper AFGL-TR-79-0214, Air Force Geophysics Laboratory, Hanscom Air Force Base, Hanscom, MA, 1979.

Shi, Z., Shao, L., Jones, T. P., Whittaker, A. G., Lu, S., Bérubé, K. A., He, T., and Richards, R. J.: Characterization of airborne individual particles collected in an urban area, a satellite city, and a clean air area in Beijing, 2001, Atmos. Environ., 37, 40974108, 2003.

Shinozuka, Y., Clarke, A. D., Howell, S. G., Kapustin, V. N., and Huebert, B. J., Sea-salt vertical profiles over the Southern and tropical Pacific oceans: Microphysics, optical properties, spa- 
tial variability, and variations with wind speed, J. Geophys. Res., 109(D24201), doi:10.1029/2004JD004975, 2004.

Sinha, P., Hobbs, P. V., Yokelson, R. J., Christian, T. J., Kirchstetter, T. W., and Bruintjes, R.: Emissions of trace gases and particles from two ships in the southern Atlantic Ocean, Atmos. Environ., 37, 2139-2148, 2003.

Smirnov, A., Holben, B. N., Eck, T. F., Dubovik, O., and Slutsker, I.: Cloud screening and quality control algorithms for the AERONET database, Remote Sens. Environ., 73, 337-349, 2000.

Song, C. H. and Carmichael, G. R.: A three-dimensional modeling investigation of the evolution processes of dust and sea-salt particles in east Asia, J. Geophys. Res., 106(D16), 18 131-18 154, doi:10.1029/2000JD900352, 2001.

Song, C. H., Meier, K., Weber, R. J., Kapustin, V., and Clarke, A.: Dust composition and mixing state inferred from airborne composition measurements during ACE-Asia C130 Flight 6, Atmos. Environ., 39, 359-369, 2005.

Stelson, A. W. and Seinfeld, J. H.: Relative humidity and pH dependence of the vapour pressure of ammonium nitrate-nitric acid solutions at $25^{\circ} \mathrm{C}$. Dependence of the ammonium nitrate dissociation constant. Atmos. Environ., 16, 993-1000, 1982.

Streets, D. G., Bond, T. C., Carmichael, G. R., Fernandes, S. D., Fu, Q., He, D., Klimont, Z., Nelson, S. M., Tsai, N. Y., Wang, M. Q., Woo, J. H., and Yarber, K. F.: An inventory of gaseous and primary aerosol emissions in Asia in the year 2000, J. Geophys. Res., 108(D21), 8809, doi:10.1029/2002JD003093, 2003.

Streets, D. G., Zhang, Q., Wang, L., He, K., Hao, J., Tang, Y., and Carmichael, G. R.: Revisiting China's $\mathrm{CO}$ emissions after TRACE-P: Synthesis of inventories, atmospheric modeling and observations, J. Geophys. Res., in press, 2006.

Svenningsson, B., Rissler, J., Swietliki, E., Mircea, M., Bilde, M., Facchini, M. C., Decasari, S., Fuzzi, S., Zhou, J., Monster, J., and Roseenhorn, T.: Hygroscopic growth and critical supersaturation for mixed aerosol particles of inorganic and organic compounds of atmospheric relevance, Atmos. Chem. Phys., 5, 2833-2877, 2005 .

Swietlicki, E., Zhou, J. C., Covert, D. S., Hameri, K., Busch, B., Vakeva, M., Dusek, U., Berg, O. H., Wiedensohler, A., Aalto, P., Makela, J., Martinsson, B. G., Papaspiropoulos, G., Mentes, B., Frank, G., and Stratmann, F.: Hygroscopic properties of aerosol particles in the northeastern Atlantic during ACE-2, Tellus, 52, 201-227, 2000.

Tang, I. and Munkelwitz, H. R.: Aerosol growth studies, III, Ammonium bisulfate aerosols in a moist atmosphere, J. Aerosol. Sci., 8, 321-330, 1977.

Tang, I. N.: Chemical and size effects of hygroscopic aerosols on light scattering coefficients, J. Geophys. Res., 101, 19245 $19250,1996$.

Tang, I. N., Tridico, A. C., and Fung, K. H.: Thermodynamic and optical properties of sea salt aerosols, J. Geophys. Res., 102(D19), 23 269-23 276, doi:10.1029/97JD01806, 1997.

Tang, Y., Carmichael, G. R., Seinfeld, J. H., Dabdub, D., Weber, R. J., Huebert, B., Clarke, A. D., Guazzotti, S. A., Sodeman, D. A., Prather, K. A., Uno, I., Woo, J.-H., Streets, D. G., Quinn, P. K., Johnson, J. E., Song, C.-H., Sandu, A., Talbot, R. W., and Dibb, J. E.: Three-dimensional simulations of inorganic aerosol distributions in East Asia during spring 2001, J. Geophys. Res., 109(D19S23), doi:10.1029/2003JD004201, 2004.
Tang, Y., Carmichael, G. R., Uno, I., Woo, J. H., Kurata, G., Lefer, B., Shetter, R. E., Huang, H., Anderson, B. E., Avery, M. A., Clarke, A. D., and Blake, D. R.: Influences of biomass burning during the Transport and Chemical Evolution Over the Pacific (TRACE-P) experiment identified by the regional chemical transport model, J. Geophys. Res., 108(D21), 8824, doi:10.1029/2002JD003110, 2003.

Taylor, J. P., Edwards, J. M., Glew, M. D., Hignett, P., and Slingo, A.: Studies with a flexible new radiation code, II, Comparisons with aircraft short-wave observations. Q. J. R. Meteorol. Soc. 122, 839-861, 1996.

Textor, C., Schulz, M., Guibert, S., Kinne, S., Balkanski, Y., Bauer, S., Berntsen, T., Berglen, T., Boucher, O., Chin, M., Dentener, F., Diehl, T., Feichter, H., Fillmore, D., Ghan, S., Ginoux, P., Gong, S., Grini, A., Hendricks, J., Horrowitz, L., Isaksen, I., Iversen, T., Koch, D., Krol, M., Lauer, A., Lamarque, J.-F., Liu, X., Montanaro, V., Myhre, G., Penner, J., Pitari, G., Reddy, S., Seland, O., Stier, P., Takemura, T., and Tie, X.: Analysis and quantification of the diversities of aerosol life cycles within AeroCom, Atmos. Chem. Phys. Discuss., 5, 8331-8420, 2005.

Tie, X., Madronich, S., Walters, S., Edwards, D. P., Ginoux, P., Mahowald, N., Zhang, R., Lou, C., and Brasseur, G.: Assessment of the global impact of aerosols on tropospheric oxidants, J. Geophys. Res., 110(D03204), doi:10.1029/2004JD005359, 2005.

Toon, O. B. and Pollack, J. B.: A global average model of atmospheric aerosols for radiative transfer calculations, J. Appl. Meteorol., 15, 225-246, 1976.

Toon, O. B., Pollack, J. B., and Khare, B. N.: The optical constraints of several atmospheric aerosol species: Ammonium sulfate, aluminum oxide and sodium chloride, J. Geophys. Res., 81, 5733-5748, 1976

Uno, I., Carmichael, G. R., Streets, D., Satake, S., Takemura, T., Woo, J.-H., Uematsu, M., Ohta, S.: Analysis of surface black carbon distributions during ACE-Asia using a regional-scale aerosol model, J. Geophys. Res., 108(D23), 8636, doi:10.1029/2002JD003252, 2003.

Uno, I., Satake, S., Carmichael, G. R., Tang, Y., Wang, Z., Takemura, T., Sugimoto, N., Shimizu, A., Murayama, T., Cahill, T. A., Cliff, S., Uematsu, M., Ohta, S., Quinn, P. K., and Bates, T. S.: Numerical study of Asian dust transport during the springtime of 2001 simulated with the Chemical Weather Forecasting System (CFORS) model, J. Geophys. Res., 109(D19S24), doi:10.1029/2003JD004222, 2004

Uno, I., Wang, Z., Mikami, M., Chiba, M., Tanaka, T., Chun, Y. S., Lee, S. S., Shao, Y., Jung, E., Westphal, D., Liu, M., Gong, S. L., Nickovic, S., and Song, Z.: Dust Model Intercomparison Study over Asia (DMIP): Overview, J. Geophys. Res., in press, 2006

U.S. Environmental Protection Agency: National Emission Inventory (NEI), http://www.epa.gov/ttn/chief/net/1999inventory. html, 2003.

Valero, F. P., Ackerman, T. P., and Gore, W. J. Y.: The effects of the arctic haze as determined from airborne radiometric measurements during AGASP II, J. Atmos. Chem., 9, 225-244, 1989.

Vogelmann, A. M., Flatau, P. J., Szczodrak, M., Markowicz, K. M., and Minnett, P. J.: Observations of large aerosol infrared forcing at the surface, Geophys. Res. Lett., 30(12), 1655 , doi:10.1029/2002GL016829, 2003

Virkkula, A., Ahlquist, N. C., Covert, D. S., Arnott, W. P., Sheridan, P. J., Quinn, P. K., and Coffman, D. J.: Modification, cal- 
ibration and a field test of an instrument for measuring light absorption by particles. Aerosol Sci. Technol., 39(1), 68-73, doi:10.1080/027868290901963, 2005.

Wagener, R., Nemesure, S., and Schwartz, S. E.: Aerosol optical depth over oceans: Large space and time resolution retrieval and error budget from satellite radiometry, J. Atmos. Oceanic Technol., 14, 577-590, 1997.

Wang, H.-C. and John, W.: Characteristics of the Berner impactor for sampling inorganic ions, Aerosol Sci. Technol., 8, 157-172, 1988.

Wang, J., Christopher, S. A., Brechtel, F., Kim, J., Schmid, B., Redemann, J., Russell, P. B., Quinn, P., and Holben, B. N.: Geostationary satellite retrievals of aerosol optical thickness during ACE-Asia, J. Geophys. Res., 108(D23), 8657, doi:10.1029/2003JD003580, 2003.

Warneck, P.: Chemistry of the natural atmosphere, International geophysics series, v. 41, 757 p., Academic Press, San Diego, 1988.

World Climate Program: A Preliminary Cloudless Standard Atmosphere for Radiation Computation, World Meteorological Organization, Geneva, 1986.

Wiscombe, W. J. and Grams, G. W.: The backscattered fraction in two-stream approximations, J. Atmos. Sci., 33(12), 2440-2451, 1976.

Wise, M. E., Surratt, J. D., Curtis, D. B., Schilling, J. E., and Tolbert, M. A.: Hygroscopic growth of ammonium sulfate/dicarboxilic acids, J. Geophys. Res., 108(D20), 4638, doi:10.1029/2003JD003775, 2003.

Woo, J.-H., Streets, D. G., Carmichael, G. R., Tang, Y. H., Yoo, B., Lee, W. C., Thongboonchoo, N., Pinnock, S., Kurata, G., Uno, I., Fu, Q. Y., Vay, S., Sachse, G. W., Blake, D. R., Fried, A., and Thornton, D. C.: Contribution of biomass and biofuel emissions to trace gas distributions in Asia during the TRACE-P experiment, J. Geophys. Res., 108(D21), 8812, doi:10.1029/2002JD003200, 2003.

Woodcock, A. H.: Salt nuclei in marine air as a function of altitude and wind force, J. Atmos. Sci., 10(5), 362-371, 1953.

Yienger, J. J. and Levy, H.: Empirical model of global soil biogenic NOx emissions, J. Geophys. Res., 100(D6), 11447-11464, 1995.
Yu, H., Kaufman, Y., Chin, M., Feingold, G., Remer, L., Anderson, T. L., Balkanski, Y., Bellouin, N., Boucher, O., Christopher, S., DeCola, P., Kahn, R., Koch, D., Loeb, N., Schulz, M., Takemura, T., and Zhou, M.: A review of measurement-based assessment of aerosol direct radiative effect and forcing, Atmos. Chem. Phys., 6, 613-666, 2006.

Zhang, D. and Iwasaka, Y.: Size change of Asian dust particles caused by sea salt interaction measurements in southwestern Japan, Geophys. Res. Lett., 31(L15102), doi:10.1029/2004GL020087, 2004.

Zhang, D., Iwasaka, Y., Shi, G., Zang, J., Matsuki, A., and Trochkine, D.: Mixture state and size of Asian dust particles collected at southwestern Japan in spring 2000, J. Geophys. Res., 108, 124, doi:10.1029/2003JD003869, 2003a.

Zhang, D., Zhang, J., Shi, G., Iwasaka, Y., Matsuki, A., and Trochkine, D.: Mixture state of individual Asian dust particles at a coastal site of Quingdao, China, Atmos. Environ., 37, 38953901, 2003b.

Zhang, Q., Stainier, C. O., Jayne, J. T., Canagaratna, M. R., Worsnop, D. R., Pandis, S. N., and Jimenez, J. L.: Insights into the chemistry of new particle formation and growth events in Pittsburg based upon aerosol mass spectrometry, Environ. Sci. Technol., 38, 4797-4809, 2004.

Zhang, X. Y., Gong, S. L., Shen, Z. X., Mei, F. M., Xi, X. X., Liu, L. C., Zhou, Z. J., Wang, D., Wang, Y. Q., and Cheng, Y.: Characterization of soil dust aerosol in China and its transport and distribution during 2001 ACE Asia: 1. Network Observations, J. Geophys. Res., 108(D9), 4261, doi:10.1029/2002JD002632, 2003.

Zhang, Y., Pun, B., Vijayaraghavan, K., Wu, S.-Y., Seigneur, C., Pandis, S. N., Jacobson, M. Z, Nenes, A., and Seinfeld, J. H.: Development and application of the Model of Aerosol Dynamics, Reaction, Ionization, and Dissolution (MADRID), J. Geophys. Res., 109(D01202), doi:10.1029/2003JD003501, 2004.

Zhou, J. C., Swietlicki, E., Berg, O. H., Aalto, P. P., Hameri, K., Nilsson, E. D., and Leck, C.: Hygroscopic properties of aerosol particles over the central Arctic Ocean during summer, J. Geophys. Res., 106(D23), 32 111-32 123, 2001.

Zimmer, C. E. and Larsen, R. I.: Calculating air quality and its control, J. Air Poll. Control Assoc., 15(12), 565-572, 1965. 